\title{
ANÁLISE DO COMPORTAMENTO À FLEXÃO DE PAINÉIS SANDUÍCHE COM FACES DE ARGAMASSA ARMADA E NÚCLEO DE ESPUMA RÍGIDA DE POLIURETANO DERIVADO DE ÓLEO DE MAMONA
}

\begin{abstract}
ALEXANDRE ARAÚJO BERTINI
Dissertação apresentada à Escola de Engenharia de São Carlos, da Universidade de São Paulo, como parte dos requisitos para obtenção do Título de Mestre em Engenharia de Estruturas.

ORIENTADOR: Prof. Dr. Eloy Ferraz Machado Jr.
\end{abstract}




\section{Bertini, Alexandre Araújo \\ B461a Análise do comportamento à flexão de painéis sanduíche com}

faces de argamassa armada e núcleo de espuma rígida de poliuretano derivado de óleo de mamona / Alexandre Araújo Bertini. -- São Carlos, 1995. $145 p$.

Dissertação (Mestrado) -- Escola de Engenharia de São CarlosUniversidade de São Paulo, 1995.

Orientador: Prof.Dr. Eloy Ferraz Machado Jr.

1. Painéis sanduíche (Estruturas). 2. Argamassa armada. I. Título. 
A Deus em primeiro lugar.

Aos meus pais

e aos meus irmãos,

que mesmo distantes me deram o apoio

para que terminasse esta obra. 


\section{AGRADECIMENTOS}

A Deus, senhor de minha vida, a quem devo tudo.

Ao Professor Eloy Ferraz Machado Jr. pela paciência, dedicação e orientação fornecida durante todo o desenvolvimento deste trabalho.

Aos Professores Toshiaki Takeya, João Bento de Hanai, José Samuel Giongo, Sérgio B. Proença pelas valiosas sugestões feitas.

Ao Professor Gilberto Orivaldo Chierice, a todos os técnicos do Laboratório de Quimica Analítica e Tecnologia de Polímeros - LQATP - do Instituto de Química de São Carlos- USP e ao aluno de Engenharia Mecância da EESC - USP, Maurício B. Finotti pela ajuda nos ensaios da espuma de poliuretano.

Meus sinceros agradecimentos aos técnicos do Laboratório de Estruturas da Escola de Engenharia de São Carlos - USP, pelo empenho e dedicação.

A todos os colegas e funcionários do Departamento de Engenharia de Estruturas, em especial a Nadir, Rosi, Chico e Silvia.

Á Coordenadoria de Aperfeiçoamento de Pessoal de Nivel Superior CAPES, pela bolsa concedida.

A todas as pessoas que estiveram ao meu lado, ou mesmo distantes, torcendo pelo meu sucesso, durante todo o transcorrer do curso de mestrado, dentre as quais não posso deixar de citar meus pais e os membros de minha comunidade, verdadeira família que Deus me presenteou em São Carlos. 


\section{SUMÁRIO}

RESUMO

i

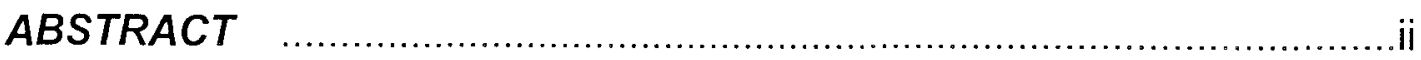

1 INTRODUÇÃO

1.1 Generalidades .............................................................................

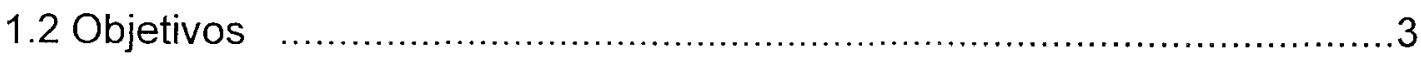

2 ESTADO DA ARTE DO PAINEL SANDUÍCHE NAS OBRAS CIVIS ......5

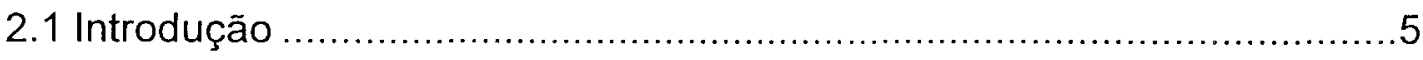

2.2 Painéis pré-fabricados de madeira f..............................................5

2.3 Sistema construtivo patenteado por VICTOR WEISMAN

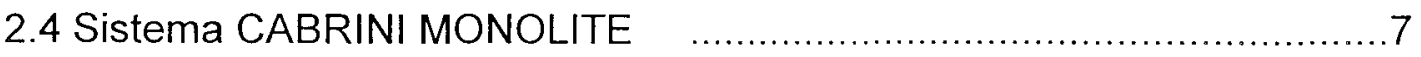

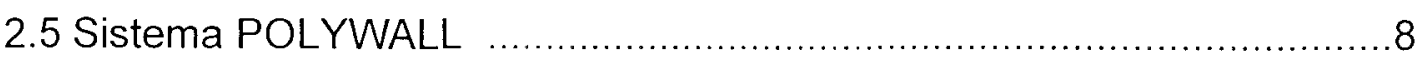

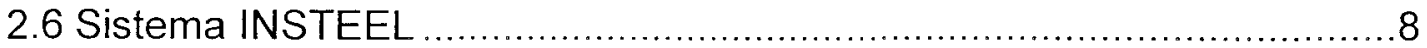

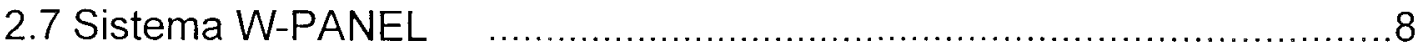

2.8 Sistema desenvolvido por CHANG …................................... 9

2.9 Sistema desenvolvido por MACHADO JÚNIOR (1991) ...................12

2.10 Painéis sanduíche pré-moldados de concreto armado ...............16

3 ANÁLISE ESTRUTURAL DE VIGAS SANDUÍCHE $\quad \ldots \ldots \ldots \ldots \ldots \ldots \ldots \ldots \ldots$

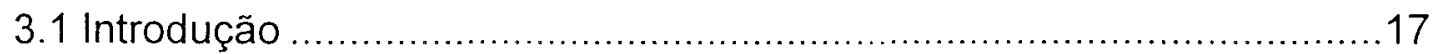

3.2 Aplicação da teoria elementar da flexão …...................................19

3.3 Flexão de vigas sanduíche com núcleo fraco e faces finas ................23

3.4 Flexão em vigas sanduíche com núcleos fracos e faces grossas ....26

3.4.1 Viga simplesmente apoiada com carga concentrada no meio do vão .....................................................30

3.4.2 Viga simplesmente apoiada com carregamento

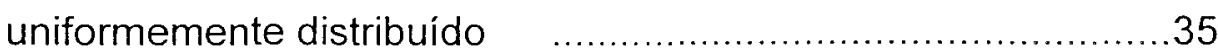

3.4.3 Viga simplesmente apoiada com carga concentrada aplicada em dois pontos equidistantes 


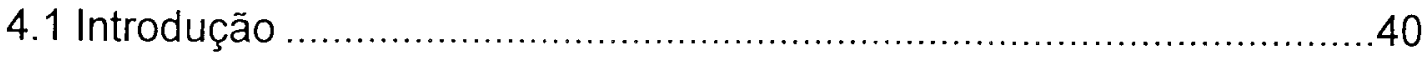

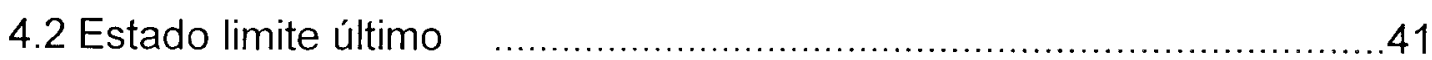

4.2.1 Determinação do momento fletor resistente de cálculo segundo as especificações da NBR 6118

4.2.1.1 Hipóteses de cálculo

4.2.1.2 Caso em que a linha neutra se encontra na face comprimida acima da armadura

4.2.1.3 Caso em que a linha neutra se encontra na face comprimida abaixo da armadura

4.2.1.4 Caso em que a linha neutra se encontra no núcleo 47

4.2.1.5 Solução dos sistemas de equações …..............................48

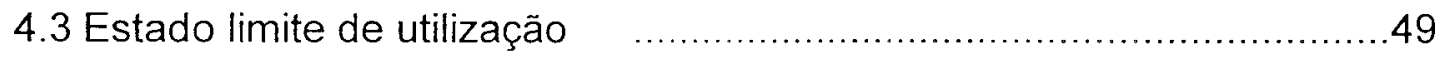

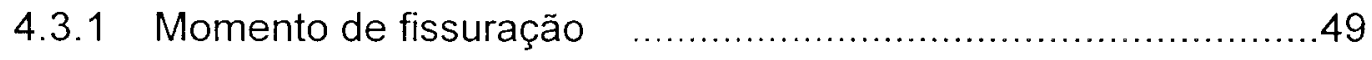

4.3.1.1 Hipóteses de cálculo ......................................................49

4.3.1.2 Caso em que a linha neutra se localiza

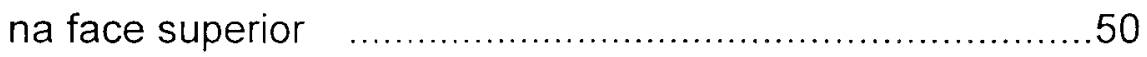

4.3.1.3 Caso em que a linha neutra se localiza no núcleo _..........52

4.3.2 Verificação do estado de deformação excessiva .......................54

4.3.2.1 Caso em que a linha neutra se localiza

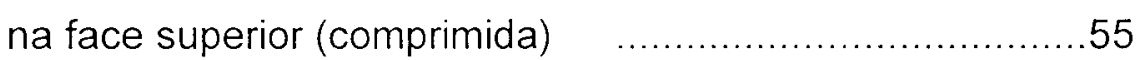

4.3.2.2 Caso em que a linha neutra se localiza no núcleo ...........56

4.3.2.3 Indicações para o cálculo dos deslocamentos segundo a norma de argamassa armada (NB-1259) ..........58

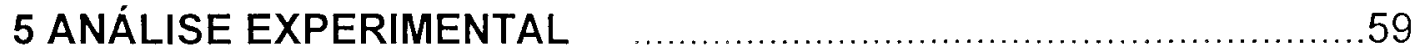

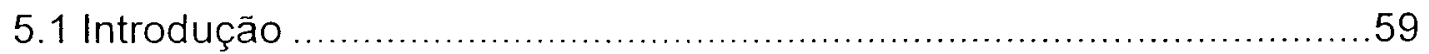

5.2 Definição das características dos materiais dos modelos …...........60

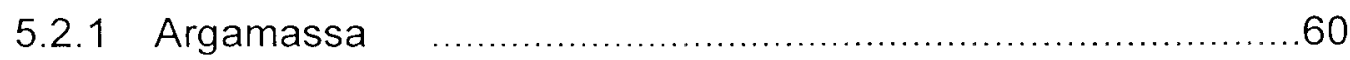

5.2.2 Armadura: tipo e disposição ………..................................60

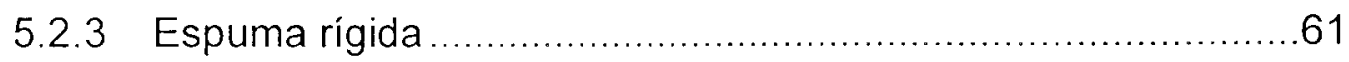

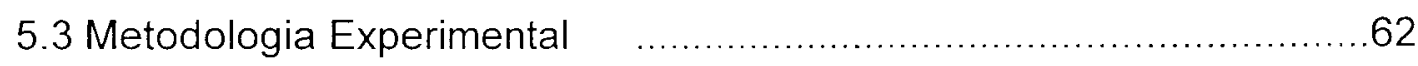

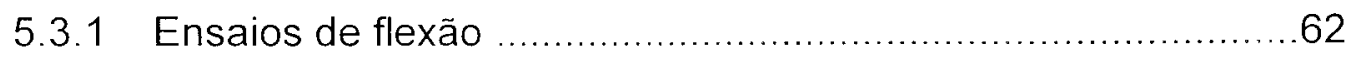

5.3.1.1 Descrição dos ensaios ……...................................62

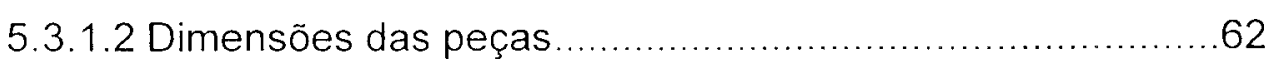

5.3.1.3 Fôrma para moldagem das placas de face ....................63 
5.3.1.4 Moldagem, adensamento e cura ....................................63

5.3.1.5 Fôrma para moldagem da viga sanduíche ....................65

5.3.1.6 Esquemas estático e de carregamento ...........................68

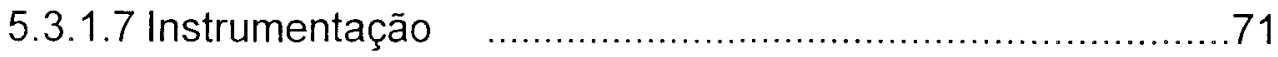

5.3.2 Ensaios de cisalhamento da espuma rígida ..........................73

5.3.2.1 Descrição dos ensaios …................................................. 74

5.3.2.2 Dimensões dos modelos …................................................ 75

5.3.2.3 Fôrma para moldagem da espuma ……........................77

5.3.2.4 Moldagem e preparação para o ensaio ……...................78

5.3.2.5 Esquema estático e de carregamento ...........................79

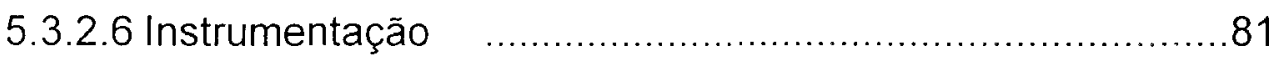

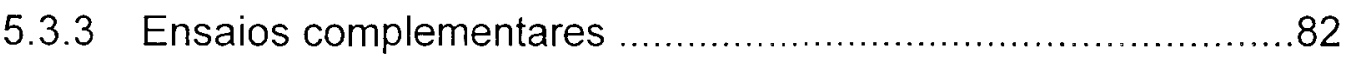

5.3.3.1 Ensaios de caracterização das argamassas empregadas em cada uma das séries

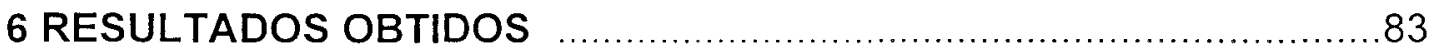

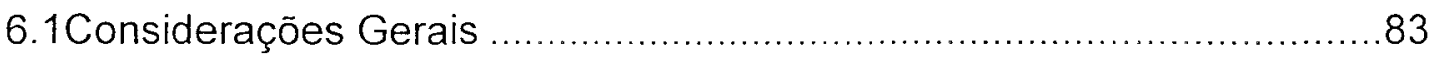

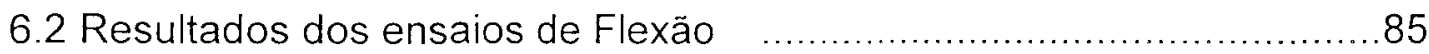

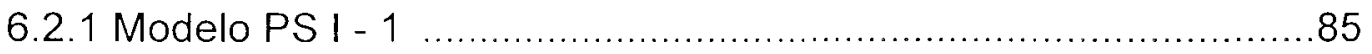

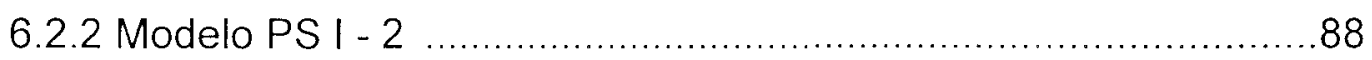

6.2.3 Controle de resistência da argamassa

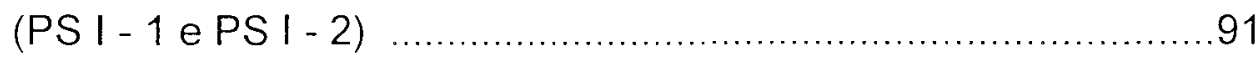

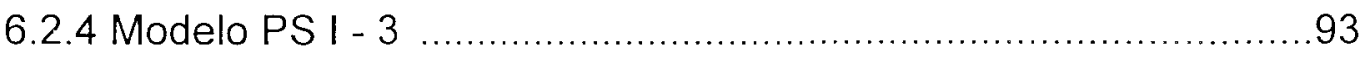

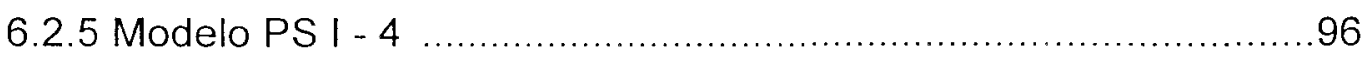

6.2.6 Controle de resistência da argamassa

(PS I - 3 e PS I - 4) …………………

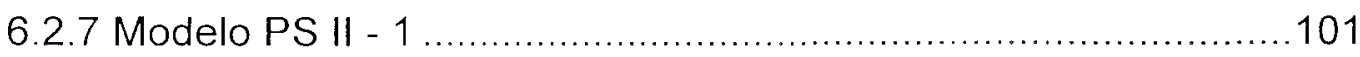

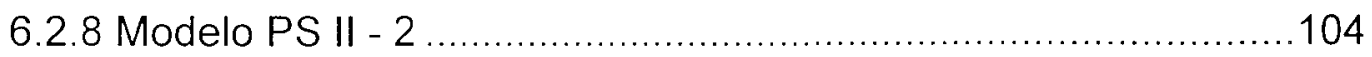

6.2.9 Controle de resistência da argamassa

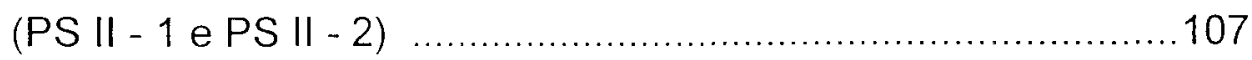

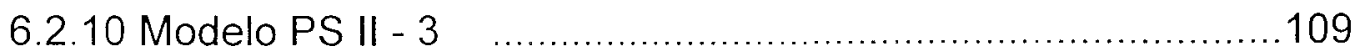

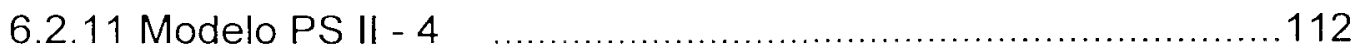

6.2.12 Controle de resistência da argamassa
(PS II - 3 e PS II - 4)

6.3 Resultados dos ensaios de Cisalhamento da Espuma rígida de poliuretano 


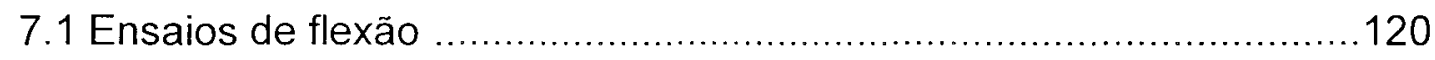

7.1.1 Carga de fissuração ……................................................120

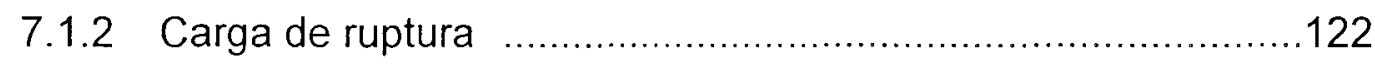

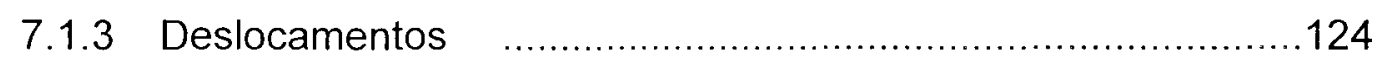

7.2 Ensaios de Cisalhamento da espuma rigida ....................................131

7.2.1 Limite de proporcionalidade e módulo de

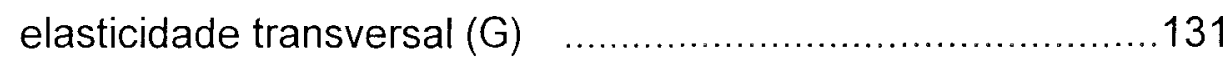

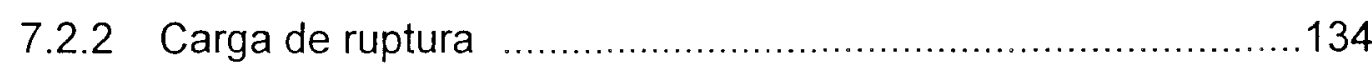

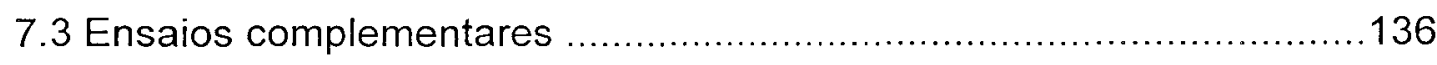

8 CONCLUSÕES

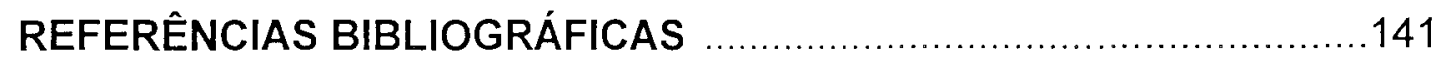

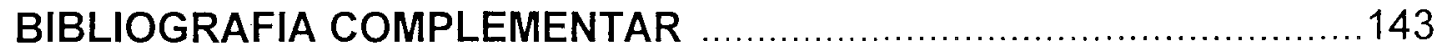




\section{RESUMO}

\section{BERTINI, A.A. Análise do comportamento à flexão de painéis sanduíche}

com faces de argamassa armada e núcleo de espuma rígida de poliuretano derivado de óleo de mamona. São Carlos, 1995. 145p. Dissertação (Mestrado) - Escola de Engenharia de São Carlos, Universidade de São Paulo.

Recentemente, tem se verificado aplicações de painéis sanduiche como elementos estruturais e não estruturais na Construção Civil, principalmente empregados em edificações. Painéis sanduíche, com faces de argamassa armada e núcleo de espuma rígida de poliuretano derivado de óleo de mamona, são estudados visando o emprego em edificações. $\mathrm{O}$ comportamento à flexão destes painéis, é estudado através de ensaios de flexão com vigas submetidas a carregamentos nos terços do vão. Alguns modelos teóricos para o cálculo do deslocamento são propostos e comparados com os deslocamentos obtidos nos ensaios. Ensaios de cisalhamento da espuma são feitos a fim de se determinar o seu módulo de deformação transversal, bem como a resistência ao cisalhamento. Obtémse da análise dos resultados dos ensaios, parâmetros para projeto deste elemento.

Palavras-chave: painel sanduíche; flexão; argamassa armada; espuma rígida de poliuretano; óleo de mamona; 


\section{ABSTRACT}

Bertini, A.A. Bending behavior of sandwich panels with ferrocement faces and stiff foam core of castor oil polyurethane. São Carlos, 1995. 145p. Master Science Dissertation - Escola de Engenharia de São Carlos, Universidade de São Paulo.

Sandwich panels have been used as structural or nonstructural elements in the Civil Construction, mainly in building. A kind of sandwich panel, with ferrocement faces and stiff foam core of castor oil polyurethane, is studied aiming its use in building. The bending behavior of these panels is studied through bending tests with beams loaded at the third parts of the span. Some theoretical models for the deflection calculation are proposed and compared with the experimental values obtained in the tests. Shear tests on the polyurethane foam were done to determinate its shear modulus and its shear strength. Design parameters are obtained from the analysis of the experimental results.

Keywords: sandwich panel; bending; ferrocement; polyurethane foam; castor oil. 


\section{INTRODUÇÃO}

\subsection{Generalidades}

Painéis sanduíche ficaram mais conhecidos na utilização em estruturas de aviões durante a Segunda Guerra Mundial. Por apresentar simultaneamente características de leveza e resistência, estes componente foram bastante utilizados para esta finalidade. Mais recentemente tem se verificado uma maior aplicação de estruturas sanduiche como elementos (estruturais ou não estruturais) para Construção Civil, principalmente empregados em edificações.

O primeiro trabalho publicado relatando os princípios da "construção sanduíche" foi feito por W. Fairbairn (An account of the construction of the Britannia and conway and tubular bridges, JOHN WEALE et al, London, 1849). É provável que a idéia "sanduiche" tenha ocorrido independentemente por parte de vários engenheiros em diferentes épocas e lugares, sendo que qualquer pesquisa que se faça sobre a história do painel sanduíche provavelmente registrará trabalhos atribuídos a Leonardo da Vinci, conforme ALLEN(1969).

Uma construção sanduiche compreende uma combinação de alternativas diferentes, de materiais simples ou compostos, reunidos e intimamente fixados um em relação ao outro, tal que o uso das propriedades de cada material empregado atribui vantagens estruturais para o conjunto como um todo.

Um tipo simples de sanduiche pode ser visto na fig.1.1. Consiste de duas faces resistentes, separadas por uma camada espessa de um material menos denso e menos resistente que as faces. 


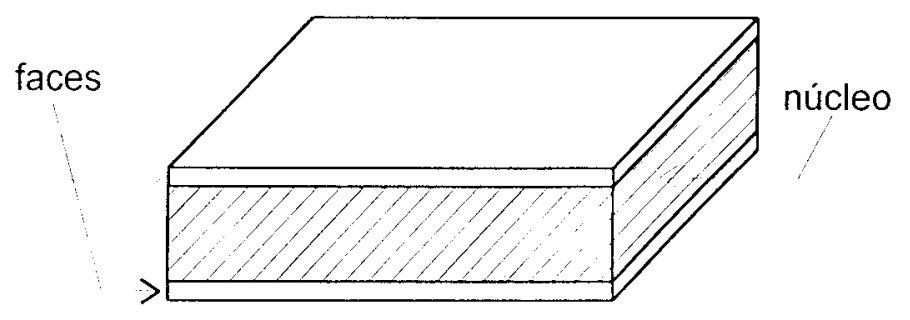

FIGURA 1.1. Painel Sanduíche

O núcleo, assim como as faces, tem funções vitais para o funcionamento estrutural do sanduíche. Ele é responsável pela manuntenção de uma distância correta entre as faces e também pela transferência de esforços. A resistência à flexão dos materiais comumente utilizados como núcleo, possui valor baixo e é geralmente desprezada. $\mathrm{O}$ material do núcleo deve ter rigidez suficiente para que resista ao cisalhamento, evitando que as faces escorreguem uma em relação a outra.

O núcleo, além das funções estruturais, garante o conforto térmicoacústico. Existem certos empregos de painéis sanduíche que aproveitam do material do núcleo apenas esta última função, deixando a função estrutural para conectores metálicos ou nervuras, estes últimos é que garantem a composição do sanduiche.

Painéis sanduiche para estruturas de aviões utilizam geralmente faces de metal com núcleo do tipo "favos de mel" ou corrugado. O núcleo tipo "favos de mel" ("honeycomb") é composto por tiras finas de uma liga de alumínio ou de aço, fig.1.2. O tipo corrugado é formado for uma chapa metálica dobrada conforme fig.1.2.

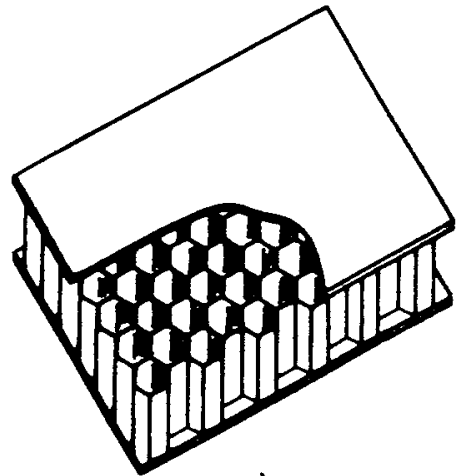

a)

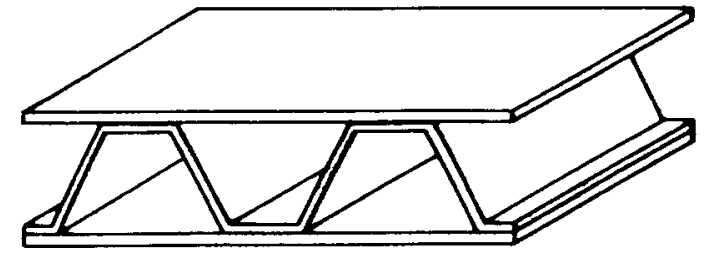

b)

FIGURA 1.2. a) Núcleo tipo honeycomb. b) Núcleo tipo corrugado 
No emprego deste componente na Construção Civil, os materiais das faces comumente utilizados são a argamassa armada e o concreto armado, podendo ser usado também aço ou alumínio. Como material do núcleo são utilizados espumas rigidas de poliuretano e poliestireno, pré-expandidas ou expandidas no local.

São usados ainda várias combinações de materiais na composição de painéis sanduiche para uma grande gama de empregos. Como materiais de face pode-se encontrar, além dos que já foram expostos: madeira compensada, cimento amianto, plásticos e papelão. Como material do núcleo pode-se ainda empregar: madeira compensada, papelão empregnado com resina, gesso e resinas plásticas.

Como se vê a "idéia sanduiche" se constitui em combinar dois materiais de características diferentes para formar um elemento com características melhoradas com relação aos materiais que o originaram.

\subsection{Objetivos}

Painéis do tipo sanduíche, com faces de argamassa armada, têm atraído particular atenção na produção de componentes pré-moldados para emprego na indústria da Construção Civil com ênfase em edificações.

Os painéis são geralmente dotados de nervuras e/ou conectores unindo as faces, proporcionando, sob a ação de cargas transversais, a necessária transferência das tensões de cisalhamento, fazendo com que o elemento funcione como um material perfeitamente composto. Neste caso, o espaço entre as faces é preenchido na execução do sanduiche com um material que proporcione isolamento térmico-acústico, além de facilitar a confecção deste componente. O processo de industrialização fica prejudicado, pois são necessárias várias operações para confecção do painel.

Na Escola de Engenharia de São Carlos foi desenvolvido um sistema construtivo que consistia de painéis sanduíche ligados por encaixe a seco em elementos pré-moldados. Os painéis eram feitos com faces de argamassa armada, onde a camada intermediária (núcleo) consistia de espuma rigida de poliuretano expandida "in loco" entre as faces. O núcleo era responsável tanto pelo isolamento térmico-acústico como pela 
composição do elemento, não existindo conectores nem nervuras, MACHADO Jr.(1991).

As possibilidades de fabricação industrializada para este sistema são muito maiores, pois as placas de face podem ser executadas em pistas horizontais independentes da operação de execução do núcleo.

As perspectivas do emprego destes componentes como elementos estruturais e semi-estruturais industrializados são muito grandes, justificando assim a análise do seu comportamento estrutural. Necessitando uma melhor caracterização das propriedades mecânicas de interesse dos materiais da face e do núcleo, em complementação aos estudos feitos por MACHADO Jr.(1991), planejou-se uma revisão de forma a abranger os aspectos do emprego, análise estrutural e projeto de painéis sanduiche.

A análise estrutural tem por objetivo o estudo do comportamento à flexão de painéis sanduíche, que devido a relação de suas dimensões (largura,comprimento e altura) podem ser analisados como vigas estreitas.

Um dos objetivos especificos deste trabalho é o estudo de painéis sanduiche de faces de argamassa armada e núcleo de poliuretano expandido derivado de óleo de mamona, isento de CFC. Procura-se o estabelecimento de um modelo matemático, que exprima o comportamento estrutural do elemento como um todo, levando-se em conta a resistência individual à flexão das faces e a baixa resistência ao cisalhamento do núcleo.

É objetivo também, devido à falta de dados precisos na literatura, a determinação do módulo de elasticidade transversal do material do núcleo através de ensaios prescritos em normas, como é o caso da ASTM C 27361 e ASTM C 393-62, a determinação das propriedades mecânicas de interesse da argamassa e da armadura, e a obtenção da rigidez à flexão das faces e do sanduiche através de ensaios complementares.

Através de ensaios de flexão com painéis, convenientemente preparados, objetiva-se finalmente, adequar o modelo teórico ao problema real e a partir dai obter critérios para dimensionamento e verificação. 


\section{ESTADO DA ARTE DO PAINEL SANDUÍCHE NAS OBRAS CIVIS}

\subsection{Introdução}

Painéis sanduiche foram bastante utilizados em estruturas de aviões durante a segunda guerra mundial, e a partir daí o projeto e a análise do comportamento deste tipo de painel tem sido amplamente estudado e divulgado.

A idéia de aplicação deste componente, na Construção Civil, não é recente, sendo empregado pela primeira vez na década de 1930.

Em geral a utilização de painéis sanduíche em obras civis está associada a habitações, sendo usado em divisórias, paredes, forros e pisos.

Vários materiais são utilizados como faces, como por exemplo: madeira compensada, argamassa armada e concreto armado. Como núcleo, são geralmente utilizados materiais como: poliuretano ou poliestireno expandidos, gesso, papelão e madeira compensada.

\subsection{Painéis pré-fabricados de madeira}

Na década de 1930 foi desenvolvido e patenteado pelo Forest Products Laboratory nos Estados Unidos, um sistema construtivo para préfabricação de habitações em painéis sanduíche de madeira.

Os painéis eram utilizados como paredes, telhados e piso, que consistiam de faces de madeira compensada, coladas em ambos os lados a enrijecedores longitudinais de madeira. $O$ vazio entre as faces era preenchido posteriormente com material isolante. 
Os painéis tinham $122 \mathrm{~cm}$ de largura por $427 \mathrm{~cm}$ de comprimento. As faces tinham espessuras diferentes, sendo que uma tinha $1,6 \mathrm{~cm}$ e a outra $1,0 \mathrm{~cm}$ de espessura. Estas eram coladas a três enrijecedores de seção $5 \mathrm{~cm}$ $x 15 \mathrm{~cm}$, conferindo a transmissão dos esforços, e garantindo que as faces não deslizassem uma em relação a outra.

Este sistema de painéis leves com enrijecedores, foi empregado na construção de casas nos Estados Unidos. Um protótipo foi construído e seu estado, passados alguns anos, mostrou-se em excelentes condições.

Em estudos experimentais posteriores, desenvolveu-se um núcleo do tipo "honeycomb" de papelão, tratado com resina fenolítica, o qual conferia rigidez e proteção às condições severas de umidade. Este tipo de núcleo substituia os enrijecedores fazendo com que o painel trabalhasse como um verdadeiro sanduíche.

\subsection{Sistema construtivo baseado em pré-painéis}

Victor Weisman patenteou nos Estados Unidos em 1967, um sistema construtivo para fabricação de casas com painéis pré-fabricados que consistia de placas de poliestireno ou poliuretano, no qual eram armadas com tela soldada, disposta em cada uma das faces e ligadas por meio de barras eletrosoldadas.

$\mathrm{Na}$ obra os painéis eram montados colocando-se um ao lado do outro, fazendo sua conexão superpondo telas soldadas às juntas. As instalações elétricas e hidráulicas eram embutidas entre o núcleo e a armadura.

Os painéis eram usados como paredes exteriores e interiores, forros e telhados. As aberturas de portas e janelas são feitas simplesmente cortando-se os pré-painéis e fazendo reforços nos cantos com telas soldadas.

Somente quando todos os painéis eram conectados, é que estes recebiam um revestimento de argamassa, que varia de $2,5 \mathrm{~cm}$ a $3,8 \mathrm{~cm}$ de espessura de cada lado. Este revestimento, era feito por meios tradicionais de emboçamento ou por processos mais modernos que empregam mecanismos de jateamento da argamassa sob pressão, no qual resulta num painel rigido e uma estrutura monolitica sem juntas. 
As especificações exatas dos painéis sanduiche e as técnicas de construção dependem do fabricante do painel. Segundo PICKARD (1990), quatro empresas nos Estados Unidos e quinze fora dele fabricam painéis deste tipo. Os painéis são diferenciados entre os fabricantes pela armadura, tipo de espuma do núcleo e espessura dos painéis.

Outros sistemas construtivos utilizam o pré-painel na confecção do sanduíche, descrever-se-á a seguir características particulares de alguns destes sistemas.

\subsection{Sistema CABRINI MONOLITE}

O sistema MONOLITE já havia sido utilizado em vários países europeus: Alemanha, Espanha, França, Inglaterra e Itália. Na América do Sul, foi utilizado inicialmente na Argentina e posteriormente foi trazido para o Brasil. O painel CABRINI MONOLITE utilizado no Brasil é constituído de uma placa de poliestireno expandido recortada em formato ondulado (fig.2.1). O formato ondulado das placas de poliestireno facilita no momento da argamassagem. De cada lado da placa de poliestireno são colocadas telas soldadas (reforço estrutural do painel) as quais são ligadas entre si por meios de fios soldados transversais, que atravessam a tela.

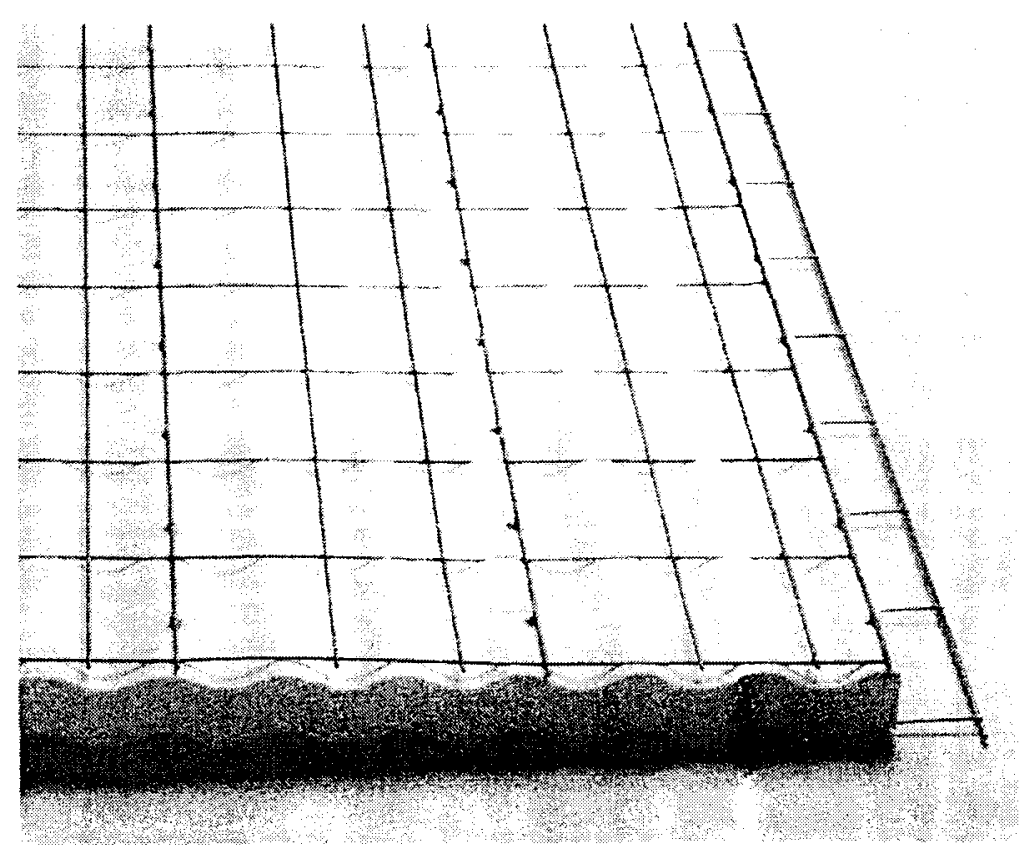

FIGURA 2.1. Painel Monolite. 


\subsection{Sistema POLYWALL}

O sistema POLYWALL, utilizado em Singapura como parede divisória interna em residências, foi motivo de estudo de LEE et al (1986), que buscava aumentar a resistência do painel para estender o seu uso a paredes externas. As placas podem ser montadas por jateamento da argamassa ou por processos tradicionais, dependendo da disponibilidade de equipamentos. A armadura das placas mantém uma distância do núcleo de poliestireno. A ligação entre as placas ainda podia ser reforçada com nervuras armadas com treliça metálica.

\subsection{Sistema INSTEEL}

O sistema INSTEEL pertence à Insteel Construction System, sediada na Geórgia, Estados Unidos. O sistema é caracterizado pelo uso de equipamentos de projeção de mistura seca sob pressão para moldagem das placas. Este equipamento requer mão de obra qualificada para ser operado. A armadura e os conectores são de aço inoxidável, estando numa configuração de uma treliça tridimensional que dá maior rigidez ao conjunto após a moldagem das placas.

\subsection{Sistema W-PANEL}

O sistema W-PANEL consiste de uma estrutura espacial treliçada, fabricada com duas telas de malhas quadradas de fios $n^{\circ} 14$, soldados $e$ espaçados de 50,8 mm. Para manter o espaçamento, também de $50,8 \mathrm{~mm}$, entre as telas e produzir o efeito treliça, são soldados fios individuais de mesmo diâmetro em diagonal, unindo as superficies de cada tela (fig. 2.2)

A diferença fundamental deste para os outros sistemas, é que, somente após a fabricação da estrutura esta recebe no seu interior uma aplicação de poliuretano em forma de espuma rigida, afastada do plano de cada face da armadura de $12,7 \mathrm{~mm}$. Esta providência permite que os fios da armadura recebam um recobrimento de argamassa adequado, durante sua aplicação na obra, manualmente ou por projeção. A espessura da camada que recobre os fios, de cada lado do painel, é de $22 \mathrm{~mm}$. 
A medida padrão do W-PANEL é de $1,20 \mathrm{~m}$ de largura por $2,5 \mathrm{~m}$ de altura, pesando aproximadamente $12 \mathrm{~kg}$.

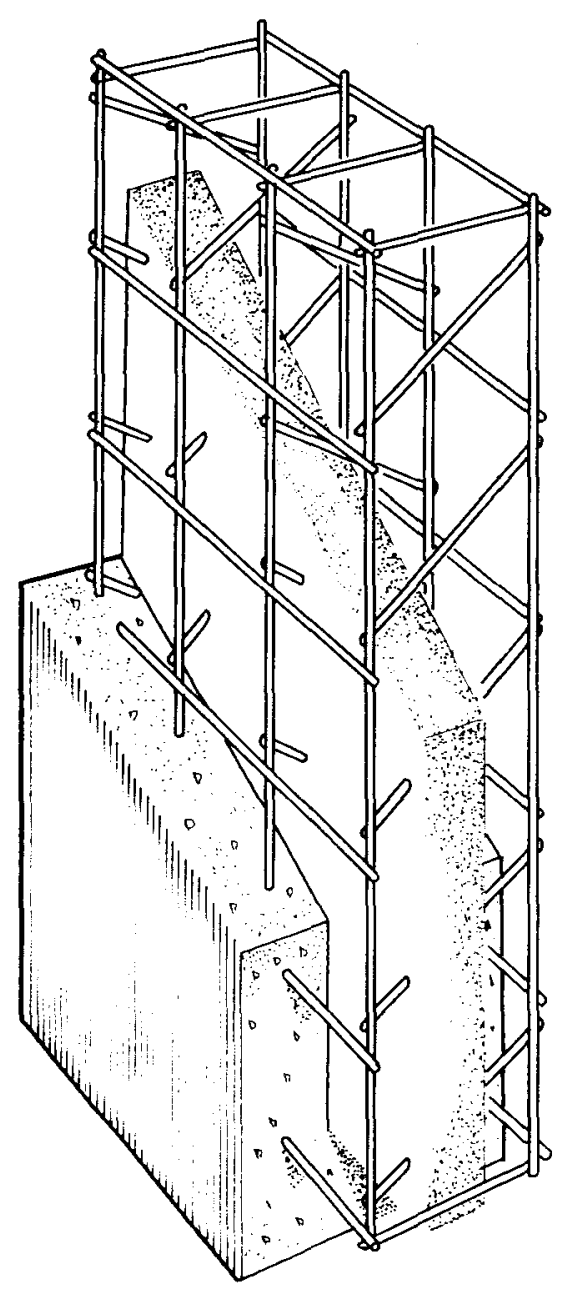

FIGURA 2.2. W-Panel

\subsection{Sistema desenvolvido por CHANG}

Este sistema foi desenvolvido nos Estados Unidos entre os anos de 1968 e 1970, com o incentivo do governo federal que subsidiou o desenvolvimento e a construção de casas populares para atender a uma demanda crítica por habitaçōes daquela época. Todo o sistema era produzido e montado inteiramente na fábrica em dois módulos, que eram transportados em carretas para o local definitivo. 
O painel sanduiche era utilizado como componente das paredes, piso e coberturas. As faces, executadas em argamassa armada tinham $12,7 \mathrm{~mm}$ de espessura, armados com duas camadas de tela de arame galvanizado. Para garantir o efeito sanduíche, as faces eram unidas por nervuras (fig.2.3).

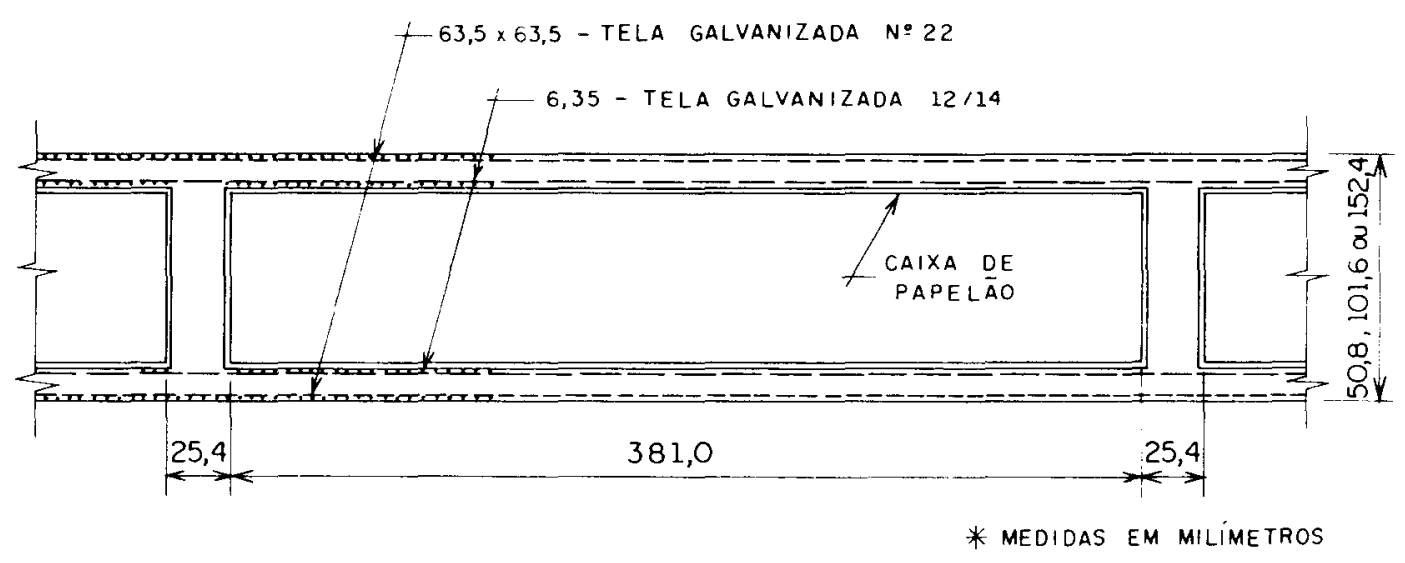

FIGURA 2.3. Seção transversal do painel desenvolvido por CHANG

A moldagem era executada horizontalmente sobre mesa metálica, sendo que para confecção das nervuras, utilizou-se formas de papelāo tipo caixão perdido.

Cuidados especiais com o lançamento, controle de espessura e trabalhabilidade da argamassa eram tomadas através de equipamentos de vibração e aditivos. As instalações elétricas e hidráulicas eram embutidas antes da peça ser fundida. As juntas de parede-piso e parede-cobertura, eram executadas em concreto armado no local (fig.2.4).

O sistema foi modificado posteriormente em 1974 por CHANG, tendo sido adaptado para construção pré-moldada "in loco", conforme CHANG (1983). 


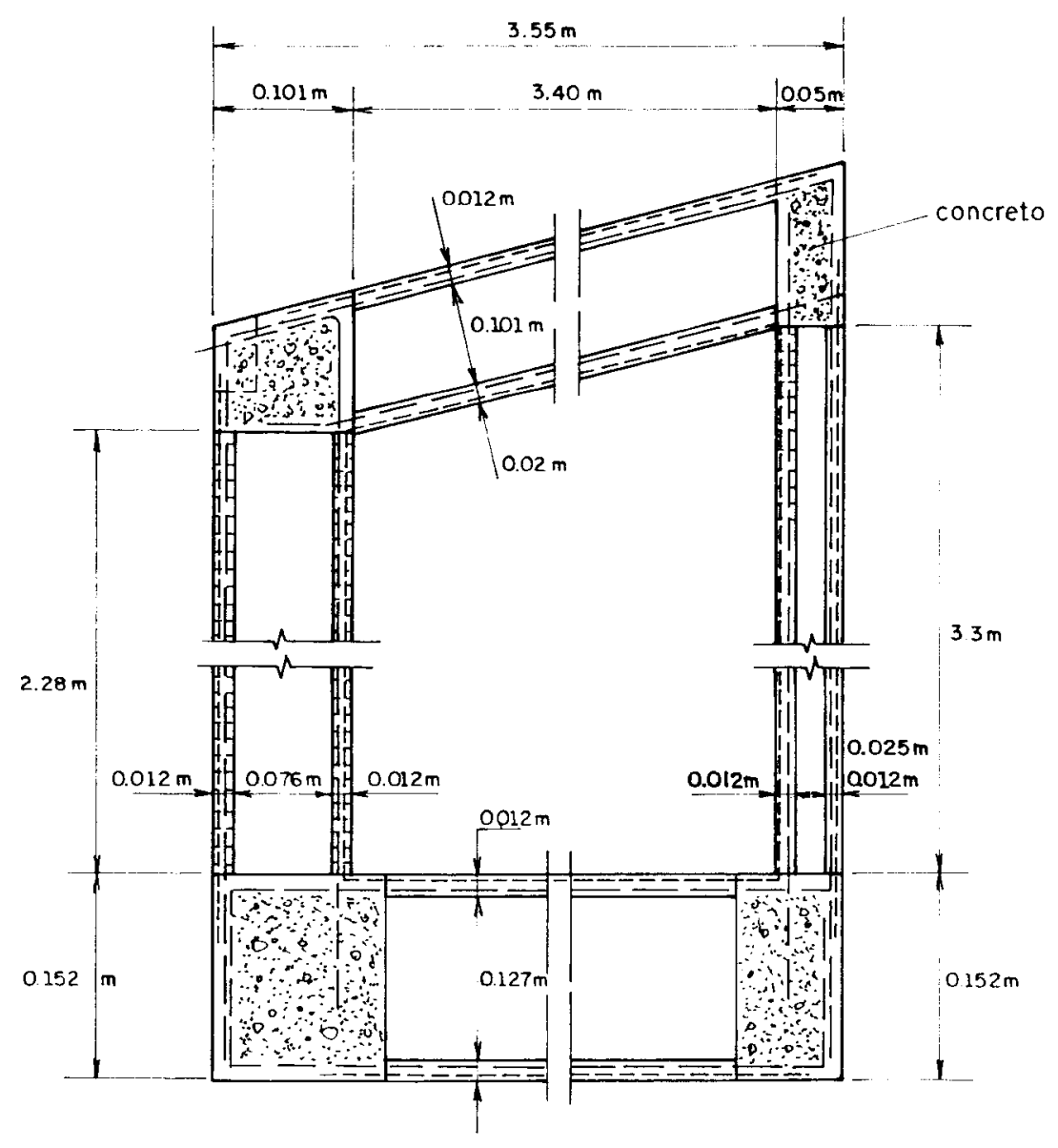

FIGURA 2.4. Detalhes das conexões entre parede-piso e parede telhado. 


\subsection{Sistema desenvolvido por MACHADO JÚNIOR (1991)}

Este sistema foi desenvolvido em pesquisa que resultou em tese de doutorado. Uma das caracteristicas deste sistema é que os componentes são pré-fabricados, necessitando apenas sua montagem na obra. O painel sanduiche foi utilizado como parede interna e externa e tinha como característica marcante a leveza dos componentes - todas elas sem exceção podem ser manuseadas por dois homens - dispensando equipamentos sofisticados durante a construção.

Eram dois os elementos estruturais: painéis do tipo sanduiche com placas de face de argamassa armada de $11 \mathrm{~mm}$ de espessura, e núcleo de espuma rígida de poliuretano expandido "in loco" entre as faces. Os painéis eram dotados de canaletes nas laterais e no topo, através dos quais eram feitas as conexões entre estes componentes. O segundo elemento básico era formado por perfis pré-moldados, também de argamassa armada, que permitiam a união entre os painéis, nas mais diversas situações das paredes, constituindo encaixes ou juntas secas (fig. 2.5).

Uma característica singular deste painel é que a transferência de esforços de cisalhamento era conferida pelo núcleo de espuma rígida de poliuretano, não se utilizando neste caso conectores.

O sistema previa instalações elétricas e hidráulicas aparentes ou previamente embutidas em painéis apropriados para esta finalidade.

Um protótipo, com $24,25 \mathrm{~m}^{2}$ de área construida (fig.2.6), foi montado com a finalidade da verificação da eficiência do sistema construtivo quanto à simplicidade e rapidez de montagem, bem como quanto à durabilidade e habitabilidade da edificação

As placas de face, de argamassa armada, foram feitas com uma tela de fio de aço soldado de malha $25 \times 50 \mathrm{~mm}^{2}$ e diâmetro dos fios de $2 \mathrm{~mm}$.

O núcleo de espuma rígida de poliuretano foi expandido "in loco" entre as faces, ao contrário dos outros sistemas construtivos, que na sua grande maioria utiliza painéis isolantes pré-expandidos. 


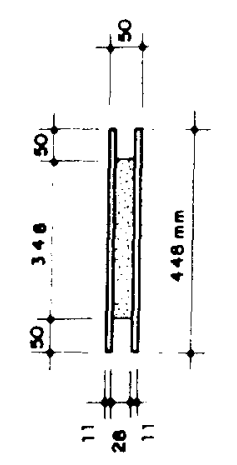

$2470 \mathrm{~mm}$
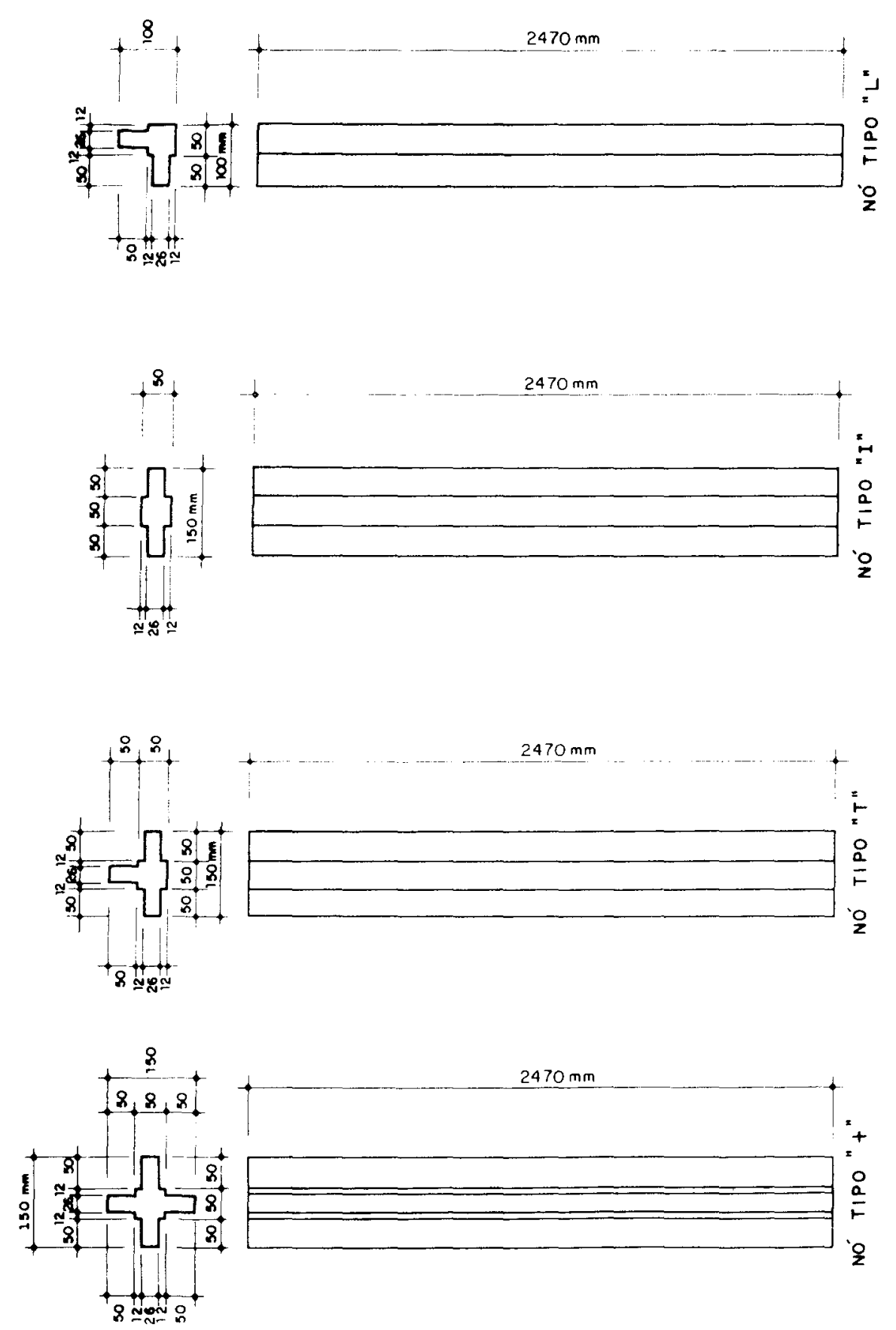

FIGURA 2.5. Elementos de ligação e painel sanduíche. À esquerda seção longitudinal e a direita seção transversal. 


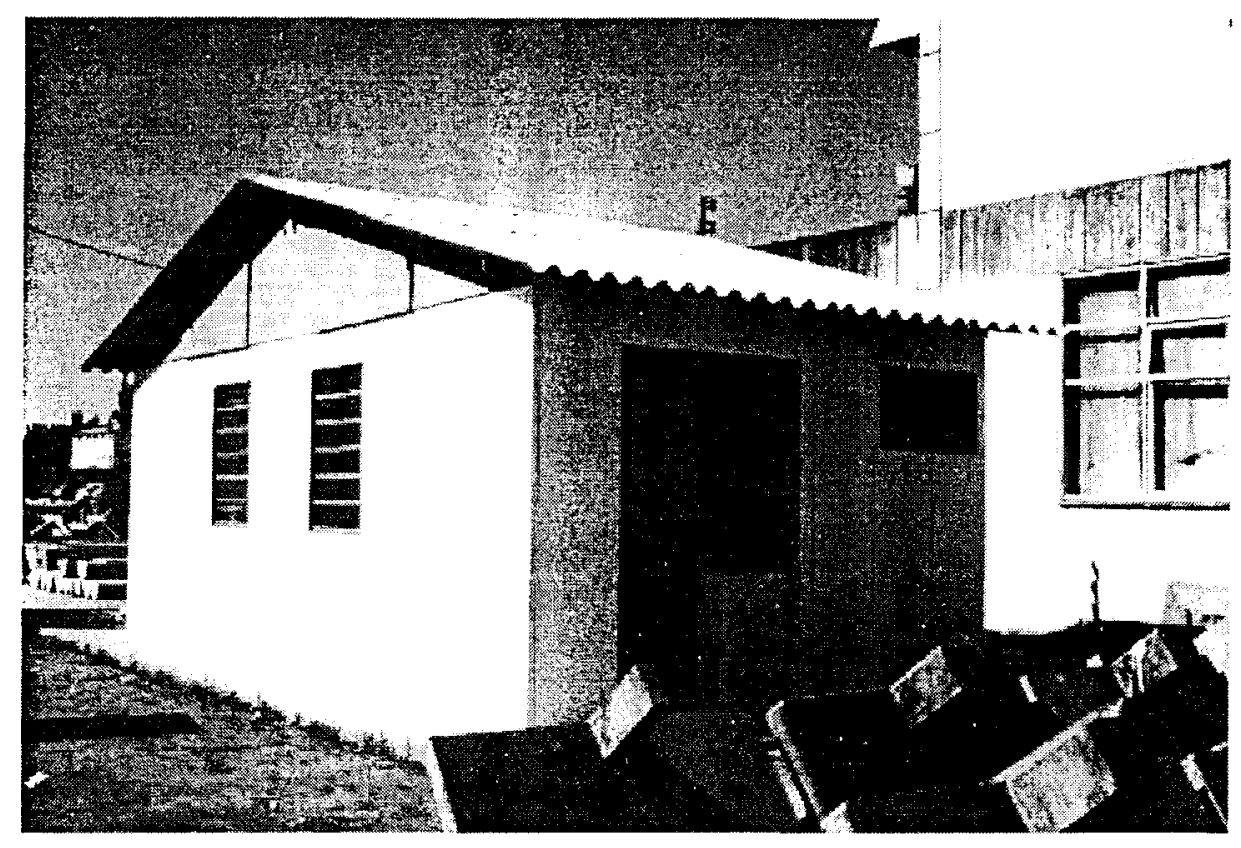

FIGURA 2.6. Protótipo da casa.

Após a montagem das paredes, o conjunto é consolidado por uma cinta de amarração, passando através dos canaletes superiores dos painéis e de furos existentes na parte superior dos elementos de união. A fig.2.8 mostra o detalhe da cinta superior, bem como o detalhe da amarração do painel com a fundação. 


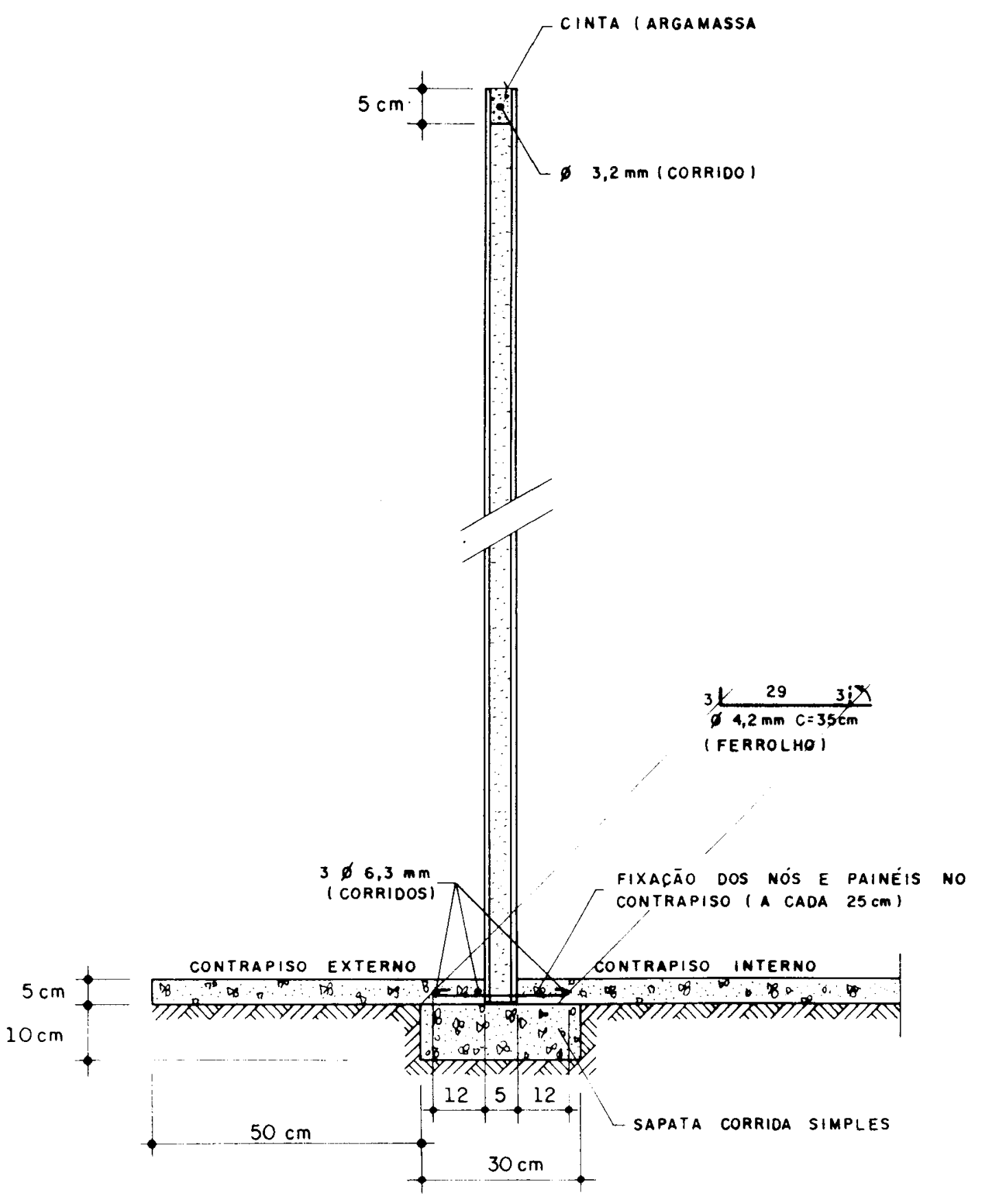

FIGURA 2.7. Detalhe da fixação dos painéis e elementos de ligação no contrapiso e cinta de amarração superior. 


\subsection{Painéis sanduíche pré-moldados de concreto armado}

Alguns tipos de painéis bastante empregados na América do Norte e na Europa utilizam como faces placas de concreto armado.

Para este tipo de sanduíche, o material do núcleo tem apenas a função isolante podendo ser espuma rígida de poliuretano ou poliestireno. A transferência dos esforços é feita através de conectores, que podem ter formas ou disposições das mais variadas como mostra a fig.2.8.

Este tipo de painel possui geralmente de $4 \mathrm{~m}$ a $17 \mathrm{~m}$ de comprimento por $1 \mathrm{~m}$ a $2,4 \mathrm{~m}$ de largura. O seu uso tem se verificado em habitações, edificações comerciais de baixa altura e armazéns.
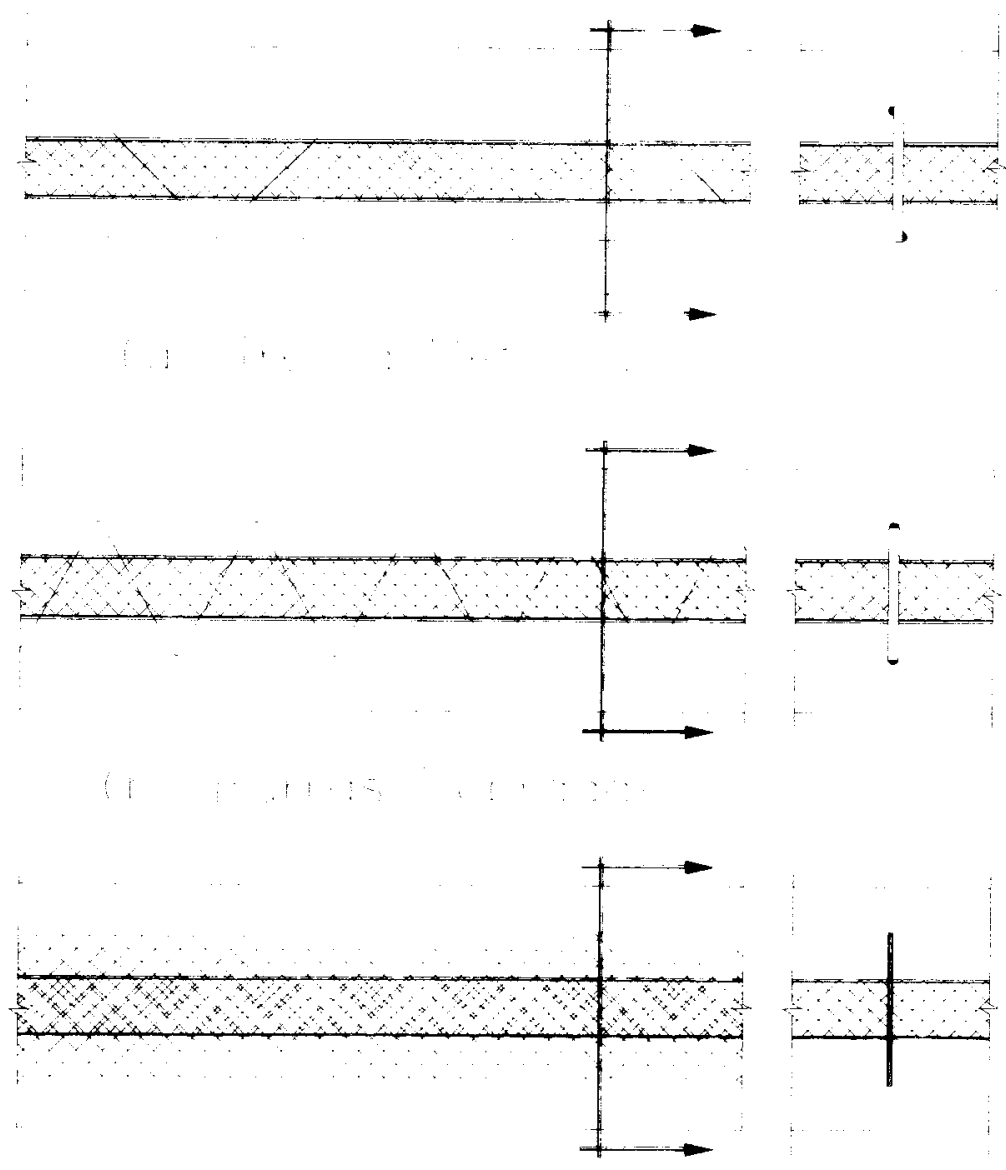

FIGURA 2.8. Alguns tipos de conectores metálicos. Á esquerda seção longitudinal e a direita seção transversal. 


\section{ANÁLISE ESTRUTURAL DE VIGAS SANDUÍCHE}

\subsection{Introdução}

Painéis sanduiche são elementos de considerável eficiência estrutural, conseguida através da separação das faces por um núcleo de um material de baixa densidade. Este último, quando possui um valor do módulo de deformação transversal muito baixo, proporciona uma considerável deformação transversal, e em consequência tem-se um aumento no deslocamento transversal do painel, tratado aqui como viga. A influência da deformação transversal do núcleo, associada em alguns casos à rigidez das faces, no comportamento à flexão, necessita de teorias apropriadas para sua análise.

Este assunto vem sendo estudado e discutido por vários engenheiros de forma a se resolver o problema analítica e numericamente.

PLANTEMA (1966), analisa inicialmente o problema de flexão de vigas sanduíche considerando os efeitos separados da força cortante e do momento fletor, introduzindo o conceito de energia de deformação para um elemento $d x$ da viga.

ALLEN (1969), faz um estudo completo sobre painéis sanduíche. O estudo inicia aplicando a teoria simples de vigas da Resistência dos Materiais, fazendo uma discussão sobre face fina (pouca rigidez à flexão) e núcleo fraco (nenhuma rigidez à flexão). Em seguida é feita a análise de vigas com faces grossas (significativa rigidez à flexão) e núcleo fraco, considerando isoladamente, por superposição, os efeitos do momento fletor e da força cortante.

HARTSOCK; CHONG (1976) mostram o desenvolvimento matemático para o cálculo de deslocamentos e tensões para painéis (vigas) com faces 
grossa e núcleo fraco (rigidez à flexão desprezivel). Os momentos fletores e as forças cortantes que agem na seção da viga e os que agem nas faces são tratadas separadamente, superpondo-se, de modo a se obter, através da solução de uma equação diferencial de segunda ordem, a expressão para o deslocamento, dado as condições de contorno e carregamentos atuantes.

HARTSOCK ainda faz neste mesmo trabalho uma comparação da teoria desenvolvida, ensaiando-se à flexão, vigas sanduiche de faces de metal e núcleo de espuma rígida de poliuretano expandida entre as faces, sujeita à carga uniformemente distribuida ao longo do vão, obtendo resultados que validam suas expressões.

FROSTIG (1993), fez uma investigação analítica do comportamento à flexão de vigas sanduíche, com núcleo fraco e diafragmas transversais unidos as faces, usando principios variacionais. As faces e os diafragmas são modelados como vigas e o núcleo é analisado pela teoria da elasticidade bidimensional. É determinado ainda a interação entre o núcleo e o diafragma. A presença do diafragma afeta o comportamento da viga de forma global e local. Estes efeitos são importantes para a segurança da estrutura e são determinados pela análise da viga inteira, bem como na vizinhança do diafragma

HA (1993), apresentou a solução do problema construindo uma matriz de rigidez para a viga sanduiche, sujeito a carregamentos e condições de contorno arbitrários. A teoria é aplicada para faces grossas (boa rigidez à flexão) e faces finas (baixa rigidez à flexão), com ou sem nervuras fazendo a conexão entre as faces.

O problema pode ser ainda resolvido por modelagem numérica através do Método dos Elementos Finitos. Segundo HA (1990), vários modelos de elementos finitos tem sido propostos para análise de placas sanduiche. As características destes elementos variam muito em termos de complexibilidade de formulação, precisão e aplicação.

HINTON, E; OWEN (1984), desenvolveu um programa para análise de cascas e placas de laminados compostos, que utiliza elementos finitos isoparamétricos de 8 e 9 nós, com matriz de rigidez obtida através da integração numérica de gauss, sendo que ao longo da espessura aplica-se o Método de Estrato (Layered model). Pode-se levar em consideração a deformação transversal. O procedimento interativo da solução do sistema não linear, é feita através de algoritmos do tipo Newton Raphson, podendo 
levar em conta a não linearidade do tipo física (plastificação e geométrica). O modelo constitutivo elástico permite levar em conta, caracteristicas de anisotropia.

A seguir, é feito um estudo detalhado sobre vigas sanduíche de forma a se obter expressões explícitas para os deslocamentos e tensões baseado na formulação de ALLEN (1969).

\subsection{Aplicação da teoria elementar da flexão}

A viga sanduíche ilustrada na fig.3.1 consiste de duas faces de espessura $t$, intercalada por um material de baixa densidade (núcleo) e espessura $c$. A altura total da viga é h e a largura é b.

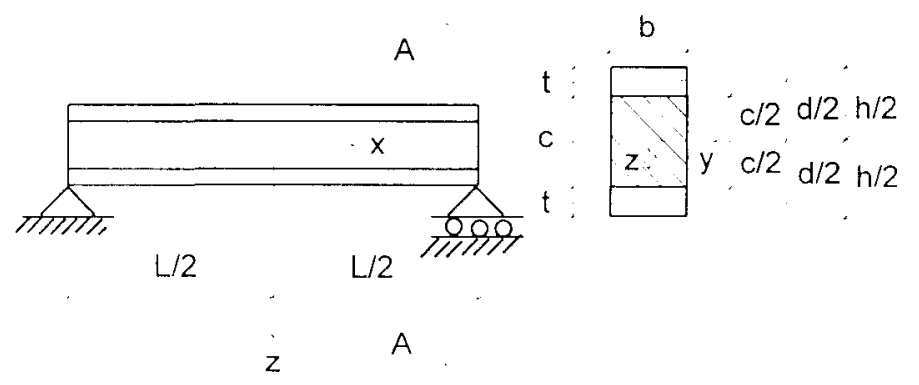

FIGURA 3.1. Viga Sanduiche. Caracteristica geométricas

As três camadas são supostas perfeitamente aderidas uma à outra e o material das faces é muito mais rígido em relação ao núcleo. Assume-se também que o material das faces e do núcleo são ambos isotrópicos. A viga sanduíche em estudo é uma viga estreita, tal que as tensões na direção y podem ser consideradas despreziveis.

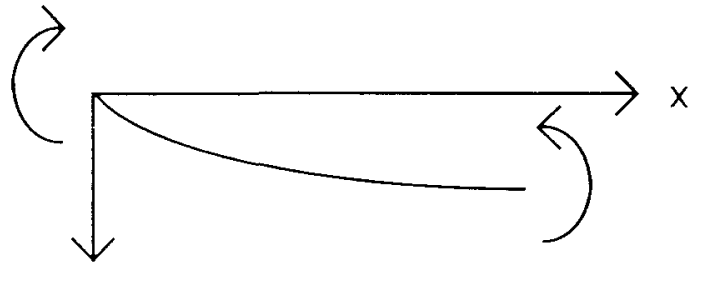

(a)

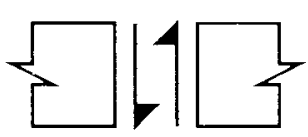

(b)

FIGURA 3.2. Convenção de sinais. a) Deslocamento e momento positivos, curvatura negativa. b) Força cortante, tensão cisalhante e deformação transversal positivos. 
As tensões e os deslocamento transversais deste tipo de viga podem ser encontrados, numa primeira aproximação, pelo uso da teoria simples da flexão. Supõem-se que as seções transversais permanecem planas, tomadas normalmente ao seu eixo longitudinal, quando submetida à flexão. Esta suposição leva à relação momento $\times$ curvatura $(M \times 1 / R)$ :

$$
\frac{M}{E l}=-\frac{1}{R}
$$

O sinal negativo introduzido na eq.(3.1) está de acordo com a convenção de sinal da fig.3.2. El é a rigidez à flexão, que para uma viga simples é o módulo de elasticidade longitudinal (E) multiplicado pelo momento de inércia (I). A viga da fig.3.1 é uma viga de seção composta, assim, sua rigidez à flexão, é a soma das rigidezes das duas partes separadas, faces e núcleo, calculadas em relação ao eixo central da seção inteira. Então tem-se:

$$
D=E_{f} \frac{b t^{3}}{6}+E_{f} \frac{b t d^{2}}{2}+E_{c} \frac{b c^{3}}{12}
$$

onde $E_{f}$ e $E_{c}$ são os módulos de elasticidade das faces e do núcleo respectivamente e d a distância entre os eixos centrais das faces.

Os primeiros dois termos da eq. (3.2) representam as rigidezes das faces, associadas com a flexão em torno do eixo central da seção transversal. Destes dois, o primeiro representa a rigidez das faces em relação aos seus próprios eixos centrais. O terceiro termo representa a rigidez à flexão do núcleo.

$\mathrm{Na}$ prática o segundo termo é muito maior que os outros dois, os quais podem portanto nos casos usuais, ser desprezados. O primeiro termo é menor que $1 \%$ do segundo quando:

$$
3\left(\frac{d}{t}\right)^{2}>100
$$

$\mathrm{O}$ erro cometido ao se desprezar o terceiro termo é muito pequeno, desde que a condição $d / t>5,77$ seja atendida. Vigas sanduíche com faces de metal atendem a esta condição, sendo que por outro lado, vigas com 
faces grossa e baixa resistência, como é o caso de argamassa armada e cimento amianto, não satisfazem.

O terceiro termo é menor que $1 \%$ do segundo (podendo ser desprezado) quando:

$$
6 \frac{E_{F}}{E_{C}} \frac{t}{c}\left(\frac{d}{c}\right)^{2}>100
$$

As tensões nas faces podem ser determinadas pelo uso da teoria simples da flexão, adaptada a natureza da seção, podendo-se escrever:

$$
\sigma_{f}=\frac{M z}{D} E_{f} \quad\left(\frac{c}{2} \leq z \leq \frac{h}{2} \quad ; \quad-\frac{h}{2} \leq z \leq-\frac{c}{2}\right)
$$

A máxima tensão nas faces se dá quando $\mathrm{z}$ é igual $\mathrm{a} \pm \mathrm{h} / 2$ :

$$
\left(\sigma_{\mathrm{f}}\right)_{\text {má } x}= \pm \frac{M E_{f}}{D} \frac{h}{2} .
$$

A tensão cisalhante, pela teoria ordinária da flexão, para uma viga de seção homogênea e altura $z$, é:

$$
\tau=\frac{V M_{S}}{\mathrm{lb}} .
$$

Onde $\mathrm{V}$ é a força cortante da seção considerada, I é o momento de inércia da seção em relação ao seu eixo axial, b é a largura e $M_{\mathrm{s}}$ é o momento de área da parte da seção para $z>z_{1}$. A distribuição de tensão cisalhante para uma seção I é mostrada na fig.3.3.
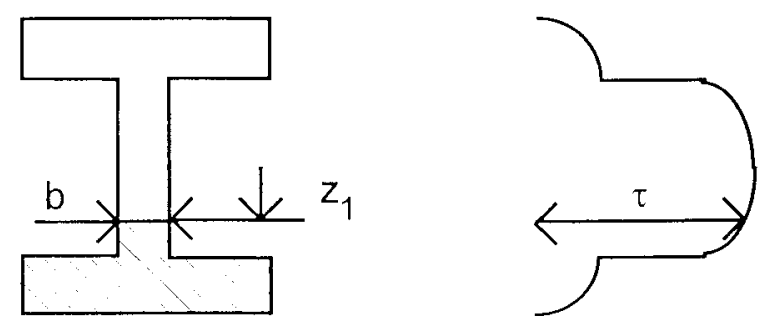

FIGURA 3.3.Distribuição de tensão cisalhante numa viga de seção I. 
Para uma viga composta semelhante à viga da fig.3.1, a eq.(3.7) deve ser modificada a fim de se levar em conta os módulos de elasticidade dos diferentes componentes da seção:

$$
\tau=\frac{V}{D b} \sum\left(M_{s} E\right)
$$

Onde $D$ é a rigidez à flexão da viga sanduíche e $\sum\left(M_{S} E\right)$ representa o produto de $M_{S}$ por $E$ para a parte da seção onde $z>z_{1}$. Se calcularmos a tensão cisalhante em uma altura $z$ no núcleo da viga sanduíche da fig.3.1, obtem-se:

$$
\sum(S E)=E_{f} \frac{b t d}{2}+\frac{E_{c} b}{2}\left(\frac{c}{2}+z\right)\left(\frac{c}{2}-z\right) .
$$

Substituindo a eq.(3.9) em (3.8), tem-se:

$$
\tau=\frac{V}{D}\left[E_{f} \frac{t d}{2}+\frac{E_{c}}{2}\left(\frac{c^{2}}{4}-z^{2}\right)\right]
$$

Pode-se da mesma maneira encontrar a expressão da tensão cisalhante para as faces. A fig.3.4 mostra a distribuição de tensões para a seção completa.

A relação entre a máxima e a mínima tensão cisalhante no núcleo, é $\left(1+\frac{E_{C}}{E_{f}} \frac{1}{4} \frac{c^{2}}{t d}\right)$. Esta expressão é menor que $1 \%$ se atender a seguinte condição:

$$
4 \frac{E_{f}}{E_{c}} \frac{t}{c} \frac{d}{c}>100
$$

Logo, se a condição (3.11) for atendida, pode-se considerar a tensão no núcleo constante. Como a relação $\mathrm{d} / \mathrm{c}$ é para os casos usuais, próxima da unidade, as condições (3.4) e (3.11) são similares, podendo-se concluir que, quando o núcleo é fraco para proporcionar uma contribuição significativa para a rigidez do sanduiche, a tensão cisalhante pode ser considerada constante em toda a altura do núcleo. Então pode-se escrever $E_{C}=0$, que substituindo em (3.10), tem-se: 


$$
\tau=\frac{V}{D} \frac{E_{f} t d}{2}
$$

Se tivermos ao mesmo tempo, as condições (3.3), (3.4) e (3.11) atendidas, ou seja, faces com pouca rigidez à flexão e núcleo fraco, pode-se além de considerar $E_{c}=0$, desprezar o primeiro termo da eq.(3.2), obtendose para a tensão cisalhante:

$$
\tau=\frac{V}{b d}
$$

A fig.3.4.b mostra a distribuição de tensões para núcleo fraco com distribuição parabólica nas faces, e a fig.3.4.c representa a distribuição de tensões para núcleos fracos e faces com pouca rigidez à flexão, observando-se uma distribuição linear, tanto no núcleo como nas faces.

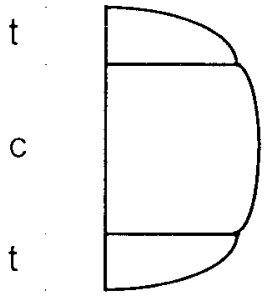

(a)

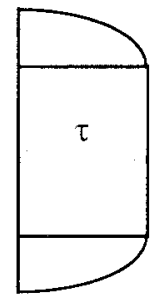

(b)

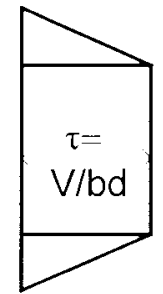

(c)

FIGURA 3.4. Distribuição de tensões na viga sanduíche. (a) Seção composta; (b) Efeito do núcleo fraco. (c) Efeito do núcleo fraco desprezando a rigidez das faces.

\subsection{Flexão de vigas sanduíche com núcleo fraco e faces finas}

Neste caso despreza-se a rigidez à flexão local das faces (condição (3.3) satisfeita), bem como a rigidez à flexão do núcleo, e a tensão cisalhante é constante em toda a altura do núcleo, satisfazendo as condições (3.4) e (3.11). Em consequência a tensão cisalhante fica determinada pela eq.(3.13) e a rigidez à flexão da viga pode ser escrita: 


$$
D=E_{f} \frac{b t d^{2}}{2}
$$

Os deslocamentos podem ser calculados separadamente por superposição dos efeitos do momento fletor e da força cortante. A ação do momento fletor resultará num deslocamento $a_{1}$, que pode ser calculado supondo um núcleo com o módulo de elasticidade transversal $(G)$ infinito. A força cortante causará uma deformação transversal no núcleo, conforme fig. 3.5, provocando um deslocamento adicional $a_{2}$.

Utilizando o princípios dos trabalhos virtuais (P.T.V.), pode-se determinar o deslocamento a no meio do vão da viga, para um dado estado de deslocamento, utilizando como estado de forças uma carga unitária no meio da viga. Logo, aplicando o P.T.V., tem-se:

$$
a=a_{1}+a_{2}=\int_{\text {estr. }} M d \phi+\int_{\text {estr. }} V d a_{2}
$$

Onde $d \phi=(\bar{M} / E I) d x$, para o estado de descolamentos dado, e pode-se ainda, encontrar uma relação entre $d a_{2} / d x$ e a deformação transversal do núcleo $(\gamma)$ a partir da fig.3.5:

$$
a_{2}^{\prime}=\frac{d a_{2}}{d x}=\gamma \frac{c}{d}=\frac{\bar{V}}{G b d} \frac{c}{d}=\frac{\bar{V}}{A G}
$$

onde $\mathrm{G}$ é o módulo de deformação transversal do núcleo e $\mathrm{A}=\mathrm{bd}^{2} / \mathrm{c}$.

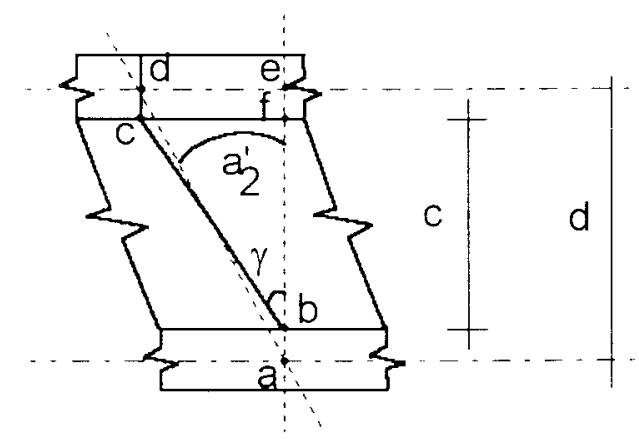

FIGURA 3.5. Deformação transversal de uma viga sanduiche 
Então, $d a_{2}=\frac{\bar{V}}{A G} d x$. Substituindo as expressões de $d a_{2}$ e $d \phi$ na eq.(3.15) tem-se:

$$
a=a_{1}+a_{2}=\frac{5 q L^{4}}{384 D}+\frac{q L^{2}}{8 A G}
$$

Por meio da eq.(3.17), dado o estado de deslocamento, determina-se facilmente o deslocamento no centro da viga. A seguir, é dado expressões de deslocamentos no centro do vão, de uma viga simplesmente apoiada de comprimento $\mathrm{L}$, para alguns casos particulares de carregamentos.

Carga uniformemente distribuida $q$ ao longo do comprimento $L$ da viga:

$$
a=a_{1}+a_{2}=\frac{5 q L^{4}}{384 D}+\frac{q L^{2}}{8 A G} .
$$

Força F concentrada no centro do vão da viga:

$$
a=a_{1}+a_{2}=\frac{F L^{3}}{48 D}+\frac{F L}{4 A G}
$$

Força $F / 2$ concentrada nos terços do vão da viga:

$$
a=a_{1}+a_{2}=\frac{23 F L^{3}}{1296 D}+\frac{F L}{6 A G} .
$$

Força F/2 concentrada nos quartos do vão da viga:

$$
\mathrm{a}=\mathrm{a}_{1}+\mathrm{a}_{2}=\frac{11 \mathrm{FL}}{768 \mathrm{D}}+\frac{\mathrm{FL}}{8 \mathrm{AG}} .
$$




\subsection{Flexão em vigas sanduíche com núcleos fracos e faces grossas}

Neste caso a rigidez à flexão das faces não é desprezada, considerando-se agora o primeiro termo da expressão (3.1), ou seja, a condição (3.3) não é satisfeita. São aplicadas as condições (3.4) e (3.11), isto é, o núcleo não contribui para a rigidez à flexão da viga e a tensão cisalhante é constante em toda a altura do núcleo (fig.3.4.b).

A distribuição de tensões normais nas faces, fica representado pela fig. 3.6.

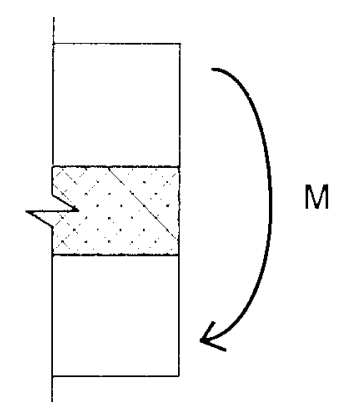

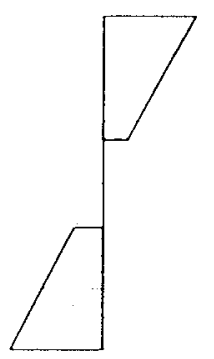

(a)

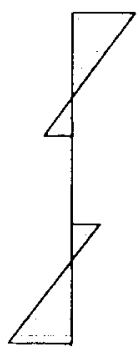

(b)

FIGURA 3.6. Distribuição de tensões normais para vigas sanduíche. a) Interação total entre as faces. b) Interação parcial entre as faces

A distribuição mostrada na fig.3.6b é provocada pela deformação transversal do núcleo, que causa nas faces uma flexão em torno de seus próprios eixos. Esta flexão local das faces, reduzem o deslocamento provocado pela deformação do núcleo. Este efeito é mostrado na fig.3.7.

Em muitos casos na prática, especialmente em faces finas, o efeito da deformação transversal do núcleo é pequeno. Quando as faces são grossas (como argamassa armada, cimento amianto e madeira compensada por exemplo) e o núcleo é fraco (espuma rígida de poliuretano ou poliestireno) este efeito é muito importante na análise da flexão.

Podemos analisar este caso superpondo os efeitos, considerando inicialmente um sanduíche com núcleo rígido $(G=\infty)$ atuando uma carga $q_{1}$ por unidade de comprimento. O deslocamento $a_{1}$ é calculado de acordo com a teoria elementar da flexão. Este deslocamento é associado a um momento fletor $M_{1}$ e a uma força cortante $V_{1}$, onde:

$$
-V_{1}=D a_{1}^{\prime \prime \prime}=E\left(I_{f}-I_{f}\right) a_{1}^{\prime \prime \prime}+E l_{f} a_{1}^{\prime \prime \prime} .
$$




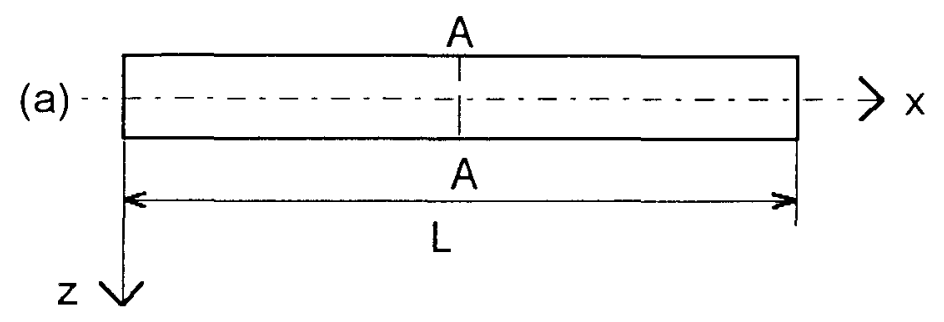

(b)
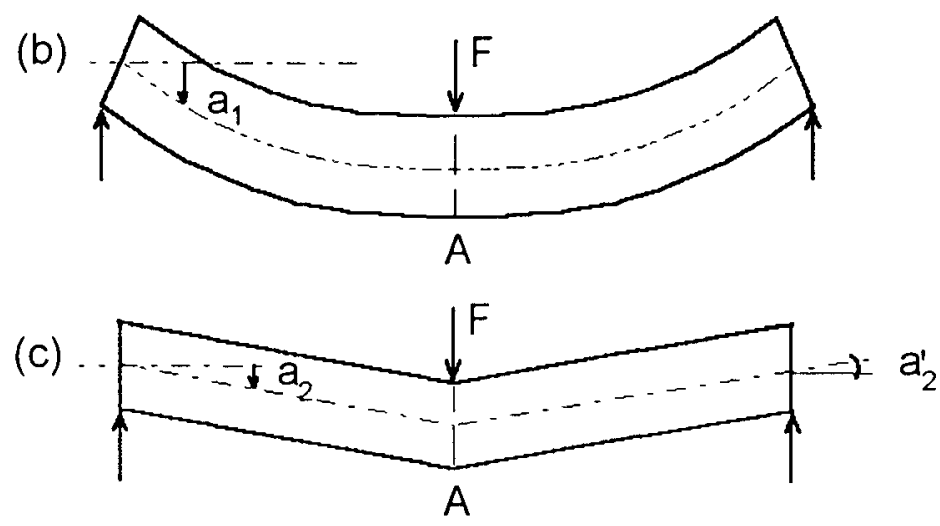

(d)

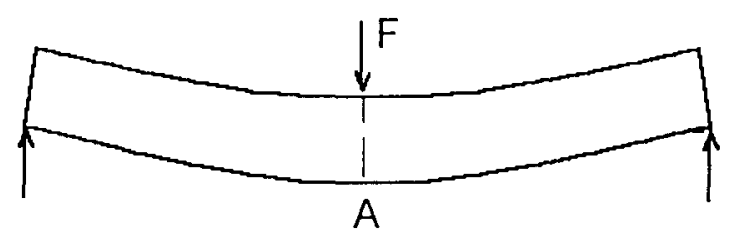

FIGURA 3.7. Flexão de vigas sanduíche. (a) viga sanduíche; (b) deslocamentos devido à flexão, $\mathrm{G}=\infty$; (c) deslocamentos devido à deformação do núcleo; (d) superposição dos efeitos.

A diferenciação é feita em relação a $x$. E é o módulo de elasticidade das faces, l é o momento de inércia das faces em relação ao eixo da viga e I é a soma dos momentos de inércia das faces em relação aos seus próprios eixos.

$$
\begin{aligned}
& I=\frac{b t^{3}}{6}+\frac{b t d^{2}}{2}, \\
& I_{f}=\frac{b t^{3}}{6} .
\end{aligned}
$$

O primeiro termo do lado direito da eq.(3.22) representa a força cortante submetida pela viga, sem considerar a flexão local das faces, logo a tensão cisalhante possui uma distribuição igual a fig.3.4c. Este termo pode 
ser escrito como - $\tau b d$, onde $\tau$ é a tensão cisalhante no núcleo. Substituindo na eq.22, tem-se:

$$
-V_{1}=-b d \tau+E l_{f} a_{1}^{\prime \prime \prime}
$$

Sabe-se que:

$$
q_{1}=-V_{1}^{\prime} ; \quad V_{1}=M_{1}^{\prime} ; \quad M_{1}=-D a_{1}^{\prime \prime}
$$

A tensão cisalhante $\tau$, ocasiona uma deformação transversal no núcleo $\gamma=\tau / G$, que corresponde a um deslocamento adicional $a_{2}$. As faces devem participar deste deslocamento, devendo portanto estar sujeito a uma outra distribuição de carga $q_{2}$, força cortante $V_{2}$ e momento fletor $M_{2}$, tal que:

$$
q_{2}=-V_{2}^{\prime} ; \quad V_{2}=M_{2}^{\prime} ; \quad M_{2}=-E l_{f} a_{2}^{\prime \prime}
$$

A carga total, força cortante, momento fletor e deslocamento, são agora:

$$
\begin{aligned}
& q=q_{1}+q_{2} \\
& V=V_{1}+V_{2} \\
& M=M_{1}+M_{2} \\
& a=a_{1}+a_{2}
\end{aligned}
$$

Pode-se dizer então que a viga sanduiche submetida a um carregamento total q sofre dois tipos distintos de deslocamentos, $a_{1}$ e $a_{2}$. O primeiro representa o deslocamento calculado a partir da teoria elementar da flexão, associada a força cortante $V_{1}$ dividida entre as faces e núcleo (eq.25). O segundo representa o deslocamento devido à deformação do núcleo provocada por $V_{1}$. As faces participam deste deslocamento fletindo em relação aos seus próprios eixos, fazendo também sofrerem uma força cortante $V_{2}$. A soma de $V_{1}$ e $V_{2}$ é a força cortante aplicada na viga.

Da eq.(3.16) tem-se:

$$
\gamma=\frac{d}{c} a_{2}^{\prime} .
$$


Podendo-se escrever para a tensão cisalhante, a partir de (3.32):

$$
\tau=\frac{\mathrm{d}}{\mathrm{c}} \mathrm{G} \mathrm{a}_{2}^{\prime}
$$

Substituindo $\tau$ na eq.(3.25), tem-se:

$$
-\mathrm{V}_{1}=-A G a_{2}^{\prime}+E I_{f} a_{1}^{\prime \prime \prime}
$$

Rearranjando a eq.(3.34) e substituindo $V_{1}=-D a_{1}^{\prime \prime}$, chega-se:

$$
a_{2}^{\prime}=-\frac{D}{A G}\left(1-\frac{l_{f}}{I}\right) a_{1}^{\prime \prime \prime}=+\frac{V_{1}}{A G}\left(1-\frac{l_{f}}{l}\right)
$$

A força cortante total é dado por:

$$
V=V_{1}+V_{2}=V_{1}-E I_{f} a_{2}^{\prime \prime \prime}
$$

Da equação (3.35) tira-se $a_{2}^{\prime \prime \prime}$, que substituindo em (3.36) chega-se a equação diferencial dada por:

$$
V_{i}^{\prime \prime}-k^{2} V_{1}=-k^{2} V
$$

onde, $\quad k^{2}=\frac{A G}{E I_{f}\left(1-\frac{l_{f}}{l}\right)}$.

Em qualquer problema em que $V$ é dado em função de $x$ pode-se encontrar $V_{1}$. Os valores de $M_{1}, a_{1}, q_{1}, M_{2}, a_{2}$ e $q_{2}$ podem ser encontrados por diferenciação e integração. Calculados estes valores, pode-se facilmente determinar as tensões nomais nas faces e as tensões cisalhantes no núcleo.

A seguir são estudados alguns casos particulares de carregamentos em vigas sanduíche, simplesmente apoiada, com faces grossas e núcleo fraco 


\subsubsection{Viga simplesmente apoiada com carga concentrada no meio do vão}

Por simetria pode-se considerar somente a metade da viga, o qual é - mesmo que considerar uma viga engastada em $A$ com a carga concentrada F/2 em B, conforme mostra a fig.3.8.

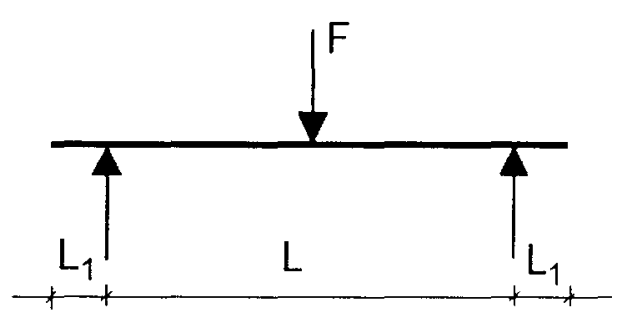

a)

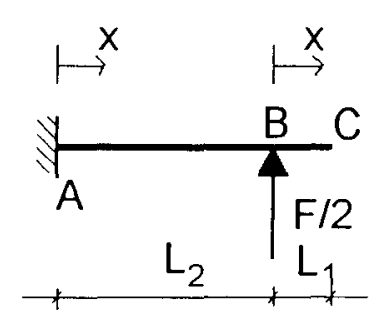

b)

FIGURA 3.8. a) Viga com carga $F$ concentrada no centro. b) Parte direita da viga.

Na parte $A B$, com origem de $x$ em $A$, a força cortante é - $F / 2$ e a solução geral da equação diferencial ( eq.(3.37)) de segunda ordem é dada por:

$$
-V_{1}=\underbrace{C_{1} e^{k x}+C_{2} e^{-k x}}_{\text {soluçẫ hom ogê nea }}+\underbrace{\frac{F}{2}}_{\text {soluça âo particular }}
$$

Sabe-se que $: \operatorname{senh}(k x)=\frac{e^{k x}-e^{-k x}}{2} e \cosh (k x)=\frac{e^{k x}+e^{-k x}}{2}$ e ainda,

$$
\begin{aligned}
& \operatorname{senh}(k x)+\cosh (k x)=e^{k x}, \\
& -\operatorname{senh}(k x)+\cosh (k x)=e^{-k x} .
\end{aligned}
$$

Substituindo-se as eq.(3.22), (3.40) e (3.41) em (3.39), chega-se a:

$$
D a_{1}^{\prime \prime \prime}=-V_{1}=C_{1} \cosh (k x)+C_{2} \operatorname{senh}(k x)+\frac{F}{2}
$$


Através de integrações sucessivas da eq.(3.42), tem-se:

$E l a_{1}=\frac{C_{1}}{k^{3}} \operatorname{senh}(k x)+\frac{C_{2}}{k^{3}} \cosh (k x)+\frac{F x^{3}}{12}+C_{3} x^{2}+C_{4} x+C_{5 .}(3.43)$

Pode-se escrever a eq.(3.35) da seguinte forma:

$$
V_{1}=E l_{f} a_{2}^{\prime} k^{2}
$$

Substituindo a eq.(3.44) em (3.42) e integrando, obtém-se:

$$
-E I_{f} a_{2}=\frac{C_{1}}{k^{3}} \operatorname{senh}(k x)+\frac{C_{2}}{k^{3}} \cosh (k x)+\frac{F x}{2 k^{2}}+C_{6}
$$

São verificadas cinco condições de contorno para a viga no trecho $A B$, enquanto nas eq.(3.43) e (3.45) apresentam-se seis constantes, $C_{1}$ $\mathrm{C}_{6}$.

i) $x=0, \quad a_{1}=0$

$$
\mathrm{C}_{5}+\frac{\mathrm{C}_{2}}{\mathrm{k}^{3}}=0 \text {. }
$$

ii) $\mathrm{x}=0, \quad \mathrm{a}_{1}^{\prime}=0$

$$
\frac{\mathrm{C}_{1}}{\mathrm{k}^{2}}+\mathrm{C}_{4}=0 \text {. }
$$

iii) $x=0, \quad a_{1}^{\prime \prime \prime}=0$

$$
\mathrm{C}_{1}+\frac{\mathrm{F}}{2}=0 \text {. }
$$

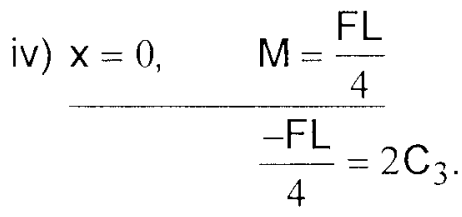

$$
\text { v) } \frac{x=0, \quad a_{2}=0}{\frac{\mathrm{C}_{2}}{\mathrm{k}^{3}}+\mathrm{C}_{6}=0}
$$


Resolvendo este sistema de cinco equações e seis incógnitas, encontra-se:

$$
C_{1}=-\frac{F}{2} ; C_{3}=-\frac{F L}{8} ; C_{4}=+\frac{F}{2 k^{2}} ; C_{5}=C_{6}=-\frac{C_{2}}{k^{3}} .
$$

No trecho $\mathrm{BC}$, com a origem do eixo $\mathrm{x}$ em $\mathrm{B}$, a força cortante total é zero. A solução da equação diferencial fica sendo somente a parte homogênea, tem-se portanto:

$$
-V_{1}=\underbrace{B_{1} e^{k x}+B_{2} e^{-k x}}_{\text {solução homogênea }}
$$

Que pode ser escrita da seguinte forma, segundo as eq.(3.40) e (3.41):

$$
-V_{1}=B_{1} \cosh (k x)+B_{2} \operatorname{senh}(k x)
$$

A partir da eq.(3.52) pode-se chegar de forma análoga a equações semelhantes ao do trecho $A B$, a menos dos termos que contém $F$.

$$
\begin{gathered}
\mathrm{Ela}_{1}=\frac{B_{1}}{k^{3}} \operatorname{senh}(k x)+\frac{B_{2}}{k^{3}} \cosh (k x)+B_{3} x^{2}+B_{4} x+B_{5} \\
-E_{f} a_{2}=\frac{B_{1}}{k^{3}} \operatorname{senh}(k x)+\frac{B_{2}}{k^{3}} \cosh (k x)+B_{6} .
\end{gathered}
$$

São introduzidas nas eq.(3.53) e (3.54), 6 incógnitas, $B_{1}-B_{6}$, e no trecho $\mathrm{BC}$ são verificadas quatro condições de contorno:

$$
\begin{aligned}
& \text { vi) } \begin{array}{l}
\mathrm{x}=0, \quad \mathrm{a}_{1}=0 \\
5+\frac{\mathrm{B}_{2}}{\mathrm{k}^{3}}
\end{array}=0 . \\
& \text { vii) } \mathrm{x=0,} \quad \frac{\mathrm{a}_{2}=0}{\frac{\mathrm{B}_{2}}{\mathrm{k}^{3}}+\mathrm{B}_{6}}=0 .
\end{aligned}
$$


viii) $x=L_{1} \quad a_{1}^{\prime \prime}=0$

$$
\frac{B_{1}}{k} \operatorname{senh}\left(k L_{1}\right)+\frac{B_{2}}{k} \cosh \left(k L_{1}\right)+2 B_{3}=0 .
$$

ix) $x=L_{1}, \quad a_{2}^{\prime \prime}=0$

$$
\frac{B_{1}}{k} \operatorname{senh}\left(k L_{1}\right)+\frac{B_{2}}{k} \cosh \left(k L_{1}\right)=0 .
$$

As condições de contorno viii) e ix) partem da consideração dos momentos $M_{1}$ e $M_{2}$ serem iguais a zero em $x=L_{1}$, ou seja, a seção da extremidade é livre para rotacionar. Das eq.(3.55) a (3.58), chega-se:

$$
\mathrm{B}_{2}=-\mathrm{B}_{1} \tanh \left(\mathrm{kL}_{1}\right) ; \quad \mathrm{B}_{3}=0 ; \quad \mathrm{B}_{5}=\mathrm{B}_{6}=\frac{\mathrm{B}_{1}}{\mathrm{k}^{2}} \tanh \left(\mathrm{kL}_{1}\right) .
$$

Para resolver a indeterminação das eq.(3.50) e (3.59), resta ainda estabelecer a continuidade em B. É evidente que $a_{1}^{\prime}, a_{2}^{\prime}, a_{1}^{\prime \prime}$ e $a_{2}^{\prime \prime}$ devem ser contínuas. Somente duas condições de continuidade bastam para encontrar as incógnitas necessárias para resolver o problema do trecho $A B$.

x) $a_{2}^{\prime}$ é contínua em $B$

$$
C_{1} \cosh \left(\frac{k L}{2}\right)+C_{2} \operatorname{senh}\left(\frac{k L}{2}\right)+\frac{F}{2}=B_{1} .
$$

xi) $a_{1}^{\prime \prime}$ é contínua em $B$

$$
C_{1} \operatorname{senh}\left(\frac{k L}{2}\right)+C_{2} \cosh \left(\frac{k L}{2}\right)+\left(\frac{F L}{4}+2 C_{3}\right) k=B_{2}+2 B_{3} k
$$

Substituindo ${ }_{2}, B_{3}, C_{1}$ e $C_{3}$ das eq.(3.50) e (3.59), nas eq.(3.60) e (3.61), encontra-se $\mathrm{C}_{2}$ do sistema de equações formado.

$$
\mathrm{C}_{2}=\beta_{1} \frac{\mathrm{F}}{2}
$$

onde,

$\beta_{1}=\frac{\operatorname{senh}(\theta)-(1-\cosh (\theta)) \tanh (\phi)}{\operatorname{senh}(\theta) \tanh (\phi)+\cosh (\theta)} ; \quad \theta=\frac{k L}{2} ; \quad \phi=k L_{1}$. (3.63) 
Desta forma os valores das constantes $\mathrm{C}_{1}-\mathrm{C}_{6}$ são conhecidas. Substituindo-se nas eq. (3.43) e (3.45) tem-se a expressão do deslocamento, $a$, em função de $x$, no trecho $A B$. A eq.(3.33) pode ser usada como a expressão da tensão cisalhante no núcleo, $\tau$, em função de $x$, na mesma região. A tensão normal na face, pode ser escrita como:

$$
\sigma=M_{1} \frac{c+2 t}{2 l}+M_{2} \frac{t}{2 l_{f}}
$$

Derivando com relação a $x$, as eq.(3.43) e (3.45), obtém-se as expressões de $M_{1}$ e $M_{2}$, que substituindo na eq. (3.64) tem-se a expressão para a tensão normal $\sigma$, em função de $x$ no trecho $A B$. Os resultados destas operações são mostradas a seguir:

$$
\begin{aligned}
& \begin{array}{r}
a=-\frac{F x^{2} L}{24 E I}\left(3-\frac{2 x}{L}\right)-\frac{F L}{4 A G}\left(1-\frac{I_{f}}{l}\right)^{2}\{ \\
\left\{\frac{2 x}{L}-\frac{2}{k L}[\operatorname{senh}(k x)+\right. \\
\left.\left.+\beta_{1}(1-\cosh (k x))\right]\right\}
\end{array} \\
& \tau=-\frac{F}{2 b d}\left(1-\frac{l_{f}}{l}\right)\left(1-\cosh (k x)+\beta_{1} \operatorname{senh}(k x)\right), \\
& \sigma=\frac{F L}{4}\left\{\left[\left(1-\frac{2 x}{L}\right)-\frac{2}{k L}\left(\beta_{1} \cosh (k x)-\operatorname{senh}(k x)\right)\right] \frac{c+2 t}{2 l}+\right. \\
& \left.+\frac{2}{k L}\left(\beta_{1} \cosh (k x)-\operatorname{senh}(k x)\right) \frac{t}{2 l_{f}}\right\} .
\end{aligned}
$$

Os valores máximos de $a, \tau$ e $\sigma$ ocorrem em $x=L / 2, x=(1 / k) \tanh ^{-1} \beta_{1}$ e $x=0$, respectivamente:

$$
\begin{aligned}
& a_{\text {má } x}=-\frac{F L^{3}}{48 E I}-\frac{F L}{4 A G}\left(1-\frac{I_{f}}{l}\right)^{2} \psi_{1}, \\
& \tau_{\text {má } x}=-\frac{F}{2 b d}\left(1-\frac{I_{f}}{1}\right) \psi_{2},
\end{aligned}
$$




$$
\begin{aligned}
& \sigma_{\text {má } x}=\frac{F L}{4}\left[\frac{c+2 t}{2 l} \psi_{3}+\frac{t}{2 l_{f}}\left(1-\psi_{3}\right)\right], \\
& \psi_{1}=1-\frac{\operatorname{senh}(\theta)+\beta_{1}(1-\cosh (\theta))}{\theta} \\
& \psi_{2}=1-\sqrt{1-\beta_{1}^{2}}, \\
& \psi_{3}=1-\frac{\beta_{1}}{\theta} .
\end{aligned}
$$

Se G tender para zero, não haverá interação entre as faces e elas se comportaram de forma isolada. A expressão do deslocamento fica:

$$
a_{\text {max }}=-\frac{F L^{3}}{48 E I_{f}}
$$

Se G tender para o infinito, a deformação transversal do núcleo é desprezada, com interação total entre as faces. O deslocamento é dado por:

$$
a_{\text {máx }}=-\frac{F L^{3}}{48 E l}
$$

Se a espessura da face tender para zero a eq.(3.68) é particularizada para o caso do ítem 3.3, eq.(3.19).

\subsubsection{Viga simplesmente apoiada com carregamento uniformemente distribuído.}

Considere-se a viga da fig.3.9.a, de comprimento $L$ e balanço nos extremos de $L_{1}$. Por simetria, pode-se utilizar a metade da viga (fig.3.9.b) para análise da flexão, como foi feito no ítem anterior.

No trecho $A B$, com a origem de $x$ em $A$, a força cortante é -qx. $A$ solução da eq.(3.37), substituindo o valor de $V$, é dado por:

$$
-V_{1}=C_{1} \cosh (k x)+C_{2} \operatorname{senh}(k x)+q x
$$


De maneira análoga ao que foi feito para a força concentrada no meio do vão, através de integrações da eq.(3.76), e aplicando as condições de contorno e de continuidade em $B$, obtém-se as expressões para $a, \tau$ e $\sigma$ :

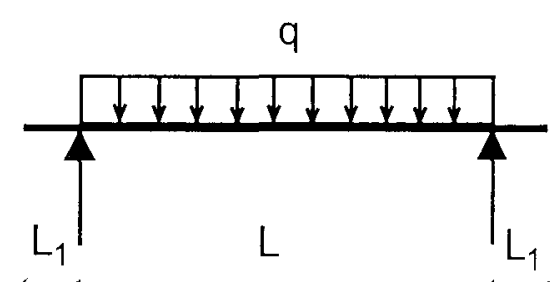

a)

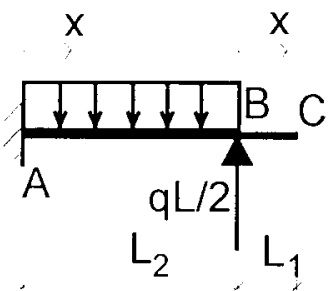

b)

FIGURA 3.9. a)Viga com carga uniformemente distribuída. b) parte direita da viga.

Condiçōes de contorno:

i) $x=0, \quad a_{1}=0$

ii) $\mathrm{x}=0, \quad \mathrm{a}_{1}^{\prime}=0$

iii) $x=0, \quad a_{1}^{\prime \prime \prime}=0$

iv) $x=0, \quad M=\frac{q^{2}}{8}$

vi) $\mathrm{x}=0, \quad \mathrm{a}_{2}=0$

vi) $\mathrm{x}=0, \quad \mathrm{a}_{1}=0$

vii) $\mathrm{x}=0, \quad \mathrm{a}_{2}=0$

viii) $x=L_{1}, \quad a_{1}^{\prime \prime}=0$

ix) $x=L_{1}, \quad a_{2}^{\prime \prime}=0$

x) $a_{2}^{\prime}$ e $a_{1}^{\prime \prime}$ continua em B 


$$
\begin{aligned}
& a=-\frac{q x^{2} L^{2}}{48 E I}\left(3-\frac{2 x^{2}}{L^{2}}\right)-\frac{q}{A G}\left(1-\frac{l_{f}}{l}\right)^{2}\left[\frac{x^{2}}{2}+\frac{\beta_{2} L^{2}}{4 \theta}(1-\cosh (k x))\right] \\
& \tau=-\frac{q L}{2 b d}\left(1-\frac{I_{f}}{l}\right)\left[\frac{2 x}{L}-\beta_{2} \operatorname{senh}(k x)\right] \\
& \begin{array}{l}
\sigma=\frac{q L^{2}}{8}\left\{\left[\left(1-\frac{4 x^{2}}{L^{2}}\right)-\frac{2}{\theta^{2}}\left(1-\beta_{2} \theta \cosh (k x)\right)\right] \frac{c+2 t}{2 l}+\right. \\
\left.\qquad \frac{2}{\theta^{2}}\left(1-\beta_{2} \theta \cosh (k x)\right) \frac{t}{2 I_{f}}\right\}
\end{array} \\
& \text { Onde, } \beta_{2}=\frac{1 / \theta+\tan (\phi)}{\cosh (\theta)+\operatorname{senh}(\theta) \tan (\phi)} ; \quad \theta=\frac{k L}{2} ; \quad \phi=k_{1}
\end{aligned}
$$

\subsubsection{Viga simplesmente apoiada com carga concentrada aplicada em dois pontos equidistantes}

Uma viga carregada em dois pontos equidistantes é mostrada na fig.3.10. A região central é sujeita a um momento fletor constante de $-F L_{b}$ fletindo segundo um arco de um círculo de curvatura $+F L_{b} / E l$. Este fato é usado para obter a rigidez à flexão El de vigas homogêneas, medindo-se o deslocamentos de três pontos na região central.

Este método pode ser usado também para a determinação da rigidez à flexão de vigas sanduíche com faces e núcleo rígidos, onde pode-se supor que na região central a força cortante é nula, não existindo deformação transversal, e o momento fletor é constante. Quando as faces são grossas e o núcleo é fraco, estas considerações não podem serem feitas e a região central não flete como um arco de um círculo.

$A$ força cortante $V$ é igual $a+F$ no trecho $B C$ e zero no trecho $A B$ e $\mathrm{CD}$. A solução da equação diferencial (3.37) é dada por:

$$
-V_{1}=B_{1} \cosh (k x)+B_{2} \operatorname{senh}(k x)-F .
$$




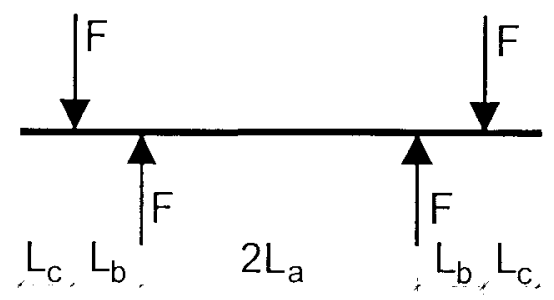

a)

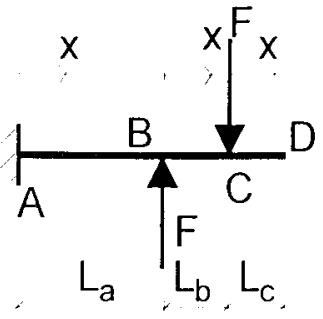

b)

FIGURA 3.10. a) Viga com quatro pontos de carregamentos. b) lado direito da viga

Procedendo-se da mesma maneira dos itens anteriores e aplicandose as condições de contorno e de continuidade em B e em C, obtém-se a expressão do deslocamento $\mathrm{a}$.

Condições de contorno:

$\begin{array}{ll}\text { trecho } A B \quad & \left\{\begin{array}{l}x=0, \\ a_{1}=a_{1}^{\prime}=a_{1}^{\prime \prime \prime}=a_{2}=0, \\ M=-F L_{b} .\end{array}\right. \\ \text { trecho } B C \quad\left\{\begin{array}{l}x=0, \\ a_{1}=a_{2}=0, \\ M=-F L_{b} .\end{array}\right. \\ \text { trecho } C D \quad\left\{\begin{array}{l}x=0, \\ a_{1}=a_{2}=0, \\ x=L_{c}, \quad a_{1}^{\prime \prime}=a_{2}^{\prime \prime}=0 .\end{array}\right.\end{array}$

Em B e C $a_{1}^{\prime}, a_{2}^{\prime \prime}, a_{1}^{\prime \prime}$ são contínuas.

O deslocamento, a tensão normal e a tensão cisalhante no núcleo são dados por:

$$
\begin{aligned}
& a=\frac{F L_{b}}{2} \frac{x^{2}}{E l}+\frac{\beta_{3} F}{a^{3} E I_{f}}(1-\cosh (k x))\left(1-\frac{I_{f}}{l}\right) \\
& \sigma=-\frac{F \beta_{3} \cosh (k x)}{k}\left(\frac{c+2 t}{1}+\frac{t}{I_{f}}\right)-\frac{F L_{b}}{l}(c+2 t)
\end{aligned}
$$




$$
\tau=-F \frac{d}{c k^{2}} \frac{G}{E_{f}} \beta_{3} \operatorname{senh}(k x)
$$

$$
\text { Onde, } \quad \beta_{3}=\frac{\operatorname{senh}\left(k L_{c}\right)-\operatorname{senh}\left(k\left(L_{b}+L_{c}\right)\right)}{\cosh \left(k\left(L_{a}+L_{b}+L_{c}\right)\right)} \text {. }
$$




\section{DIMENSIONAMENTO DE VIGAS SANDUÍCHE À FLEXÃO}

\subsection{Introdução}

A investigação do comportamento à flexão realizada neste trabalho, é para o caso particular de vigas sanduiche de faces de argamassa armada com núcleo de espuma rígida de poliuretano derivado de óleo vegetal, isento de CFC, expandido entre as faces.

Para este tipo de sanduiche é verificada na análise experimental tratada mais adiante, uma considerável deformação transversal do núcleo, devida a este ser fraco. Esta deformação transversal não pode ser desprezada no cálculo de deslocamentos e esforços da viga, bem como no dimensionamento, porém, neste capítulo será feito um estudo, para efeito de comparação, considerando a viga com o módulo de elasticidade do núcleo, $G$ muito grande, de modo que a deformação transversal seja muito pequena e possa ser desprezada, e as faces possam ter uma interação total entre elas.

Primeiro será feita a dedução das equações para a determinação do momento fletor resistente para o estado limite último, e em seguida mostrarse-á a dedução da equação para o momento de fissuração (estado limite de utilização). 


\subsection{Estado limite último}

\subsubsection{Determinação do momento fletor resistente de cálculo segundo as especificações da NBR 6118}

O cálculo do momento fletor resistente, no estado limite último, da viga submetida à flexão simples, foi feita com as hipóteses de cálculo prescritas pela NBR 6118/80 (Projeto e Execução de Obras de Concreto Armado). Todo o cálculo é feito para o estado limite último correspondente à ruína por ruptura e por deformação plástica excessiva.

\subsubsection{Hipóteses de cálculo}

As hipótese de cálculo prescritas pela NBR 6118 para a determinação do momento fletor resistente de cálculo no estado limite último, são as seguintes:

i) As seções transversais planas permanecem planas depois da peça sofrer deformações;

ii) Os casos possiveis de deformações, para peças submetidas à flexão simples são os representados pelos domínios 2, 3, 4 (fig.4.1);

- Domínio 2: flexão simples sem ruptura da argamassa $\varepsilon_{\mathrm{c}}<3,5 \%$ e $\varepsilon_{\mathrm{s}}$ igual ao máximo permitido $\left(\varepsilon_{\mathrm{s}}=10 \%\right)$;

- Dominio 3: flexão simples (seção subarmada) com ruptura à compressão da argamassa e com escoamento do aço $\left(\varepsilon_{\mathrm{s}} \geq \varepsilon_{y \mathrm{~d}}\right)$;

- Domínio 4: flexão simples ( seção superarmada) com ruptura à compressão da argamassa e aço tracionado sem escoamento $\left(\varepsilon_{\mathrm{s}}<\varepsilon_{y d}\right)$. 


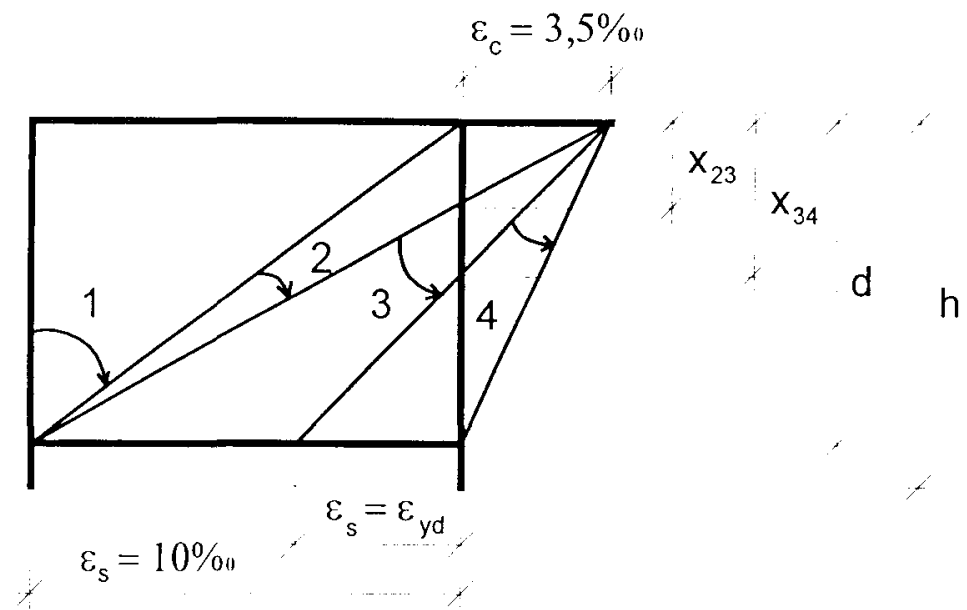

FIGURA 4.1. Domínios de deformações (NBR 6118).

iii) O encurtamento convencional de ruptura da argamassa nas seções não inteiramente comprimidas (flexão simples) é igual a 3,5\% \%

iv) O alongamento máximo permitido ao longo da armadura de tração, mais próxima da borda tracionada, é de $10 \%$;

v) A distribuição de tensões na argamassa é um diagrama parábolaretângulo simplificado de acordo a NBR 6118. O diagrama parábolaretângulo pode ser substituido por um diagrama retangular de altura $y=0,8 x$ com a seguinte tensão, considerando uma seção de largura constante:

$$
\sigma_{c d}=0,85 f_{c d}=\frac{0,85 f_{c k}}{\gamma_{c}}
$$

vi) A resistência à tração do concreto $\left(f_{t k}\right)$ é desprezada;

vii) A tensão na armadura é a correspondente à deformação determinada de acordo com a posição da linha neutra, que no caso da flexão simples deve seguir os limites dos domínios da fig. 4.1. Os diagramas tensão-deformação a adotar no cálculo são os indicados na fig.4.2 para os aços classe $A$ e B; 


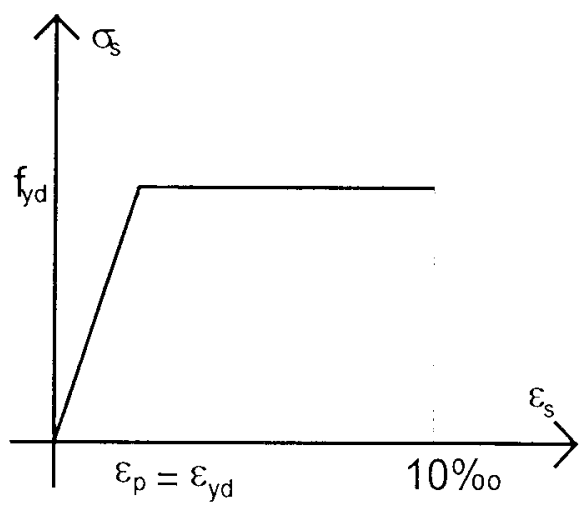

(a)

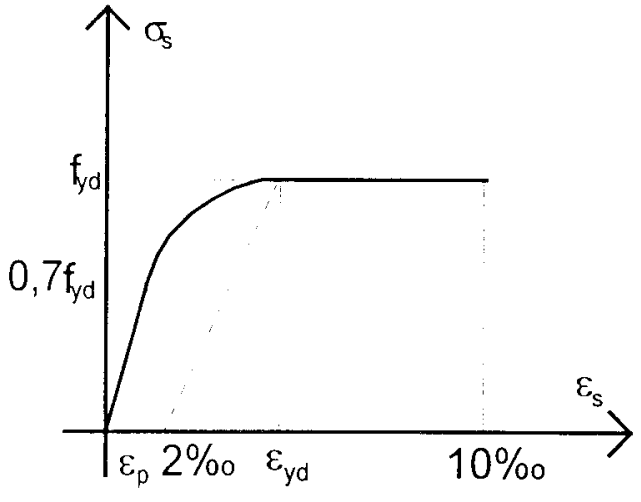

(b)

FIGURA 4.2. Diagrama de tensão-deformação do aço. a) Aço classe A. b) Aço classe B.

O módulo de deformação longitudinal da tela soldada será tomado igual ao dos fios que a constituem, s $=210.000 \mathrm{MPa}$;

viii) Os coeficientes de ponderação das resistências dos materiais, $\gamma_{c}$ para a argamassa e $\gamma_{s}$ para os aços da tela, são indicados na NBR 6118.

O coeficiente de majoração $\left(\gamma_{1}\right)$ deve ser definido de acordo com os critérios da NBR 8681.

A seguir são feitas as deduções das equações que fornecem o valor do momento fletor resistente de cálculo, para uma seção composta (seção sanduíche), analisando três casos possíveis para a posição da linha neutra: na face comprimida acima da armadura, na face comprimida abaixo da armadura e no núcleo.

\subsubsection{Caso em que a linha neutra se encontra na face comprimida acima da armadura}

A seção transversal da fig.4.3 está submetida à ação do momento fletor solicitante de cálculo $\left(\mathrm{M}_{\mathrm{rd}}\right)$. Fazendo-se um corte na peça por um plano perpendicular ao eixo da viga, para manter o equilibrio, a seção deve estar submetida a ações das resultantes normais dos fios das tela e da argamassa comprimida. 


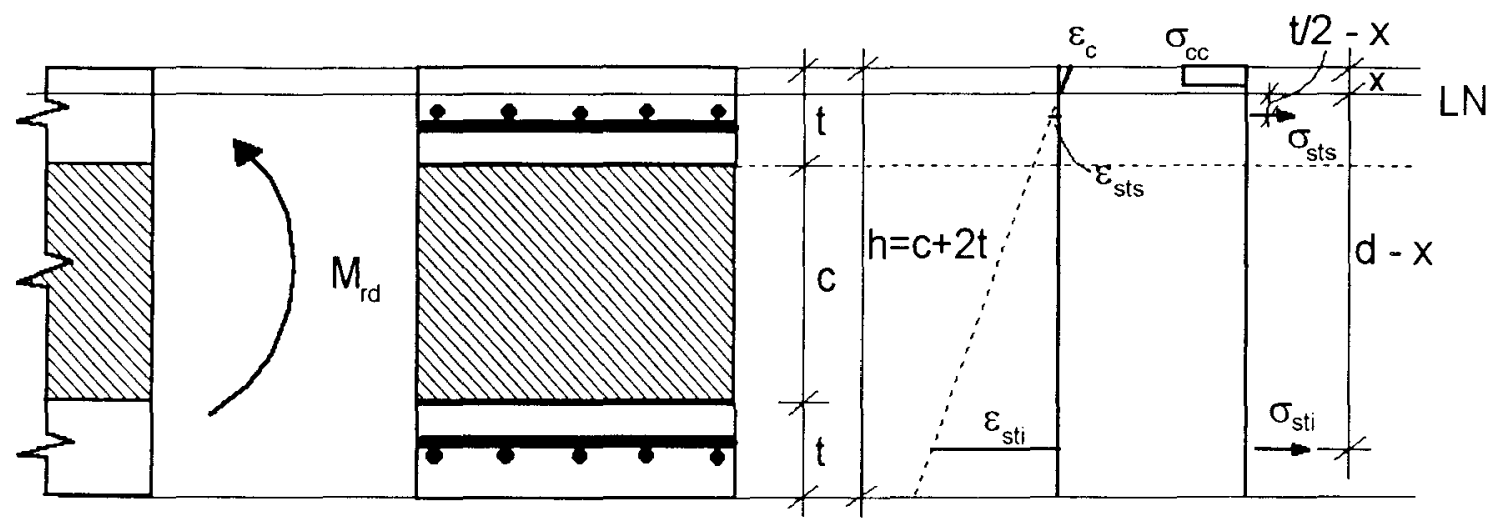

FIGURA 4.3. Flexão simples. Linha neutra na face comprimida acima da armadura.

Fazendo o equilíbrio das forças normais, que atuam na seção, resulta:

$$
\mathrm{R}_{\mathrm{cc}}=\mathrm{R}_{\mathrm{sts}}+\mathrm{R}_{\mathrm{sti}}
$$

onde:

$R_{c c}$ : resultante das tensões de compressão na argamassa;

$R_{\text {sts }}$ : resultante das tensões de tração da armadura da face superior;

$\mathrm{R}_{\mathrm{sfi}}$ : resultante das tensões de tração da armadura da face inferior;

O momento fletor $M_{r d}$ deve ser equilibrado pelas forças internas. Fazendo-se então o equilíbrio de momentos das forças resultantes em relação à força de tração no aço da face inferior, tem-se:

$$
M_{r d}=\gamma_{f} M_{k}=R_{c c}\left(d-\frac{0,8 x}{2}\right)-R_{s t s}\left(d-\frac{t}{2}\right)
$$

onde, $M_{k}$ : Momento fletor solicitante de serviço.

$\mathrm{x}$ : distância da fibra mais comprimida à linha neutra;

d: distância da borda mais comprimida à armadura da face tracionada.

As resultantes no concreto e no aço podem ser escritas como: 


$$
\begin{aligned}
& \mathrm{R}_{\mathrm{cc}}=0,85 \frac{\mathrm{f}_{\mathrm{ck}}}{\gamma_{\mathrm{c}}} 0,8 \times \mathrm{b}=0,68 \mathrm{f}_{\mathrm{cd}} \times \mathrm{b} ; \\
& \mathrm{R}_{\mathrm{sts}}=\mathrm{A}_{\mathrm{s}} \sigma_{\mathrm{sts}} ; \\
& \mathrm{R}_{\mathrm{sti}}=\mathrm{A}_{\mathrm{s}} \sigma_{\mathrm{sti}} ;
\end{aligned}
$$

onde,

$\mathrm{f}_{\mathrm{ck}}$ : resistência característica à compressão do concreto;

$\mathrm{f}_{\mathrm{cd}}$ : resistência de cálculo à compressão do concreto;

b: largura da seção;

$A_{s}$ : área de aço na seção transversal da face;

$\sigma_{\text {sts: }}$ tensão no aço da face superior;

$\sigma_{\text {sti: }}$ tensão no aço da face inferior.

Substituindo as eq.(4.4) e (4.5) em (4.3), obtém-se:

$$
M_{r d}=0,68 f_{c d} \times b(d-0,4 x)-A_{s} \sigma_{s t s}\left(d-\frac{t}{2}\right)
$$

Considerando a compatibilidade de deformações segundo a fig.4.3, chega-se as seguintes equações:

$$
\frac{\varepsilon_{c}}{x}=\frac{\varepsilon_{s t i}}{d-x}=\frac{\varepsilon_{s t s}}{t / 2-x}
$$

onde,

$\varepsilon_{\mathrm{c}}$ : deformação na fibra mais comprimida de concreto;

$\varepsilon_{\text {sts: }}$ : deformação no aço da face superior;

$\varepsilon_{\text {sti: }}$ : deformação no aço da face inferior.

\subsubsection{Caso em que a linha neutra se encontra na face comprimida abaixo da armadura}

Neste caso a linha neutra passa abaixo da armadura da face superior, como mostra a fig.4.4, fazendo com que a resultante das tensões do aço desta face seja de compressão. A equação de equilíbrio das forças internas da seção da peça é dada por: 


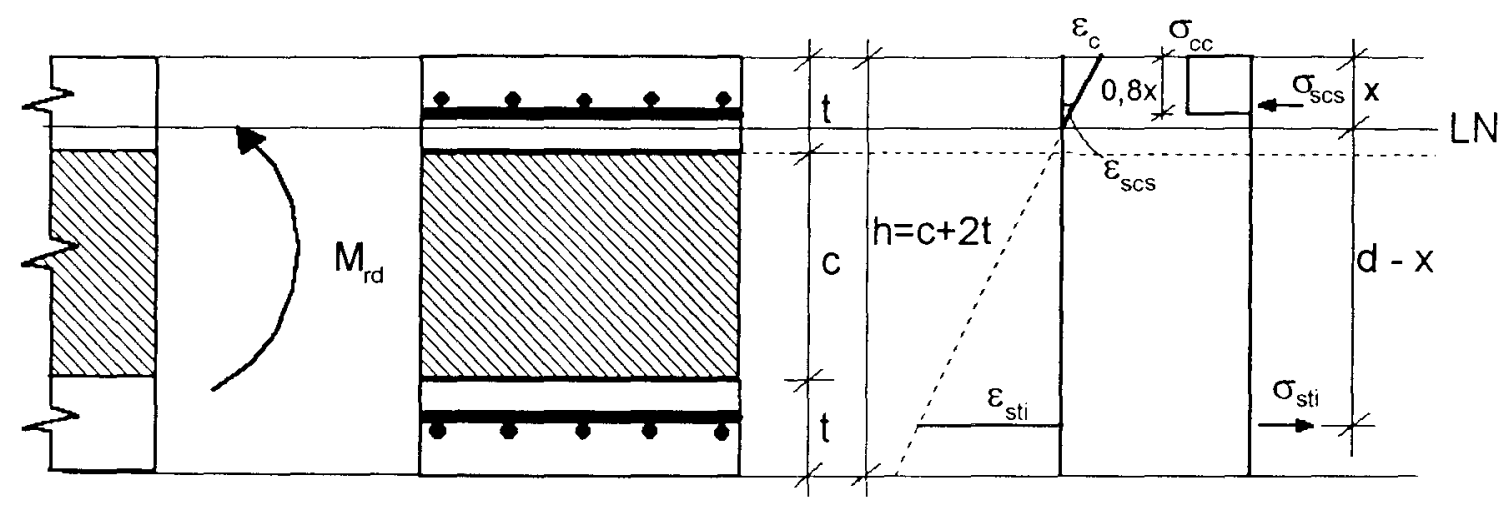

FIGURA 4.4. Flexão simples. Linha neutra na face comprimida abaixo da armadura.

$$
R_{c c}+R_{s c s}=R_{s t i}
$$

onde, $R_{\mathrm{Scs}}$ é a resultante das tensões de compressão no aço da face superior.

O momento fletor atuante em uma seção genérica, deve estar em equilibrio com o momento das resultantes das forças internas em relação a um polo fixo. Escolhendo para polo o ponto de aplicação da força $R_{s t s}$, temse:

$$
M_{r d}=\gamma_{f} M_{k}=R_{c c}\left(d-\frac{0,8 x}{2}\right)+R_{s c s}\left(d-\frac{t}{2}\right)
$$

A resultante das tensões de compressão no aço da face superior, é dada por: $R_{\mathrm{scs}}=A_{s} \sigma_{\mathrm{scs}}$. Substituindo $R_{\mathrm{scs}}$ e $R_{\mathrm{cC}}$ na eq. (4.10) resulta:

$$
M_{r d}=0,68 f_{c d} \times b(d-0,4 x)-A_{s} \sigma_{s c s}\left(d-\frac{t}{2}\right)
$$

Fazendo a compatibilidade de deformações, de acordo com a fig.4.4, obtém-se:

$$
\frac{\varepsilon_{c}}{x}=\frac{\varepsilon_{\text {sti }}}{d-x}=\frac{\varepsilon_{\text {scs }}}{x-t / 2}
$$

onde, $\varepsilon_{\text {scs }}$ é deformação no aço da face superior. 


\subsubsection{Caso em que a linha neutra se encontra no núcleo}

Neste caso a linha neutra passa abaixo da face inferior, se localizando no núcleo, fig.4.5. Fazendo-se o equilíbrio das forças internas, tem-se:

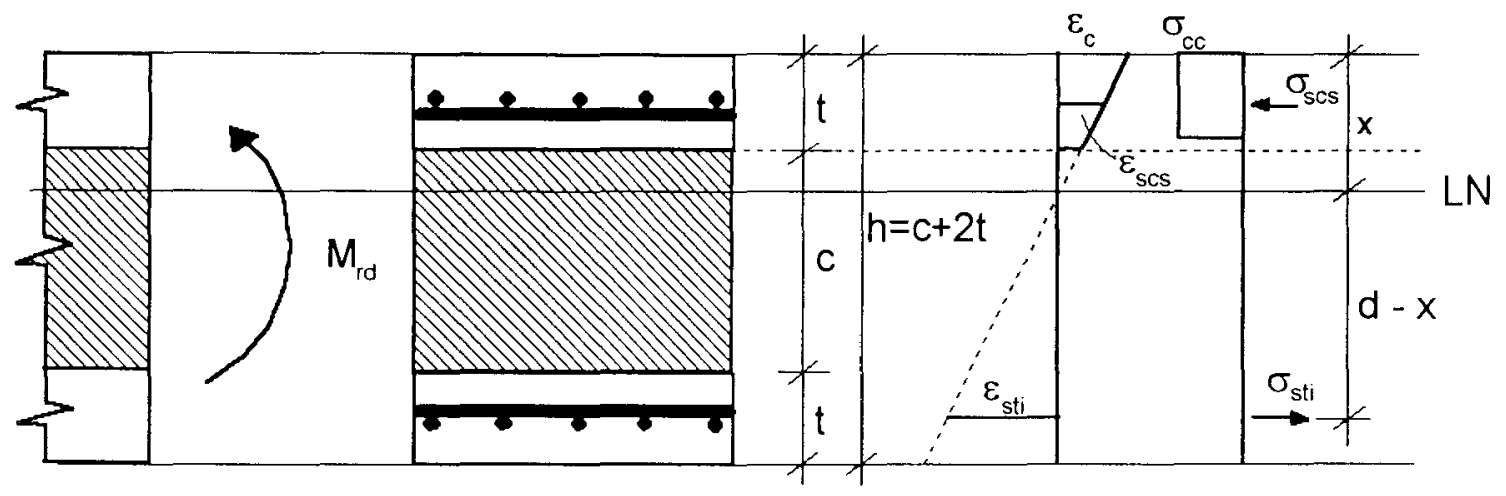

FIGURA 4.5. Flexão simples. Linha neutra localizada no núcleo.

$$
\mathrm{R}_{\mathrm{cc}}+\mathrm{R}_{\mathrm{scs}}=\mathrm{R}_{\mathrm{sti}} \text {, }
$$

Tomando-se o equilibrio de momentos das resultantes das forças internas em relação ao ponto de aplicação da força Rsts, tem-se:

$$
M_{r d}=\gamma_{f} M_{k}=R_{c c}\left(d-\frac{0,8 t}{2}\right)+R_{s c s}\left(d-\frac{t}{2}\right) .
$$

Substituindo Rscs e Rcc na eq. (4.14) resulta:

$$
M_{r d}=0,68 f_{c d} \times b(d-0,4 t)+A_{s} \sigma_{s c s}\left(d-\frac{t}{2}\right) .
$$

Fazendo a compatibilidade de deformações, de acordo com a fig.4.5, obtém-se:

$$
\frac{\varepsilon_{c}}{x}=\frac{\varepsilon_{\text {sti }}}{d-x}=\frac{\varepsilon_{\text {scs }}}{x-t / 2}
$$




\subsubsection{Solução dos sistemas de equações}

O problema é resolvido por processo iterativo, adotando-se a posição da linha neutra. Com a deformação de ruptura do concreto definido e usando as equações de compatibilidade, determinam-se as deformações no aço da tela da face superior e inferior. Conhecendo-se os diagramas tensãodeformação do aço que compõem as telas, determinam-se as tensões na armadura das faces.

Determinando-se as resultantes de compressão na argamassa, na tela comprimida e na tela tracionada, verifica-se através das equaçōes de equilibrio se a linha neutra escolhida produz equilibrio. Em caso positivo, a linha neutra proposta é a definitiva, no estado limite último, para a seção em estudo e para as hipóteses de cálculo escolhidas. Em caso contrário, repete-se o processo, tantas vezes quantas necessárias para se obter o equilibrio das forças normais.

Com a linha neutra determinada, obtém-se o valor do momento fletor resistente de cálculo usando as equações deduzidas para um dos três casos estudados. Através deste valor define-se o momento fletor solicitante de cálculo, determinando-se a ação caracteristica que se pode aplicar à viga em estudo. 


\subsection{Estado limite de utilização}

São assumidas aqui as mesmas considerações feitas no ítem anterior, no qual a deformação transversal do núcleo não é levada em conta, seguindo-se as prescrições da NBR 6118 para o estado limite de utilização.

As verificações dos estados limites de utilização, são feitas considerando os carregamentos, ou seja, as solicitaçōes de serviço previstas para o uso normal das peças fletidas.

\subsubsection{Momento de fissuração}

\subsubsection{Hipóteses de cálculo}

As hipóteses de cálculo adotadas são as mesmas utilizadas para peças fletidas de concreto armado, que supöe o material homogêneo, isotrópico e elástico

A formulação teórica do problema, seguindo as proposições da NBR 6118, assume as seguintes hipóteses:

i) A deformação de ruptura à tração da argamassa é igual a 1,5×2,7 $f_{t k} E_{c}$, onde $f_{t k}$ e $E_{c}$ são a resistência à tração e o módulo de elasticidade longitudinal da argamassa, respectivamente;

ii) O diagrama de tensões de compressão na argamassa é triangular e a tensão na zona tracioada é uniforme e igual a $\mathrm{f}_{\mathrm{k} k}$;

iii) seções transversais planas permanecem planas.

O efeito da retração deve sempre ser levado em conta e pode ser considerado, de maneira simplificada e somente nas condições correntes de utilização do material, supondo-se a tensão de tração igual a $0,75 f_{\mathrm{tk}} \mathrm{e}$ desprezando-se a armadura.

Com base nestas hipóteses e considerando a seção da viga sanduíche, desprezando a contribuição das armaduras e conhecendo-se a resistência à tração da argamassa, pode-se determinar o momento fletor de 
fissuração $\left(M_{r}\right)$ no estádio $l b$, através das equações de equilibrio para as forças normais e equações de compatibilidade de deformações.

Nos ítens seguintes são deduzidas as equaçōes que fornecem o momento fletor de fissuração, para a seção em estudo, considerando dois casos possiveis da posição da linha neutra.

\subsubsection{Caso em que a linha neutra se localiza na face superior}

Com base nas hipóteses feitas anteriormente, os diagramas de tensões e deformações, na seção transversal, são mostrados na fig.4.6.
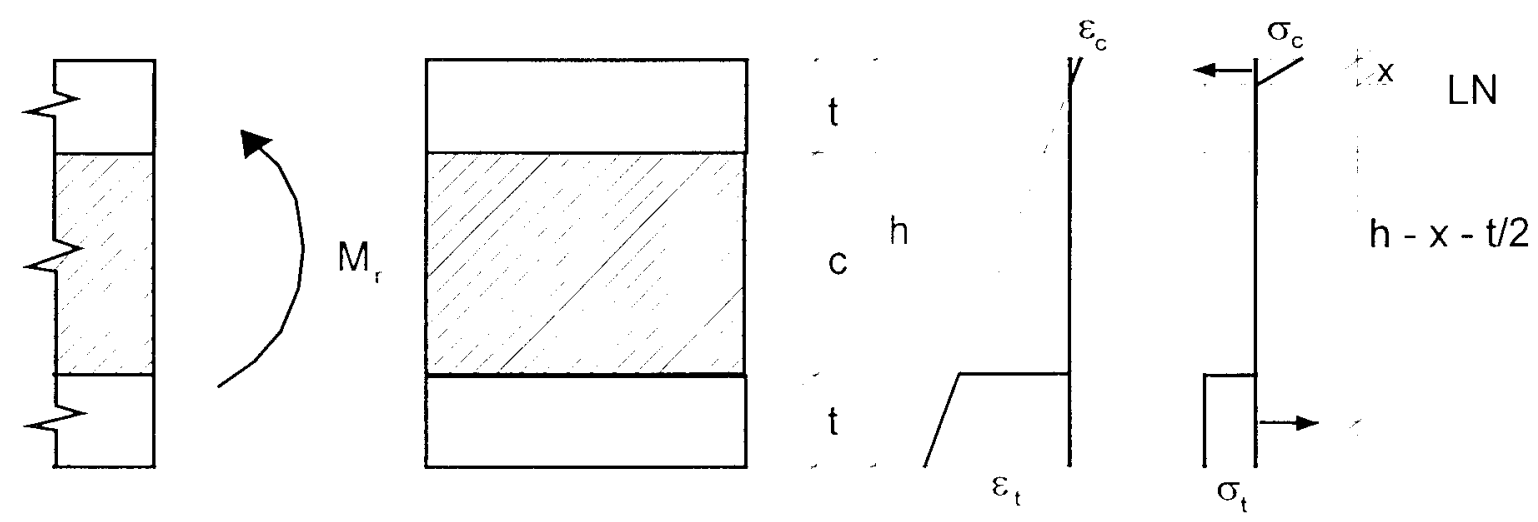

FIGURA 4.6. Momento de fissuração da argamassa. Formulação teórica de acordo com a NBR 6118. Linha neutra passando na face superior.

$$
\begin{aligned}
& \varepsilon_{t}=1,5 \cdot 2,7 f_{t j} / E_{c}=4,05 f_{t j} / E_{c} \\
& \sigma_{t}=f_{t j} \text { (sem consideração da retração), ou } \\
& \sigma_{t}=0,75 f_{t j} \text { (com consideração da retração), }
\end{aligned}
$$

onde,

$\varepsilon_{1}$ : deformação especifica da argamassa à tração;

$f_{t:}$ : resistência média a tração dos corpos de prova à idade de ensaio;

$\mathrm{E}_{\mathrm{c}}$ : módulo de deformação longitudinal da argamassa. 
Para o caso da seção da fig.4.6, sujeita a flexão normal simples, temse:

i) Equações de compatibilidade de deformações:

$$
\frac{\varepsilon_{c}}{x}=\frac{\varepsilon_{t}}{h-x}=\frac{4,05 f_{t j}}{E_{c}(h-x)} .
$$

ii) Equações de equilíbrio:

$$
\sum N=0 \quad \sigma_{c} b x / 2=\sigma_{t} t b=f_{t j} t b
$$

$\sum M=M_{r} \quad \frac{\sigma_{c} \times b}{2}\left(\frac{2 x}{3}+h-x-\frac{t}{2}\right)=M_{r}$,

onde,

$\varepsilon_{c}$ : deformação específica da argamassa à compressão;

$x$ : distância da fibra mais comprimida à linha neutra;

h: altura total da seção transversal;

b: largura da seção transversal;

$\sigma_{c}$ : tensão normal de compressão na argamassa;

$M_{r}$ : momento de fissuração.

Pode-se escrever, para esse estágio de comportamento:

$$
\sigma_{\mathrm{c}}=\mathrm{E}_{\mathrm{c}} \varepsilon_{\mathrm{c}}
$$

Substituindo a eq.(4.23) em (4.21), obtém-se:

$$
\varepsilon_{c}=\frac{2 f_{t j} t}{E_{c} x} .
$$

Combinando-se as eq.(4.20) e (4.24), tem-se:

$$
x=\frac{2 \text { th }}{4,05+2 t}
$$

Substituindo a eq.(4.25) em (4.21) e (4.22), chega-se: 


$$
\begin{gathered}
\sigma_{c}=\frac{f_{\mathrm{tj}}(4,05+2 t)}{h} \\
M_{r}=\left(\frac{4,05 h+1,333 h t-2,025 t-t^{2}}{4,05+2 t}\right) f_{t j} t b
\end{gathered}
$$

Da eq.(4.27), substituindo os valores de $h, t, b$ e $f_{t j}$ determina-se o momento de fissuração para a viga sanduiche.

\subsubsection{Caso em que a linha neutra se localiza no núcleo}

Para este caso o diagrama de deformações e tensões são mostrados através da fig.4.7.

Seguindo-se os mesmos passos do item anterior, tem-se:

i) Equação de compatibilidade de deformações:

$$
\frac{\varepsilon_{c}}{x}=\frac{\varepsilon_{t}}{h-x}=\frac{4,05 f_{t j}}{E_{c}(h-x)} .
$$

ii) Equações de equilíbrio:

$$
\sum N=0 \quad\left(\frac{\sigma_{c}+f}{2}\right) t b=\sigma_{t} t b=f_{t j} t b
$$

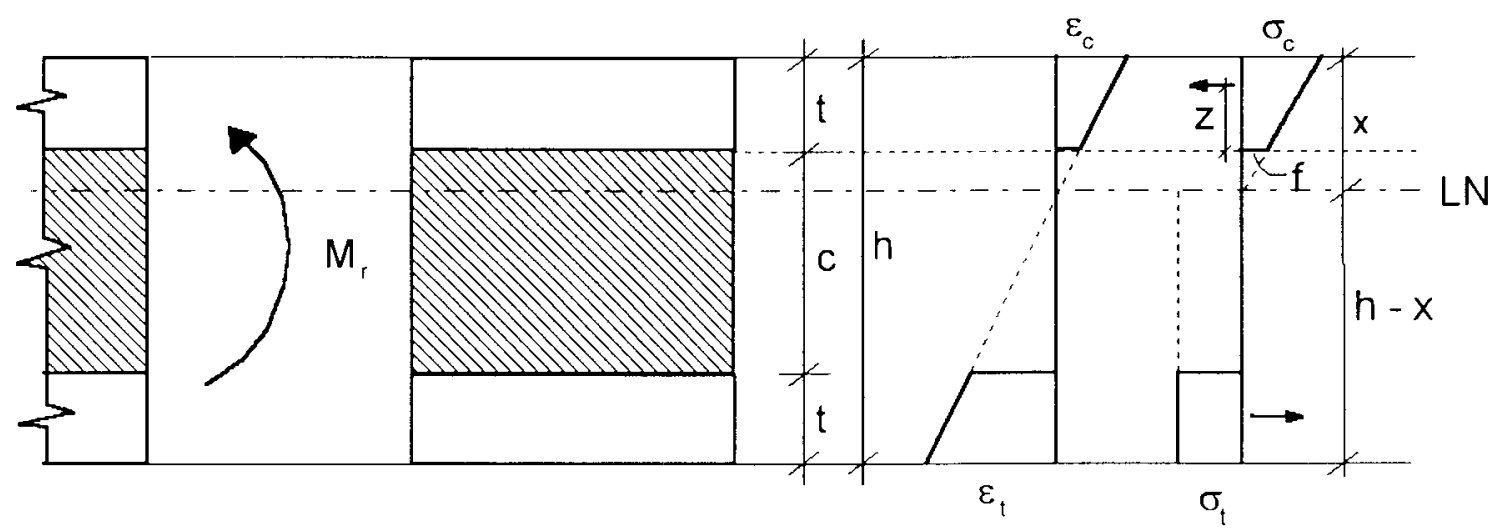

FIGURA 4.7. Momento de fissuração da argamassa. Formulação teórica de acordo com a NBR 6118. Linha Neutra passando no núcleo. 


$$
\sum M=M_{r} \quad\left(\frac{\sigma_{c}+f}{2}\right) t b(z+c+t / 2)=M_{r},
$$

onde,

$$
f=\frac{\sigma_{c}(x-t)}{x}
$$

e

$$
z=\frac{2 \sigma_{c}+f}{\sigma_{c}+f} \cdot \frac{t}{3}
$$

Substituindo a eq.(4.31) em (4.29), resulta:

$$
\frac{\sigma_{c}}{2}\left(\frac{2 x-t}{x}\right)=f_{t j}
$$

Combinando-se as eq.(4.23) e (4.33), tem-se

$$
\varepsilon_{c}=\frac{2 f_{t j}}{E_{c}(2 x-t)} .
$$

Substituindo a eq.(4.34) em (4.28), obtém-se:

$$
x=\frac{2 c+8,05 t}{10,1}
$$

Determinada a expressão para $x$, chega-se facilmente as equações para a tensão $\sigma_{\mathrm{c}}$ e o momento de fissuração $\mathrm{M}_{\mathrm{r}}$, mostrado a seguir:

$$
\sigma_{c}=\frac{f_{\mathrm{tj}}(\mathrm{c}+4,025 \mathrm{t})}{\mathrm{c}+1,5 \mathrm{t}}
$$

e

$$
M_{r}=f_{t j} t b\left(\frac{2+\varphi}{1+\varphi} \cdot \frac{t}{3}+c+\frac{t}{2}\right)
$$

onde:

$$
\varphi=\frac{c-1,025 t}{c+4,025 t}
$$


Para se fazer a consideração simplificada da retração, basta multiplicar por 0,75 os valores obtidos de $\sigma_{c}$ e $M_{r}$ para os dois casos estudados.

\subsubsection{Verificação do estado de deformação excessiva}

Os valores dos deslocamentos, provenientes das deformações, não devem ser maiores que os indicados na NBR 6118, no caso de peças moldadas no local e, maiores que os preconizado pela NBR 9062 para peças pré-moldadas.

De acordo com a NBR 6118 deve-se observar os seguintes limites para vigas e lajes:

a) As flechas medidas a partir do plano que contém os apoios, quando atuarem todas as ações, não devem ultrapassar $l / 300$ ( $l$ é o vão teórico) e, no caso de balanços $l / 150$;

b) Os deslocamentos causados pelas cargas acidentais não deve ser maior que $l / 500$ e $l / 250$ no caso de balanços.

No caso de elementos pré-moldados a NBR 9062 estipula valores limites de flechas e contra-flechas em função da utilização do elemento estrutural. Para elementos estruturais de cobertura sem contato nos apoios, com outros elementos, estruturais ou não, as limitações indicadas são as seguintes:

c) l/150 de contra-flecha (flecha negativa) iniciais de longo prazo, incluindo o efeito das cargas permanentes;

d) / 1400 de flechas positivas, considerando carga eventual de empoçamento de água;

e) l/200 de flechas positivas, nos casos em que o elemento tenha inclinação que evite o empoçamento de água.

Quando os elementos estruturais de cobertura estiverem em contato com outros elementos estruturais ou não estruturais, nas regiões fora dos apoios, a variação da flecha, calculada para as ações de longa duração e carga acidental, não deve ser maior que l/250.

No caso de elementos de piso, que não suportem ou que não tenham contato com elementos não estruturais, a flecha positiva máxima, quando todas as cargas estiverem agindo, devem ser igual a: 
f) $l / 500$, no caso de flecha inicial;

g) l/300, no caso de flecha medida a longo prazo.

A variação da flecha, calculada para ações de longa duração e carga acidental não deve ser maior que $l / 250$.

Os limites indicados devem ser obedecidos no caso de elementos de piso que suportem ou que estejam em contato, fora dos apoios, com elementos estruturais ou não estruturais.

$\mathrm{Na}$ verificação do estado de deformação excessiva deve-se calcular o momento de inércia supondo a peça em serviço, isto é, no estádio II, peça fissurada e distribuição linear de tensões na região comprimida da viga.

No estádio II, o concreto abaixo da linha neutra é considerado fissurado, não contribuindo para a resistência da peça. A posição da linha neutra é calculada considerando que o momento estático, da seção da argamassa comprimida, acima da linha neutra, e da seção de aço da face inferior, transformada em seção de concreto, é igual a zero

Para homogeneizar a seção, basta multiplicar as áreas de armadura por:

$$
\alpha_{e}=\frac{E_{s}}{E_{c}}
$$

Assim a área de concreto homogeneizada, fica:

$$
A_{c h}=\alpha_{e} A_{s}+A_{c}
$$

A seção homogeneizada é uma seção ideal com um só módulo de deformação longitudinal, $E_{c}$.

Considerando a viga sanduiche com faces de argamassa armada, determina-se a seguir o momento de inércia fissurado para dois casos possíveis da linha neutra para o estádio II: Linha neutra localizada na face comprimida e linha neutra localizada no núcleo.

\subsubsection{Caso em que a linha neutra se localiza na face superior (comprimida)}

Tomando-se o momento estático da seção homogeneizada igual a zero, para a linha neutra localizada na face superior, tem-se: 

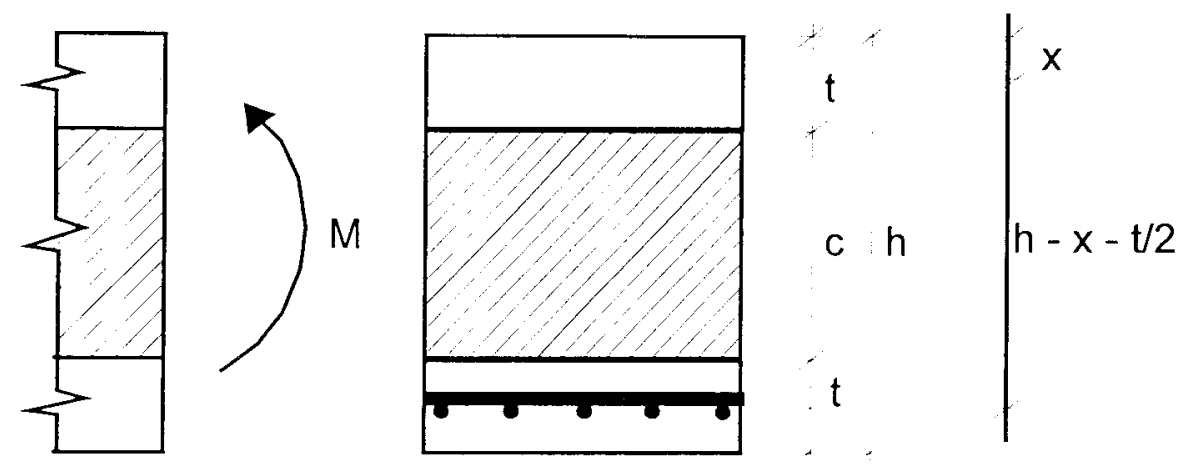

LN

FIGURA 4.9. Linha neutra localizada na face comprimida.

$$
\frac{b x^{2}}{2}-\alpha_{e} A_{s}(h-x-t / 2)=0
$$

Rearrumando-se, obtém-se:

$$
\frac{b}{2} x^{2}+\alpha_{e} A_{s} x+\alpha_{e} A_{s}(t / 2-h)=0
$$

O momento de inércia é obtido da seguinte equação:

$$
I_{\|}=\frac{b x^{3}}{3}+\alpha_{e} A_{s}(h-x-t / 2)^{2}
$$

Resolvendo-se a eq.(4.47), determina-se o valor de $x$, que susbtituindo na eq.(4.48) obtém-se o momento de inércia para o estádio II.

\subsubsection{Caso em que a linha neutra se localiza no núcleo}

De modo análogo ao ítem anterior, tomando-se o momento estático da seção homogeneizada igual a zero, para a linha neutra localizada no núcleo, tem-se: 

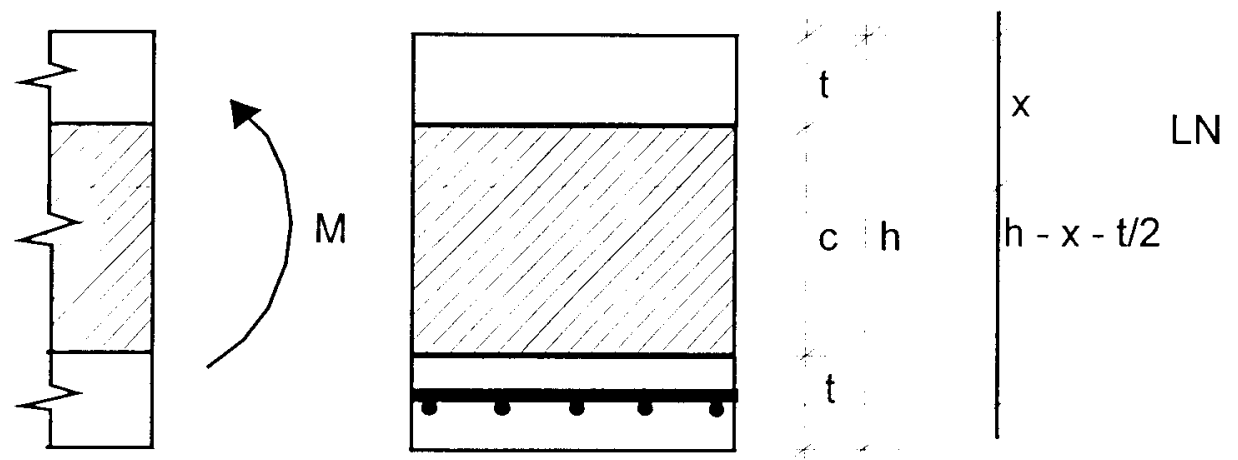

FIGURA 4.10. Linha neutra localizada no núcleo.

$$
b t(x-t / 2)-\alpha_{e} A_{s}(h-x-t / 2)=0 .
$$

Isolando o valor de $\mathrm{x}$ da eq.(4.49), obtém-se:

$$
x=\left(\frac{b t^{2}}{2}+\alpha_{e} A_{s} h-\frac{\alpha_{e} A_{s} t}{2}\right) /\left(b t+\alpha_{e} A_{s}\right)
$$

Substituindo o valor de $x$, encontrado da eq.(4.50), na eq.(4.51) determina-se o momento de inércia da seção fissurada. 


\subsubsection{Indicações para o cálculo dos deslocamentos segundo a norma de argamassa armada (NB-1259)}

Determinado o momento de inércia no estádio $I I$, pode-se então calcular os deslocamentos provenientes da flexão considerando as curvaturas fornecidas na tabela 4.1.

TABELA 4.1. Valores das curvaturas (1/r).

\begin{tabular}{lcc}
\hline \multicolumn{1}{c}{ Tipos de ações } & Curta duração & Longa duração \\
\hline $\begin{array}{l}\text { Região com pequena } \\
\text { probabilidade de formação } \\
\text { de fissuras }\left(\mathrm{M}_{\max } \leq \mathrm{M}_{\mathrm{r}}\right)\end{array}$ & $\frac{\mathrm{M}}{0,85 \mathrm{E}_{\mathrm{c}} \mathrm{I}_{\mathrm{h}}}$ & $\frac{\mathrm{M} \phi_{\mathrm{cc}}}{0,85 \mathrm{E}_{\mathrm{c}} \mathrm{I}_{\mathrm{h}}}$ \\
\hline $\begin{array}{l}\text { Região com grande } \\
\text { probabilidade de formação } \\
\text { de fissuras }\left(\mathrm{M}_{\max }>\mathrm{M}_{\mathrm{r}}\right)\end{array}$ & $\frac{\mathrm{M}}{0,85 \mathrm{E}_{c} \mathrm{I}_{\mathrm{r}}}$ & $\frac{\mathrm{M} \phi_{\mathrm{cc}}}{0,85 \mathrm{E}_{c} \mathrm{I}_{\mathrm{r}}}$ \\
\hline
\end{tabular}

onde:

$\mathrm{E}_{c}$ : Módulo de deformação longitudinal;

$\mathrm{I}_{\mathrm{h}}$ : Momento de inércia da seção homogeneizada, que simplificadamente pode ser considerado igual ao momento de inércia da seção geométrica;

$\mathrm{I}_{\Gamma}$ : Momento de inércia da seção fissurada, que simplificadamente pode ser considerado igual ao momento de inércia da seção no estádio II $\left(l_{\| 1}\right) ;$

$\phi_{c c}$ : Coeficiente que considera o efeito da fluência da argamassa, cujos valores constam na tabela 4.2;

$M_{\text {máx: }}$ : Momento máximo;

$M_{r}$ : Momento de fissuração.

TABELA 4.2. Valores dos coeficientes $\phi_{c c}$.

\begin{tabular}{lcc}
\hline Umidade ambiental média & Cura normal & Cura a vapor \\
\hline $40 \%$ ou mais & 2,6 & 3,0 \\
\hline menor que $40 \%$ & 3,9 & 4,5 \\
\hline
\end{tabular}




\section{ANÁLISE EXPERIMENTAL}

\subsection{Introdução}

$\mathrm{Na}$ fase experimental deste trabalho, foram executados ensaios de flexão em vigas sanduíches, com faces de argamassa armada, e ensaios de cisalhamento da espuma rígida (ER) de poliuretano utilizada como núcleo.

Em uma etapa preliminar foram estudadas e fixadas as principais caracteristicas dos modelos a ensaiar, em vista dos ensaios descritos na literatura e em normas específicas sobre os procedimentos destes ensaios.

Com o intuito de predizer o comportamento dos modelos a ensaiar, a fim de se poder fazer uma programação dos trabalhos, foram ensaiados inicialmente alguns exemplares de vigas e da ER.

Nos dois tipos de ensaios realizados ( flexão de vigas e cisalhamento da espuma) aplicou-se carregamento às peças até que elas atingissem a ruptura. Ao longo das etapas de carregamento, foram sendo acompanhados os deslocamentos e as deformações das peças.

No ensaio de flexão foram observadas a carga responsável pelo aparecimento da primeira fissura visivel e a carga de ruptura das peças.

No ensaio de cisalhamento da espuma verificou-se as cargas para o qual o material deixa de trabalhar no regime elástico e a que atinge a resistência máxima (ruptura da peça). 


\subsection{Definição das características dos materiais dos modelos}

\subsubsection{Argamassa}

A argamassa utilizada na moldagem das placas de face, foi preparada na proporção de 1:2,5 em massa, com relação água/cimento de 0,45. O cimento utilizado foi o Cimento Portland Comum (CP 32). Com este traço o consumo de cimento ficou com aproximadamente $580 \mathrm{~kg}$ por metro cúbico de argamassa. Este traço tem sido bastante utilizado em diversos trabalhos realizados no Laboratório de Estrutura da EESC - USP.

Como agregado miúdo utilizou-se areia natural, enquadrada como areia média dentro dos limites granulométricos da NBR 7211 - "Agregado para concreto".

\subsubsection{Armadura: tipo e disposição}

Optou-se por utilizar telas soldadas como armadura das placas de face, variando-se o número de camadas, com a intenção de se fazer uma investigação da influência da armadura no comportamento à flexão do sanduiche.

A tela soldada utilizada possui as seguintes especificações segundo o fabricante (TELCON S.A. - Indústria e comércio):

TABELA 5.1. Especificações da tela soldada utilizada na confecção dos modelos

\begin{tabular}{|c|c|c|c|c|c|c|c|c|}
\hline \multirow[t]{2}{*}{ Designação } & \multicolumn{3}{|c|}{$\begin{array}{c}\text { Espaçamento } \\
\text { entre fios }\end{array}$} & \multicolumn{2}{|c|}{$\begin{array}{l}\text { Diâmetro dos } \\
\text { fios } \\
\end{array}$} & \multicolumn{2}{|c|}{$\begin{array}{l}\text { Seção dos } \\
\text { fios }\end{array}$} & \multirow{2}{*}{$\begin{array}{l}\text { Peso } \\
\mathrm{kgf} / \mathrm{m}^{2}\end{array}$} \\
\hline & $\begin{array}{c}\text { Long } \\
\mathrm{cm}\end{array}$ & & $\begin{array}{c}\text { Transv. } \\
\mathrm{cm}\end{array}$ & $\begin{array}{c}\text { Long. } \\
\mathrm{mm}\end{array}$ & $\begin{array}{c}\text { Transv. } \\
\mathrm{mm}\end{array}$ & $\begin{array}{l}\text { Long. } \\
\mathrm{cm}^{2} / \mathrm{m}\end{array}$ & $\begin{array}{c}\text { Transv } \\
\vdots \\
\mathrm{cm}^{2} / \mathrm{m} \\
\end{array}$ & \\
\hline EL $126 / 63$ & 2,5 & $x$ & 2,5 & 2,0 & $\times \quad 2,0$ & 1,26 & $\times 0,63$ & 1,48 \\
\hline
\end{tabular}

Largura: máxima de $0,95 \mathrm{~m}$

comprimento: $60 \mathrm{~m}$

Aço: CA 60 
Com esta tela foram estudados arranjos representativos das armaduras usuais de argamassa armada. Foram feitos dois tipos de arranjos de armadura para os modelos.

O primeiro, designado PS I, constituiu-se de duas telas soldadas justa postas, com as malhas desencontradas (fig.5.1a), representando uma peça de argamassa armada com uma considerável seção de aço.

O segundo, designado PS II, compreendeu peças de argamassa armada com uma única tela, representando uma peça pouca armada (fig.5.1b).

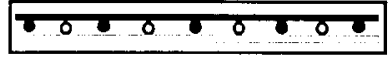

$1,25 \mathrm{~cm}$

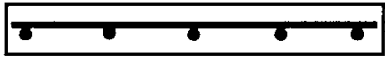

$2,5 \mathrm{~cm}$

(a)

(b)

FIGURA 5.1. Arranjos das armaduras dos modelos. a) PS I. b) PS II

\subsubsection{Espuma rígida}

$\mathrm{Na}$ confecção do painel sanduiche, utilizou-se como núcleo uma espuma rígida de poliuretano (ER) derivado de óleo vegetal, isenta de CFC, cujos componentes ER 170 e FNC 40 foram produzidos pelo Laboratório de Química Analitica e Tecnologia de Polímeros - LQATP - do Instituto de Química de São Carlos, da Universidade de São Paulo - IQSC - USP. Os componentes foram misturados na relação $1: 2$, em massa, proporcionando uma densidade média após a expansão de $78,0 \mathrm{~g} / \mathrm{dm}^{3}$.

Os componentes da espuma são misturados e homogeneizados, lançando-se a mistura entre as faces de argamassa armada no interior de uma fôrma. A mistura expande, aderindo às faces, resultando uma espuma rígida responsável pela transferência de esforços de interação entre as placas de face quando a viga é solicitada. 


\subsection{Metodologia Experimental}

\subsubsection{Ensaios de flexão}

\subsubsection{Descrição dos ensaios}

Os ensaios de flexão foram realizados com a aplicação de carga em vigas simplesmente apoiadas, medindo-se os deslocamentos transversais e as deformações específicas correspondente às diversas etapas de carregamento. Foi observado a carga de primeira fissura, como também se acompanhou o aparecimento das fissuras posteriores correspondentes às etapas de carregamento.

Foram ensaiadas duas séries de vigas sanduiche (PS I e PS II), cada uma com 4 exemplares, totalizando 8 vigas. Ainda ensaiaram-se placas de face isoladamente, em número de duas, cada uma representando o arranjo de armadura de cada série. O ensaio das faces serviu apenas para verificação do desempenho quando esta trabalha de forma isolada.

\subsubsection{Dimensões das peças}

A espessura total da viga foi de $55 \mathrm{~mm}$, sendo as faces com $12,5 \mathrm{~mm}$ intercaladas com o núcleo de espessura de $30 \mathrm{~mm}$.

O comprimento adotado foi de $1300 \mathrm{~mm}$, definindo-se um vão teórico de $1250 \mathrm{~mm}$. A largura utilizada para os exemplares foi de $110 \mathrm{~mm}$, possibilitando na face uma boa distribuição dos fios longitudinais da malha da tela soldada utilizada como armadura.

As dimensões da viga, mostradas na fig.5.2, foram adotadas para todos os exemplares das duas séries, e foram obtidas segundo as prescrições da ASTM C 393 - 62 e de algumas dimensões encontradas na literatura que continham ensaios similares. 

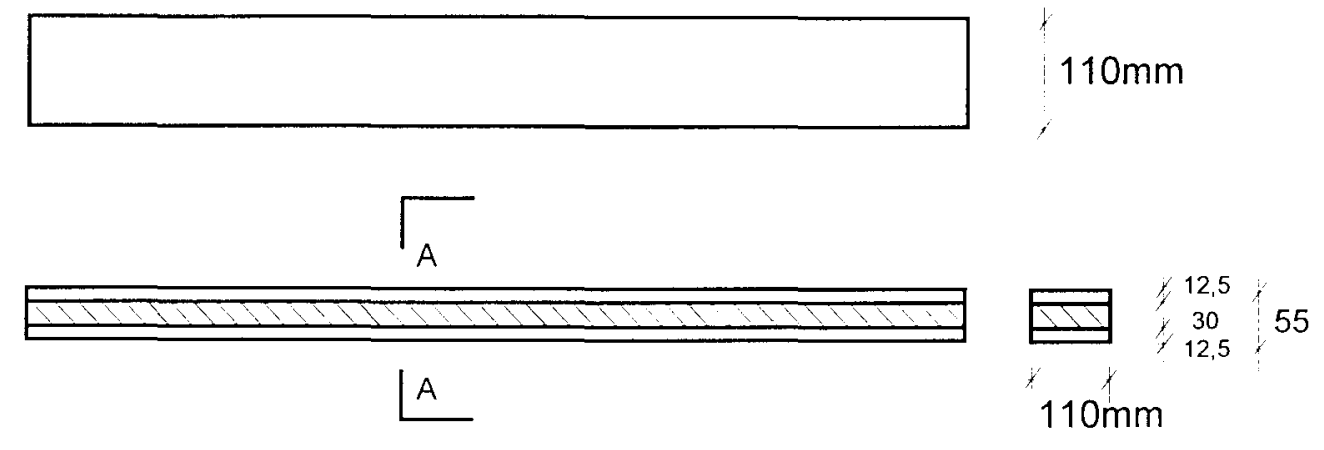

$1300 \mathrm{~mm}$

corte $A A$

FIGURA 5.2. Dimensões da viga sanduíche.

\subsubsection{Fôrma para moldagem das placas de face}

As placas de faces eram previamente confeccionadas, utilizando-se fôrmas metálicas. Quatro faces de duas vigas, de uma mesma série, eram excecutadas ao mesmo tempo.

A fig.5.3 mostra as dimensões $e$ as características da fôrma idealizada para moldagem das faces.

\subsubsection{Moldagem, adensamento e cura}

Em cada argamassagem eram executadas quatro faces. As armaduras que eram compostas de mais de uma tela, eram amarradas, formando um conjunto único. As telas eram colocadas sobre a fôrma, onde eram colocados espaçadores plásticos de $6,0 \mathrm{~mm}$ de diâmetro que garantia o recobrimento mínimo de $6,0 \mathrm{~mm}$ em uma das faces.

Após a preparação da armadura, a peça era então argamassada manualmente. $O$ adensamento da argamassa foi feito por uma mesa vibratória, com tempo total de vibração de aproximadamente $1 \mathrm{~min} 30 \mathrm{~s}$.

As placas eram retiradas da fôrma após um tempo de 24 horas e colocadas submersas em um tanque com água, para realização da cura, durante 7 dias, e então eram retiradas para instrumentação. 


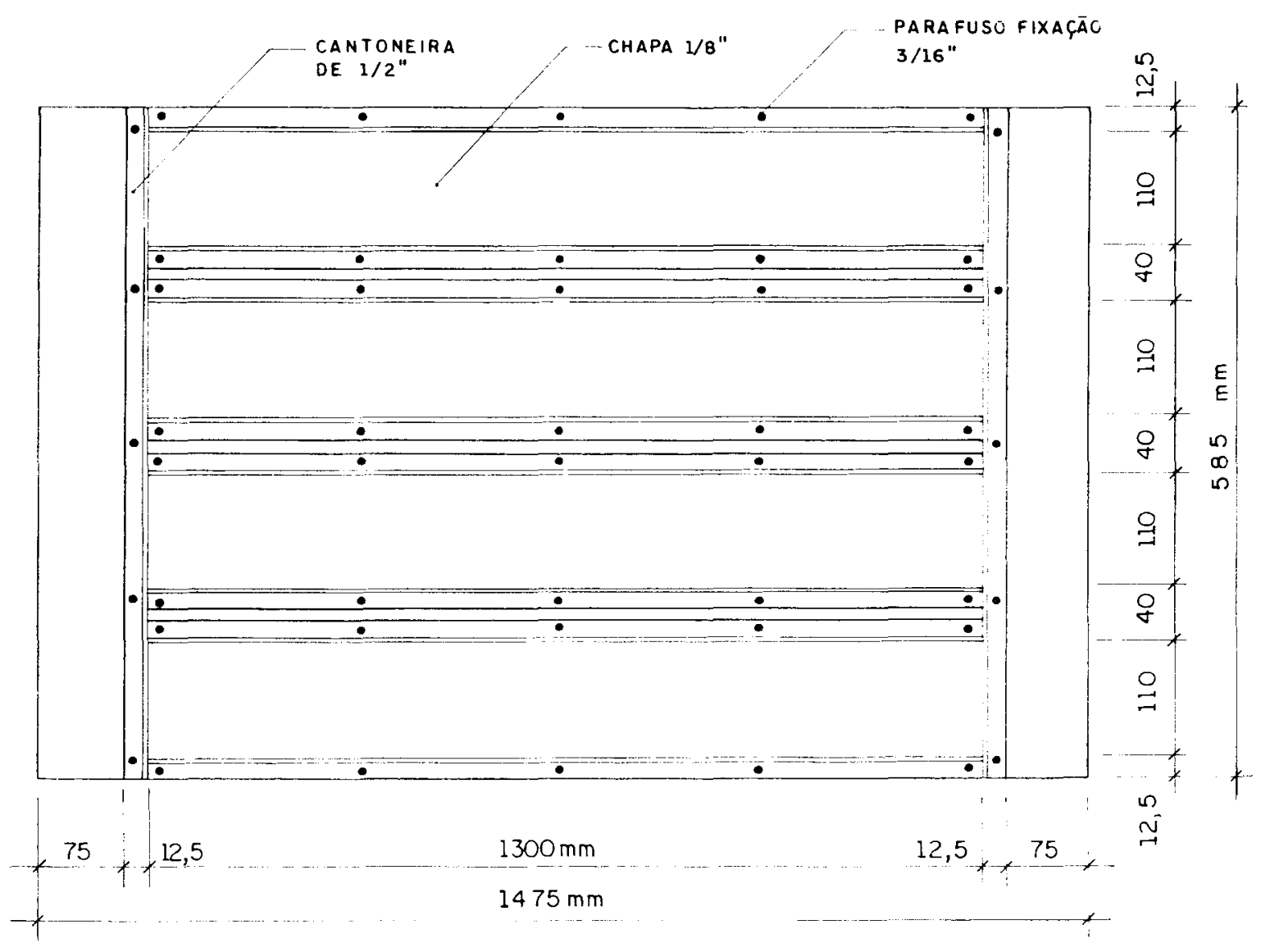

FIGURA 5.3. Forma de chapa metálica para moldagem das placas de face. 


\subsubsection{Fôrma para moldagem da viga sanduíche}

Depois de moldadas e devidamente instrumentadas, as faces, de mesmo arranjo de armadura, eram colocadas em uma fôrma especialmente construída para a confecção da viga, fig.5.4.

A fôrma era composta de 4 partes, unidas por parafusos. $O$ formato em $\mathrm{L}$ das partes laterais, facilitava sua montagem e desmontagem. As duas placas de face necessárias para a confecção da viga sanduíche eram colocadas cuidadosamente no interior da fôrma, de modo a ficarem espaçadas de $30 \mathrm{~mm}$. Feito isto, a fôrma era fechada na parte inferior, deixando-se aberta a parte superior para a colocação da mistura da espuma rígida.

A pesagem e a preparação da mistura dos componentes do núcleo era feita separadamente, em um recipiente apropriado. Os componentes eram misturados numa proporção de $1: 2$, pesando-se $120 \mathrm{~g}$ de ER $170 \mathrm{e}$ $240 \mathrm{~g}$ de FNC 40 respectivamente, conforme é descrito no item 5.2.3, com o auxilio de um misturador, fig.5.5, durante um tempo de aproximadamente 10 segundos.

Terminado o tempo de mistura, o material era imediatamente lançado no interior da fôrma, entre as faces, pela parte superior conforme mostra fig.5.6. Em seguida, a parte superior era fechada, e a mistura começava a expandir no interior da fôrma, até que se preenchesse todos os vazios entre as faces. Após um tempo de 20 minutos do lançamento da mistura, a viga era retirada da fôrma para que fosse terminada sua instrumentação, fig.5.7. As vigas prontas eram estocadas durante 7 dias antes de serem ensaiadas, a fim de que a espuma atingisse sua resistência máxima. 


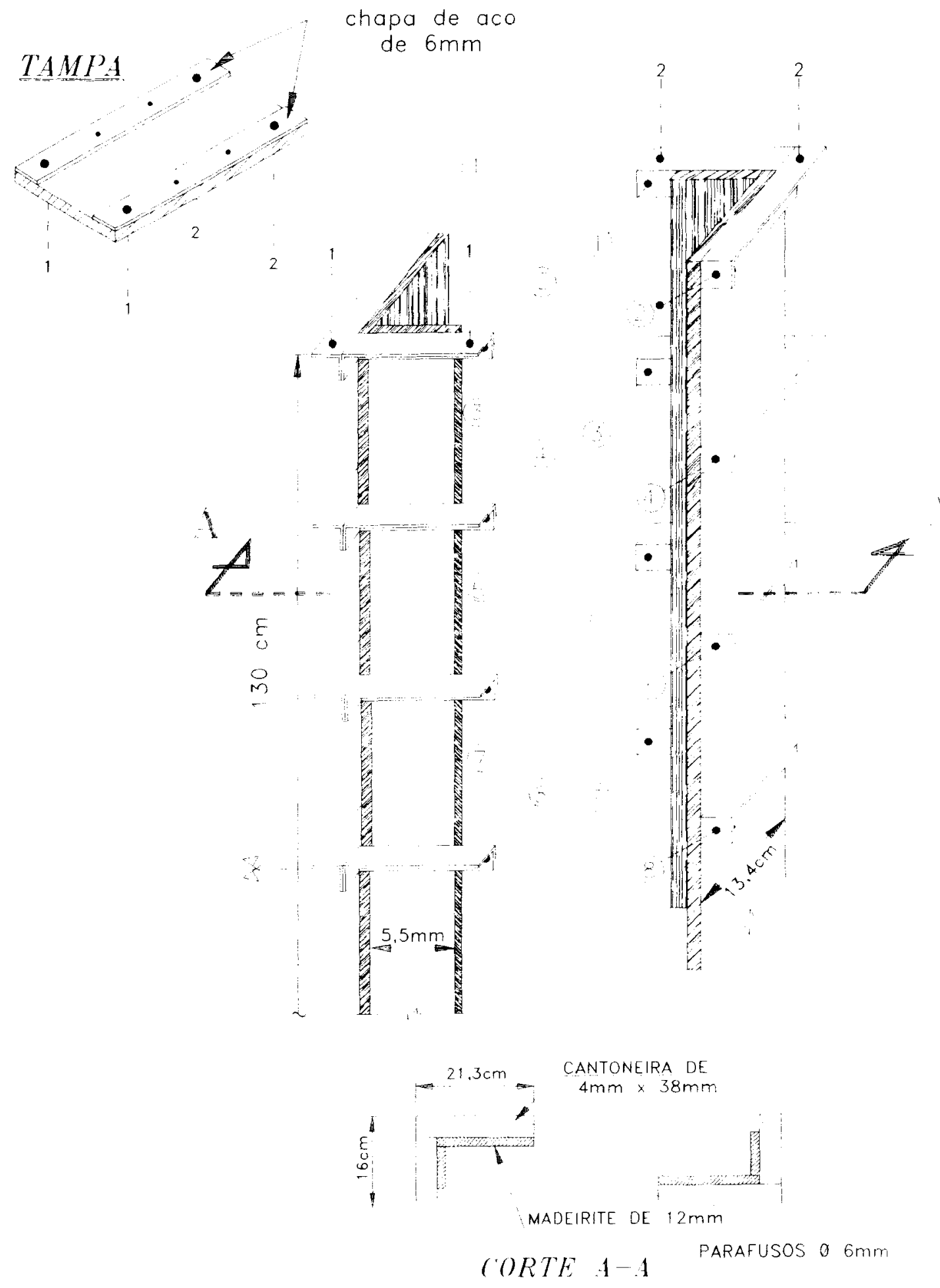

FIGURA 5.4. Fôrma para moldagem da viga sanduíche. 


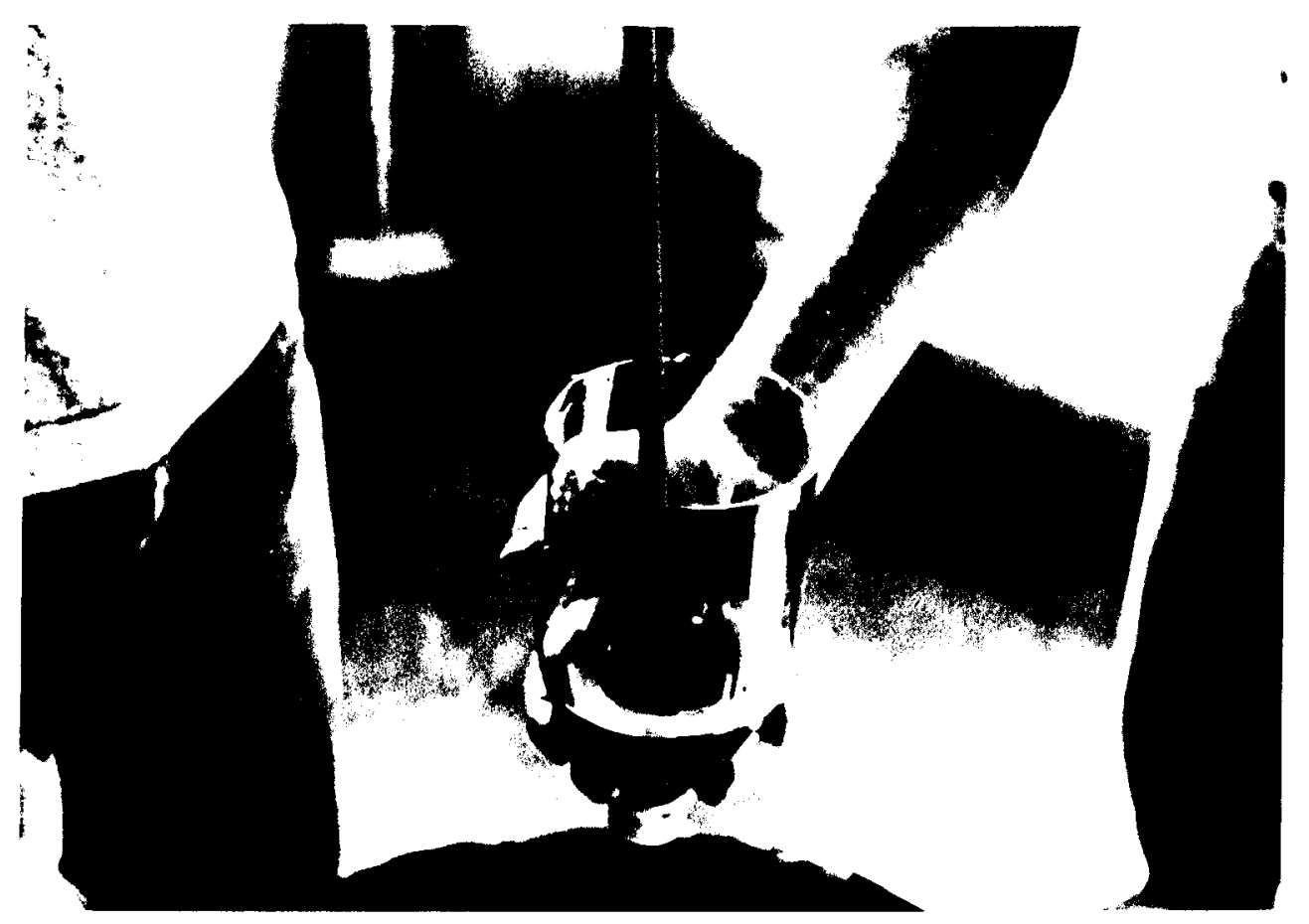

FIGURA 5.5. Mistura dos componentes da espuma rígida.

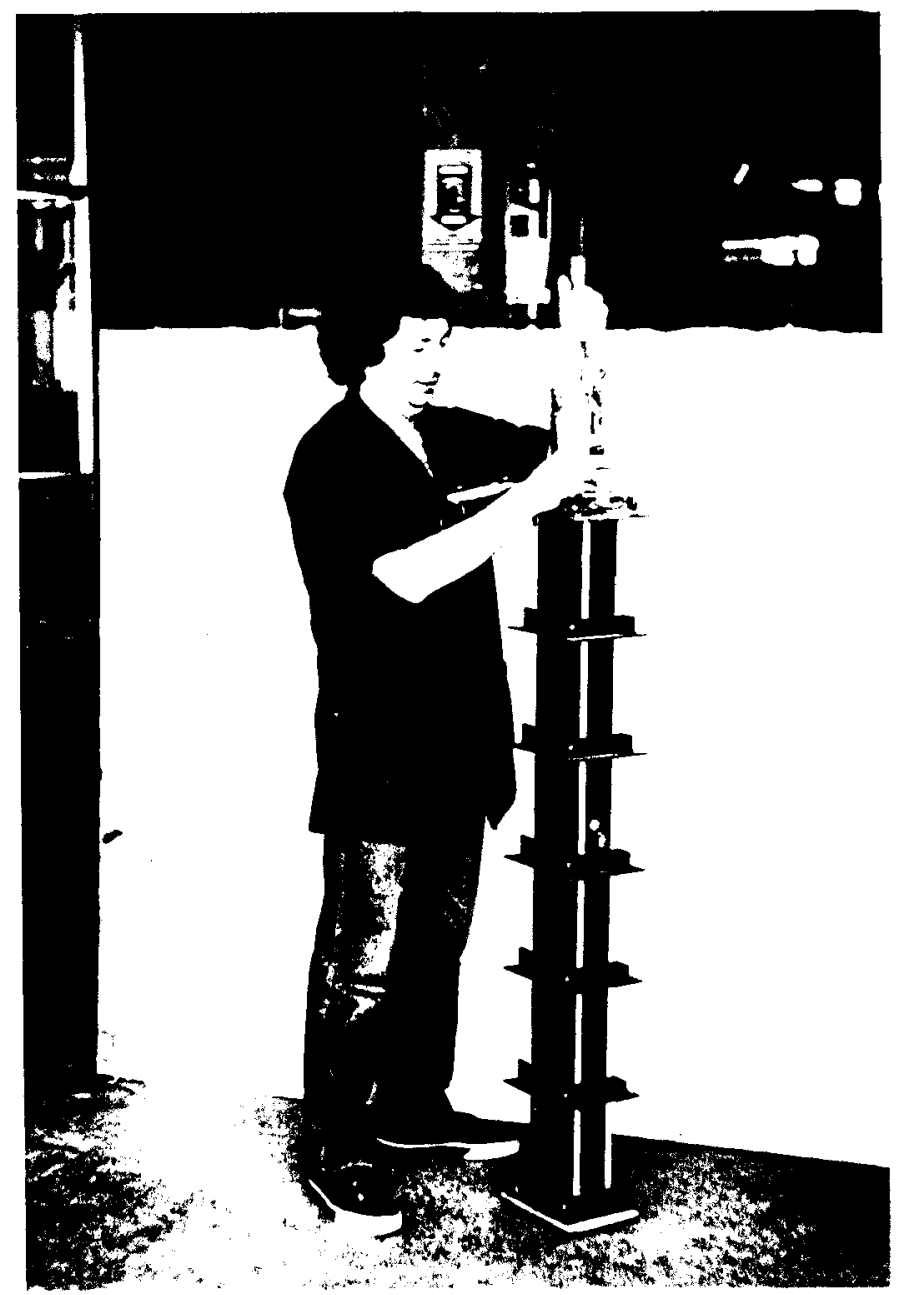

FIGURA 5.6. Colocação da mistura dos componentes da espuma no interior da fôrma entre as faces 


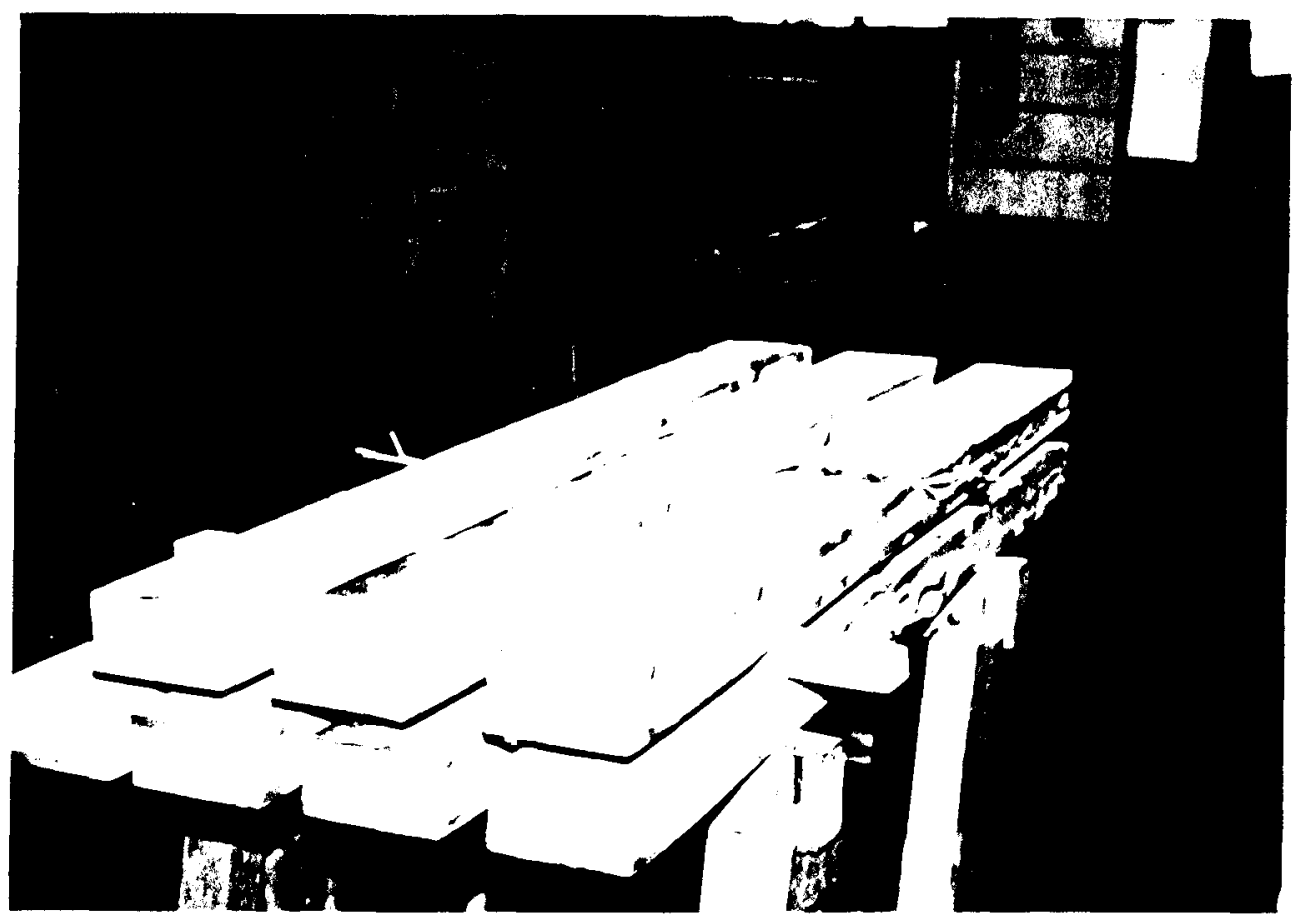

FIGURA 5.7. Exemplares estocados após a desforma.

\subsubsection{Esquemas estático e de carregamento}

A fig.5.8 mostra o esquema estático utilizado nos ensaios de flexão, no qual adotou-se uma viga livremente apoiada.

$\begin{array}{lll}\bar{\nabla} & \bar{\nabla} \\ 25 \mathrm{~mm} & 1250 \mathrm{~mm} & 25 \mathrm{~mm} \\ & 1300 \mathrm{~mm} & \end{array}$

FIGURA 5.8. Esquema estático adotado.

Em alguns ensaios preliminares realizados, verificou-se uma considerável flexibilidade na viga nos carregamentos próximos da ruptura. Já se prevendo isso, optou-se desde o inicio por se utilizar um pórtico "pendular", conforme mostra fig.5.9 (o mesmo empregado nos trabalhos de BALLARIN (1989)), pois nos apoios de aparelhos tradicionais (roletes), devido a flexibilidade da viga, causaria uma instabilidade com uma tendência a sair totalmente fora da posição, prejudicando o andamento do ensaio 


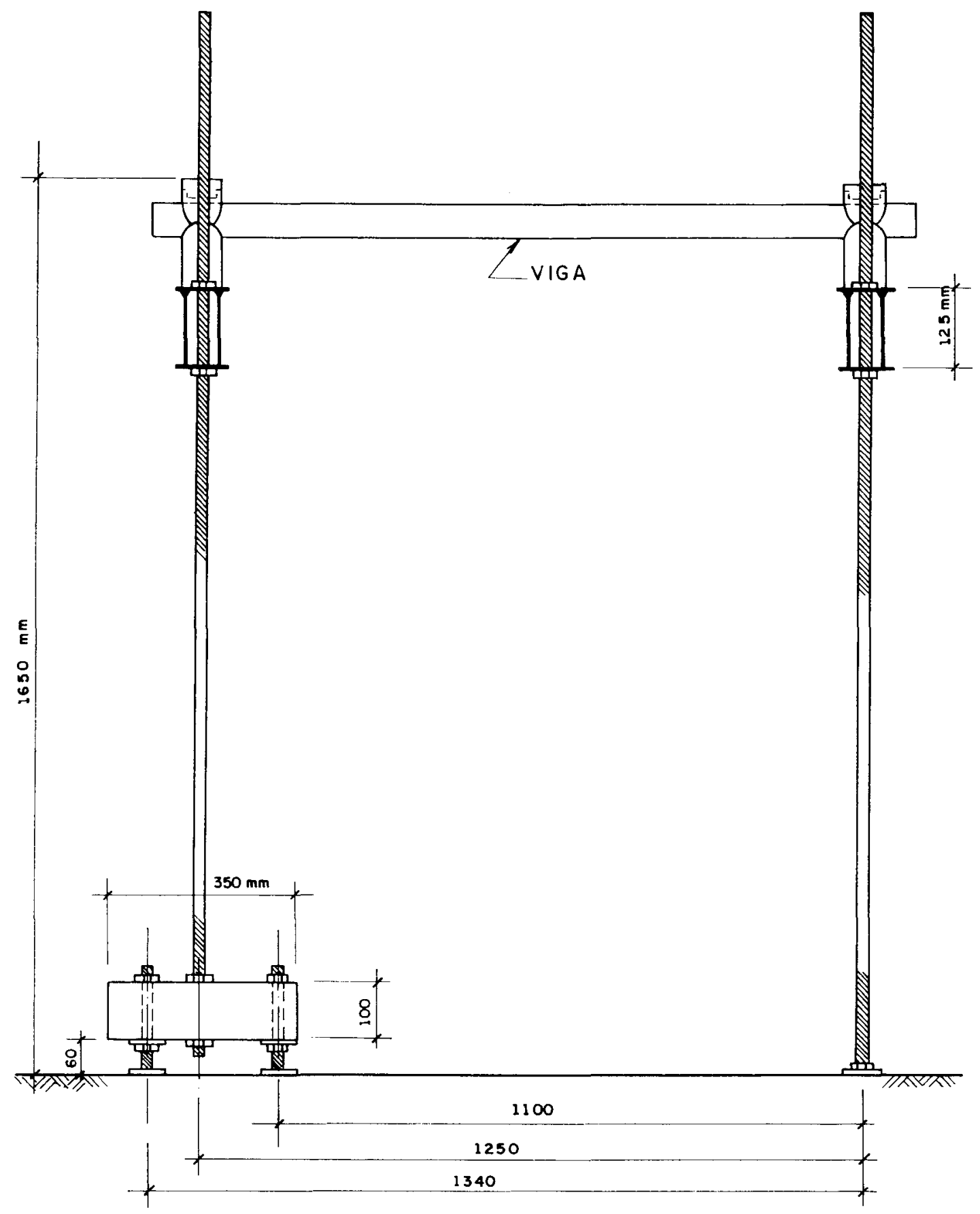

FIGURA 5.9. Pórtico pendular utilizado nos ensaios de flexão.

Com a utilização deste tipo de pórtico, garantiu-se portanto a realização ininterrupta do ensaio até atingir a carga de ruptura das vigas, sem haver perda de estabilidade dos aparelhos de apoios.

O carregamento foi aplicado conforme mostra a fig.5.10. As forças foram aplicadas de baixo para cima, concentrando-se aproximadamente nos 
terços dos vãos. O sentido do carregamento facilitou a observação e acompanhamento das fissuras.

A força foi aplicada através de um cilindro hidráulico acoplado a uma bomba hidráulica, utilizando-se o aparato mostrado na fig.5.11.

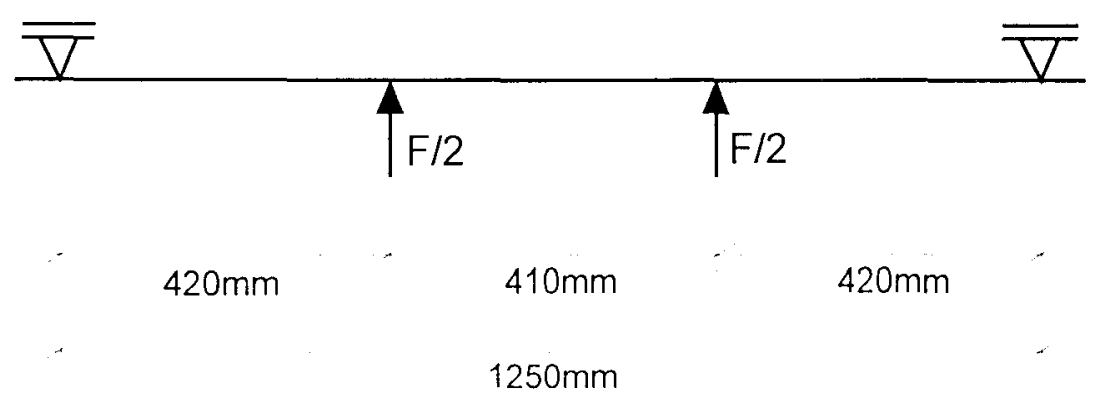

FIGURA 5.10. Esquema de carregamento.

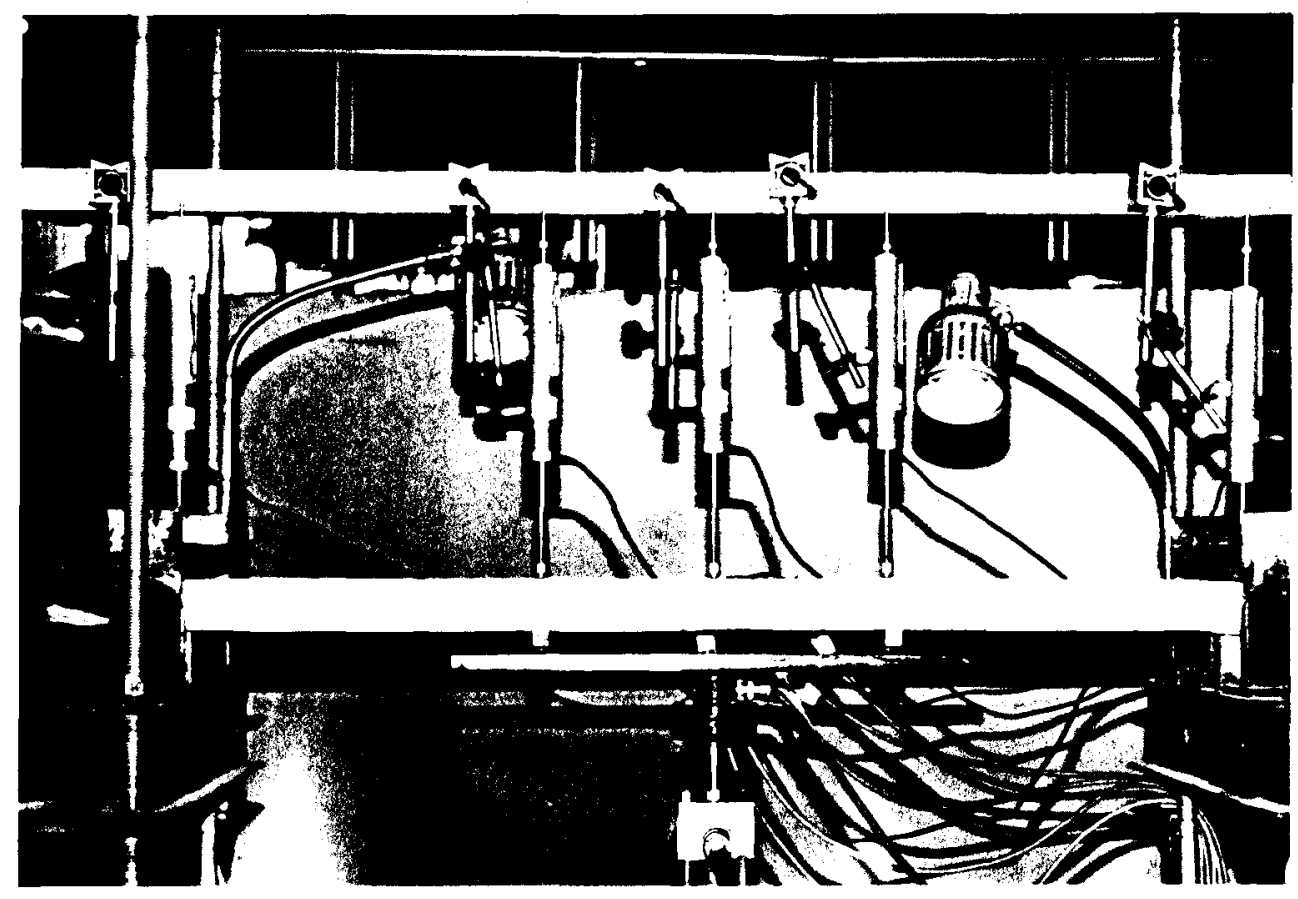

FIGURA 5.11. Aparato para a aplicação da força através do cilindro hidráulico. 
A programação do carregamento foi feita para que a peça atingisse a ruptura. A magnitude da carga de ruptura foi prevista através dos ensaios preliminares. A cada etapa de carregamento, 0 incremento de carga utilizado foi de $80 \mathrm{~N}$.

Para todos os ensaios foi inicialmente aplicado um carregamento equivalente a um incremento de carga $(80 \mathrm{~N})$, com posterior descarga, com o intuito de acomodar a viga e o pórtico de reação. Após esta carga e descarga, o ensaio era reiniciado, com etapas crescentes de carregamento.

\subsubsection{Instrumentação}

O carregamento foi aplicado nos terços do vão da viga através do aparato mostrado na fig.5.11, por meio de um cilindro hidráulico de capacidade de $50 \mathrm{kN}$, acoplada a uma bomba hidráulica de acionamento manual. Utilizou-se uma célula de carga de capacidade de $10 \mathrm{kN}$, marca Shinkoh, modelo LC - 1A, para medição e controle do carregamento aplicado.

Os deslocamentos transversais da viga foram medidos por meio de transdutores elétricos de sensibilidade $0,05 \mathrm{~mm}$, com um curso de $100 \mathrm{~mm}$, de marca Kiowa e modelo DT $100 \mathrm{~A}$, posicionados em cinco pontos ao longo da viga, conforme mostra a fig.5.12.

Foram medidos ainda as deformações no meio do vão para as duas placas de face e na armadura da face superior (tracionada), utilizando extensômetros elétricos de resistência, com base de $5 \mathrm{~mm}$, marca Kiwoa, modelo KFG - $5-120$ - C1 - 11. Foram dispostos, para cada face, dois extensômetros de cada lado e dois para a armadura, dispostos na largura da viga. A fig.5.13 mostra o posicionamento dos extensômetros na seção da viga. 


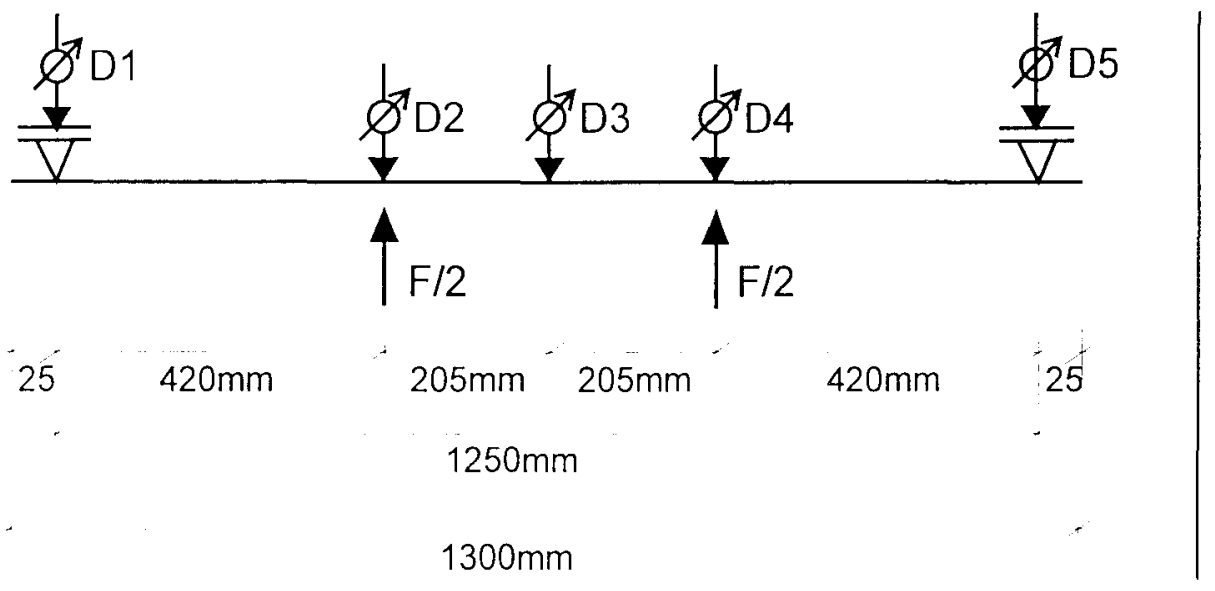

FIGURA 5.12. Posicionamento dos transdutores elétricos.

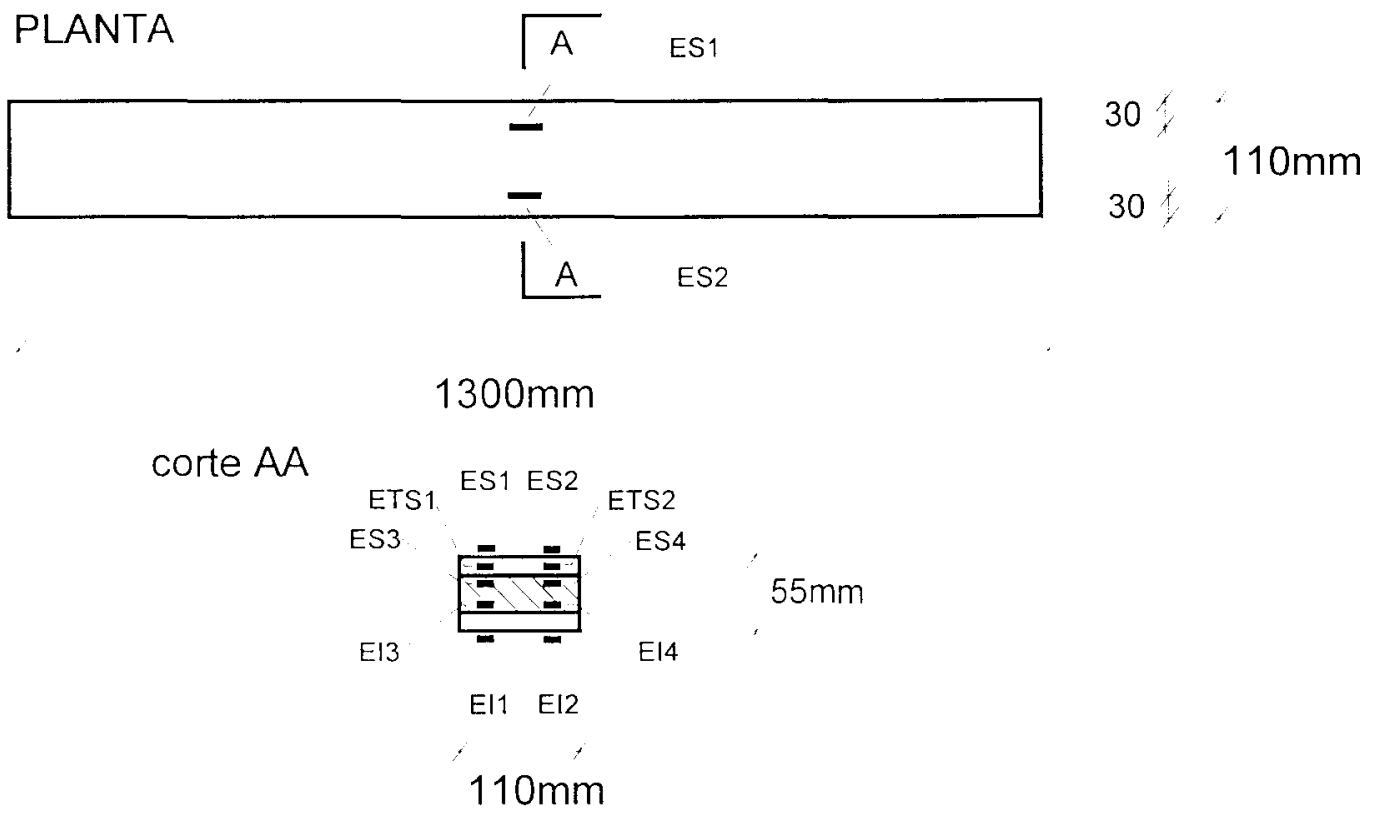

FIGURA 5.13. Posicionamento dos extensômetros elétricos.

- ES1 e ES2 $\rightarrow$ extensômetros da placa superior - face de cima

- ES3 e ES4 $\rightarrow$ extensômetros da placa superior - face de baixo

- ETS1 e ETS2 $\rightarrow$ extensômetros da armadura - placa superior

- El1 e El2 $\rightarrow$ extensômetros da placa inferior - face de cima

- El3 e El4 $\rightarrow$ extensômetros da placa inferior - face de baixo 
Utilizou-se para registro das leituras indicados pela célula de carga, pelos transdutores e pelos extensômetros elétricos, um sistema de aquisição de dados de marca Measurements Group, modelo System 4000, conforme mostra fig. 5.14

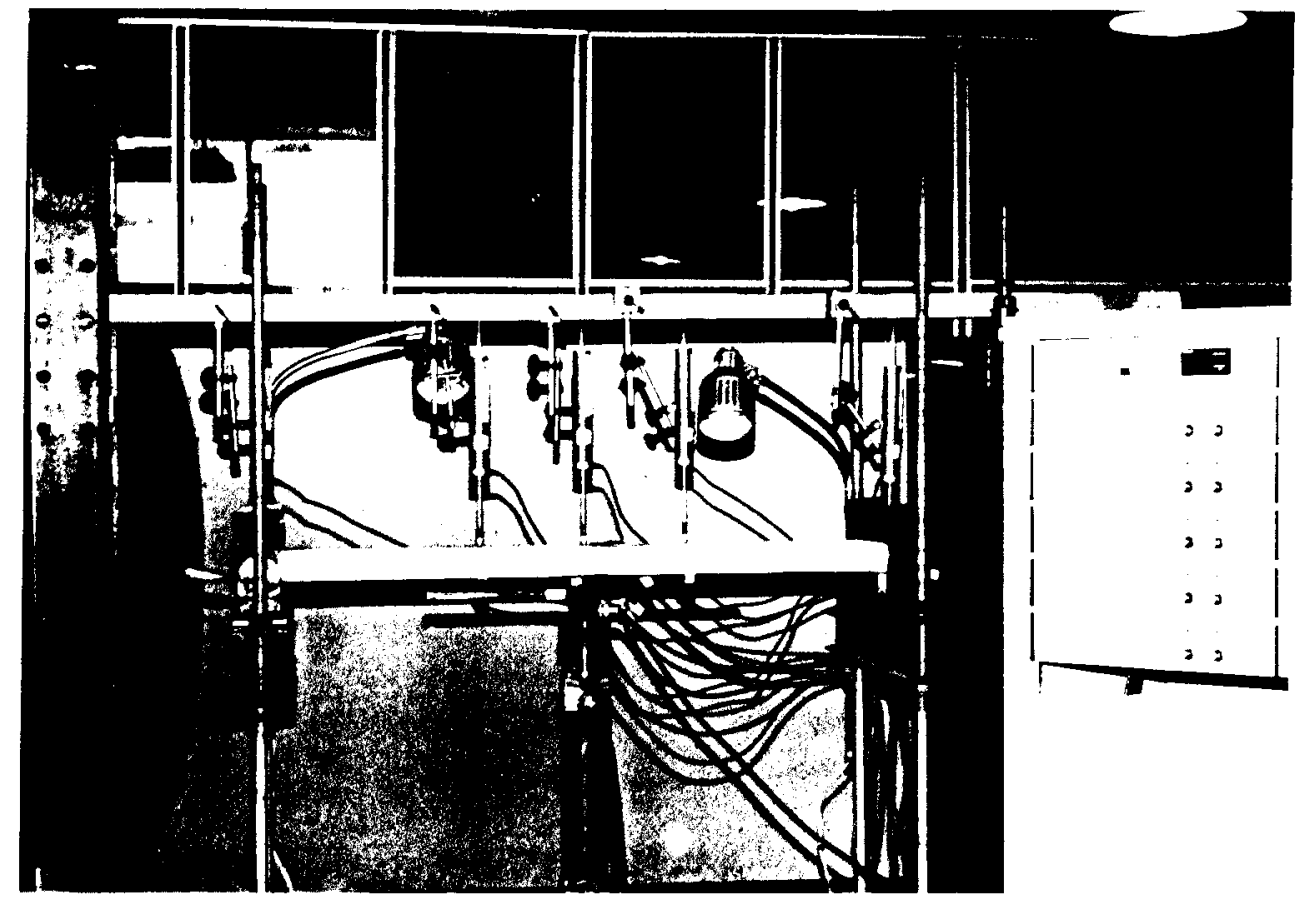

FIGURA 5.14. Viga preparada para o ensaio, com instrumentação posicionada ligados ao sistema de aquisição de dados

\subsubsection{Ensaios de cisalhamento da espuma rígida}

O valor do módulo de deformação transversal da espuma rígida de poliuretano é fundamental na análise do comportamento à flexão da viga sanduíche. Para determinaçāo do valor desta característica de cisalhamento da espuma, foram executados ensaios de cisalhamento segundo a norma americana ASTM C 273 - 61 - Standart test method for shear properties in flatwise plane of flat sandwich constructions or sandwich cores - descritos a seguir. 


\subsubsection{Descrição dos ensaios}

A ASTM C 273 - 61 recomenda que os corpos de prova sejam obtidos através de cortes do próprio painel sanduíche, colando chapas de aço nas faces desta amostra com a finalidade de receber a carga aplicada. Diante da dificuldade para se obter as amostras desta forma, optou-se por se conduzir ensaio diretamente com o material do núcleo, confeccionando o corpo de prova da espuma rigida em fôrmas apropriadas, colando-a diretamente à chapas de aço de 9,5mm de espessura conforme mostra a fig.5.19.

O conjunto de chapas de aço coladas ao corpo de prova da espuma, é submetido a uma carga de compressão por uma máquina com velocidade de deformação constante, submetendo a espuma a um estado puro de cisalhamento.

Foram ensaiados dez corpos de prova da espuma rígida, procurandose manter constante os valores de suas densidades.

Através das medidas dos deslocamentos relativos entre as faces, registradas através de um extensômetro acoplado nas placas de suporte, e da carga no limite de proporcionalidade da espuma, determinou-se para cada corpo de prova ensaiado o módulo de deformação transversal da espuma, seguindo o seguinte procedimento, indicado pela ASTM C 273-61:

$$
\tau=\frac{F}{L b}
$$

onde: $\tau=$ tensão de cisalhamento;

$F=$ carga aplicada no corpo de prova;

$L=$ comprimento do corpo de prova;

$b=$ largura do corpo de prova.

A deformação transversal é calculada como:

$$
\gamma=\frac{r}{c}
$$

onde: $r$ = deslocamento relativo entre as placas;

$\mathrm{c}=$ espessura do corpo de prova. 
O módulo G é então calculado diretamente como sendo:

$$
\mathrm{G}=\frac{\tau}{\gamma}
$$

Observou-se ainda os valores das cargas de ruptura para cada modelo, bem como as respectivas deformações do núcleo. Substituindo-se a carga de ruptura da na eq.(5.1) obteve-se para cada corpo de prova a resistência ao cisalhamento.

\subsubsection{Dimensões dos modelos}

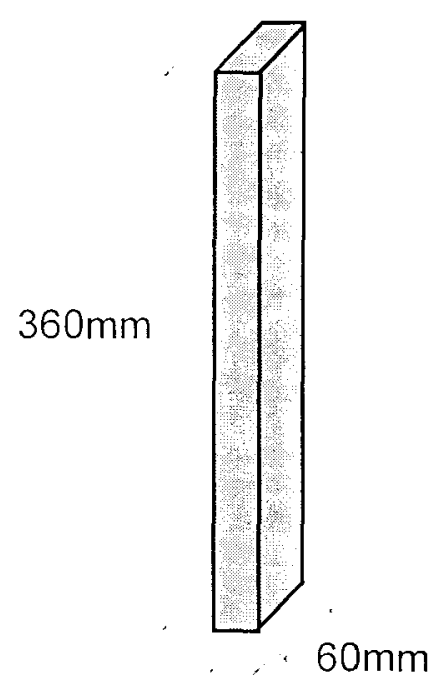

$30 \mathrm{~mm}$

FIGURA 5.15. Dimensões dos corpos de prova de ER ensaiados

Os corpos de prova eram prismáticos, com 360mm de comprimento, $60 \mathrm{~mm}$ de largura e $30 \mathrm{~mm}$ de espessura (fig.5.15). A espessura do núcleo dos exemplares foi definida pela espessura do núcleo dos painéis utilizados nos ensaios de flexão, as demais dimensões foram determinadas a partir da relação 12:1 recomendada pela ASTM C 273 - 61. 


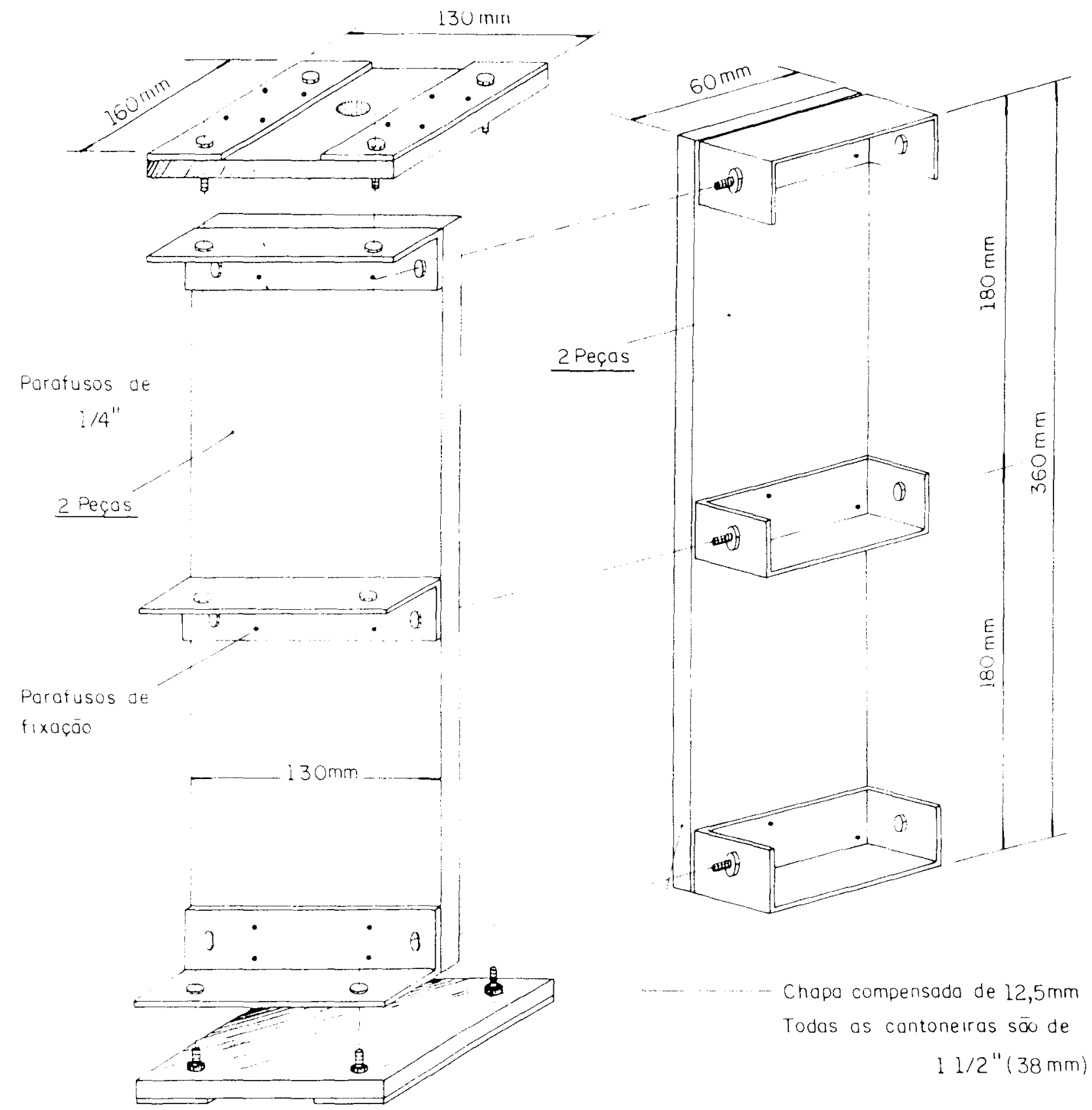

FIGURA 5.16. Detalhes e dimensões da fôrma do corpo de prova da espuma. 


\subsubsection{Fôrma para moldagem da espuma}

Para moldagem do corpo de prova da espuma, confeccionou-se uma forma feita de madeira compensada de $12,5 \mathrm{~mm}$ de espessura, revestida com plástico e enrigecida com cantoneiras de $38 \mathrm{~mm}$.

A fôrma era composta de 6 partes, 4 laterais e 2 tampas, conforme mostra fig.5.16. As partes eram encaixadas e aparafusadas. Na tampa da parte superior da fôrma foi deixado um buraco no centro, de diâmetro de $25 \mathrm{~mm}$, para a introdução da mistura da ER.

A fig. 5.17 mostra a fôrma montada, pronta para moldagem de um corpo de prova da ER.

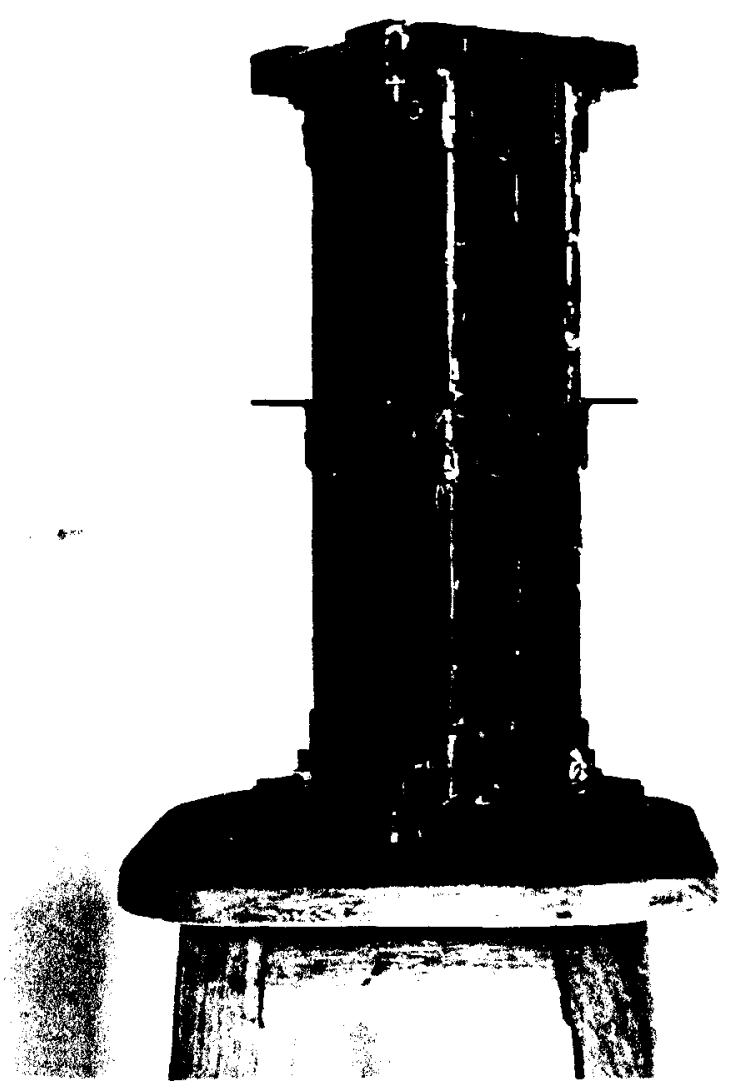

FIGURA 5.17. Fôrma para moldagem dos exemplares. 


\subsubsection{Moldagem e preparação para o ensaio}

O processo de moldagem dos corpos de prova da ER foi semelhante à moldagem da viga sanduíche descrito no item 5.3.1.5.

Após terem sido pesados e misturados os componentes, $20 \mathrm{~g}$ de ER 170 e $40 \mathrm{~g}$ de FNC 40, a mistura era introduzida pela tampa da parte superior e imediatamente fechada durante aproximadamente 20 minutos (fig.5.18), até que se terminasse a expansão da espuma. Terminado este tempo, a fôrma era desmontada para retirada do corpo de prova. Fazia-se então a limpeza na fôrma montando-se em seguida para nova moldagem.

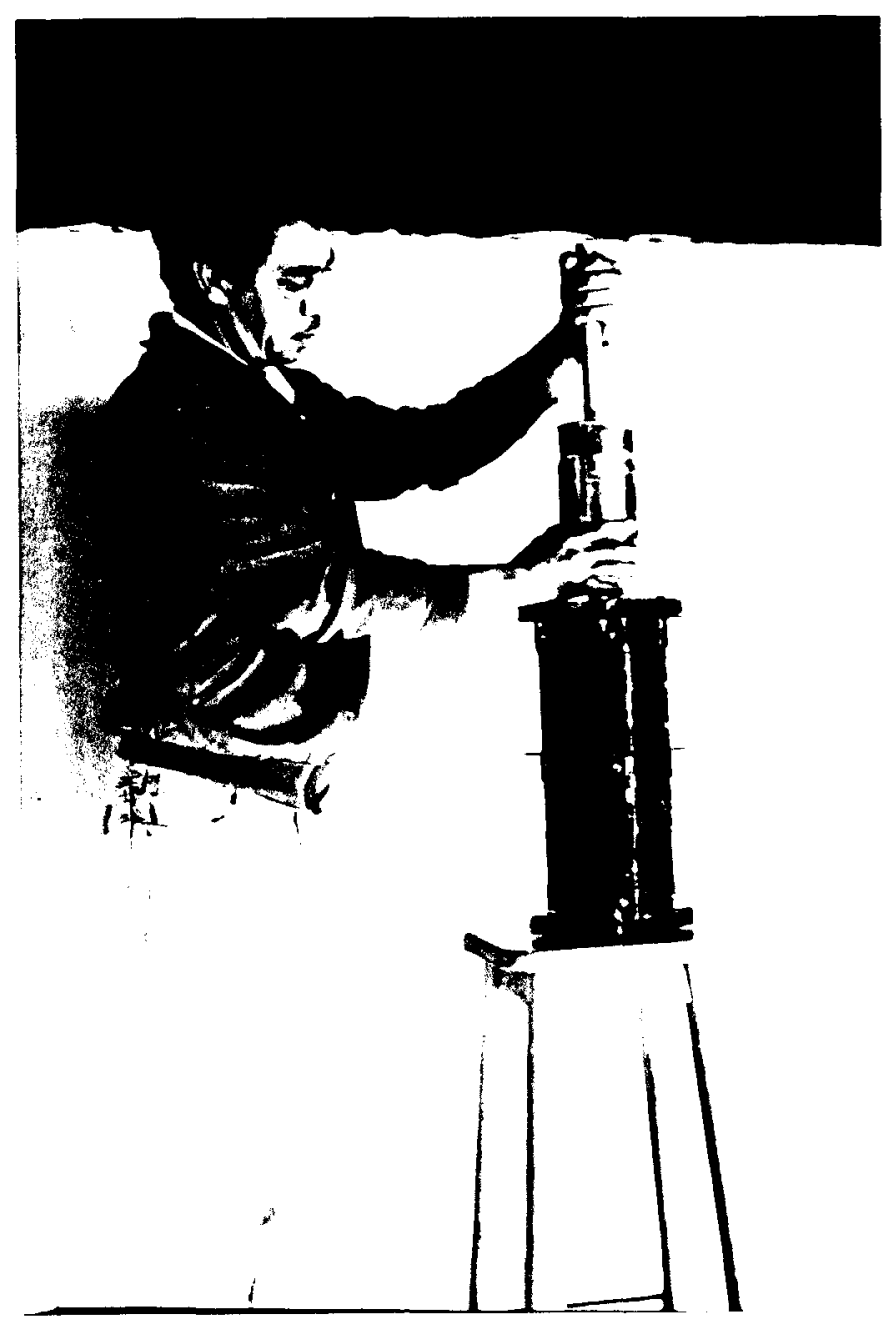

FIGURA 5.18. Moldagem da espuma rígida.

Moldado o exemplar, era feita a colagem nas placas de aço. Entre a moldagem e ensaio, era observado um tempo mínimo de 7 dias para que a espuma atingisse sua resistência máxima. 


\subsubsection{Esquema estático e de carregamento}

A norma ASTM C 273 - 61, admite a execução do teste com aplicação de carga de tração ou de compressão no dispositivo de ensaios. Devido a maior simplicidade de montagem do aparato, decidiu-se pelo ensaio de compressão.

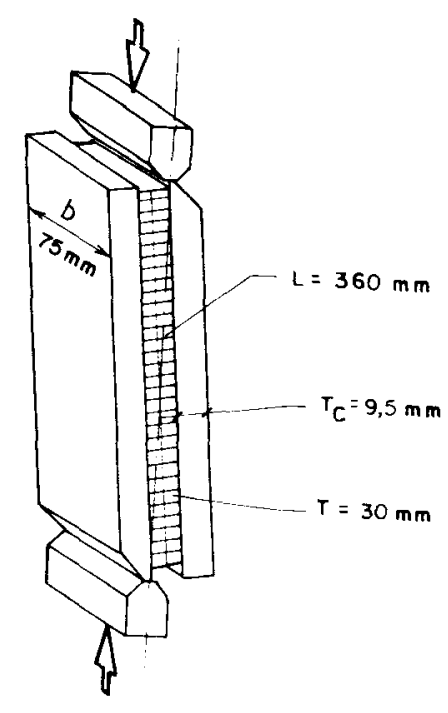

FIGURA 5.19. Esquema do carregamento do ensaio de cisalhamento da ER.

Duas placas de aço, para suporte do corpo de prova, com $380 \mathrm{~mm}$ de comprimento, $9,5 \mathrm{~mm}$ de espessura e $75 \mathrm{~mm}$ de largura, foram confeccionadas com uma das extremidades chanfradas à $45^{\circ}$ no sentido do comprimento.

O corpo de prova foi colado nas placas de aço com adesivo derivado do óleo de mamona, cujos componentes Q-442 e FN-329 foram misturados na proporção de 1:2, em massa, produzidos pelo LQATP - USP. O prazo mínimo observado entre a colagem e 0 ensaio foi de 48 horas.

A fig.5.19 mostra o esquema para a realização do ensaio de cisalhamento da espuma através da aplicação da carga de compressão nas faces. 
Foi registrado para cada ensaio, a carga correspondente ao limite de proporcionalidade da ER e a de ruptura.

A fig.5.20 mostra o aparato de ensaio, podendo-se observar todo os dispositivos utilizados para sua realização.
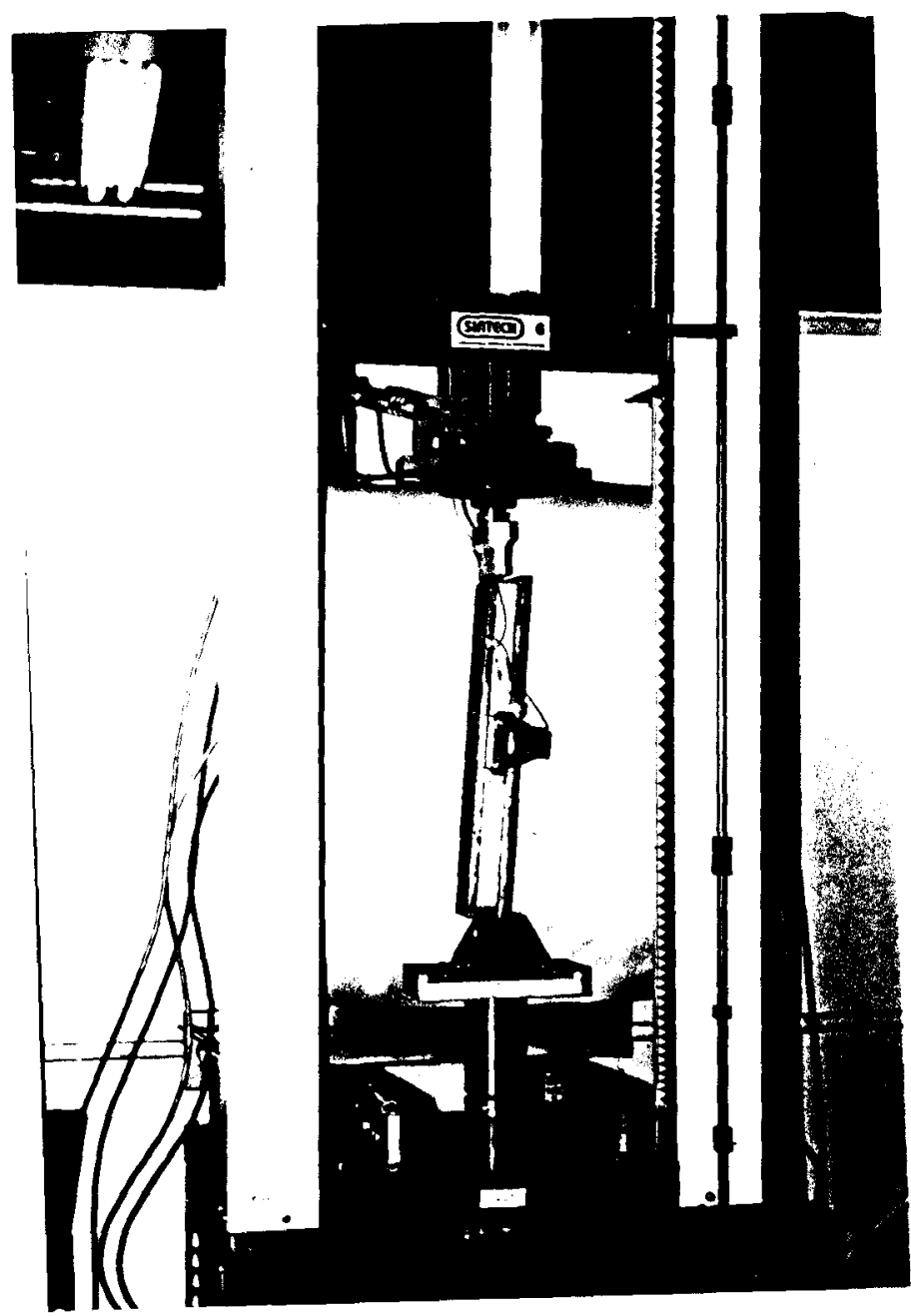

FIGURA 5.20. Aparato de ensaio utilizado. 


\subsubsection{Instrumentação}

Os ensaios foram realizados com máquina universal SINTECH-6, com velocidade de deformação constante. A carga aplicada foi medida através de célula de carga com capacidade de $45 \mathrm{kN}$. Os deslocamentos relativos, entre as placas de aço, foram medidos na região central das placas com extensômetro modelo MTS 632.25B-50 da SINTECH, com sensibilidade de $0,01 \mathrm{~mm}$. A célula de carga e o extensômetro estavam acoplados a um sistema de aquisição de dados, onde os resultados do ensaio foram processados, através do programa Test Works $2.0 \mathrm{da}$ SINTHEC. A fig 5.21 mostra o detalhe e posicionamento do extensômetro.

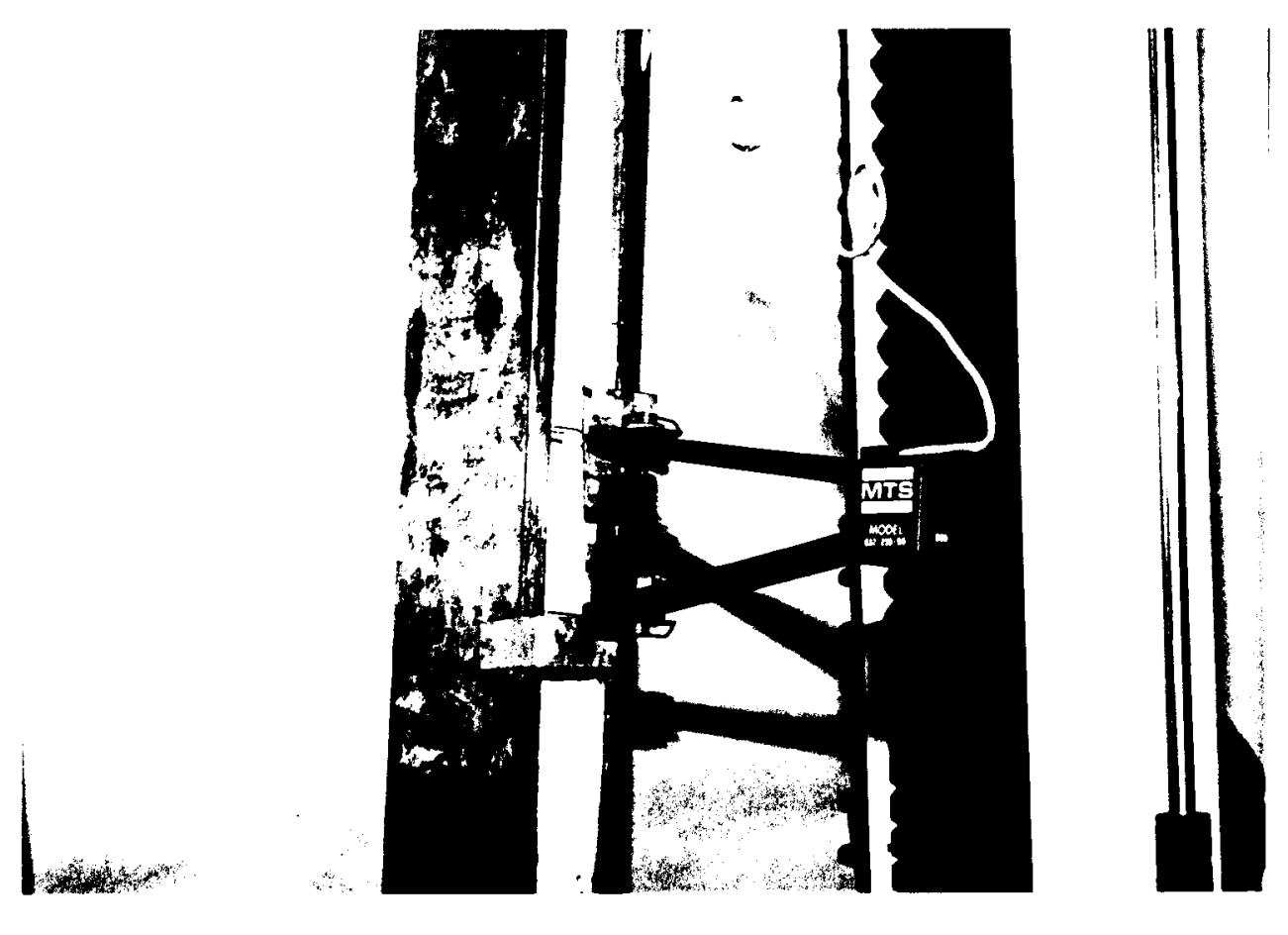

FIGURA 5.21. Detalhe do extensômetro. 


\subsubsection{Ensaios complementares}

\subsubsection{Ensaios de caracterização das argamassas empregadas em cada uma das séries}

O controle da argamassa empregada na execução de cada argamassagem das séries de flexão foi feito através de ensaio de ruptura de 9 corpos de prova cilíndricos de $50 \mathrm{~mm}$ de diâmetro e $100 \mathrm{~mm}$ de comprimento. A moldagem e ensaio dos corpos de prova da argamassa atenderam ao prescrito pela NBR 7215 - "Ensaio de Cimento Portland", NBR 7222/83 "Argamassas e Concreto - Resistência a tração por compressão diametral de corpos-de-prova cilíndricos" e NBR 8522/84 "Concreto Determinação do módulo de deformação estática e diagrama tensão $x$ deformação". Para as 4 argamassagens foram ensaiados 4 séries de corpos de prova cilindricos, totalizando 36 .

A distribuição de corpos de prova por ensaio, foi a seguinte:

- 3 corpos de prova para compressão axial a 7 dias de idade;

- 3 corpos de prova para compressão axial à mesma idade de ensaio dos exemplares da série considerada, sendo um desses instrumentados para determinação do módulo de elasticidade longitudinal (28 dias);

- 3 corpos de prova para compressão diametral à mesma idade de ensaio dos exemplares da série considerada (28 dias);

Os três corpos de prova utilizados para cada tipo de ensaio é um procedimento adotado em outros trabalhos realizados no Laboratório de Estruturas do Departamento de Engenharia de Estruturas da EESC - USP 


\section{RESULTADOS OBTIDOS}

\subsection{Considerações gerais}

Os resultados experimentais observados nos ensaios são apresentados neste capítulo, mantendo-se para cada exemplar a mesma ordem de apresentação.

Para os ensaios de flexão são apresentados na primeira página, para cada modelo, a tabela de deslocamentos absolutos em função da força aplicada e os gráficos força $x$ deslocamento, feitos também para os deslocamentos absolutos D2, D3, D4 (fig.5.12), calculados a partir dos deslocamentos relativos, medidos nos ensaios, subtraindo-se a média dos valores dos deslocamentos relativos dos apoios (defletômetros D1 e D5 da fig.5.12), para os deslocamentos D3 e proporcionalmente aos deslocamentos D2 e D4. Os valores das cargas de ruptura e de primeira fissura são indicados abaixo da tabela.

A segunda página traz as tabelas com os valores das deformações, bem como os diagramas força $x$ deformação, medidas através de extensômetros elétricos posicionados nas faces da viga e na armadura tracionada. As posições dos extensômetros elétricos foram mostrados na fig. 5.13.

O controle das resistências à tração e à compressão da argamassa, foram feitos para cada argamassagem, sendo que em cada argamassagem foram executadas 4 placas de faces, para confecção de 2 exemplares de vigas. Os resultados obtidos para os 9 corpos de prova moldados para cada 2 modelos são apresentados logo em seguida da apresentação dos resultados dos respectivos exemplares. Os diagramas tensão x deformação, são também apresentados na mesma página, com a indicação do módulo de deformação longitudinal tangente na origem, determinados por regressão polinomial dos pontos da curva. 
Para determinação dos diagramas tensão $\mathrm{x}$ deformação da argamassa, apenas um corpo de prova foi instrumentado para cada modelo.

O valor da resistência à tração dos corpos de prova de argamassa foi determinado com a expressão:

$$
\mathrm{f}_{\mathrm{t}}=\frac{2}{\pi} \frac{\mathrm{F}_{\mathrm{cp}}}{\phi_{\mathrm{cp}} l_{\mathrm{cp}}}
$$

onde:

$$
\begin{aligned}
F_{\mathrm{cp}}= & \text { força última aplicada durante o ensaio do corpo de prova } \\
& \text { cilíndrico submetido a compressão diametral; } \\
\phi_{\mathrm{Cp}}= & 50 \mathrm{~mm} \text {, diâmetro do corpo de prova; } \\
l_{\mathrm{cp}}= & 100 \mathrm{~mm} \text {, comprimento do corpo de prova; }
\end{aligned}
$$

As páginas que abrem a apresentação dos resultados dos ensaios de cada modelo indicam as datas de moldagem e de ensaio.

Para os ensaios de cisalhamento da espuma rígida, é apresentada na primeira página uma tabela com o resumo dos principais resultados obtidos, e nas páginas seguintes são apresentados os gráficos carga $x$ deslocamento relativo entre as placas de apoio, indicando para cada corpo de prova o módulo de elasticidade transversal, $G$, determinado a partir das prescrições da norma ASTM C 273 - 61. 
6.2 Resultados dos ensaios de Flexão

6.2.1 Modelo PS I - 1

Moldagem: 23 / março / 1995

Ensaio: 20 / abril / 1995 
TABELA 6.1. Ensaio de flexão. PS I - 1.

\begin{tabular}{ccccc}
\hline Etapa & $\begin{array}{c}\text { Força } \\
(\mathrm{N})\end{array}$ & \multicolumn{3}{c}{$\begin{array}{c}\text { DESLOCAMENTOS TRANSVERSAIS } \\
(\mathrm{mm})\end{array}$} \\
\cline { 3 - 5 } & & $\mathrm{D} 2$ & $\mathrm{D} 3$ & $\mathrm{D} 4$ \\
\hline 0 & 0 & 0.03 & 0.00 & 0.04 \\
1 & 80 & 0.67 & 0.69 & 0.62 \\
2 & 0 & 0.11 & 0.05 & 0.06 \\
3 & 80 & 0.69 & 0.71 & 0.63 \\
4 & 160 & 1.27 & 1.39 & 1.19 \\
5 & 240 & 2.00 & 2.14 & 1.88 \\
6 & 320 & 2.78 & 2.97 & 2.59 \\
7 & 400 & 3.63 & 3.88 & 3.35 \\
8 & 480 & 4.40 & 4.72 & 4.16 \\
9 & 560 & 5.36 & 5.75 & 5.05 \\
10 & 640 & 6.52 & 7.04 & 6.31 \\
11 & 720 & 7.55 & 8.14 & 7.28 \\
12 & 800 & 8.93 & 9.68 & 8.74 \\
13 & 880 & 10.05 & 10.93 & 9.84 \\
14 & 960 & 11.73 & 12.79 & 11.57 \\
15 & 1040 & 13.13 & 14.31 & 13.04 \\
16 & 1120 & 15.90 & 17.45 & 16.14 \\
17 & 1200 & 20.10 & 22.52 & 21.42 \\
18 & 1280 & 23.60 & 26.92 & 26.15 \\
\hline
\end{tabular}

Ruptura por cisalhamento da espuma $\mathrm{Fu}=1280 \mathrm{~N}$

Carga da primeira fissura $F_{r}=1040 \mathrm{~N}$

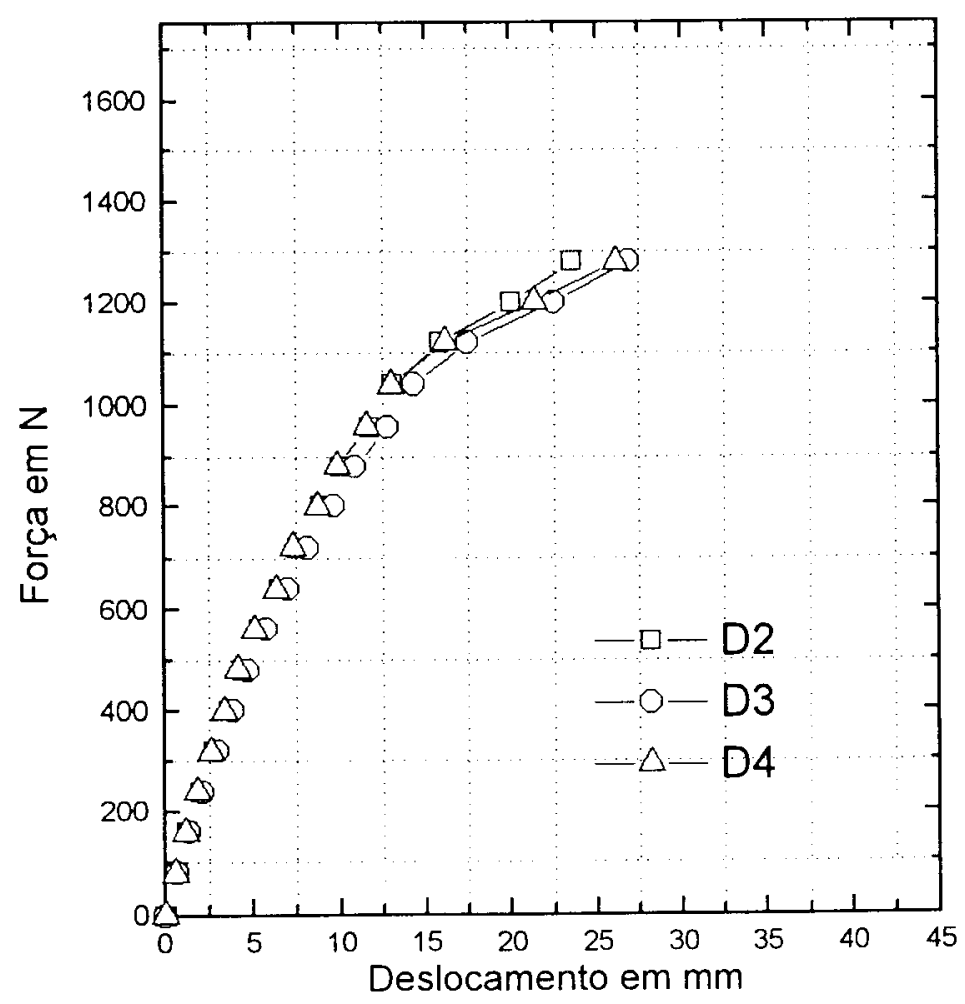

FIGURA 6.1. Gráfico Força x Deslocamento. PS I - 1. 
TABELA 6.2. Deformações medidas do ensaio de flexão com extensômetros elétricos. PS I - 1.

\begin{tabular}{|c|c|c|c|c|c|c|c|c|c|c|c|}
\hline \multirow[t]{2}{*}{ Etapa } & \multirow{2}{*}{$\begin{array}{c}\text { Força } \\
(\mathrm{N})\end{array}$} & \multicolumn{10}{|c|}{ DEFORMAÇÃO $(\mathrm{mm} / \mathrm{m})$} \\
\hline & & ES1 & ES2 & ES3 & ES4 & ETS1 & $\overline{\text { ETS2 }}$ & $\overline{E l 1}$ & $\bar{E} 2$ & $E I 3$ & $E \mid 4$ \\
\hline 0 & 0 & 0,00 & 0,00 & 0,00 & 0,00 & 0,00 & 0,00 & 0,00 & 0,00 & 0,00 & 0,00 \\
\hline 1 & 80 & 0,03 & 0,03 & $-0,01$ & $-0,02$ & 0,01 & 0,01 & $-0,03$ & $-0,03$ & 0,01 & 0,01 \\
\hline 2 & 0 & 0,00 & 0,00 & 0,00 & 0,00 & 0,00 & 0,00 & 0,00 & 0,00 & 0,00 & 0,00 \\
\hline 3 & 80 & 0,03 & 0,03 & $-0,02$ & $-0,02$ & 0,01 & 0,03 & $-0,03$ & $-0,03$ & 0,02 & 0,01 \\
\hline 4 & 160 & 0,05 & 0,06 & $-0,03$ & $-0,03$ & 0,01 & 0,02 & $-0,05$ & $-0,05$ & 0,03 & 0,03 \\
\hline 5 & 240 & 0,08 & 0,10 & $-0,04$ & 0,04 & 0,03 & 0,08 & $-0,08$ & $-0,08$ & 0,04 & 0,02 \\
\hline 6 & 320 & 0,09 & 0,13 & $-0,05$ & $-0,06$ & 0,03 & 0,04 & $-0,10$ & $-0,10$ & 0,05 & 0,05 \\
\hline 7 & 400 & 0,10 & 0,16 & $-0,06$ & $-0,07$ & 0,04 & 0,05 & $-0,13$ & $-0,12$ & 0,06 & 0,07 \\
\hline 8 & 480 & 0,11 & 0,18 & $-0,07$ & $-0,07$ & 0,05 & 0,06 & $-0,15$ & $-0,15$ & 0,07 & 0,08 \\
\hline 9 & 560 & 0,11 & 0,20 & $-0,06$ & $-0,06$ & 0,07 & 0,07 & $-0,18$ & $-0,17$ & 0,09 & 0,09 \\
\hline 10 & 640 & 0,11 & 0,27 & $-0,06$ & $-0,06$ & 0,09 & 0,09 & $-0,21$ & $-0,20$ & 0,09 & 0,10 \\
\hline 11 & 720 & 0,12 & 0,33 & $-0,08$ & $-0,08$ & 0,12 & 0,11 & $-0,24$ & $-0,23$ & 0,11 & 0,11 \\
\hline 12 & 800 & 0,13 & 0,55 & $-0,11$ & $-0,10$ & 0,17 & 0,17 & $-0,27$ & $-0,26$ & 0,12 & 0,13 \\
\hline 13 & 880 & 0,15 & 0,72 & $-0,11$ & $-0,08$ & 0,20 & 0,20 & $-0,30$ & $-0,28$ & 0,14 & 0,14 \\
\hline 14 & 960 & 0,22 & 0,84 & $-0,08$ & $-0,03$ & 0,25 & 0,26 & $-0,33$ & $-0,31$ & 0,15 & 0,15 \\
\hline 15 & 1040 & 0,63 & 0,98 & $-0,03$ & 0,07 & 0,29 & 0,32 & $-0,35$ & $-0,33$ & 0,16 & 0,16 \\
\hline 16 & 1120 & 0,99 & 1,25 & 0,70 & 0,82 & 0,47 & 0,48 & $-0,38$ & $-0,36$ & 0,17 & 0,17 \\
\hline 17 & 1200 & 1,17 & 1,42 & 1,00 & 1,10 & 0,55 & 0,55 & $-0,41$ & $-0,39$ & 0,20 & 0,20 \\
\hline 18 & 1280 & 1,25 & 1,51 & 1,28 & 1,37 & 0,62 & 0,62 & $-0,44$ & $-0,42$ & 0,22 & 0,22 \\
\hline
\end{tabular}

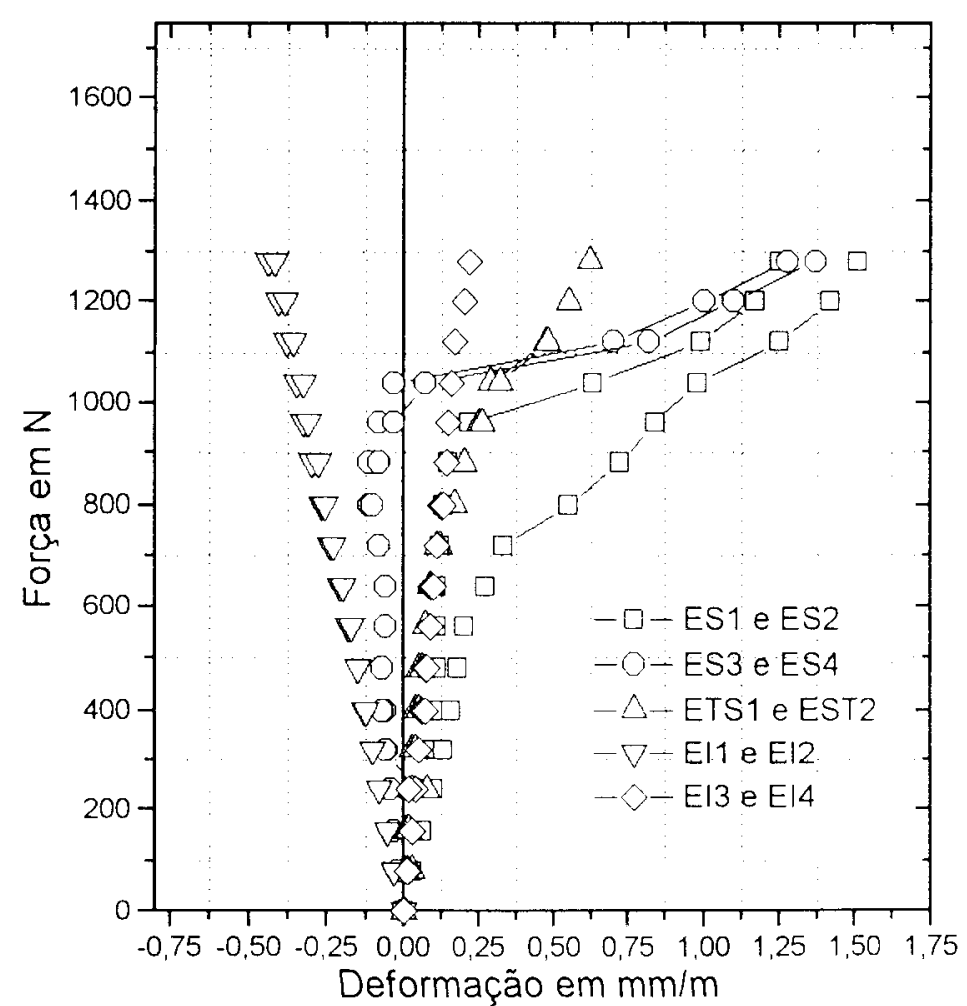

FIGURA 6.2. Gráfico Força x Deformação do ensaio de flexão. PS I - 1. 


\subsubsection{Modelo PS I - 2}

Moldagem: 23 / março / 1995

Ensaio: 20 / abril / 1995 
TABELA 6.3. Ensaio de flexão. PS I - 2.

\begin{tabular}{ccccc}
\hline Etapa & $\begin{array}{c}\text { Força } \\
(\mathrm{N})\end{array}$ & \multicolumn{3}{c}{$\begin{array}{c}\text { DESLOCAMENTOS TRANSVERSAIS } \\
(\mathrm{mm})\end{array}$} \\
\cline { 3 - 5 } & & $\mathrm{D} 2$ & $\mathrm{D} 3$ & $\mathrm{D} 4$ \\
\hline 0 & 0 & $-0,01$ & $-0,01$ & 0,01 \\
1 & 80 & 0,66 & 0,75 & 0,72 \\
2 & 0 & 0,09 & 0,07 & 0,06 \\
3 & 80 & 0,71 & 0,80 & 0,74 \\
4 & 160 & 1,38 & 1,55 & 1,40 \\
5 & 240 & 2,11 & 2,39 & 2,12 \\
6 & 320 & 2,96 & 3,36 & 3,00 \\
7 & 400 & 3,78 & 4,34 & 3,85 \\
8 & 480 & 4,85 & 5,54 & 4,90 \\
9 & 560 & 6,18 & 7,07 & 6,36 \\
10 & 640 & 7,39 & 8,39 & 7,64 \\
11 & 720 & 8,80 & 10,07 & 9,28 \\
12 & 800 & 10,65 & 12,30 & 11,50 \\
13 & 880 & 13,23 & 15,38 & 14,61 \\
14 & 960 & 16,95 & 20,08 & 19,40 \\
15 & 1040 & 20,00 & 23,87 & 23,16 \\
16 & 1120 & 26,65 & 32,34 & 31,68 \\
\hline
\end{tabular}

Ruptura por cisalhamento da espuma $\mathrm{Fu}=1120 \mathrm{~N}$

Carga da primeira fissura $F_{r}=1040 \mathrm{~N}$

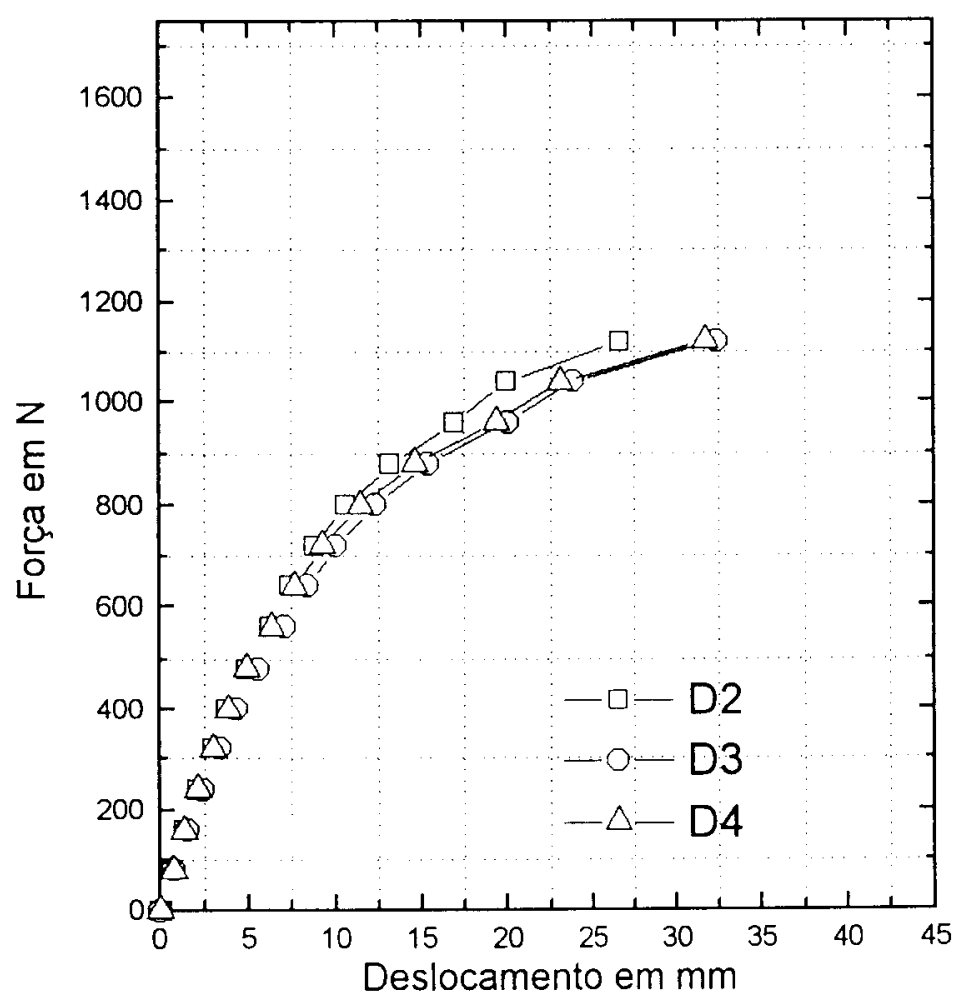

FIGURA 6.3. Gráfico Força x Deslocamento. PS I - 2. 
TABELA 6.4. Deformações medidas do ensaio de flexão com extensômetros elétricos. PS I - 2.

\begin{tabular}{cccccccccccc}
\hline Etapa & Força & \multicolumn{10}{c}{ DEFORMAÇÃO $(\mathrm{mm}) / \mathrm{m}$} \\
\cline { 2 - 12 } & $(\mathrm{N})$ & ES1 & ES2 & ES3 & ES4 & ETS1 & ETS2 & El1 & El2 & El3 & El4 \\
\hline 0 & 0 & 0,00 & 0,00 & 0,00 & 0,00 & 0,00 & 0,00 & 0,00 & 0,00 & 0,00 & 0,00 \\
1 & 80 & 0,02 & 0,03 & $-0,02$ & $-0,03$ & 0,02 & 0,02 & $-0,02$ & $-0,03$ & 0,02 & 0,02 \\
2 & 0 & 0,00 & 0,00 & 0,00 & 0,00 & 0,01 & 0,00 & 0,00 & 0,00 & 0,00 & 0,00 \\
3 & 80 & 0,03 & 0,03 & $-0,02$ & $-0,03$ & 0,03 & 0,02 & $-0,03$ & $-0,03$ & 0,02 & 0,02 \\
4 & 160 & 0,05 & 0,06 & $-0,03$ & $-0,05$ & 0,05 & 0,03 & $-0,05$ & $-0,05$ & 0,04 & 0,03 \\
5 & 240 & 0,08 & 0,10 & $-0,05$ & $-0,08$ & 0,07 & 0,05 & $-0,08$ & $-0,08$ & 0,05 & 0,05 \\
6 & 320 & 0,12 & 0,13 & $-0,06$ & $-0,11$ & 0,11 & 0,08 & $-0,11$ & $-0,11$ & 0,08 & 0,07 \\
7 & 400 & 0,54 & 0,73 & $-0,07$ & $-0,12$ & 0,16 & 0,10 & $-0,14$ & $-0,15$ & 0,10 & 0,10 \\
8 & 480 & 0,85 & 0,91 & $-0,07$ & $-0,15$ & 0,20 & 0,14 & $-0,18$ & $-0,19$ & 0,13 & 0,12 \\
9 & 560 & 1,02 & 1,01 & $-0,06$ & $-0,16$ & 0,24 & 0,19 & $-0,20$ & $-0,21$ & 0,14 & 0,13 \\
10 & 640 & 1,11 & 1,08 & $-0,06$ & $-0,17$ & 0,27 & 0,21 & $-0,22$ & $-0,24$ & 0,15 & 0,14 \\
11 & 720 & 1,17 & 1,13 & $-0,06$ & $-0,16$ & 0,30 & 0,24 & $-0,25$ & $-0,27$ & 0,17 & 0,16 \\
12 & 800 & 1,23 & 1,18 & $-0,10$ & $-0,15$ & 0,34 & 0,28 & $-0,28$ & $-0,30$ & 0,19 & 0,17 \\
13 & 880 & 1,37 & 1,25 & $-0,14$ & $-0,15$ & 0,39 & 0,33 & $-0,30$ & $-0,33$ & 0,21 & 0,19 \\
14 & 960 & 1,55 & 1,38 & $-0,24$ & $-0,16$ & 0,47 & 0,42 & $-0,34$ & $-0,38$ & 0,23 & 0,21 \\
15 & 1040 & 1,75 & 1,51 & $-0,32$ & $-0,18$ & 0,54 & 0,50 & $-0,37$ & $-0,41$ & 0,25 & 0,23 \\
16 & 1120 & 2,24 & 1,84 & $-0,51$ & $-0,35$ & 0,70 & 0,66 & $-0,43$ & $-0,47$ & 0,30 & 0,27 \\
\hline
\end{tabular}

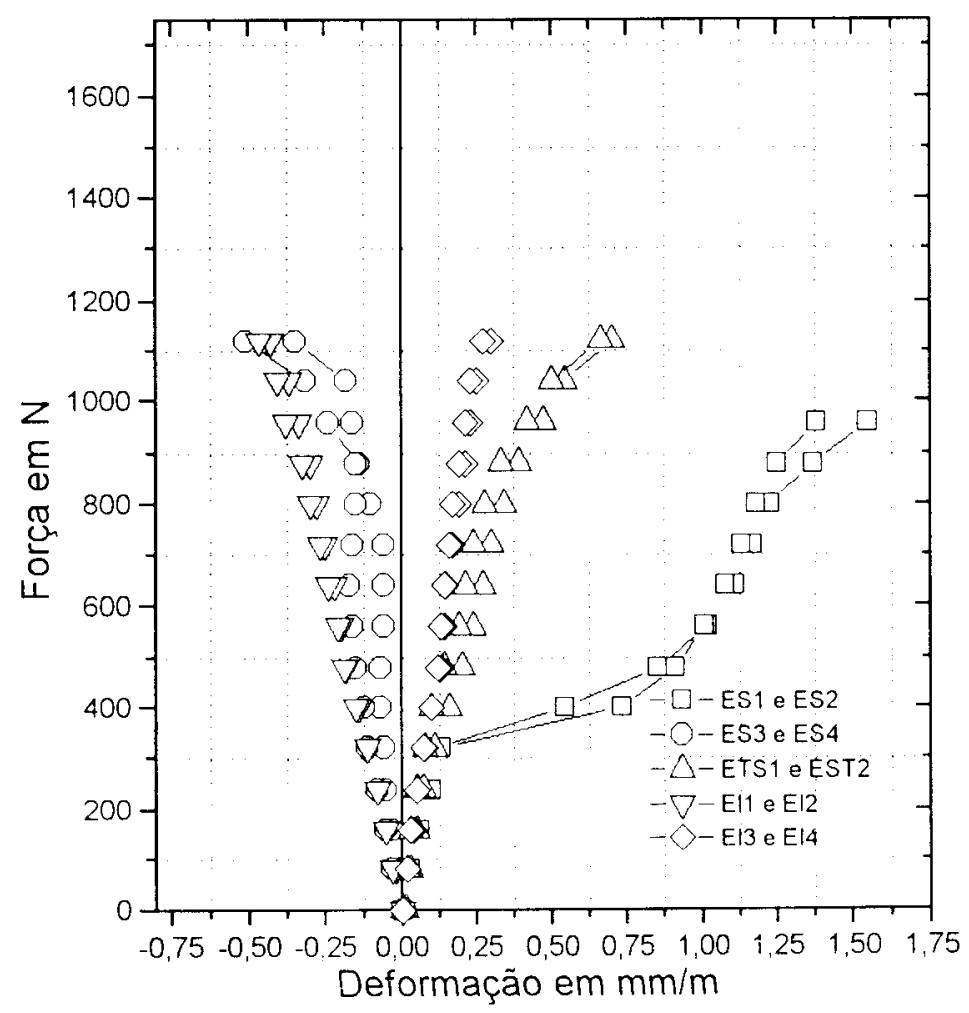

FIGURA 6.4. Gráfico Força x Deformação do ensaio de flexão. PS I - 2. 


\subsubsection{Controle de resistência da argamassa}

$$
\text { (PS I - 1 e PS I - 2) }
$$


TABELA 6.5. Resultados do controle de resistência da argamassa para as séries PS I - 1 e PS I - 2.

\begin{tabular}{cccc}
\hline & $\begin{array}{c}\text { Resistência à compressão } \\
(\mathrm{MPa})\end{array}$ & $\begin{array}{c}\text { Resistência à tração } \\
(\mathrm{MPa})\end{array}$ \\
\hline Idade & 7 dias & 28 dias & 28 dias \\
\hline & 22,92 & 33,74 & 3,66 \\
& 22,92 & 35,65 & 3,50 \\
Média & 22,92 & 34,38 & 3,34 \\
\hline
\end{tabular}

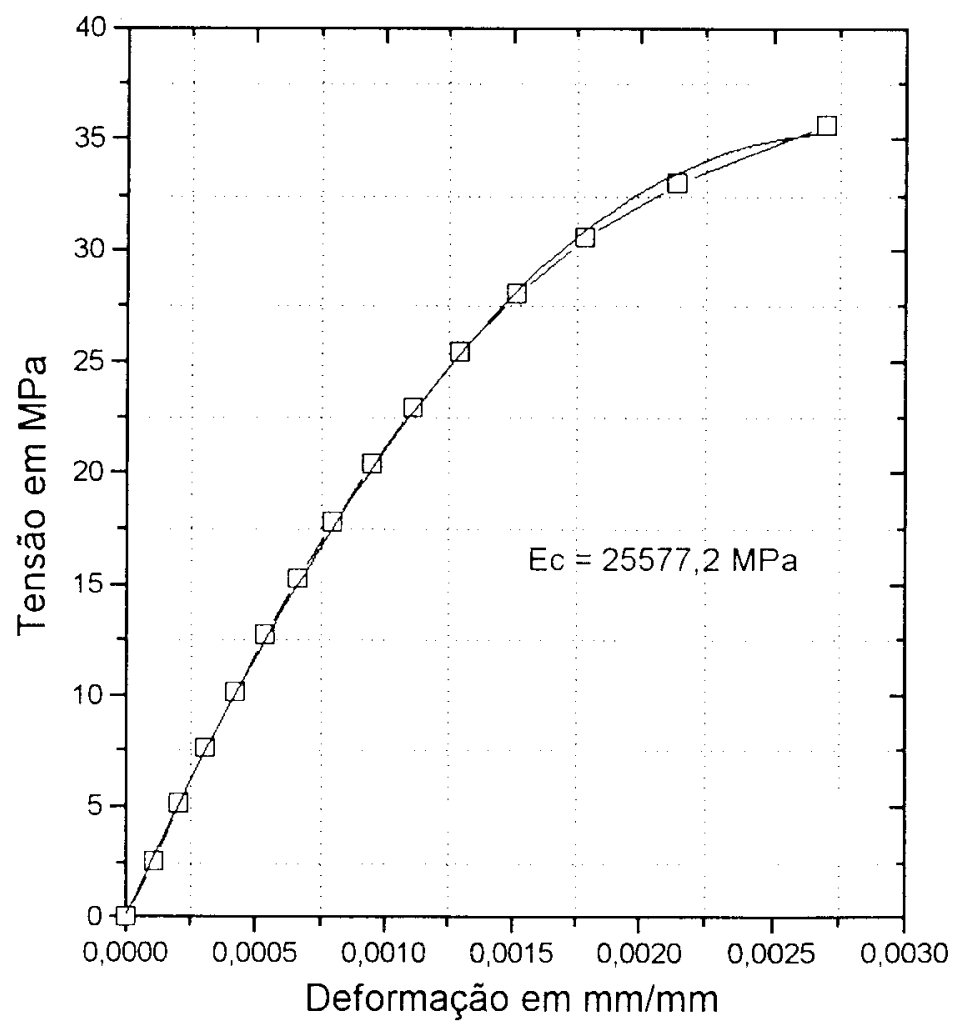

FIGURA 6.5. Gráfico Tensão x Deformação do ensaio de compressão do corpo de prova da argamassa. 
6.2.4 Modelo PS I - 3

Moldagem: 27 / março / 1995

Ensaio: 24 / abril / 1995 
TABELA 6.6. Ensaio de flexão. PS I - 3.

\begin{tabular}{ccccc}
\hline Etapa & $\begin{array}{c}\text { Força } \\
(\mathrm{N})\end{array}$ & \multicolumn{3}{c}{ DESLOCAMENTOS TRANSVERSAIS } \\
\cline { 3 - 5 } & & $\mathrm{m} 2$ & $\mathrm{D} 3$ & $\mathrm{D} 4$ \\
\hline & 0 & 0,02 & $-0,02$ & 0,01 \\
1 & 80 & 0,60 & 0,64 & 0,56 \\
2 & 0 & 0,07 & 0,09 & 0,06 \\
3 & 80 & 0,58 & 0,61 & 0,53 \\
4 & 160 & 1,22 & 1,31 & 1,14 \\
5 & 240 & 1,90 & 2,02 & 1,76 \\
6 & 320 & 2,58 & 2,77 & 2,36 \\
7 & 400 & 3,44 & 3,66 & 3,15 \\
8 & 480 & 4,29 & 4,50 & 3,91 \\
9 & 560 & 5,06 & 5,32 & 4,65 \\
10 & 640 & 5,94 & 6,23 & 5,49 \\
11 & 720 & 6,87 & 7,19 & 6,31 \\
12 & 800 & 7,83 & 8,23 & 7,25 \\
13 & 880 & 8,72 & 9,20 & 8,15 \\
14 & 960 & 10,02 & 10,57 & 9,39 \\
15 & 1040 & 11,59 & 12,30 & 10,98 \\
16 & 1120 & 12,83 & 13,63 & 12,18 \\
17 & 1200 & 14,05 & 14,94 & 13,40 \\
18 & 1280 & 15,77 & 16,80 & 15,15 \\
19 & 1360 & 18,18 & 19,46 & 17,78 \\
20 & 1440 & 21,17 & 22,83 & 21,20 \\
21 & 1520 & 23,87 & 25,93 & 24,31 \\
22 & 1600 & 26,96 & 29,65 & 28,30 \\
\hline
\end{tabular}

Ruptura por cisalhamento da espuma $\mathrm{Fu}=1600 \mathrm{~N}$

Carga da primeira fissura $F_{r}=720 \mathrm{~N}$

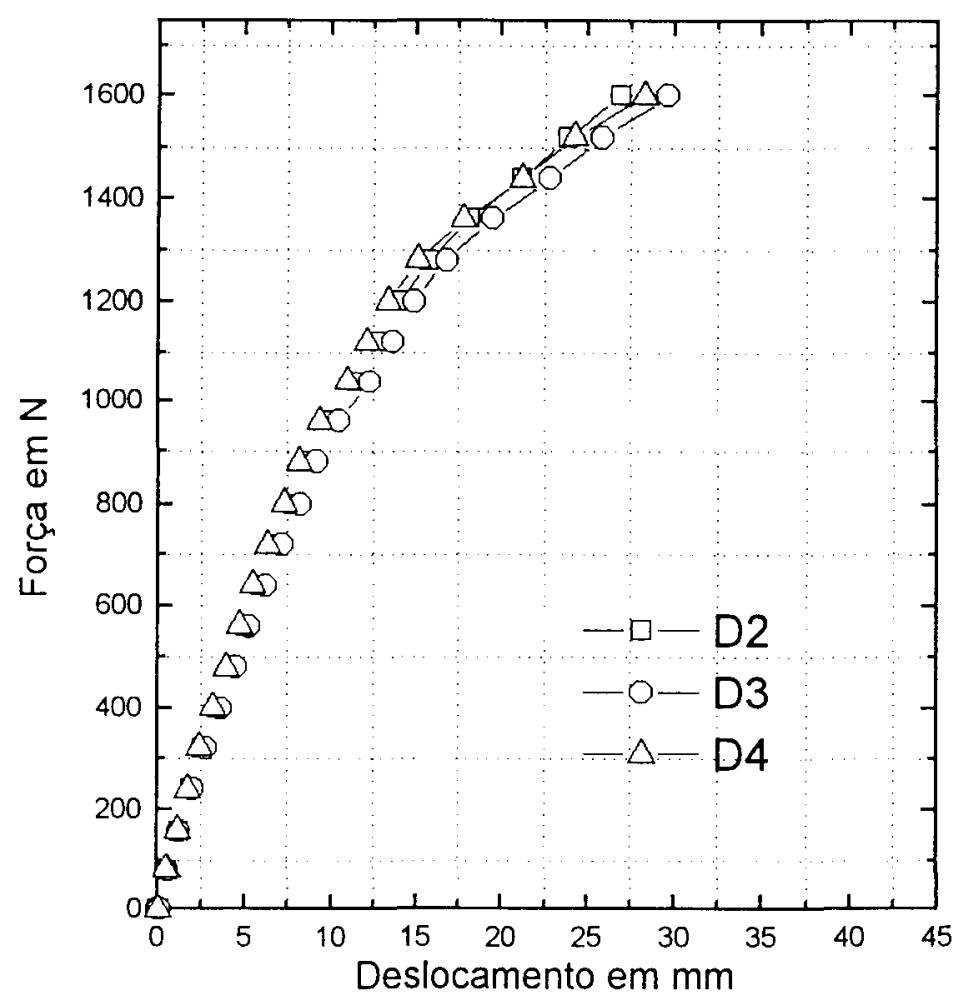

FIGURA 6.6. Gráfico Força x Deslocamento. PS I - 3 
TABELA 6.7. Deformaçōes medidas do ensaio de flexão com extensômetros elétricos. PS I - 3 .

\begin{tabular}{ccccccccccccc}
\hline Etapa & Força & \multicolumn{10}{c}{ DEFORMAÇÃO $(\mathrm{mm}) / \mathrm{m}$} \\
\cline { 3 - 11 } & $(\mathrm{N})$ & ES1 & ES2 & ES3 & ES4 & ETS1 & ETS2 & El1 & El2 & El3 & El4 \\
\hline 0 & 0 & 0,00 & 0,00 & 0,00 & 0,00 & 0,00 & 0,00 & 0,00 & 0,00 & 0,00 & 0,00 \\
1 & 80 & 0,02 & 0,02 & $-0,01$ & $-0,01$ & 0,01 & 0,01 & $-0,02$ & $-0,02$ & 0,01 & 0,01 \\
2 & 0 & 0,00 & 0,00 & 0,00 & 0,00 & 0,00 & 0,01 & 0,00 & 0,00 & 0,00 & 0,00 \\
3 & 80 & 0,02 & 0,02 & $-0,01$ & $-0,01$ & 0,01 & 0,01 & $-0,02$ & $-0,02$ & 0,01 & 0,01 \\
4 & 160 & 0,05 & 0,04 & $-0,02$ & $-0,02$ & 0,03 & 0,03 & $-0,04$ & $-0,04$ & 0,02 & 0,02 \\
5 & 240 & 0,07 & 0,06 & $-0,03$ & $-0,02$ & 0,04 & 0,06 & $-0,06$ & $-0,06$ & 0,03 & 0,03 \\
6 & 320 & 0,09 & 0,06 & $-0,04$ & $-0,02$ & 0,07 & 0,09 & $-0,08$ & $-0,08$ & 0,03 & 0,03 \\
7 & 400 & 0,11 & 0,07 & $-0,04$ & $-0,02$ & 0,11 & 0,14 & $-0,10$ & $-0,10$ & 0,04 & 0,05 \\
8 & 480 & 0,12 & 0,09 & $-0,04$ & $-0,01$ & 0,15 & 0,19 & $-0,12$ & $-0,12$ & 0,05 & 0,06 \\
9 & 560 & 0,13 & 0,09 & $-0,05$ & $-0,01$ & 0,19 & 0,23 & $-0,14$ & $-0,14$ & 0,06 & 0,06 \\
10 & 640 & 0,14 & 0,10 & $-0,05$ & 0,01 & 0,23 & 0,28 & $-0,17$ & $-0,17$ & 0,07 & 0,07 \\
11 & 720 & 0,14 & 0,10 & $-0,04$ & 0,02 & 0,27 & 0,33 & $-0,19$ & $-0,19$ & 0,08 & 0,09 \\
12 & 800 & 0,14 & 0,11 & $-0,04$ & 0,03 & 0,31 & 0,38 & $-0,21$ & $-0,21$ & 0,09 & 0,10 \\
13 & 880 & 0,13 & 0,12 & $-0,02$ & 0,05 & 0,34 & 0,42 & $-0,24$ & $-0,24$ & 0,10 & 0,11 \\
14 & 960 & 0,13 & 0,13 & 0,01 & 0,06 & 0,37 & 0,47 & $-0,26$ & $-0,26$ & 0,12 & 0,12 \\
15 & 1040 & 0,11 & 0,87 & 0,05 & 0,08 & 0,49 & 0,54 & $-0,30$ & $-0,29$ & 0,14 & 0,14 \\
16 & 1120 & 0,11 & 0,98 & 0,06 & 0,09 & 0,53 & 0,57 & $-0,32$ & $-0,32$ & 0,15 & 0,15 \\
17 & 1200 & 0,11 & 1,06 & 0,09 & 0,09 & 0,56 & 0,61 & $-0,34$ & $-0,33$ & 0,16 & 0,16 \\
18 & 1280 & 0,10 & 1,14 & 0,11 & 0,10 & 0,61 & 0,67 & $-0,37$ & $-0,36$ & 0,17 & 0,18 \\
19 & 1360 & 0,10 & 1,28 & 0,13 & 0,08 & 0,69 & 0,76 & $-0,40$ & $-0,38$ & 0,18 & 0,18 \\
20 & 1440 & 0,10 & 1,39 & 0,13 & 0,06 & 0,74 & 0,83 & $-0,42$ & $-0,40$ & 0,20 & 0,20 \\
21 & 1520 & 0,11 & 1,52 & 0,14 & 0,06 & 0,81 & 0,90 & $-0,45$ & $-0,42$ & 0,22 & 0,22 \\
22 & 1600 & 0,11 & 1,68 & 0,14 & 0,06 & 0,88 & 0,98 & $-0,47$ & $-0,45$ & 0,24 & 0,24 \\
\hline
\end{tabular}

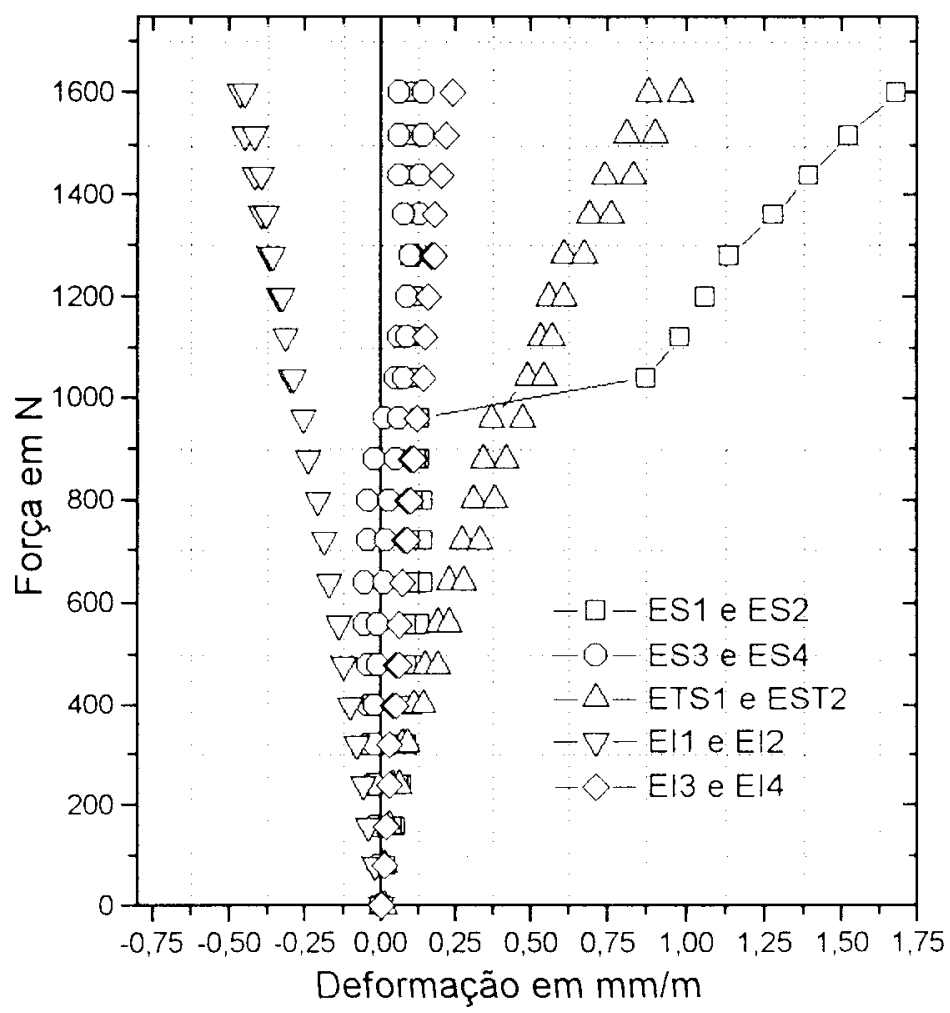

FIGURA 6.6. Gráfico Força x Deformação do ensaio de flexão. PS I - 3. 


\subsubsection{Modelo PS I - 4}

Moldagem: 27 / março / 1995

Ensaio: 24 / abril / 1995 
TABELA 6.8. Ensaio de flexão. PS I - 4.

\begin{tabular}{ccccc}
\hline Etapa & $\begin{array}{c}\text { Força } \\
(\mathrm{N})\end{array}$ & \multicolumn{3}{c}{$\begin{array}{c}\text { DESLOCAMENTOS TRANSVERSAIS } \\
(\mathrm{mm})\end{array}$} \\
\cline { 3 - 5 } & & $\mathrm{D} 2$ & $\mathrm{D} 3$ & $\mathrm{D} 4$ \\
\hline 0 & 0 & 0,00 & 0,00 & 0,00 \\
1 & 80 & 0,67 & 0,77 & 0,66 \\
2 & 0 & 0,00 & 0,02 & $-0,01$ \\
3 & 80 & 0,67 & 0,77 & 0,66 \\
4 & 160 & 1,31 & 1,51 & 1,28 \\
5 & 240 & 2,06 & 2,35 & 2,00 \\
6 & 320 & 2,80 & 3,15 & 2,69 \\
7 & 400 & 3,58 & 4,07 & 3,48 \\
8 & 480 & 4,47 & 5,07 & 4,38 \\
9 & 560 & 5,37 & 6,01 & 5,28 \\
10 & 640 & 6,38 & 7,18 & 6,28 \\
11 & 720 & 7,45 & 8,30 & 7,36 \\
12 & 800 & 8,78 & 9,77 & 8,82 \\
13 & 880 & 10,07 & 11,16 & 10,08 \\
14 & 960 & 11,48 & 12,69 & 11,58 \\
15 & 1040 & 13,90 & 15,40 & 14,15 \\
16 & 1120 & 15,79 & 17,49 & 16,20 \\
17 & 1200 & 18,01 & 19,95 & 18,53 \\
18 & 1280 & 20,53 & 22,80 & 21,31 \\
19 & 1360 & 23,43 & 26,12 & 24,56 \\
20 & 1440 & 25,99 & 29,13 & 27,58 \\
21 & 1520 & 28,43 & 32,00 & 30,47 \\
22 & 1600 & 32,06 & 36,45 & 35,10 \\
\hline Rupyyy & 160 &
\end{tabular}

Ruptura por cisalhamento da espuma $\mathrm{Fu}=1600 \mathrm{~N}$

Carga da primeira fissura $F_{r}=720 \mathrm{~N}$

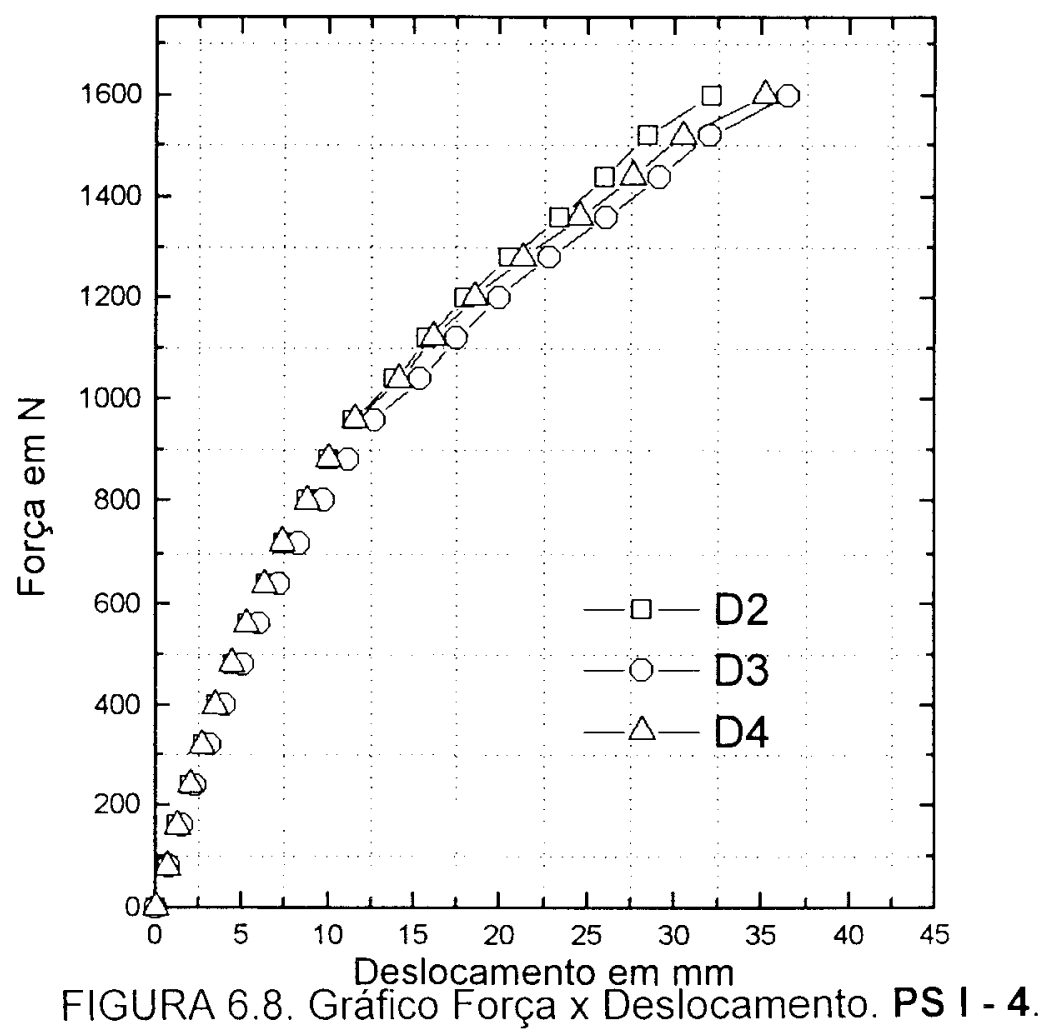


TABELA 6.9. Deformações medidas do ensaio de flexão com extensômetros elétricos. PS I - 4.

\begin{tabular}{cccccccccccc}
\hline Etapa & Força & \multicolumn{10}{c}{ DEFORMAÇÃO $(\mathrm{mm}) / \mathrm{m}$} \\
\cline { 3 - 11 } & $(\mathrm{N})$ & ES1 & ES2 & ES3 & ES4 & ETS1 & ETS2 & El1 & El2 & El3 & El4 \\
\hline 0 & 0 & 0,00 & 0,00 & 0,00 & 0,00 & 0,00 & 0,00 & 0,00 & 0,00 & 0,00 & 0,00 \\
1 & 80 & 0,09 & 0,07 & $-0,02$ & $-0,04$ & 0,02 & 0,02 & $-0,03$ & $-0,03$ & 0,01 & 0,02 \\
2 & 0 & 0,00 & 0,00 & 0,00 & 0,00 & 0,00 & 0,00 & 0,00 & 0,00 & 0,00 & 0,00 \\
3 & 80 & 0,09 & 0,07 & $-0,02$ & $-0,04$ & 0,02 & 0,02 & $-0,03$ & $-0,03$ & 0,01 & 0,02 \\
4 & 160 & 0,17 & 0,14 & $-0,04$ & $-0,07$ & 0,05 & 0,04 & $-0,06$ & $-0,05$ & 0,03 & 0,05 \\
5 & 240 & 0,27 & 0,22 & $-0,06$ & $-0,11$ & 0,07 & 0,06 & $-0,08$ & $-0,08$ & 0,04 & 0,07 \\
6 & 320 & 0,36 & 0,30 & $-0,08$ & $-0,14$ & 0,10 & 0,07 & $-0,11$ & $-0,10$ & 0,05 & 0,09 \\
7 & 400 & 0,46 & 0,39 & $-0,11$ & $-0,17$ & 0,10 & 0,10 & $-0,14$ & $-0,13$ & 0,11 & 0,13 \\
8 & 480 & 0,55 & 0,47 & $-0,13$ & $-0,19$ & 0,15 & 0,12 & $-0,16$ & $-0,15$ & 0,08 & 0,12 \\
9 & 560 & 0,63 & 0,54 & $-0,14$ & $-0,21$ & 0,18 & 0,14 & $-0,19$ & $-0,17$ & 0,09 & 0,13 \\
10 & 640 & 0,71 & 0,61 & $-0,16$ & $-0,23$ & 0,20 & 0,16 & $-0,21$ & $-0,19$ & 0,10 & 0,15 \\
11 & 720 & 0,77 & 0,67 & $-0,16$ & $-0,23$ & 0,22 & 0,18 & $-0,23$ & $-0,21$ & 0,10 & 0,15 \\
12 & 800 & 0,85 & 0,74 & $-0,16$ & $-0,23$ & 0,25 & 0,20 & $-0,25$ & $-0,23$ & 0,11 & 0,16 \\
13 & 880 & 0,91 & 0,79 & $-0,16$ & $-0,23$ & 0,28 & 0,23 & $-0,27$ & $-0,25$ & 0,11 & 0,17 \\
14 & 960 & 0,98 & 0,86 & $-0,17$ & $-0,23$ & 0,31 & 0,26 & $-0,29$ & $-0,27$ & 0,12 & 0,18 \\
15 & 1040 & 1,08 & 0,95 & $-0,18$ & $-0,25$ & 0,36 & 0,29 & $-0,32$ & $-0,30$ & 0,14 & 0,19 \\
16 & 1120 & 1,14 & 1,03 & $-0,17$ & $-0,24$ & 0,41 & 0,33 & $-0,34$ & $-0,33$ & 0,15 & 0,20 \\
17 & 1200 & 1,22 & 1,12 & $-0,18$ & $-0,25$ & 0,46 & 0,36 & $-0,36$ & $-0,35$ & 0,15 & 0,21 \\
18 & 1280 & 1,30 & 1,22 & $-0,19$ & $-0,26$ & 0,52 & 0,40 & $-0,39$ & $-0,37$ & 0,17 & 0,23 \\
19 & 1360 & 1,38 & 1,32 & $-0,19$ & $-0,26$ & 0,57 & 0,46 & $-0,41$ & $-0,39$ & 0,18 & 0,24 \\
20 & 1440 & 1,48 & 1,45 & $-0,21$ & $-0,27$ & 0,63 & 0,48 & $-0,44$ & $-0,42$ & 0,19 & 0,25 \\
21 & 1520 & 1,60 & 1,57 & $-0,22$ & $-0,27$ & 0,69 & 0,53 & $-0,46$ & $-0,44$ & 0,20 & 0,26 \\
22 & 1600 & 1,75 & 1,75 & $-0,26$ & $-0,30$ & 0,77 & 0,58 & $-0,49$ & $-0,47$ & 0,21 & 0,28 \\
\hline
\end{tabular}

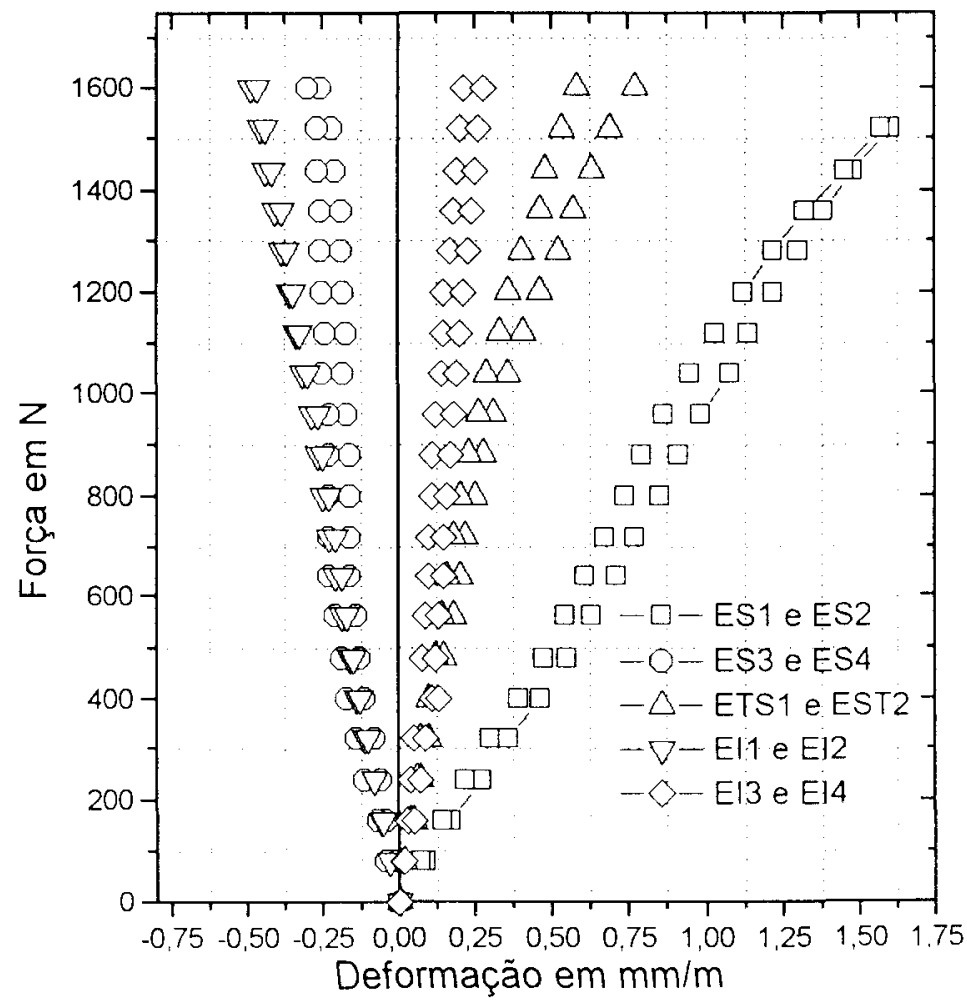

FIGURA 6.8. Gráfico Força x Deformação do ensaio de flexão. PS I - 4. 
6.2.6 Controle de resistência da argamassa (PS I - 3 e PS I - 4) 
TABELA 6.10. Resultados do controle de resistência da argamassa para as séries PS I - 3 e PS I - 4

\begin{tabular}{cccc}
\hline & \multicolumn{2}{c}{$\begin{array}{c}\text { Resistência à compressão } \\
(\mathrm{MPa})\end{array}$} & $\begin{array}{c}\text { Resistência à tração } \\
(\mathrm{MPa})\end{array}$ \\
\hline Idade & 7 dias & 28 dias & 28 dias \\
\hline & 26,10 & 40,11 & 4,30 \\
& 28,01 & 37,56 & 3,82 \\
Média & 28,01 & 40,74 & 3,50 \\
\hline
\end{tabular}

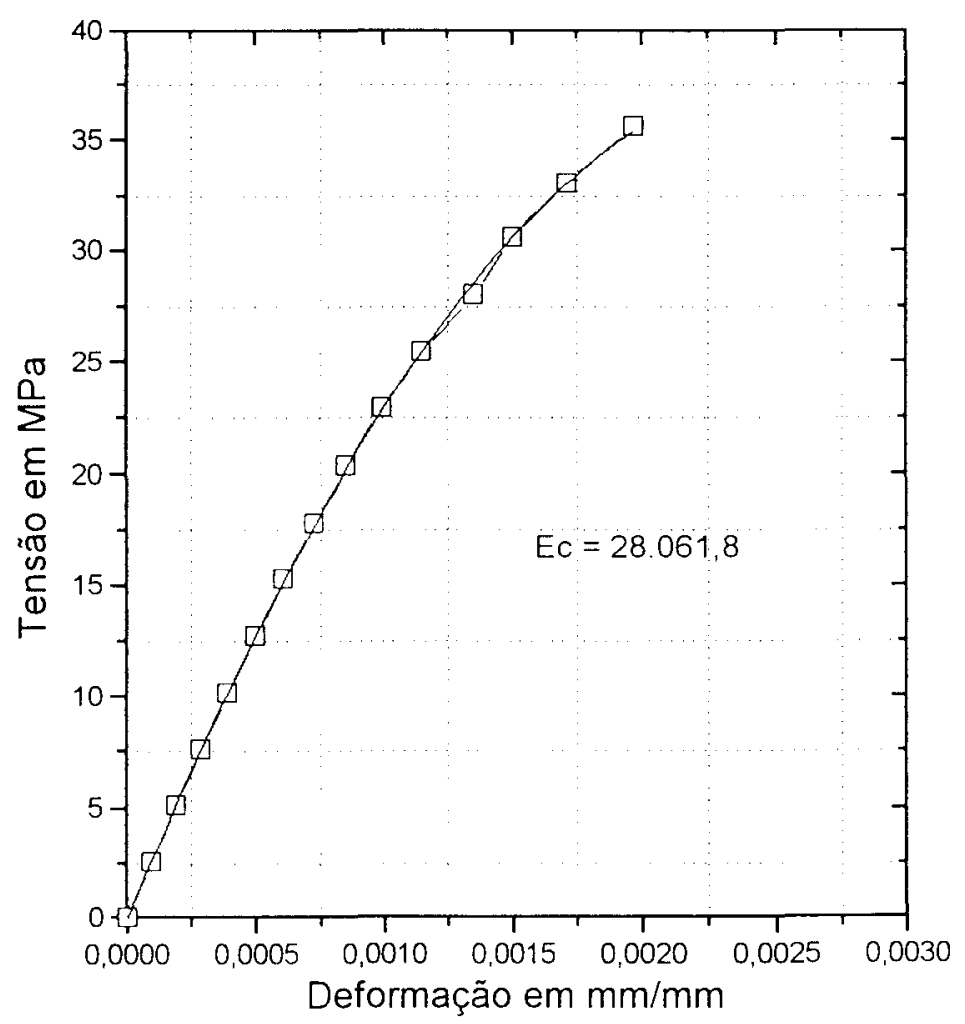

FIGURA 6.10. Gráfico Tensão x Deformação do ensaio de compressão do corpo de prova da argamassa. 


\subsubsection{Modelo PS II - 1}

Moldagem: 29 / março / 1995

Ensaio: 26 / abril / 1995 
TABELA 6.11. Ensaio de flexão. PS II - 1.

\begin{tabular}{ccccc}
\hline Etapa & $\begin{array}{c}\text { Força } \\
(\mathrm{N})\end{array}$ & \multicolumn{3}{c}{$\begin{array}{c}\text { DESLOCAMENTOS TRANSVERSAIS } \\
(\mathrm{mm})\end{array}$} \\
\cline { 3 - 5 } & & $\mathrm{D} 2$ & $\mathrm{D} 3$ & $\mathrm{D} 4$ \\
\hline 0 & 0 & 0,00 & 0,00 & 0,00 \\
1 & 80 & 0,63 & 0,73 & 0,61 \\
2 & 0 & 0,12 & 0,12 & 0,11 \\
3 & 80 & 0,66 & 0,76 & 0,68 \\
4 & 160 & 1,31 & 1,48 & 1,28 \\
5 & 240 & 2,13 & 2,35 & 2,04 \\
6 & 320 & 2,92 & 3,22 & 2,76 \\
7 & 400 & 3,82 & 4,21 & 3,61 \\
8 & 480 & 4,71 & 5,15 & 4,48 \\
9 & 560 & 5,80 & 6,34 & 5,46 \\
10 & 640 & 6,70 & 7,31 & 6,36 \\
11 & 720 & 8,17 & 8,87 & 7,75 \\
12 & 800 & 9,52 & 10,28 & 9,09 \\
13 & 880 & 11,26 & 12,17 & 10,79 \\
14 & 960 & 13,18 & 14,32 & 12,78 \\
15 & 1040 & 14,95 & 16,23 & 14,56 \\
16 & 1120 & 16,87 & 18,39 & 16,56 \\
17 & 1200 & 18,92 & 20,66 & 18,74 \\
18 & 1280 & 22,22 & 24,47 & 22,38 \\
19 & 1360 & 26,47 & 29,46 & 27,38 \\
\hline
\end{tabular}

Ruptura por cisalhamento da espuma $\mathrm{Fu}=1360 \mathrm{~N}$

Carga da primeira fissura $F_{r}=880 \mathrm{~N}$

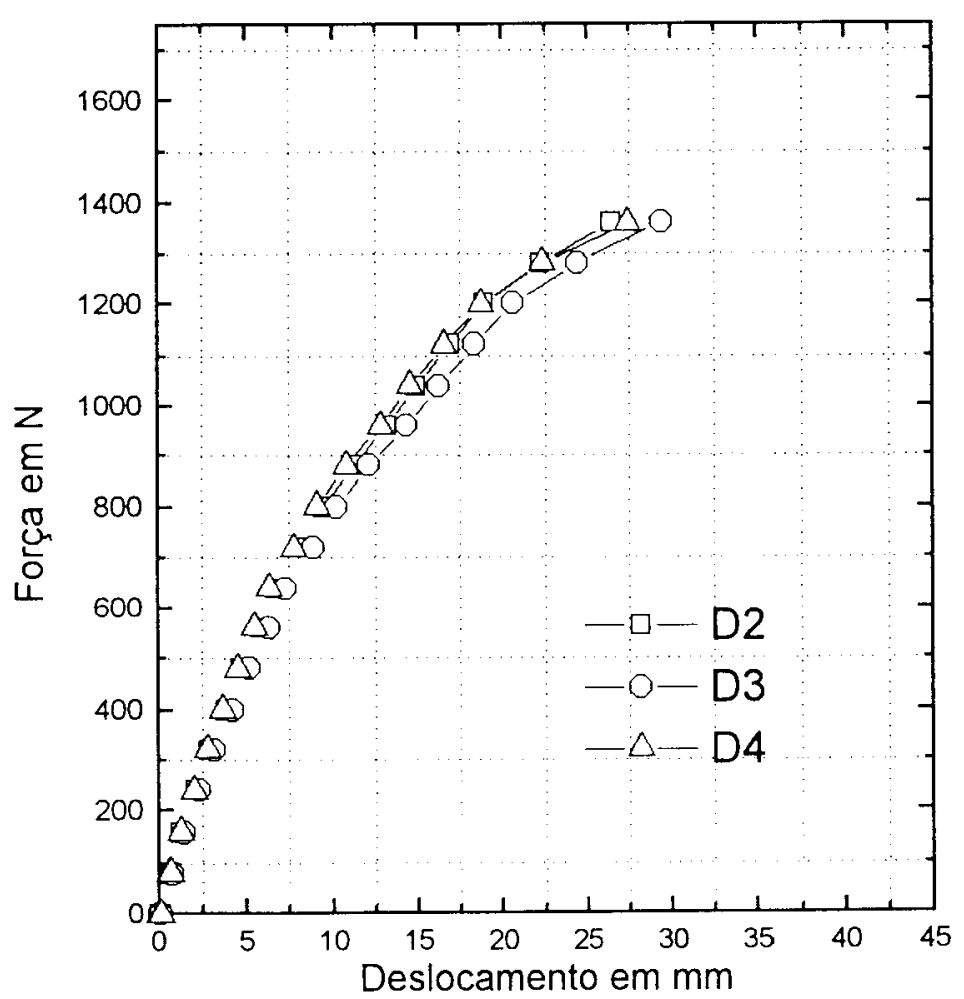

FIGURA 6.11. Gráfico Força x Deslocamento. PS II - 1. 
TABELA 6.12. Deformações medidas do ensaio de flexão com extensômetros elétricos. PS II - 1 .

\begin{tabular}{cccccccccccc}
\hline Etapa & $\begin{array}{c}\text { Força } \\
\text { (N) }\end{array}$ & \multicolumn{10}{c}{ DEFORMAÇÃO $(\mathrm{mm}) / \mathrm{m}$} \\
\cline { 3 - 11 } & ES1 & ES2 & ES3 & ES4 & ETS1 & ETS2 & El1 & El2 & El3 & El4 \\
\hline 0 & 0 & 0,00 & 0,00 & 0,00 & 0,00 & 0,00 & 0,00 & 0,00 & 0,00 & 0,00 & 0,00 \\
1 & 80 & 0,02 & 0,01 & $-0,02$ & $-0,01$ & 0,01 & 0,01 & $-0,02$ & $-0,03$ & 0,01 & 0,01 \\
2 & 0 & 0,00 & 0,00 & $-0,01$ & 0,00 & 0,00 & 0,00 & 0,00 & 0,00 & $-0,01$ & 0,00 \\
3 & 80 & 0,02 & 0,01 & $-0,03$ & $-0,01$ & 0,01 & 0,01 & $-0,02$ & $-0,03$ & 0,01 & 0,01 \\
4 & 160 & 0,03 & 0,03 & $-0,06$ & $-0,02$ & 0,02 & 0,02 & $-0,05$ & $-0,05$ & 0,02 & 0,02 \\
5 & 240 & 0,04 & 0,04 & $-0,09$ & $-0,02$ & 0,03 & 0,03 & $-0,07$ & $-0,08$ & 0,03 & 0,04 \\
6 & 320 & 0,05 & 0,05 & $-0,12$ & $-0,02$ & 0,05 & 0,04 & $-0,10$ & $-0,11$ & 0,04 & 0,05 \\
7 & 400 & 0,06 & 0,05 & $-0,13$ & $-0,02$ & 0,06 & 0,06 & $-0,12$ & $-0,13$ & 0,05 & 0,06 \\
8 & 480 & 0,07 & 0,06 & $-0,14$ & $-0,01$ & 0,08 & 0,08 & $-0,15$ & $-0,16$ & 0,06 & 0,07 \\
9 & 560 & 0,05 & 0,06 & $-0,10$ & 0,01 & 0,17 & 0,14 & $-0,18$ & $-0,20$ & 0,08 & 0,09 \\
10 & 640 & 0,04 & 0,05 & $-0,06$ & 0,03 & 0,27 & 0,21 & $-0,21$ & $-0,23$ & 0,10 & 0,11 \\
11 & 720 & 0,02 & 0,04 & 0,05 & 0,06 & 0,44 & 0,34 & $-0,24$ & $-0,27$ & 0,12 & 0,13 \\
12 & 800 & 0,02 & 0,04 & 0,10 & 0,07 & 0,72 & 0,50 & $-0,26$ & $-0,30$ & 0,14 & 0,14 \\
13 & 880 & 0,01 & 0,03 & 0,22 & 0,08 & 0,98 & 0,71 & $-0,30$ & $-0,34$ & 0,17 & 0,18 \\
14 & 960 & 0,02 & 0,03 & 0,38 & 0,08 & 1,16 & 0,87 & $-0,33$ & $-0,38$ & 0,20 & 0,20 \\
15 & 1040 & 0,02 & 0,02 & 0,60 & 0,08 & 1,36 & 1,05 & $-0,36$ & $-0,41$ & 0,21 & 0,22 \\
16 & 1120 & 0,02 & 0,02 & 0,82 & 0,07 & 1,53 & 1,24 & $-0,38$ & $-0,44$ & 0,24 & 0,24 \\
17 & 1200 & 0,02 & 0,02 & 1,07 & 0,07 & 1,68 & 1,39 & $-0,41$ & $-0,48$ & 0,26 & 0,26 \\
18 & 1280 & 0,02 & 0,01 & 1,34 & 0,07 & 1,89 & 1,57 & $-0,45$ & $-0,52$ & 0,30 & 0,30 \\
19 & 1360 & 0,02 & 0,01 & 1,46 & 0,06 & 2,05 & 1,72 & $-0,49$ & $-0,57$ & 0,35 & 0,35 \\
\hline
\end{tabular}

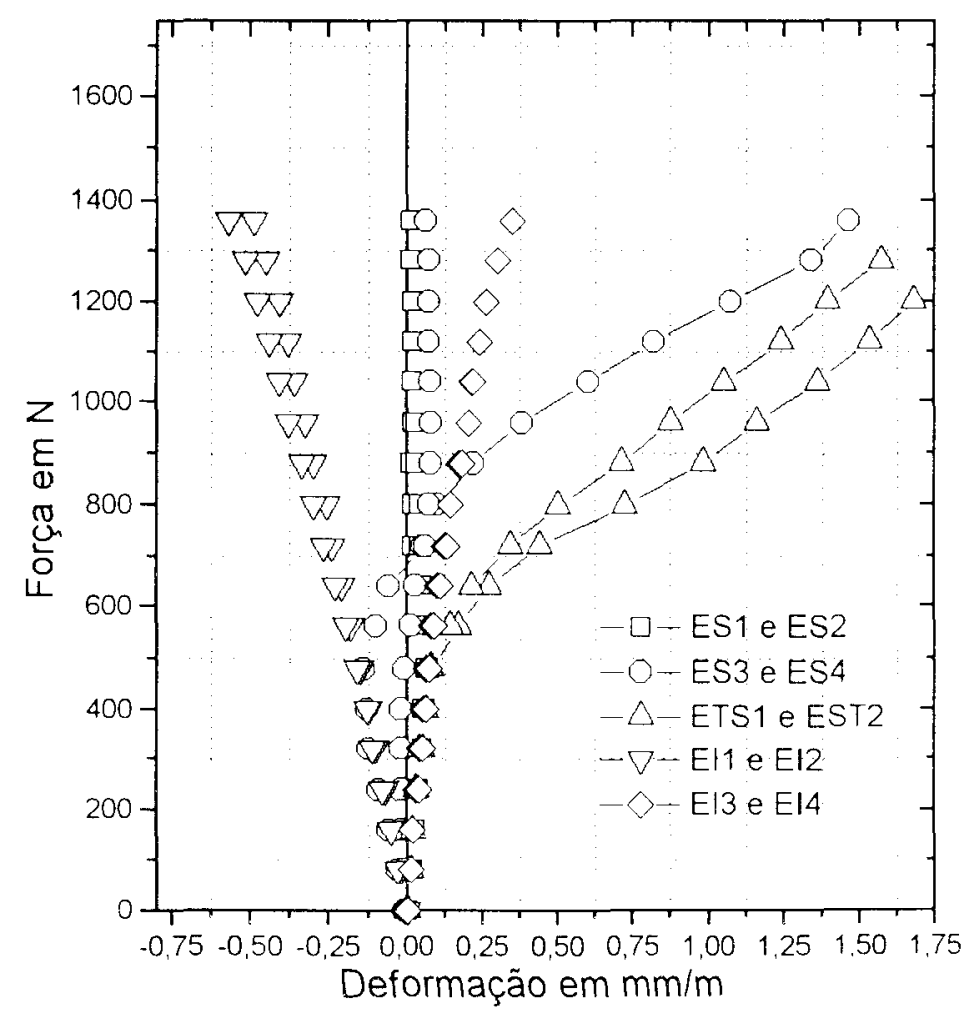

FIGURA 6.12. Gráfico Força x Deformação do ensaio de flexão. PS I - 1 
6.2.8 Modelo PS II - 2

Moldagem: 29 / março / 1995

Ensaio: 26 / abril / 1995 
TABELA 6.13. Ensaio de flexão. PS II - 2.

\begin{tabular}{ccccc}
\hline Etapa & $\begin{array}{c}\text { Força } \\
(\mathrm{N})\end{array}$ & \multicolumn{3}{c}{ DESLOCAMENTOS TRANSVERSAIS } \\
\cline { 3 - 5 } & & $\mathrm{m} 2$ & $\mathrm{D} 3$ & $\mathrm{D} 4$ \\
\cline { 3 - 5 } & 0 & 0,00 & 0,00 & 0,00 \\
\hline 0 & 80 & 0,74 & 0,83 & 0,69 \\
1 & 0 & 0,09 & 0,11 & 0,09 \\
2 & 80 & 0,77 & 0,86 & 0,76 \\
3 & 160 & 1,60 & 1,72 & 1,51 \\
4 & 240 & 2,49 & 2,68 & 2,33 \\
5 & 320 & 3,67 & 4,00 & 3,41 \\
6 & 400 & 4,79 & 5,12 & 4,44 \\
7 & 480 & 5,92 & 6,34 & 5,45 \\
8 & 560 & 7,21 & 7,65 & 6,61 \\
9 & 640 & 8,55 & 9,10 & 7,83 \\
10 & 720 & 10,22 & 10,80 & 9,38 \\
11 & 800 & 11,95 & 12,62 & 10,98 \\
12 & 880 & 14,39 & 15,19 & 13,27 \\
13 & 960 & 16,26 & 17,22 & 15,09 \\
14 & 1040 & 19,18 & 20,27 & 17,86 \\
15 & 1120 & 22,04 & 23,35 & 20,64 \\
16 & 1200 & 25,51 & 27,08 & 24,06 \\
17 & 1280 & 30,40 & 32,46 & 29,13 \\
18 & 1360 & 34,17 & 36,67 & 33,12 \\
19 & &
\end{tabular}

Ruptura por cisalhamento da espuma $\mathrm{Fu}=1360 \mathrm{~N}$

Carga da primeira fissura $F_{r}=800 \mathrm{~N}$

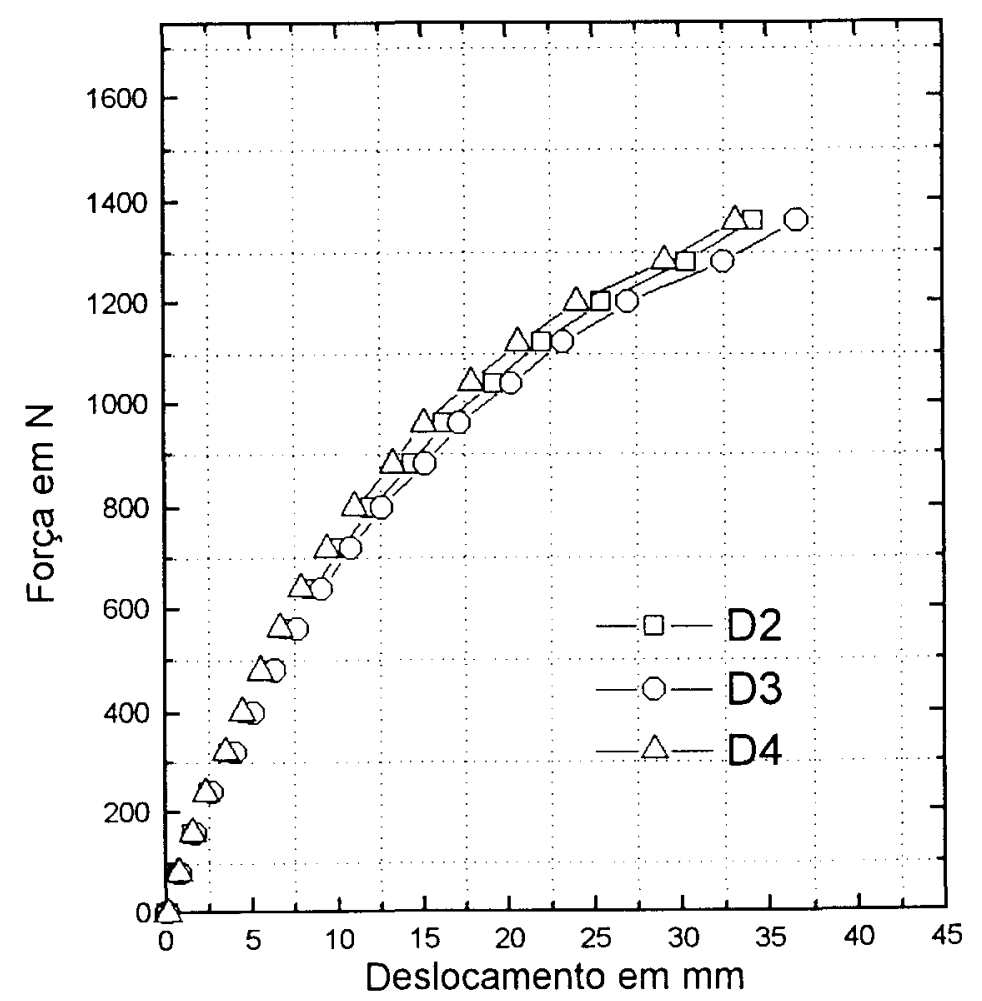

FIGURA 6.13. Gráfico Força x Deslocamento. PS II - 2. 
TABELA 6.14. Deformações medidas do ensaio de flexão com extensômetros elétricos. PS II - 2 .

\begin{tabular}{cccccccccccc}
\hline Etapa & Força & \multicolumn{10}{c}{ DEFORMAÇÄO $(\mathrm{mm}) / \mathrm{m}$} \\
\cline { 3 - 12 } & $(\mathrm{N})$ & ES1 & ES2 & ES3 & ES4 & ETS1 & ETS2 & El1 & El2 & El3 & El4 \\
\hline 0 & 0 & 0,00 & 0,00 & 0,00 & 0,00 & 0,00 & 0,00 & 0,00 & 0,00 & 0,00 & 0,00 \\
1 & 80 & 0,15 & 0,09 & $-0,01$ & $-0,01$ & 0,03 & 0,02 & $-0,03$ & $-0,03$ & 0,01 & 0,01 \\
2 & 0 & 0,04 & 0,02 & 0,00 & 0,00 & 0,01 & 0,01 & 0,00 & 0,00 & $-0,01$ & $-0,01$ \\
3 & 80 & 0,15 & 0,10 & $-0,01$ & $-0,01$ & 0,03 & 0,03 & $-0,04$ & $-0,03$ & 0,01 & 0,01 \\
4 & 160 & 0,32 & 0,22 & $-0,01$ & $-0,01$ & 0,07 & 0,05 & $-0,07$ & $-0,06$ & 0,02 & 0,02 \\
5 & 240 & 0,50 & 0,35 & $-0,01$ & $-0,01$ & 0,11 & 0,08 & $-0,10$ & $-0,09$ & 0,03 & 0,02 \\
6 & 320 & 0,63 & 0,47 & $-0,01$ & $-0,01$ & 0,16 & 0,12 & $-0,13$ & $-0,13$ & 0,04 & 0,01 \\
7 & 400 & 0,80 & 0,58 & $-0,01$ & $-0,01$ & 0,22 & 0,16 & $-0,17$ & $-0,17$ & 0,05 & 0,02 \\
8 & 480 & 0,97 & 0,68 & $-0,01$ & $-0,01$ & 0,28 & 0,20 & $-0,21$ & $-0,20$ & 0,07 & 0,03 \\
9 & 560 & 1,14 & 0,74 & $-0,01$ & 0,00 & 0,36 & 0,26 & $-0,24$ & $-0,24$ & 0,08 & 0,04 \\
10 & 640 & 1,29 & 0,79 & $-0,01$ & 0,00 & 0,44 & 0,34 & $-0,28$ & $-0,29$ & 0,10 & 0,05 \\
11 & 720 & 1,59 & 0,80 & $-0,02$ & 0,01 & 0,54 & 0,46 & $-0,31$ & $-0,33$ & 0,12 & 0,06 \\
12 & 800 & 1,92 & 0,78 & $-0,01$ & 0,02 & 0,63 & 0,56 & $-0,35$ & $-0,37$ & 0,14 & 0,07 \\
13 & 880 & 2,34 & 0,81 & $-0,02$ & 0,02 & 0,72 & 0,67 & $-0,39$ & $-0,42$ & 0,17 & 0,09 \\
14 & 960 & 2,77 & 0,78 & $-0,03$ & 0,02 & 0,82 & 0,80 & $-0,42$ & $-0,46$ & 0,19 & 0,11 \\
15 & 1040 & 3,31 & 0,72 & $-0,04$ & 0,01 & 0,95 & 0,94 & $-0,47$ & $-0,51$ & 0,21 & 0,14 \\
16 & 1120 & 3,76 & 0,70 & $-0,05$ & 0,01 & 1,06 & 1,06 & $-0,51$ & $-0,55$ & 0,24 & 0,17 \\
17 & 1200 & 4,35 & 0,73 & $-0,06$ & 0,01 & 1,20 & 1,18 & $-0,55$ & $-0,59$ & 0,27 & 0,19 \\
18 & 1280 & 4,93 & 0,74 & $-0,06$ & 0,00 & 1,34 & 1,32 & $-0,60$ & $-0,65$ & 0,30 & 0,24 \\
19 & 1360 & 5,38 & 0,76 & $-0,06$ & 0,00 & 1,45 & 1,42 & $-0,64$ & $-0,69$ & 0,33 & 0,26 \\
\hline
\end{tabular}

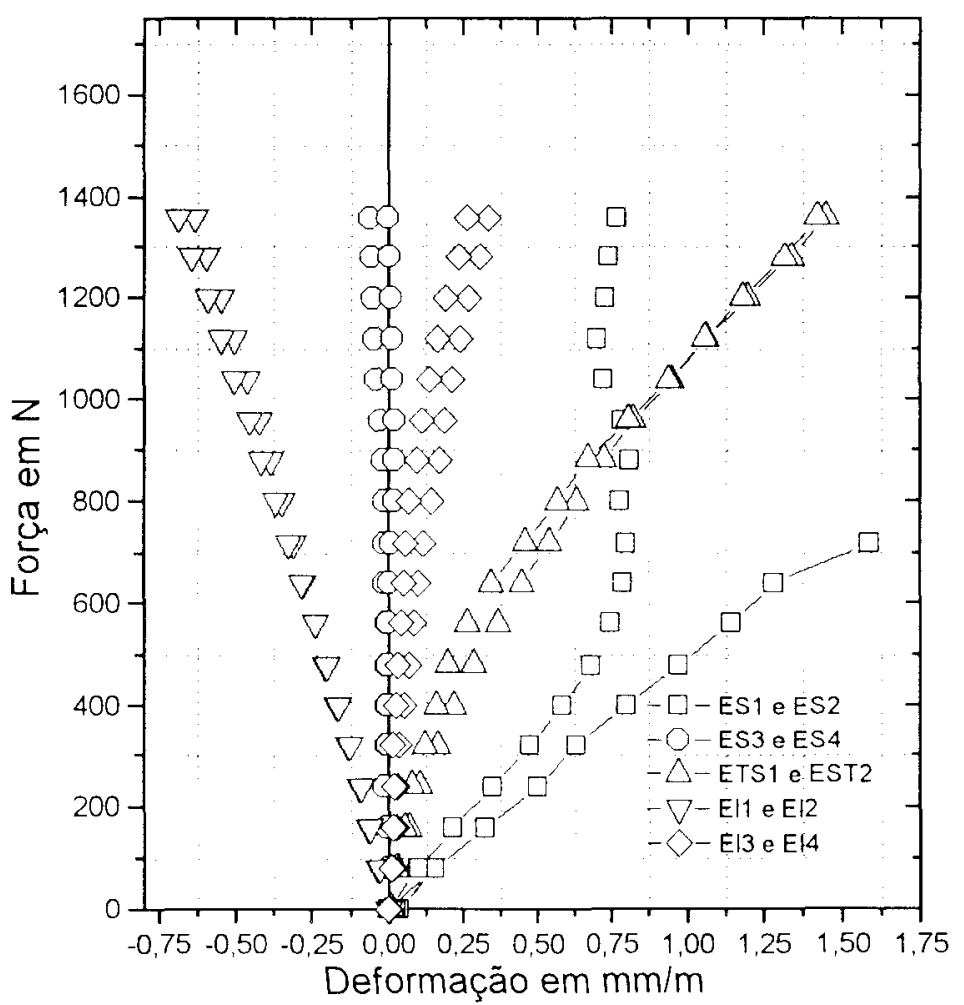

FIGURA 6.14. Gráfico Força x Deformação do ensaio de flexão. PS II - 2. 
6.2.9 Controle de resistência da argamassa

(PS II - 1 e PS II - 2) 
TABELA 6.15. Resultados do controle de resistência da argamassa para as séries PS II - 1 e PS II - 2.

\begin{tabular}{cccc}
\hline & \multicolumn{2}{c}{$\begin{array}{c}\text { Resistência à compressão } \\
(\mathrm{MPa})\end{array}$} & $\begin{array}{c}\text { Resistência à tração } \\
(\mathrm{MPa})\end{array}$ \\
\hline Idade & 7 dias & 28 dias & 28 dias \\
\hline & 21,00 & 32,47 & 3,66 \\
& 22,28 & 34,38 & 3,50 \\
& 21,65 & 33,10 & 3,34 \\
\hline Média & 21,65 & 33,32 & 3,50 \\
\hline
\end{tabular}

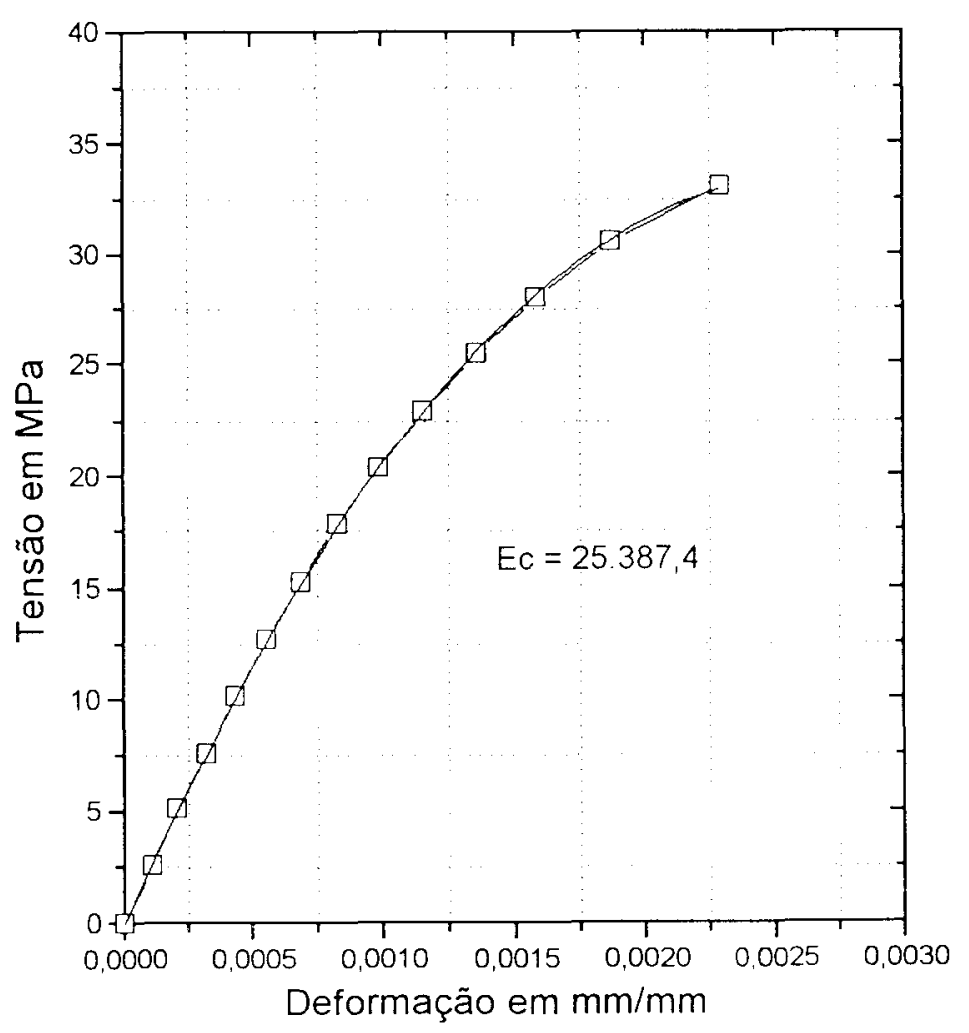

FIGURA 6.15. Gráfico Tensão x Deformação do ensaio de compressão do corpo de prova da argamassa. 


\subsubsection{Modelo PS II - 3}

Moldagem: 30 / março / 1995

Ensaio: 27 / abril / 1995 
TABELA 6.16. Ensaio de flexão. PS II - 3.

\begin{tabular}{ccccc}
\hline Etapa & $\begin{array}{c}\text { Força } \\
(\mathrm{N})\end{array}$ & \multicolumn{3}{c}{$\begin{array}{c}\text { DESLOCAMENTOS TRANSVERSAIS } \\
(\mathrm{mm})\end{array}$} \\
\cline { 3 - 5 } & & $\mathrm{D} 2$ & $\mathrm{D} 3$ & $\mathrm{D} 4$ \\
\hline 0 & 0 & 0,06 & 0,02 & $-0,03$ \\
1 & 80 & 0,74 & 0,84 & 0,70 \\
2 & 0 & 0,09 & 0,11 & 0,08 \\
3 & 80 & 0,74 & 0,84 & 0,70 \\
4 & 160 & 1,45 & 1,62 & 1,39 \\
5 & 240 & 2,28 & 2,50 & 2,17 \\
6 & 320 & 3,10 & 3,43 & 2,96 \\
7 & 400 & 3,97 & 4,39 & 3,80 \\
8 & 480 & 5,12 & 5,63 & 4,83 \\
9 & 560 & 6,31 & 6,89 & 6,16 \\
10 & 640 & 7,62 & 8,41 & 7,54 \\
11 & 720 & 9,47 & 10,34 & 9,42 \\
12 & 800 & 11,10 & 12,21 & 11,15 \\
13 & 880 & 13,06 & 14,32 & 13,11 \\
14 & 960 & 18,21 & 20,17 & 18,78 \\
15 & 1040 & 22,84 & 25,57 & 24,11 \\
16 & 1120 & 29,22 & 33,28 & 31,62 \\
17 & 1200 & 34,63 & 39,84 & 38,02 \\
\hline
\end{tabular}

Ruptura por cisalhamento da espuma $\mathrm{Fu}=1200 \mathrm{~N}$

Carga da primeira fissura $F_{r}=880 \mathrm{~N}$

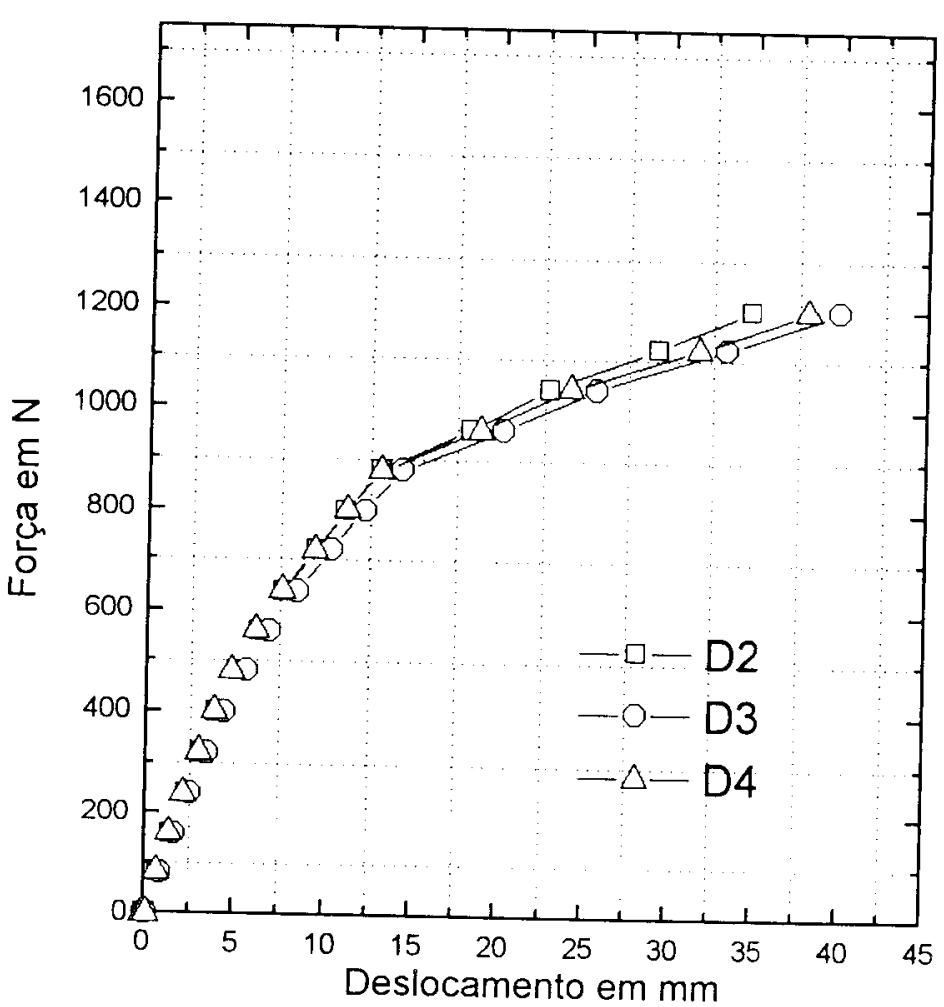

FIGURA 6.16. Gráfico Força x Deslocamento. PS II - 3. 
TABELA 6.17. Deformações medidas do ensaio de flexão com extensômetros elétricos. PS II - 3 .

\begin{tabular}{cccccccccccc}
\hline Etapa & $\begin{array}{c}\text { Força } \\
\text { (N) }\end{array}$ & \multicolumn{10}{c}{ DEFORMAÇÃO $(\mathrm{mm}) / \mathrm{m}$} \\
\cline { 3 - 12 } & ES1 & ES2 & ES3 & ES4 & ETS1 & ETS2 & El1 & El2 & El3 & El4 \\
\hline 0 & 0 & 0,00 & 0,00 & 0,00 & 0,00 & 0,00 & 0,00 & 0,00 & 0,00 & 0,00 & 0,00 \\
1 & 80 & 0,01 & 0,01 & $-0,01$ & $-0,01$ & 0,03 & 0,01 & $-0,03$ & $-0,04$ & 0,03 & 0,06 \\
2 & 0 & 0,00 & 0,00 & 0,00 & 0,00 & 0,00 & 0,00 & 0,00 & 0,00 & 0,00 & 0,02 \\
3 & 80 & 0,01 & 0,01 & $-0,01$ & $-0,01$ & 0,04 & 0,02 & $-0,03$ & $-0,04$ & 0,03 & 0,07 \\
4 & 160 & 0,02 & 0,03 & $-0,03$ & $-0,02$ & 0,07 & 0,03 & $-0,07$ & $-0,08$ & 0,06 & 0,14 \\
5 & 240 & 0,03 & 0,04 & $-0,04$ & $-0,03$ & 0,11 & 0,04 & $-0,10$ & $-0,12$ & 0,08 & 0,21 \\
6 & 320 & 0,04 & 0,05 & $-0,06$ & $-0,04$ & 0,15 & 0,06 & $-0,13$ & $-0,16$ & 0,11 & 0,27 \\
7 & 400 & 0,05 & 0,05 & $-0,07$ & $-0,05$ & 0,20 & 0,09 & $-0,17$ & $-0,20$ & 0,13 & 0,34 \\
8 & 480 & 0,04 & 0,04 & $-0,06$ & $-0,03$ & 0,24 & 0,12 & $-0,20$ & $-0,25$ & 0,16 & 0,41 \\
9 & 560 & 0,04 & 0,05 & $-0,06$ & $-0,03$ & 0,30 & 0,17 & $-0,23$ & $-0,27$ & 0,18 & 0,46 \\
10 & 640 & 0,04 & 0,04 & $-0,06$ & $-0,03$ & 0,37 & 0,23 & $-0,25$ & $-0,30$ & 0,19 & 0,48 \\
11 & 720 & 0,05 & 0,03 & $-0,05$ & $-0,02$ & 0,47 & 0,33 & $-0,27$ & $-0,32$ & 0,20 & 0,50 \\
12 & 800 & 0,04 & 0,03 & $-0,03$ & 0,00 & 0,54 & 0,41 & $-0,30$ & $-0,35$ & 0,22 & 0,53 \\
13 & 880 & 0,04 & 0,04 & $-0,02$ & 0,00 & 0,65 & 0,52 & $-0,33$ & $-0,38$ & 0,24 & 0,56 \\
14 & 960 & 0,04 & 0,04 & $-0,04$ & 0,00 & 0,77 & 0,67 & $-0,37$ & $-0,44$ & 0,28 & 0,68 \\
15 & 1040 & 0,04 & 0,05 & $-0,04$ & 0,02 & 0,91 & 0,84 & $-0,40$ & $-0,48$ & 0,29 & 0,73 \\
16 & 1120 & 0,03 & 0,06 & $-0,07$ & 0,01 & 1,05 & 0,95 & $-0,45$ & $-0,54$ & 0,31 & 0,86 \\
17 & 1200 & 0,03 & 0,07 & $-0,11$ & $-0,01$ & 1,18 & 1,06 & $-0,49$ & $-0,59$ & 0,31 & 0,93 \\
\hline
\end{tabular}

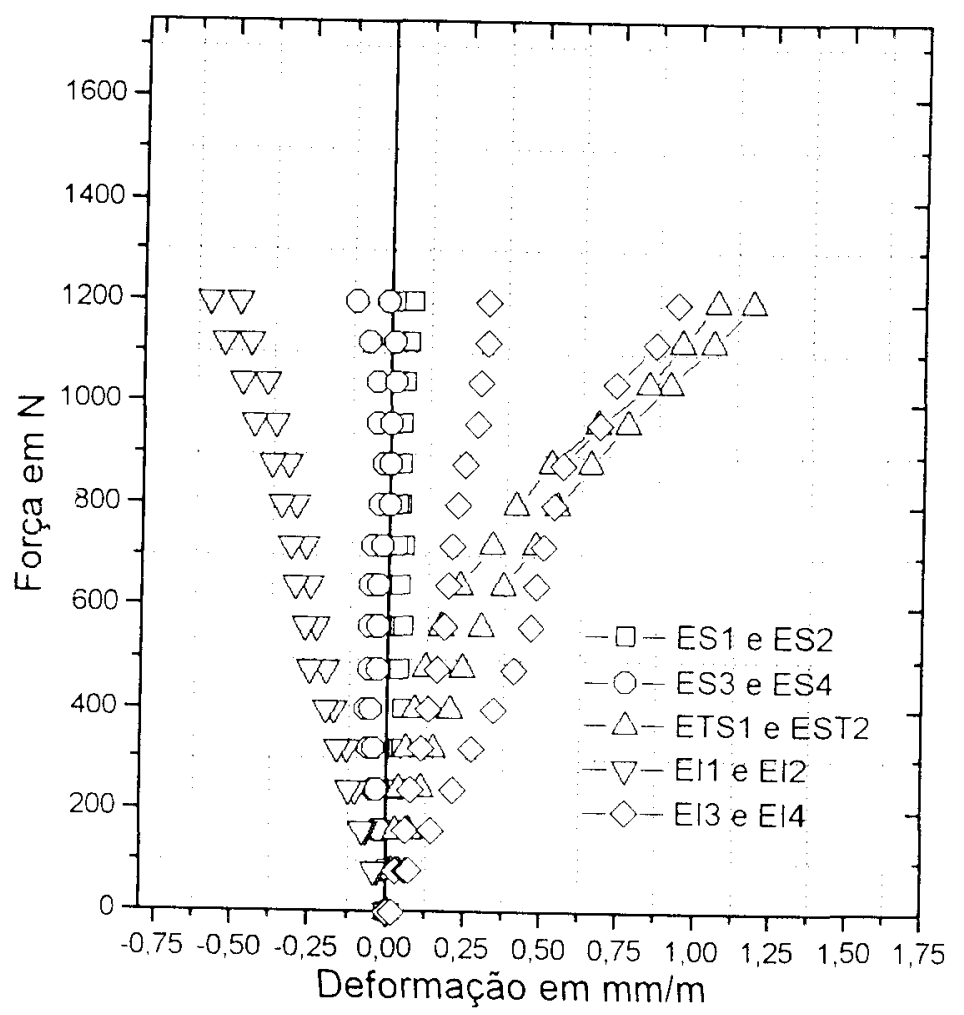

FIGURA 6.17. Gráfico Força x Deformação do ensaio de flexão. PS II - 3. 
6.2.11 Modelo PS II - 4

Moldagem: 30 / março / 1995

Ensaio: 27 / abril / 1995 
TABELA 6.18 Ensaio de flexão. PS II - 4.

\begin{tabular}{ccccc}
\hline Etapa & $\begin{array}{c}\text { Força } \\
(\mathrm{N})\end{array}$ & \multicolumn{3}{c}{$\begin{array}{c}\text { DESLOCAMENTOS TRANSVERSAIS } \\
(\mathrm{mm})\end{array}$} \\
\cline { 3 - 5 } & & $\mathrm{D} 2$ & $\mathrm{D} 3$ & $\mathrm{D} 4$ \\
\hline 0 & 0 & 0,00 & 0,04 & 0,00 \\
1 & 80 & 0,75 & 0,86 & 0,73 \\
2 & 0 & 0,09 & 0,10 & 0,09 \\
3 & 80 & 0,75 & 0,86 & 0,73 \\
4 & 160 & 1,61 & 1,82 & 1,55 \\
5 & 240 & 2,22 & 2,51 & 2,12 \\
6 & 320 & 3,09 & 3,49 & 2,97 \\
7 & 400 & 3,92 & 4,39 & 3,79 \\
8 & 480 & 4,92 & 5,48 & 4,75 \\
9 & 560 & 5,91 & 6,55 & 5,67 \\
10 & 640 & 7,53 & 8,14 & 7,07 \\
11 & 720 & 8,88 & 9,53 & 8,39 \\
12 & 800 & 10,39 & 11,04 & 9,74 \\
13 & 880 & 12,41 & 13,12 & 11,61 \\
14 & 960 & 13,94 & 14,75 & 13,06 \\
15 & 1040 & 16,17 & 17,04 & 15,23 \\
16 & 1120 & 19,51 & 20,41 & 18,31 \\
17 & 1200 & 21,85 & 22,91 & 20,56 \\
18 & 1280 & 25,67 & 27,06 & 24,53 \\
19 & 1360 & 28,96 & 30,72 & 28,13 \\
20 & 1440 & 31,37 & 33,37 & 30,68 \\
\hline
\end{tabular}

Ruptura por cisalhamento da espuma Fu $=1440 \mathrm{~N}$

Carga da primeira fissura $\mathrm{F}_{r}=560 \mathrm{~N}$

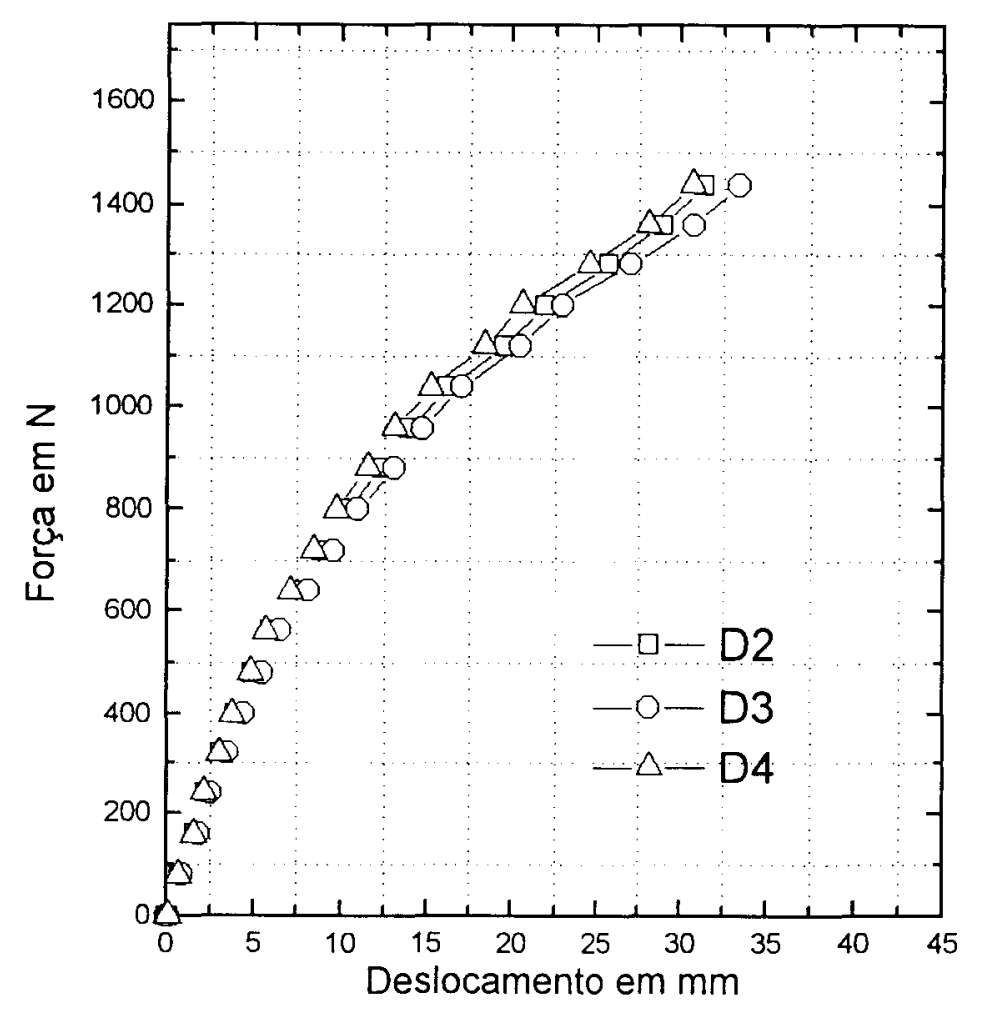

FIGURA 6.18. Gráfico Força x Deslocamento. PS II - 4. 
TABELA 6.19. Deformações medidas do ensaio de flexão com extensômetros elétricos. PS II - 4.

\begin{tabular}{|c|c|c|c|c|c|c|c|c|c|c|c|}
\hline \multirow[t]{2}{*}{ Etapa } & \multirow{2}{*}{$\begin{array}{l}\text { Força } \\
(\mathrm{N})\end{array}$} & \multicolumn{10}{|c|}{ DEFORMAÇÃO $(\mathrm{mm}) / \mathrm{m}$} \\
\hline & & ES1 & $\overline{E S 2}$ & ES3 & ES4 & $\overline{\text { ETS1 }}$ & $\overline{\text { ETS2 }}$ & El1 & $\mathrm{E} / 2$ & $\bar{E} / 3$ & $\bar{E} \mid 4$ \\
\hline 0 & $\overline{0}$ & 0,00 & 0,00 & 0,00 & 0,00 & 0,00 & 0,00 & 0,00 & 0,00 & 0,00 & 0,00 \\
\hline 1 & 80 & 0,01 & 0,02 & $-0,02$ & $-0,02$ & 0,02 & 0,02 & $-0,03$ & $-0,03$ & 0,02 & 0,02 \\
\hline 2 & 0 & 0,00 & 0,00 & 0,01 & 0,00 & 0,01 & 0,01 & 0,00 & 0,00 & 0,00 & 0,00 \\
\hline 3 & 80 & 0,01 & 0,02 & $-0,02$ & $-0,02$ & 0,02 & 0,02 & $-0,03$ & $-0,03$ & 0,02 & 0,02 \\
\hline 4 & 160 & 0,02 & 0,02 & 0,00 & $-0,01$ & 0,07 & 0,07 & $-0,06$ & $-0,07$ & 0,03 & 0,05 \\
\hline 5 & 240 & 0,03 & 0,04 & $-0,05$ & $-0,05$ & 0,09 & 0,09 & $-0,09$ & $-0,10$ & 0,05 & 0,07 \\
\hline 6 & 320 & 0,04 & 0,05 & $-0,07$ & $-0,07$ & 0,12 & 0,12 & $-0,13$ & $-0,13$ & 0,07 & 0,10 \\
\hline 7 & 400 & 0,05 & 0,07 & $-0,08$ & $-0,07$ & 0,15 & 0,15 & $-0,15$ & $-0,16$ & 0,08 & 0,11 \\
\hline 8 & 480 & 0,05 & 0,08 & $-0,06$ & $-0,07$ & 0,19 & 0,19 & $-0,18$ & $-0,19$ & 0,09 & 0,13 \\
\hline 9 & 560 & 0,06 & 0,09 & $-0,02$ & $-0,06$ & 0,23 & 0,23 & $-0,21$ & $-0,23$ & 0,11 & 0,16 \\
\hline 10 & 640 & 0,06 & 0,10 & 0,11 & 0,02 & 0,29 & 0,29 & $-0,23$ & $-0,25$ & 0,11 & 0,17 \\
\hline 11 & 720 & 0,06 & 0,11 & 0,28 & 0,10 & 0,36 & 0,34 & $-0,26$ & $-0,28$ & 0,13 & 0,18 \\
\hline 12 & 800 & 0,05 & 0,12 & 0,62 & 0,26 & 0,44 & 0,11 & $-0,28$ & $-0,30$ & 0,14 & 0,20 \\
\hline 13 & 880 & 0,04 & 0,14 & 1,38 & 0,68 & 0,59 & 0,54 & $-0,31$ & $-0,33$ & 0,15 & 0,22 \\
\hline 14 & 960 & 0,04 & 0,16 & 1,93 & 1,00 & 0,69 & 0,63 & $-0,34$ & $-0,36$ & 0,17 & 0,24 \\
\hline 15 & 1040 & 0,06 & 0,27 & 2,21 & 1,16 & 0,80 & 0,73 & $-0,35$ & $-0,38$ & 0,17 & 0,24 \\
\hline 16 & 1120 & $-0,01$ & 0,30 & 2,37 & 1,31 & 0,91 & 0,82 & $-0,38$ & $-0,41$ & 0,18 & 0,25 \\
\hline 17 & 1200 & $-0,04$ & 0,27 & 2,44 & 1,39 & 1,00 & 0,89 & $-0,41$ & $-0,44$ & 0,20 & 0,27 \\
\hline 18 & 1280 & $-0,05$ & 0,28 & 2,45 & 1,41 & 1,09 & 0,95 & $-0,44$ & $-0,48$ & 0,22 & 0,30 \\
\hline 19 & 1360 & $-0,04$ & 0,32 & 2,53 & 1,45 & 1,22 & 1,06 & $-0,47$ & $-0,51$ & 0,23 & 0,32 \\
\hline 20 & 1440 & $-0,03$ & 0,35 & 2,55 & 1,46 & 1,29 & 1,12 & $-0,50$ & $-0,54$ & 0,25 & 0,33 \\
\hline
\end{tabular}

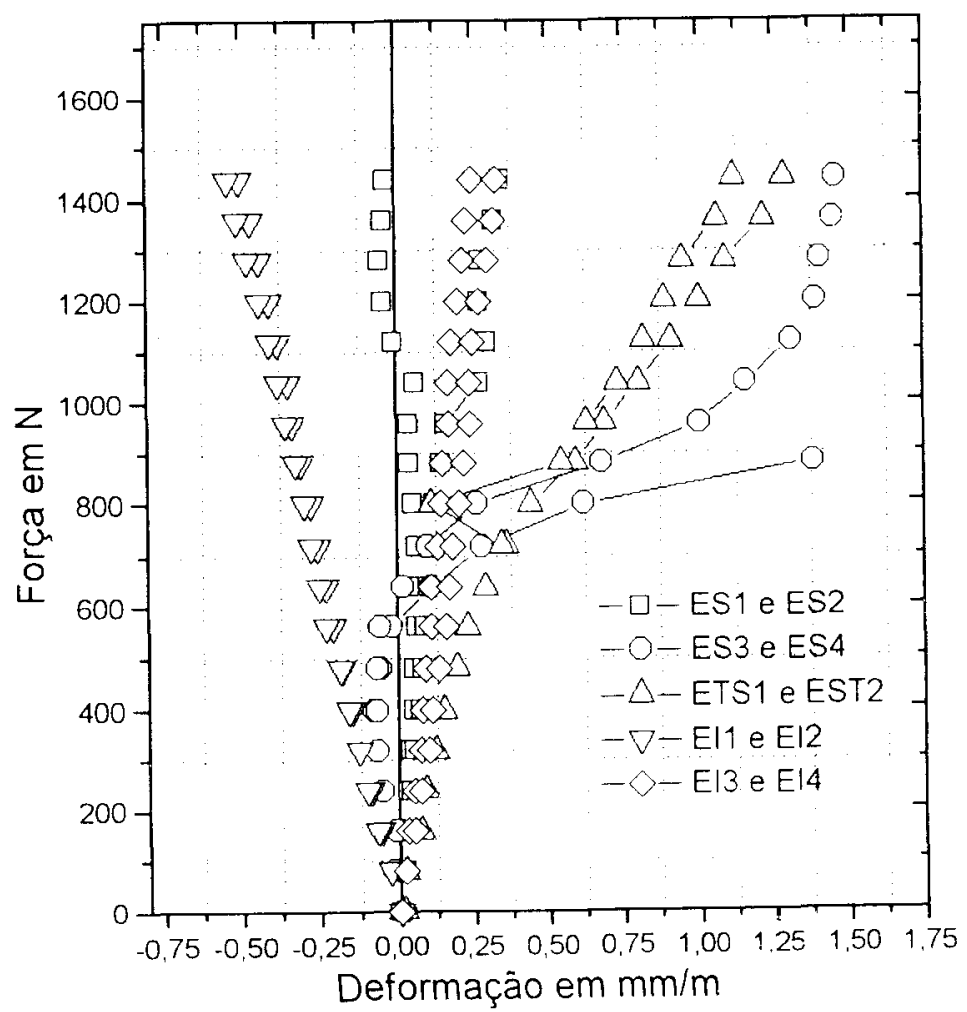

FIGURA 6.19. Gráfico Força x Deformação do ensaio de flexão. PS II - 4. 
6.2.3 Controle de resistência da argamassa (PS II - 3 e PS II - 4) 
TABELA 6.20. Resultados do controle de resistência da argamassa para as séries PS II - 3 e PS II - 4.

\begin{tabular}{cccc}
\hline & $\begin{array}{c}\text { Resistência à compressão } \\
\text { (MPa) }\end{array}$ & $\begin{array}{c}\text { Resistência à tração } \\
\text { (MPa) }\end{array}$ \\
\hline Idade & 7 dias & 28 dias & 28 dias \\
\hline & 21,65 & 31,83 & 3,18 \\
& 22,92 & 32,72 & 3,50 \\
& 22,92 & 34,25 & 3,50 \\
\hline Média & 22,50 & 32,93 & 3,40 \\
\hline
\end{tabular}

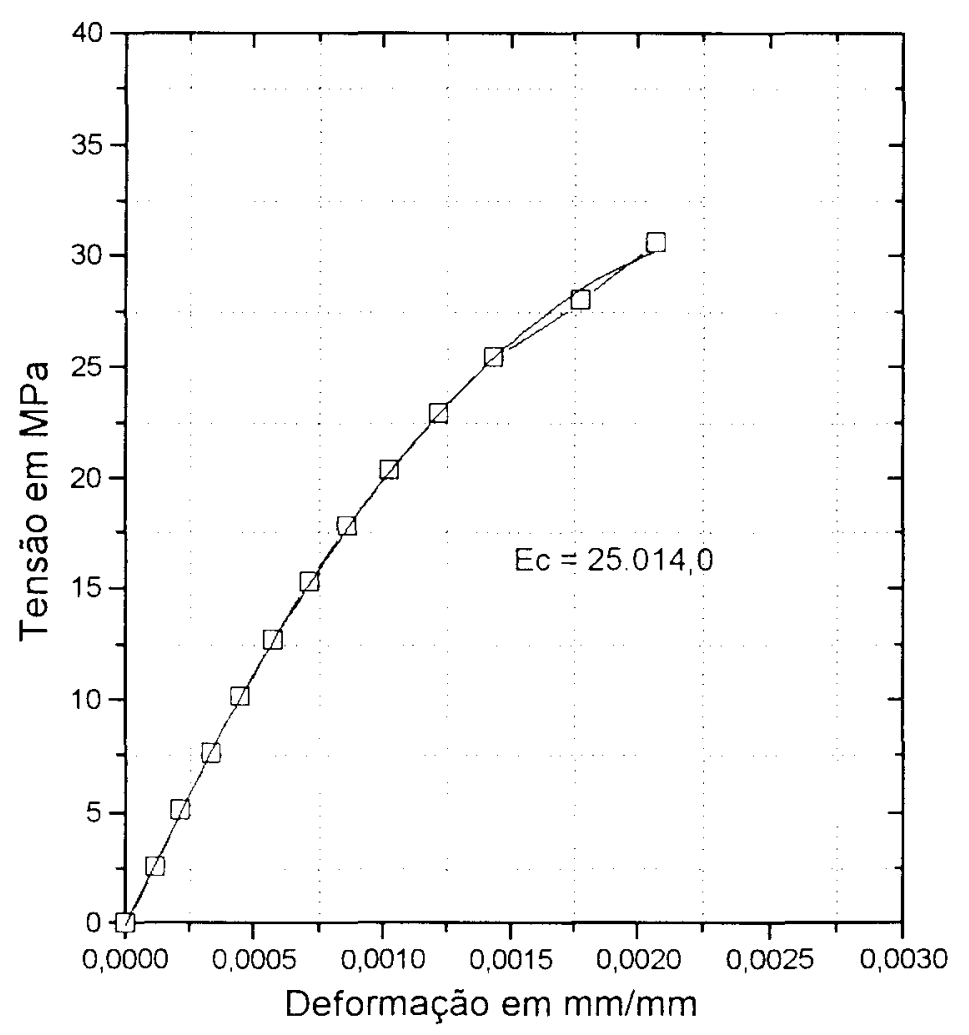

FIGURA 6.20. Gráfico Tensão x Deformação do ensaio de compressão do corpo de prova da argamassa. 
6.3 Resultados dos ensaios de Cisalhamento da Espuma rígida de poliuretano 
TABELA 6.21. Resumo dos prinicipais resultados obtidos dos ensaios de cisalhamento da espuma rígida de poliuretano.

\begin{tabular}{|c|c|c|c|c|c|}
\hline $\begin{array}{c}\text { Corpo de } \\
\text { prova }\end{array}$ & $\begin{array}{l}\text { Densidade } \\
(\mathrm{g} / \mathrm{dm} 3) \\
\end{array}$ & $\begin{array}{c}\text { Carga do } \\
\text { ponto } M^{*} \\
(\mathrm{KN})\end{array}$ & $\begin{array}{c}\text { Desloc. } \\
\text { ponto M } \\
(\mathrm{mm})\end{array}$ & $\begin{array}{c}\text { Carga de } \\
\text { ruptura** } \\
(\mathrm{KN})\end{array}$ & $\begin{array}{c}\mathrm{G} \\
(\mathrm{MPa}) \\
\end{array}$ \\
\hline 1 & 73 & 1,85 & 0,77 & 4,43 & 3,35 \\
\hline II & 91 & 3,26 & 0,89 & 7,05 & 5,09 \\
\hline III & 85 & 4,32 & 1,37 & 6,52 & 4,38 \\
\hline IV & 71 & 3,45 & 1,14 & 6,03 & 4,21 \\
\hline V & 82 & 0,52 & 0,12 & 6,75 & 5,00 \\
\hline VI & 73 & 2,29 & 0,70 & 5,54 & 4,54 \\
\hline VII & 73 & 2,94 & 0,74 & 5,97 & 4,60 \\
\hline VIII & 63 & 1,82 & 0,62 & 4,62 & 4,08 \\
\hline Média & 76,4 & 2,56 & 0,79 & 5,86 & 4,40 \\
\hline
\end{tabular}

* $\mathrm{O}$ ponto $\mathrm{M}$ representa $\mathrm{O}$ limite de proporcionalidade do gráfico Força $\mathrm{x}$ Deslocamento;

${ }^{\star *}$ A carga de ruptura é representado no gráfico Força $x$ Deslocamento pelo ponto $\mathrm{Y}$. 


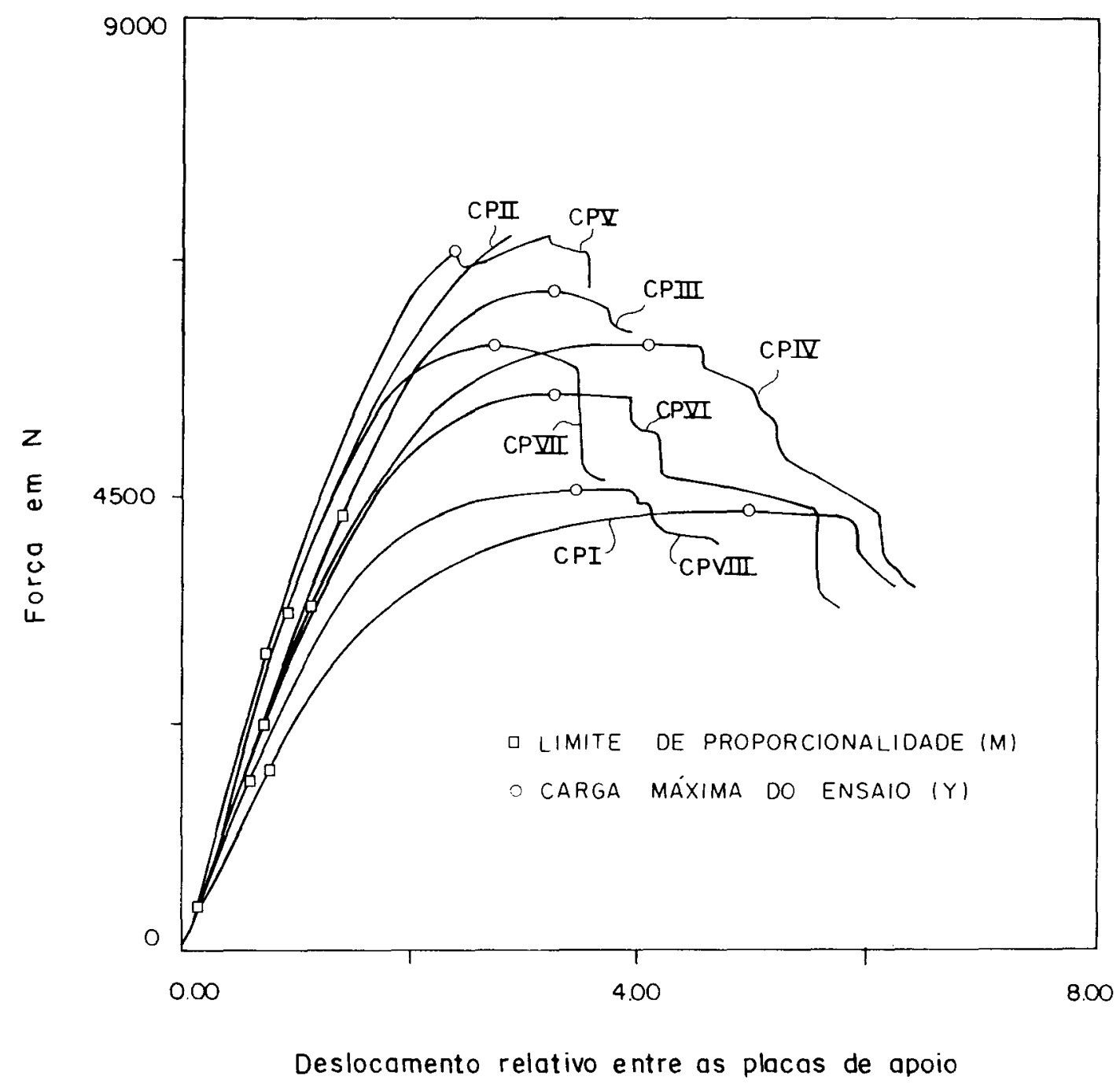

FIGURA 6.21. Gráficos Força $\times$ Deslocamento relativo entre as placas de apoio, obtidos dos ensaios de cisalhamento da espuma rígida de poliuretano. 


\section{ANÁLISE DOS RESULTADOS}

\subsection{Ensaios de flexão}

O comportamento geral de vigas sanduíche de faces de argamassa armada e núcleo de poliuretano, submetida à flexão, é diferente do comportamento de uma viga constituída apenas do material argamassa armada. Nos ensaios verificou-se bem estas diferenças.

Para efeito de comparação com os resultados obtidos nos ensaios, utilizou-se os resultados teóricos determinados a partir das expressões dadas no capitulo 3 e os critérios de cálculo apresentados nos capítulos 4 e 5 .

Pôde-se então com estes resultados teóricos, comparar resultados experimentais de carga de fissuração, carga de ruptura e deslocamentos, sendo considerado para efeitos de cálculo, uma viga sanduíche com interação total entre as faces.

\subsubsection{Carga de fissuração}

A carga de fissuração foi assumida como aquela em que se verificava na face tracionada a primeira fissura, observada com o auxilio de uma lente de aumento.

São apresentados na tabela 7.1 os momentos de fissuração $\left(M_{r}\right)$, obtidos do ensaio de flexão das vigas, com o cálculo dos respectivos índices estatísticos

Os momentos de fissuração teóricos calculados a partir das expressões apresentadas no capitulo 4 , são comparados com os valores experimentais, como mostra a tabela 7.2. É levado em conta, de forma 
simplificada, o efeito da retração, multiplicando-se a equação do momento de fissuração por 0,75 , segundo as prescrições da NBR 6118 .

TABELA 7.1 - Valores experimentais do momento de fissuração.

Painel Mom. de fissuração Painel Mom. de fissuração

\begin{tabular}{cccc} 
& $($ KNmm $)$ & & $($ KNmm $)$ \\
\hline${ }^{*}$ PS I - 1 & 218,4 & ${ }^{\star \star P S ~ I I ~-~ 1 ~}$ & 184,8 \\
PS I - 2 & 218,4 & PS II - 2 & 168,0 \\
PS I - 3 & 151,2 & PS II - 3 & 184,8 \\
PS I - 4 & 151,2 & PS II - 4 & 117,6 \\
\hline & & \\
Média & 184,8 & & 163,8 \\
Desvio padrão & 38,8 & & 31,8 \\
\hline
\end{tabular}

${ }^{*}$ PS I $\rightarrow$ vigas sanduíche com faces de argamassa armada, executadas com duas telas EL126;

**PS $\| \rightarrow$ vigas sanduíche com faces de argamassa armada, executadas com uma tela EL126.

TABELA 7.2 - Comparação de valores teóricos e experimentais do momento de fissuração, com consideração simplificada da retração (NBR6118).

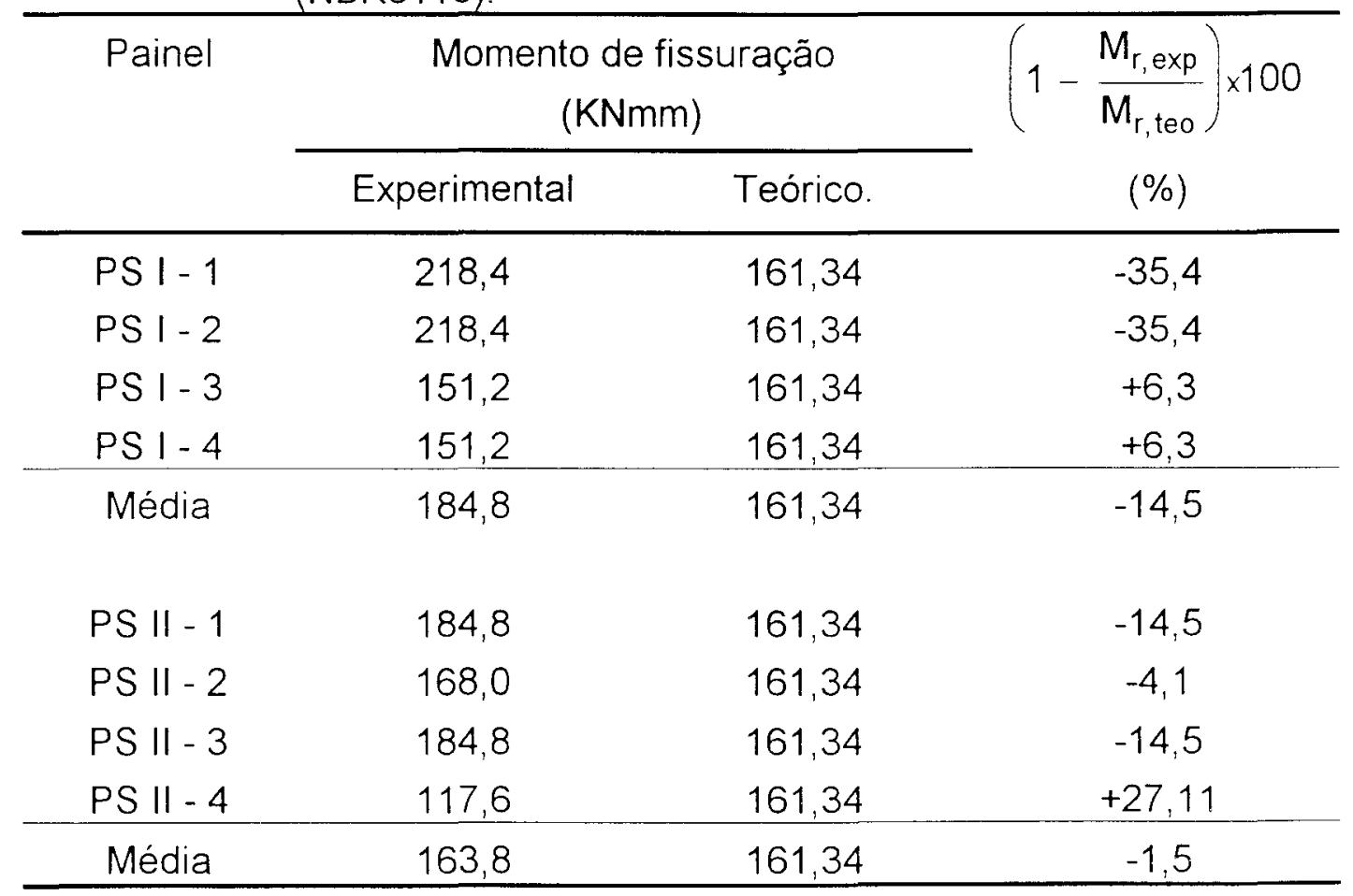


Analisando a última coluna da tabela $7.2\left(\left[1-\mathrm{M}_{\mathrm{r}, \exp } / \mathrm{M}_{\mathrm{r}, \text { teo }}\right] \times 100\right)$, observa-se que os valores do momento de fissuração, calculados teoricamente, possuem valores muito próximos dos obtidos no ensaio, principalmente os valores obtidos do ensaio da série PS II, que utiliza 1 tela EL 126 como armadura das placas de face. Com base nos resultados apresentados pode-se dizer que o valor do momento de fissuração pode ser previsto pelas equações desenvolvidas no capitulo 4 deste trabalho, de acordo com a NBR 6118.

\subsubsection{Carga de ruptura}

A carga de ruptura foi assumida como sendo aquela a partir da qual a peça não oferecia mais resistência ao carregamento. Para todos os ensaios a ruptura se deu por cisalhamento da espuma rígida. Observou-se, através de extensômetros elétricos colocados nas faces de argamassa armada (comprimida e tracionada) e na armadura da face tracionada, que os niveis de deformações, na ruptura da viga, ficaram muito abaixo da capacidade última do material da face.

Os valores experimentais médios obtidos para o momento de ruptura $\left(M_{u}\right)$ estão apresentados na tabela 7.3.

Os valores teóricos para o momento de ruptura foram calculados utilizando-se os critérios de cálculo apresentados no capítulo 4, seguindo as indicações da Normas NB-1259 (projeto e execução de argamassa armada) e NBR 6118 (projeto e execução de obras de concreto armado), considerando uma viga sanduíche de faces de argamassa armada havendo interação total entre elas.

É importante salientar que este valor teórico do momento de ruptura não representa verdadeiramente os valores experimentais, este é apenas um parâmetro de comparação.

A tabela 7.4 mostra a comparação entre os valores teóricos obtidos e os experimentais para cada ensaio. Esta grande discrepância que se observa entre estes valores é devido a ruptura ter se dado no núcleo. 
TABELA 7.3 - Valores experimentais do momento de ruptura.

\begin{tabular}{cccc}
\hline Painel & $\begin{array}{c}\text { Mom. de ruptura } \\
(\text { KNmm) }\end{array}$ & Painel & $\begin{array}{c}\text { Mom. de ruptura } \\
\text { (KNmm) }\end{array}$ \\
\hline PS I - 1 & 268,8 & PS II - 1 & 285,6 \\
PS I - & 235,2 & PS II - 2 & 285,6 \\
PS I - 3 & 336,0 & PS II - 3 & 252,0 \\
PS I - 4 & 336,0 & PS II - 4 & 302,4 \\
\hline & & & \\
Média & 294,0 & & 281,4 \\
Desvio padrão & 50,4 & & 21,1 \\
\hline
\end{tabular}

TABELA 7.4 - Comparação de valores teóricos e experimentais do momento de ruptura.

\begin{tabular}{|c|c|c|c|}
\hline \multirow[t]{2}{*}{ Painel } & \multicolumn{2}{|c|}{$\begin{array}{c}\text { Momento de ruptura } \\
(\mathrm{KNmm})\end{array}$} & \multirow{2}{*}{$\begin{array}{c}\left(1-\frac{M_{u, \exp }}{M_{u, \text { teo }}}\right. \\
(\%)\end{array}$} \\
\hline & Experimental & Teórico. & \\
\hline PSI-1 & 268,8 & 955,9 & $+71,9$ \\
\hline PSI- 2 & 235,2 & 955,9 & $+75,4$ \\
\hline PS I- 3 & 336,0 & 955,9 & $+64,9$ \\
\hline PSI- 4 & 336,0 & 955,9 & $+64,9$ \\
\hline Média & 294,0 & 955,9 & $+69,2$ \\
\hline PS II - 1 & 285,6 & 554,0 & $+48,4$ \\
\hline$P S \|-2$ & 285,6 & 554,0 & $+48,4$ \\
\hline PS II - 3 & 252,0 & 554,0 & $+54,5$ \\
\hline PS II - 4 & 302,4 & 554,0 & $+45,4$ \\
\hline Média & 281,4 & 554,0 & 49,2 \\
\hline
\end{tabular}




\subsubsection{Deslocamentos}

$\mathrm{Na}$ avaliação dos deslocamentos, utilizou-se as equações apresentadas no capítulo 3 , no qual foi discutido as soluções para o caso de capa fina (sem resistência a flexão das faces) e capa grossa (com resistência à flexão das faces. Para efeito de comparação com os resultados analíticos, determinou-se os deslocamentos através de um programa de elementos finitos para análise de cascas e placas de laminados compostos, desenvolvido por FIGUEIRAS; OWEN (1984), podendo-se levar em consideração a deformação transversal.

Ainda para efeito de comparação com os resultados experimentais, determinou-se os deslocamentos considerando:

a) a viga inteiramente composta, ou seja, com interação total entre as faces;

b) a viga sem nenhuma interação entre as faces, ou seja, sem transmissão de esforços de uma face para outra (as duas faces trabalhando isoladamente).

Considerando a viga da fig.7.1, através do Principio dos Trabalhos Virtuais, pode-se encontrar as equações para o cálculo dos deslocamentos, no meio do vão) para os casos dos ítens a) e b) do parágrafo anterior.

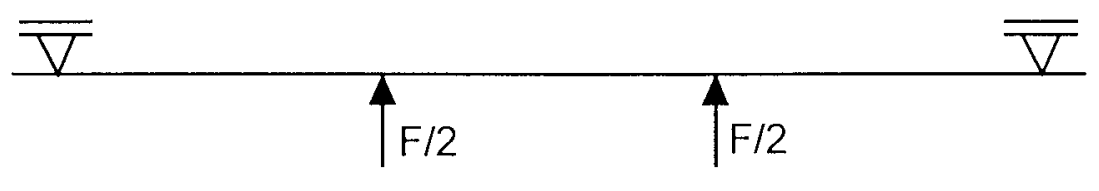
$\mathrm{L} / 3$
$L / 3$
$L / 3$

L

FIGURA 7.1 - Viga com força concentrada em dois pontos nos terços do vão.

- Viga inteiramente composta:

$$
\mathrm{a}=\frac{0,018 \mathrm{FL}^{3}}{\mathrm{El}}
$$




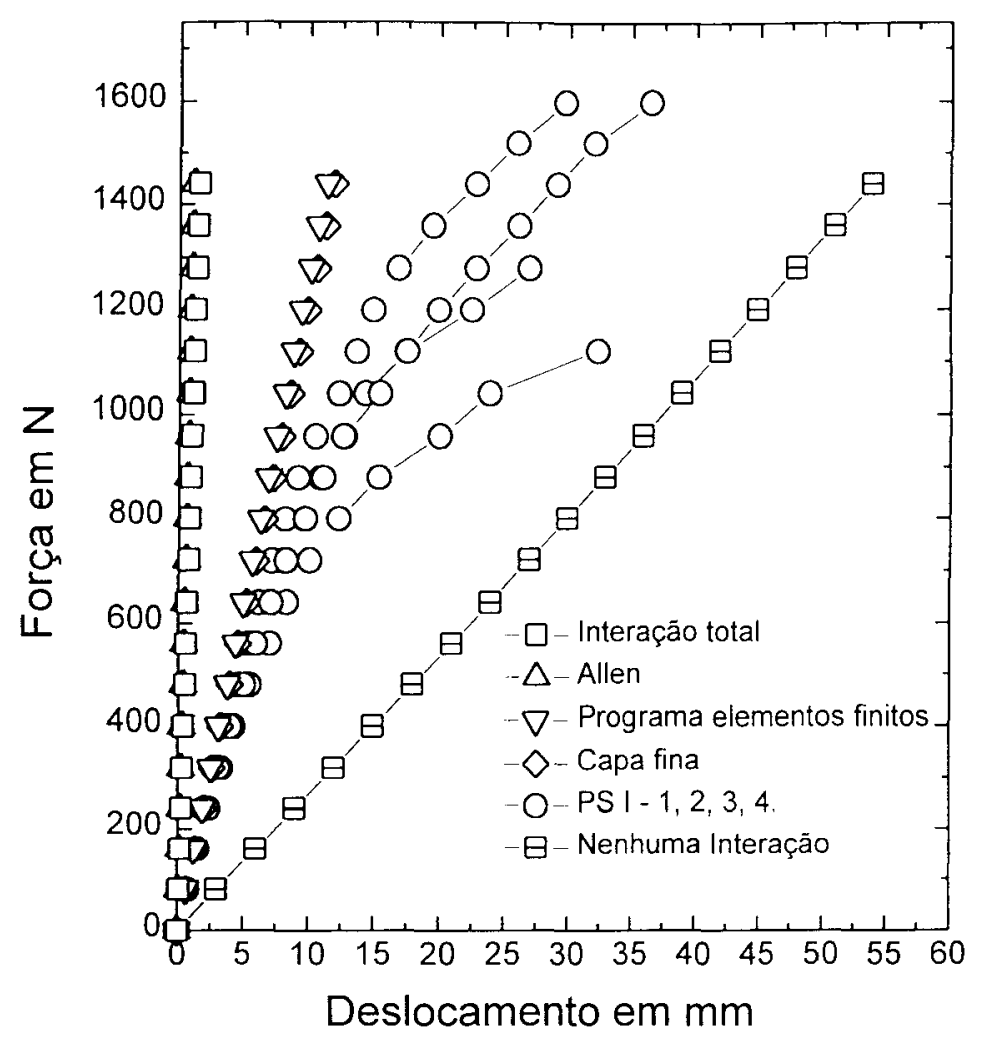

(a)

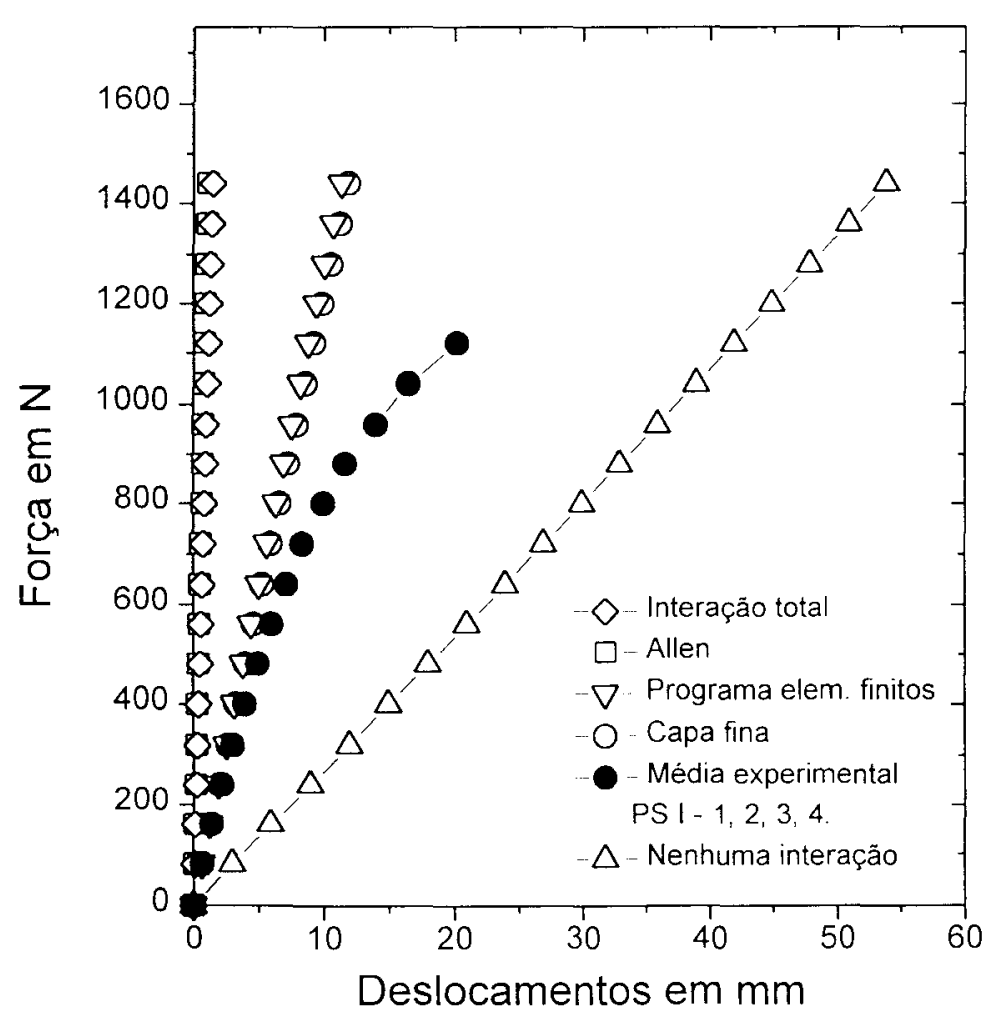

(b)

FIGURA 7.2.Gráfico Força x Deslocamento comparação teór. $x$ exper.(PS I).

a) Deslocamentos PS I - 1, 2, 3, 4 .

b) Deslocamentos médios PS I-1, 2, 3, 4 . 


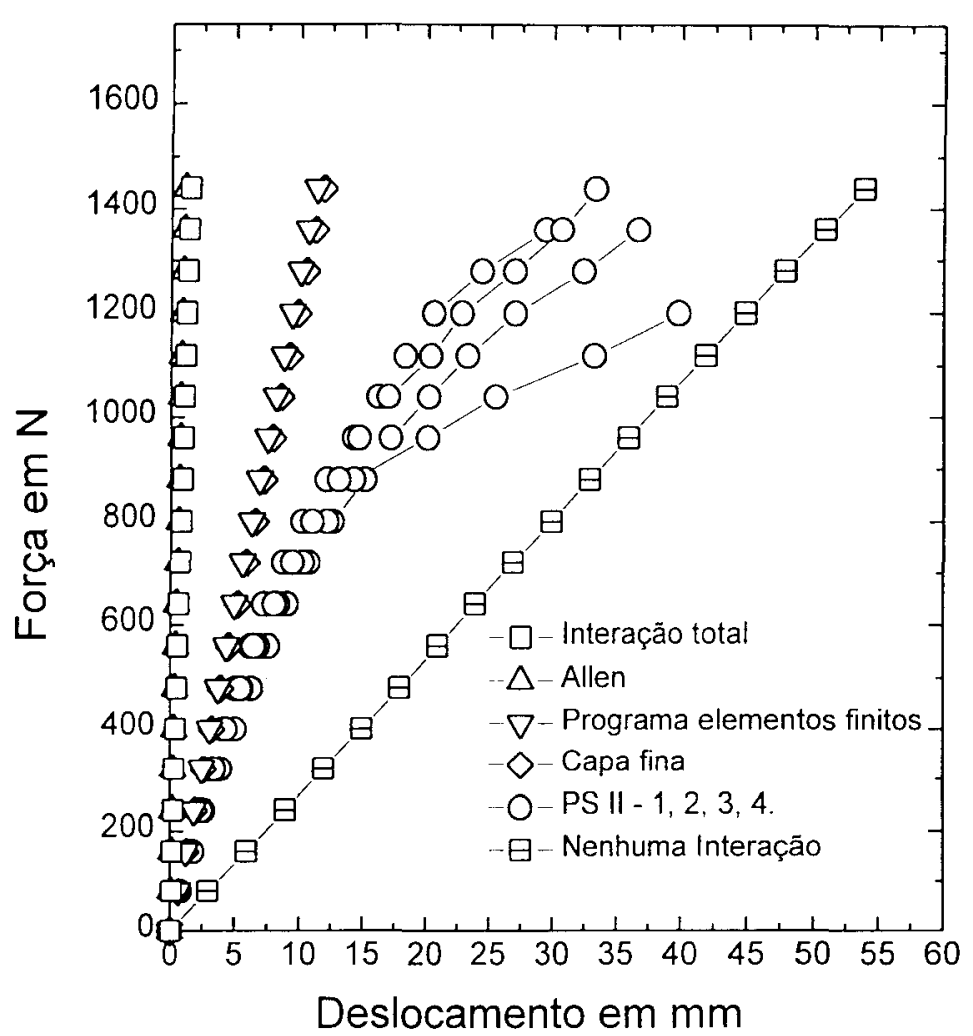

(a)

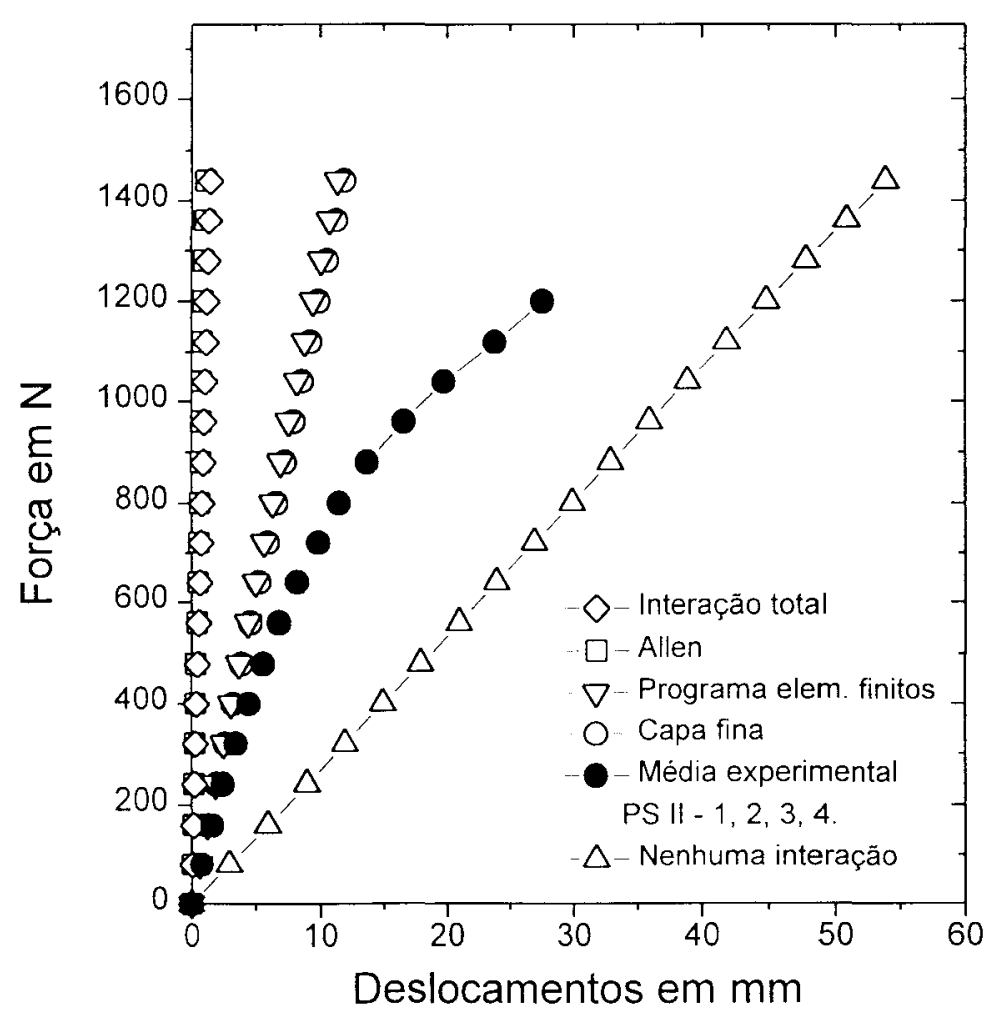

(b)

FIGURA 7.3. Gráfico Força x Deslocamento comparação teór. x exper.(PS II).

a) Deslocamentos PS II - 1, 2, 3, 4 .

b) Deslocamentos médios PS II - 1, 2, 3, 4 . 
- Viga sem nenhuma interação:

$$
a=\frac{0,009 F L^{3}}{E I_{f}}
$$

É importante observar que, para viga sem nenhuma interação, era como se tivéssemos uma das faces submetida à metade da carga.

Em uma fase preliminar procurou-se determinar os deslocamentos considerando-se análise elástica-linear, plotando-se o gráfico força $x$ deslocamento para cada exemplar ensaiada como mostram as fig.7.2 e fig.7.3.

Verifica-se nitidamente, através dos gráficos, que a deformação transversal do núcleo faz com que a viga trabalhe entre os dois extremos: interação total $(G \rightarrow \infty$ ) e nenhuma interação ( $G \rightarrow 0$ ), ficando bem clara a interação parcial das faces para a viga sanduíche.

Os gráficos mostram ainda que, as retas que mais se aproximam das curvas experimentais são as obtidas através do programa de elementos finitos e da consideração de capa fina.

Para uma análise complementar, foi construída a curva força $x$ deslocamento, utilizando as expressões da teoria de capa fina, fazendo a consideração da perda de rigidez após a fissuração. Para cada viga ensaiada foi determinado o gráfico Momento x Curvatura, a partir dos valores experimentais, podendo-se então encontrar deste gráfico, a rigidez (El) tomando-se a tangente no ponto para cada etapa de carga após a fissuração.

Os gráficos mostrados nas fig.7.4 e fig.7.5 mostram esta análise não linear, comparando-se a cada exemplar ensaiado. É importante destacar que toda a análise foi feita considerando o material elástico.

A tabela 7.5 apresenta os valores médios dos deslocamento obtidos dos ensaios para as duas séries, bem como os valores teóricos médios determinados da equação da teoria de capa fina considerando a perda de rigidez após a fissuração. É mostrada ainda nesta tabela a relação experimental/teórica para cada série. 


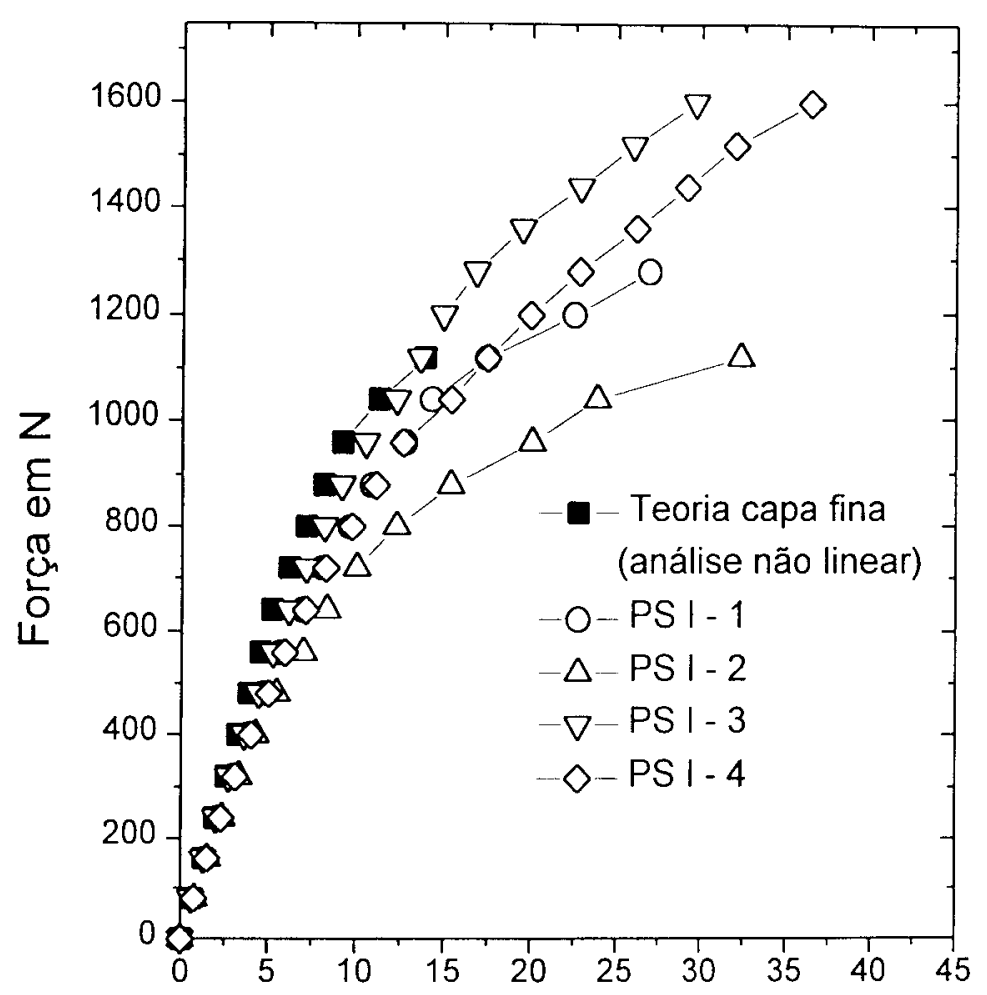

Deslocamentos em $\mathrm{mm}$

(a)

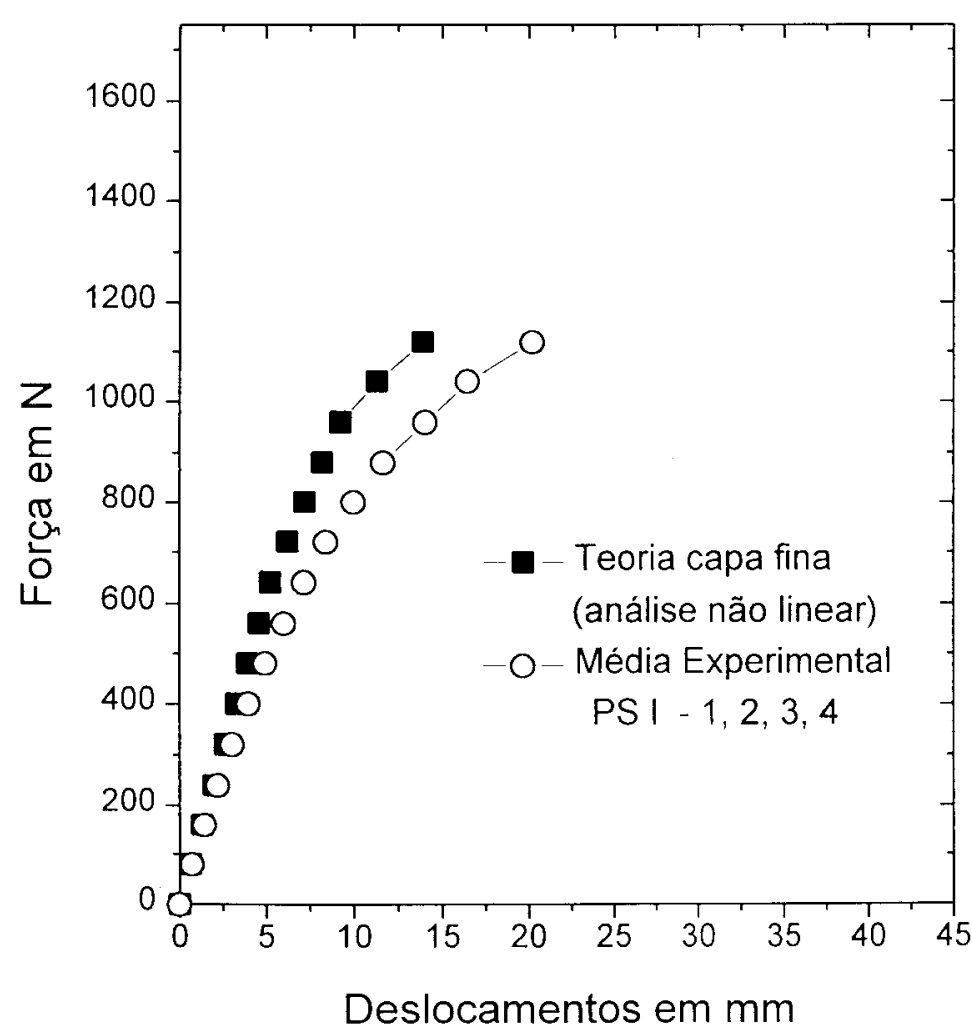

(b)

FIGURA 7.4. Gráfico Força x Desloc., comparação teórica x exper.(PSI).

a) Deslocamentos PS I - 1, 2, 3, 4.

b) Deslocamentos médios PS I - 1, 2, 3, 4. 


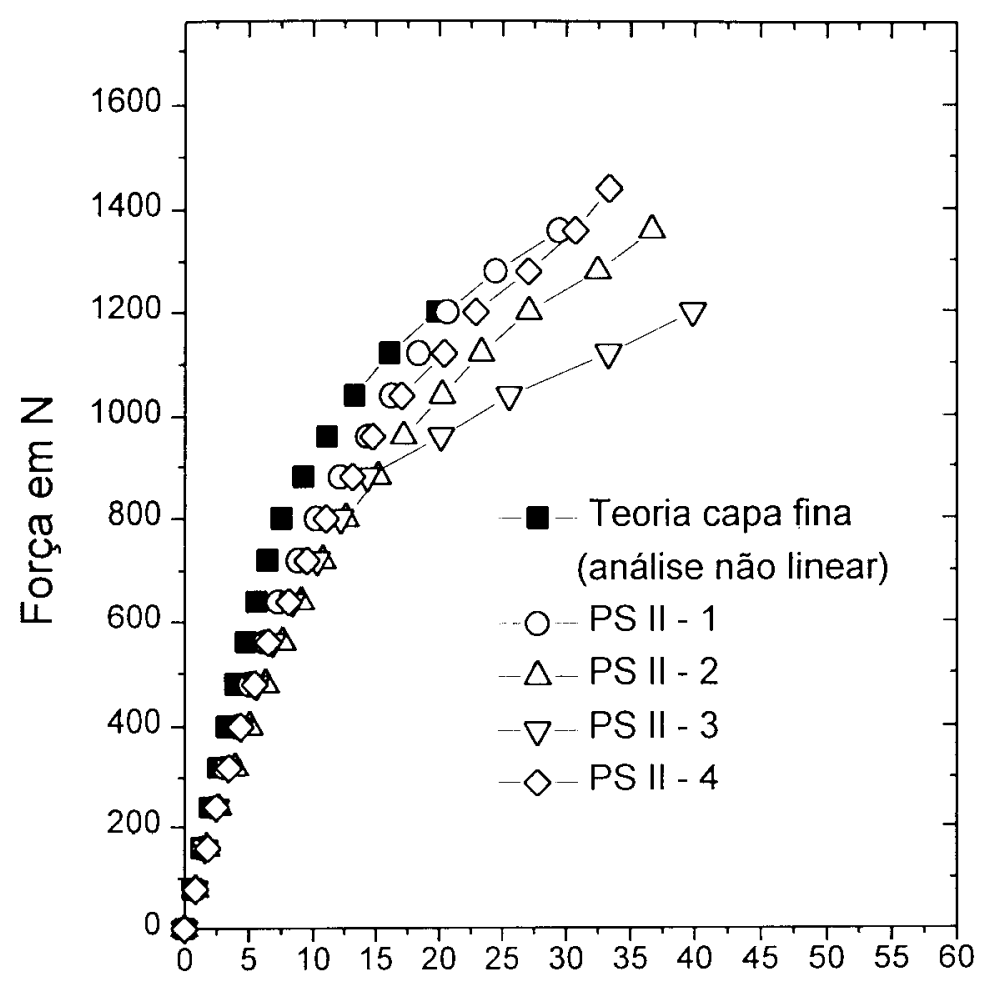

Deslocamentos em $\mathrm{mm}$

(a)

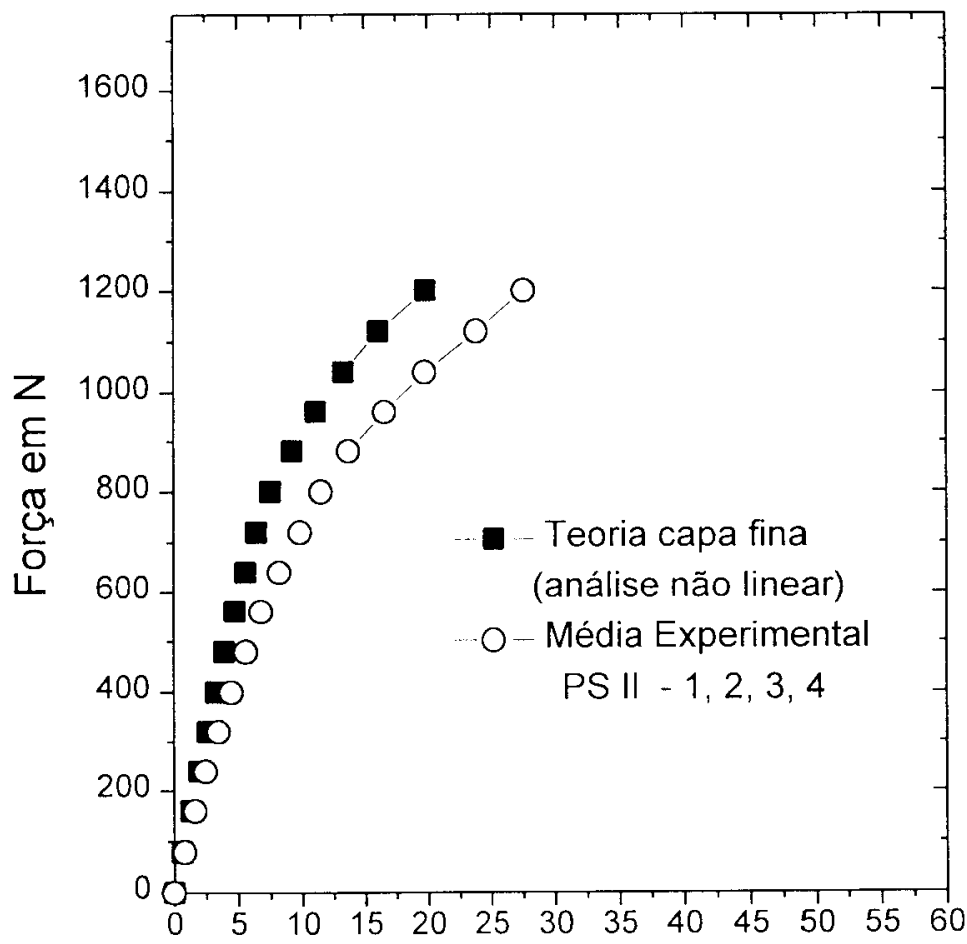

Deslocamentos em $\mathrm{mm}$

(b)

FIGURA 7.5. Gráfico Força x Desloc., comparação teórica x exper.(PSII).

a) Deslocamentos PS II - 1, 2, 3, 4 .

b) Deslocamentos médios PS $\|-1,2,3,4$. 
TABELA 7.5 - Média obtida da avaliação dos deslocamentos no meio do vão, da viga submetida à flexão.

\begin{tabular}{|c|c|c|c|c|c|c|}
\hline \multicolumn{7}{|c|}{ 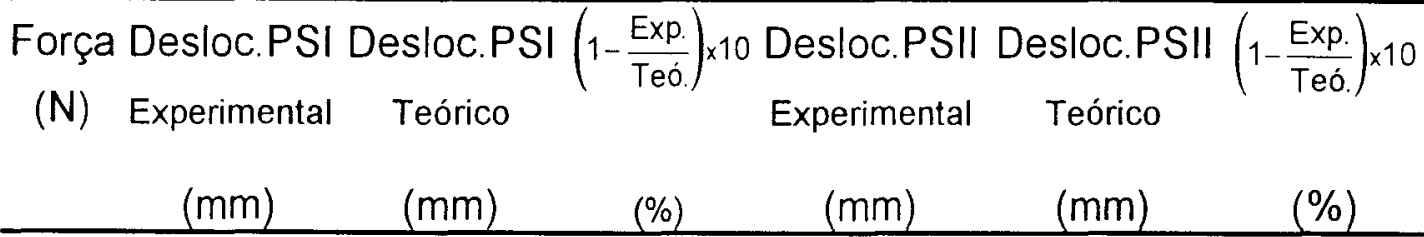 } \\
\hline 0 & 0,00 & 0,00 & 0,0 & 0,00 & 0,00 & 0,0 \\
\hline 80 & 0,72 & 0,66 & $-9,1$ & 0,83 & 0,66 & $-25,8$ \\
\hline 160 & 1,44 & 1,31 & $-9,9$ & 1,66 & 1,31 & -267. \\
\hline 240 & 2,22 & 1,97 & $-12,7$ & 2,51 & 1,97 & $-26,4$ \\
\hline 320 & 3,06 & 2,62 & $-16,8$ & 3,53 & 2,62 & $-34,7$ \\
\hline 400 & 3,99 & 3,28 & $-21,6$ & 4,53 & 3,28 & -38.1 \\
\hline 480 & 4,96 & 3,94 & $-25,9$ & 5,65 & 3,94 & $-43,4$ \\
\hline 560 & 6,03 & 4,59 & $-31,4$ & 6,85 & 4,77 & $-43,6$ \\
\hline 640 & 7,21 & 5,25 & $-37,3$ & 8,24 & 5,61 & $-46,9$ \\
\hline 720 & 8,42 & 6,23 & $-35,2$ & 9,88 & 6,45 & $-53,2$ \\
\hline 800 & 9,99 & 7,22 & $-38,4$ & 11,54 & 7,54 & $-53,1$ \\
\hline 880 & 11,67 & 8,22 & $-42,0$ & 13,70 & 9,26 & $-47,9$ \\
\hline 960 & 14,03 & 9,25 & $-51,7$ & 16,61 & 11,11 & $-49,5$ \\
\hline 1040 & 16,47 & 11,32 & $-45,5$ & 19,78 & 13,31 & $-48,6$ \\
\hline 1120 & 20,23 & 13,89 & $-45,6$ & 23,86 & 16,07 & $-48,5$ \\
\hline
\end{tabular}

Analisando os gráficos das fig.7.2 a fig. 7.5 e a tabela 7.5 pode-se dizer que o modelo mais apropriado para o cálculo dos deslocamentos de uma viga sanduíche em estudo, submetida à flexão, é o de capa fina. Inicialmente, de acordo com os dados de deformação, as faces sofrem uma flexão localizada, que acontece até próximo da primenira fissura visivel, essa flexão provoca uma fissuração, levando ao comportamento de capa fina. 


\subsection{Ensaios de Cisalhamento da espuma rígida}

O ensaio de cisalhamento da espuma foi executado, como já se disse, conforme o procedimento da ASTM C 273-61. O gráfico força $x$ deslocamento relativo entre as placas de apoio, foi traçado para todos os exemplares verificando-se o comportamento do material mostrado de forma esquemática na fig.7.6.

Os diagramas carga $x$ deslocamento relativo, para todos os modelos ensaiados, apresentam um trecho inicial retilíneo, conforme mostra a fig.7.6. $O$ ponto $M$ representa 0 limite de proporcionalidade do material, a partir deste ponto o diagrama passa a ser curvilineo passando pelo ponto $Y$, que representa a resistência máxima do material.

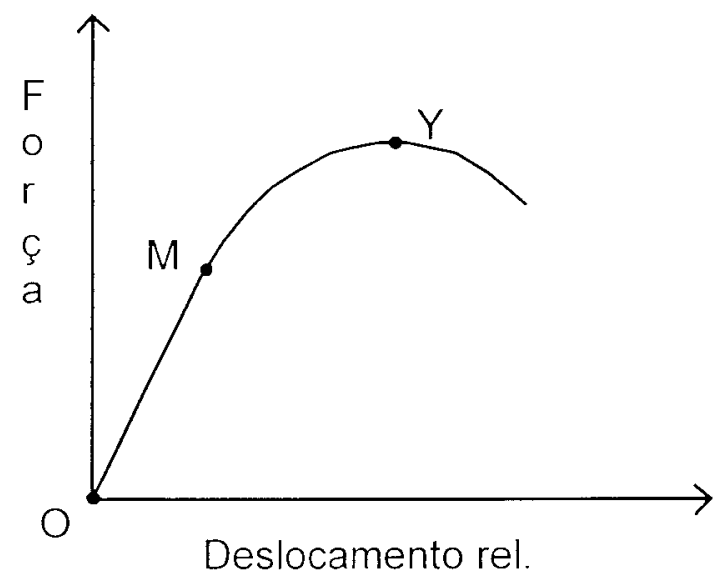

FIGURA 7.6. Diagrama força $x$ deslocamento relativo entre as placas de apoio.

\subsubsection{Limite de proporcionalidade e módulo de elasticidade transversal $(G)$}

A carga do limite de proporcionalidade assumida, foi aquela correspondente ao ponto $\mathrm{M}$ do gráfico da fig.7.6, que corresponde ao ponto em que o material não se comporta mais como elástico linear, assumindo um novo comportamento. O trecho OM da fig. 7.6 corresponde a uma reta e a partir do ponto $\mathrm{M}$ em diante o gráfico torna-se curvilineo. 
Para todos os exemplares ensaiados pôde-se determinar este ponto, e a partir dele obter o módulo de deformação transversal do material no regime elástico-linear, da maneira explicitada no item 5.3.2.1 deste trabalho.

A tabela 7.6 contém para cada modelo o valor da densidade, tensão cisalhante e deformação do corpo de prova no limite de proporcionalidade, e o módulo de deformação transversal $(G)$, bem como a média e o desvio padrão destes valores.

TABELA 7.6 - Valores obtidos do ensaio de cisalhamento da espuma rígida

\begin{tabular}{ccccc}
\hline $\begin{array}{c}\text { Corpo de } \\
\text { Prova }\end{array}$ & Densidade & $\begin{array}{c}\text { Tensão } \\
\text { Cisalhante } \\
\text { (limite de proporc) } \\
(\mathrm{MPa})\end{array}$ & $\begin{array}{c}\text { Deformação } \\
\text { Transversal } \\
\text { (limite de proporc.) } \\
(\mathrm{MPa})\end{array}$ & $\begin{array}{c}\text { Mód. Elast. } \\
\text { Transversal (G) }\end{array}$ \\
\hline CP-I & 73,0 & 0,09 & 0,03 & 3,35 \\
CP-II & 91,0 & 0,15 & 0,03 & 5,09 \\
CPIII & 85,0 & 0,20 & 0,05 & 4,38 \\
CP-IV & 71,0 & 0,16 & 0,04 & 4,21 \\
CP-V & 82,0 & 0,02 & 0,004 & 5,00 \\
CP-VI & 73,0 & 0,11 & 0,02 & 4,54 \\
CP-VII & 73,0 & 0,14 & 0,03 & 4,60 \\
CP-VIII & 63,0 & 0,08 & 0,02 & 4,08 \\
& & & 0,03 & 4,40 \\
\hline Média & 76,4 & 0,12 & 0,01 & 0,55 \\
\hline Desvio & 9,0 & 0,06 & & \\
Padrão & & &
\end{tabular}

$\mathrm{Na}$ literatura técnica revisada, foram encontrados alguns valores das caracteristicas de cisalhamento de espumas expandidas de poliestireno e poliuretano empregados nos mais variados ensaios. Apesar da deficiência de informações, os valores médios obtidos nos ensaios realizados neste trabalho, mostram-se próximos aos encontrados na literatura, para a maioria das referências. Esta comparação é mostrada na tabela 7.7 
TABELA 7.7 - Características de cisalhamento de espumas expandidas

\begin{tabular}{lccc}
\hline Referência & Material & $\begin{array}{c}\text { Densidade } \\
\left(\mathrm{g} / \mathrm{dm}^{3}\right)\end{array}$ & $\begin{array}{c}\text { Módulo G } \\
(\mathrm{MPa})\end{array}$ \\
\hline ALLEN (1967) & Poliestireno & $\mathrm{s} / \mathrm{ref}$ & $2,76 \mathrm{a}$ \\
& Poliestireno & 42 & 4,14 \\
ALLEN (1969) & Poliuretano & 72 & 4,57 \\
ALLEN (1969) & Poliuretano & $30,4 \mathrm{a} 35,2$ & $1,60 \mathrm{a}$ \\
HARTSOCK (1976) & & & 3,20 \\
& Poliuretano & s/ref & 3,04 \\
O'CONNOR (1989) & Poliuretano & $\mathrm{s} / \mathrm{ref}$ & 10,56 \\
O'CONNOR (1989) & Poliuretano & $\mathrm{s} / \mathrm{ref}$ & 4,00 \\
AICHER (1993) & Poliuretano & 40,0 & 2,60 \\
BAEHRE (1994) & Poliuretano & 40,0 & 4,10 \\
BAEHRE (1994) & Poliuretano & 76,4 & 4,40 \\
PRESENTE TRABALHO & (óleo de mamona) & & \\
\hline
\end{tabular}




\subsubsection{Carga de ruptura}

Para efeito da carga de ruptura dos ensaios de cisalhamento, o valor assumido foi o correspondente ao ponto $Y$ do gráfico da fig.7.6. É o valor máximo obtido no ensaio. A tabela 7.8 apresenta os valores obtidos para cada exemplar, bem como, os valores da média e do desvio padrão. A resistência ao cisalhamento (tensão cisalhante de ruptura) foi determinado conforme o item 5.3.2.1.

TABELA 7.8 - Valores de ruptura do ensaio de cisalhamento da espuma.

\begin{tabular}{cccc}
\hline $\begin{array}{c}\text { Corpo de } \\
\text { Prova }\end{array}$ & Densidade & $\begin{array}{c}\text { Carga de Ruptura } \\
\text { (ponto } \mathrm{Y}) \\
(\mathrm{KN})\end{array}$ & $\begin{array}{c}\text { Res. ao Cisalhamento } \\
\text { (ponto } \mathrm{Y}) \\
(\mathrm{MPa})\end{array}$ \\
\hline CP-I & 73,0 & 4,43 & 0,21 \\
CP-II & 91,0 & 7,05 & 0,33 \\
CPIII & 85,0 & 6,52 & 0,30 \\
CP-IV & 71,0 & 6,03 & 0,28 \\
CP-V & 82,0 & 6,75 & 0,31 \\
CP-VI & 73,0 & 5,54 & 0,26 \\
CP-VII & 73,0 & 5,97 & 0,28 \\
CP-VIII & 63,0 & 4,62 & 0,21 \\
& & & \\
\hline Média & 76,4 & 5,86 & 0,27 \\
\hline Desvio & 9,0 & 0,96 & 0,04 \\
Padrão & & & \\
\hline
\end{tabular}

Como já se comentou anteriormente, para os oito ensaios de flexão da viga sanduíche, a ruptura se deu por cisalhamento do núcleo. A resistência ao cisalhamento da espuma rigida, como pôde ser visto nos ensaios, é um parâmetro importante no dimensionamento e verificação de vigas sanduiche.

A tabela 7.9 mostra uma comparação dos valores das tensões últimas de cisalhamento $\left(\tau_{u}\right)$ no núcleo para cada viga ensaiada à flexão, com a 
resistência ao cisalhamento da espuma determinada a partir dos ensaios de cisalhamento. Os valores de $\tau_{u}$ para cada viga foram obtidos da eq.3.13, considerando $\mathrm{d} \cong \mathrm{c}$ :

$$
\tau_{\mathrm{u}}=\frac{\mathrm{V}}{\mathrm{bc}}
$$

onde $V$ é a força cortante máxima na viga.

Calculando $\tau_{u}$ através da eq. 7.3, é como se tivéssemos a força cortante atuando apenas no núcleo provocando uma distribuição de tensão cisalhante constante em toda a espessura da espuma. Isto pode ser justificado pela insignificante rigidez da face de argamassa armada tracionada, no instante da ruptura do núcleo, devido a um estágio de fissuração bem desenvolvido.

TABELA 7.9 - Tensões últimas de cisalhamento do núcleo.

\begin{tabular}{|c|c|c|c|}
\hline Painel & $\begin{array}{c}\text { Densidade do núcleo } \\
\left(\mathrm{g} / \mathrm{dm}^{3}\right)\end{array}$ & $\begin{array}{c}\text { Tensões últimas } \\
\text { (ensaio de flexão) } \\
(\mathrm{MPa})\end{array}$ & $\begin{array}{c}\text { Resist. ao cisalh } \\
\text { ASTM 273-61 } \\
\text { (MPa) }\end{array}$ \\
\hline PS I-1 & & 0,20 & \\
\hline PSI- 2 & & 0,17 & \\
\hline PSI - 3 & & 0,24 & \\
\hline PSI - 4 & & 0,24 & \\
\hline PS II - 1 & & 0,21 & \\
\hline PS II - 2 & & 0,21 & \\
\hline PS II - 3 & & 0,20 & \\
\hline PS II - 4 & & 0,22 & \\
\hline Média & 67 & 0,21 & 0,27 \\
\hline $\begin{array}{l}\text { Desvio } \\
\text { padrão }\end{array}$ & & 0,03 & 0,04 \\
\hline
\end{tabular}


Analisando a tabela 7.9, pode-se verificar que o valor da resistência média ao cisalhamento determinado através do ensaio de cisalhamento da espuma é aproximadamente $23,5 \%$ maior que a tensão de ruptura média obtida dos ensaios de flexão. Esta diferença pode ter sido provocada provavelmente por não se conseguir na confecção das vigas sanduiches, um núcleo com espuma rígida de mesmo padrão dos exemplares confeccionados para os ensaios de cisalhamento, podendo-se observar isto examinando os valores médios das densidades da espuma do ensaio de cisalhamento e da espuma do núcleo da viga.

\subsection{Ensaios complementares}

Os ensaios complementares de caracterização das argamassas empregadas em cada um dos exemplares das vigas, serviu como objetivo único de dar suporte aos ensaios de flexão.

A tabela 7.10 apresenta os valores médios das resistências características da argamassa aos 7 dias $\left(f_{c 7}\right)$ e 28 dias $\left(f_{c 28}\right.$ e $\left.f_{t 28}\right)$, para cada argamassagem, bem com seus respectivos módulos de deformação longitudinal $\left(E_{C}\right)$ determinados do ensaio de compressão.

As características principais das telas de aço, foram extraídos dos ensaios de caracterização das telas de aço realizados por GIONGO (1990), uma vez que as telas utilizadas nos ensaios de GIONGO pertencem ao mesmo lote de telas utilizadas na confecção das vigas do presente trabalho. A tabela 7.11 apresenta os principais parâmetros obtidos de ensaio para a tela de aço EL $126 / 63$. 
TABELA 7.10 - Resumo dos valores característicos do controle da argamassa.

\section{VALORES CARACTERÍSTICOS}

\begin{tabular}{ccccc} 
Argamassagem & $\mathrm{f}_{\mathrm{c7}}$ & $\mathrm{f}_{\mathrm{c} 28}$ & $\mathrm{f}_{\mathrm{L28}}$ & $\mathrm{E}_{\mathrm{C}}$ \\
\hline PS I - 1 e PS I - 2 & 34,59 & 45,00 & 3,50 & $25.577,19$ \\
PS I - 3 e PS I - 4 & 39,47 & 53,75 & 3,87 & $28.061,85$ \\
PS II - 1 e PS II - 2 & 33,32 & 42,50 & 3,50 & $25.387,41$ \\
PS II - 3 e PS II - 4 & 32,93 & 44,17 & 3,40 & $25.014,05$ \\
& & & & \\
\hline Média & 35,08 & 46,35 & 3,57 & 26010,12 \\
\hline Desvio padrão & 3,01 & 5,04 & 0,21 & 1387,68 \\
\hline
\end{tabular}

$\mathrm{f}_{\mathrm{c} 7}=$ resistência média da argamassa à compressão dos corpos de prova na idade de 7 dias;

$\mathrm{f}_{\mathrm{c} 28}=$ resistência média do argamassa à compressão dos corpos de prova na idade de 28 dias;

$\mathrm{f}_{128}=$ resistência média do argamassa à tração dos copos de prova na idade de 7 dias;

$\mathrm{E}_{\mathrm{C}}=$ módulo de deformação longitudinal do argamassa (tangente na origem do gráfico tensão $x$ deformação obtida do ensaio de compressão).

TABELA 7.11 - Principais características da Tela Soldada (Parâmetros de ensaios), GIONGO (1990).

TELA EL $126 / 63$ \& $2 \mathrm{~mm}$

\begin{tabular}{ccccc}
\hline$\varepsilon_{p}$ & $f_{p}$ & $\varepsilon_{y}$ & $f_{u}$ & $E_{s}$ \\
$(\% o)$ & $(\mathrm{MPa})$ & $(\% \circ)$ & $(\mathrm{MPa})$ & $(\mathrm{MPa})$ \\
\hline 1,8 & 375 & 5,7 & 869 & 208.333 \\
\hline
\end{tabular}

$\varepsilon_{p}=$ Deformação especifica do aço no limite de proporcionalidade;

$\mathrm{f}_{\mathrm{p}}=$ resistência do aço no limite de proporcionalidade;

$\varepsilon_{y}=$ Deformação especifica de escoamento do aço;

$\mathrm{f}_{\mathrm{u}}=$ resistência de escoamento do aço à tração;

$E_{S}=$ módulo de deformação longitudinal do aço. 


\section{CONCLUSÕES}

Através dos ensaios de flexão em vigas sanduíche, observou-se um considerável aumento na eficiência estrutural em relação ao comportamento isolado das faces de argamassa armada que compōem o elemento.

A resistência ao cisalhamento do material do núcleo é um fator limitante, que interfere na resistência última à flexão do painel sanduíche, visto que nos ensaios todos os modelos sofreram ruptura por cisalhamento da espuma.

A utilização de uma ou duas telas como armadura das faces de argamassa armada das vigas ensaiadas, teve pouca contribuição no comportamento à flexão e na resistência à flexão da viga como um todo, pois o núcleo de espuma rígida de poliuretano derivado de óleo vegetal é que limita o valor da ruptura.

Com base na análise dos dados experimentais obtidos da investigação do comportamento à flexão de painéis (vigas) sanduíche permite-se concluir que:

a) O cálculo do momento fletor de fissuração utilizando as hipóteses prescritas na NBR 6118, fornecem valores próximos dos obtidos dos ensaios de flexão da viga, permitindo que utilize-se estas expressões para estimar tal valor;

b) Da avaliação dos vários modelos para o cálculo dos deslocamentos de vigas sanduíche, comparando-se com valores obtidos do ensaio de flexão, conclui-se que as equações deduzidas, considerando a viga com faces finas e núcleo fraco, fornecem uma boa aproximação para se estimar o deslocamento. É interessante utilizar estas equações também pela simplicidade com que se apresentam. 
c) A ruptura dos painéis (vigas) sanduíche ensaiados neste trabalho, submetidos à flexão, é dada em função do valor da resistência ao cisalhamento da espuma rígida, ou seja, este valor é o que determina a resistência da viga à flexão, tornando-se um importante parâmetro de projeto para este elemento.

Nos ensaios de cisalhamento da espuma realizados, os exemplares utilizados foram confeccionados um a um, observando-se uma pequena variação na densidade da espuma e consequentemente no módulo de elasticidade transversal. Recomenda-se na confecção dos corpos de prova, para ensaios futuros, executá-los de uma só vez a fim de se obter a mesma densidade para cada modelo.

Enumera-se a seguir alguns estudos importantes tendo em vista a continuidade da pesquisa:

a) Estudo do comportamento à compressão axial de painéis sanduíche de faces de argamassa armada e núcleo de espuma rígida de poliuretano, sem conectores ligando as faces;

b) Estudo da relação existente entre a densidade da espuma e o seu módulo de elasticidade transversal, e sua influência nas caracteristicas térmicas e acústicas do painel;

c) Estudo dos painéis submetidos a carga dinâmica, tais como: impacto de corpo mole, impacto de corpo duro, carregamento cíclico e variação de temperatura em uma das faces;

d) Estudo do comportamento à flexão dos mesmos painéis sanduíche à flexão, utilizando conectores flexiveis ligando as faces para melhorar a interação entre elas; 
e) Estudo da discretização da armadura das faces de argamassa armada substituindo a tela soldada por fios, com adição de fibras afim de melhor os efeitos de retreção da argamassa;

f) Utilização de outros métodos para a determinação do módulo $G$ a fim de confirmar os resultados dos ensaios de cisalhamento, como por exemplo o ensaio de flexão descrito na ASTM C 393 - 62.

Tendo-se em vista que se cumpriu com os objetivos delimitados no início, as questões levantadas como propostas para futuras pesquisas apontam a necessidade da continuação dos estudos feitos aqui, afim de se conhecer mais sobre o comportamento deste elemento (painel sanduíche) variando-se parâmetros não considerados neste trabalho. 


\section{REFERÊNCIAS BIBLIOGRÁFICAS}

AICHER, S.; GIERL, M. (1993). Concetrated load aspects of sandwich panels with thick especially wood based faces. Otto Graf Journal, v.4, p.11-33.

ALLEN, H.G. (1969). Analysis and design of structural sandwich panels. Oxford, Pergamon.

ALLEN, H.G. (1967). Measurement of shear stifness of sandwich beams. Trans. J. Plastic Inst., p.359-363, Feb.

AMERICAN SOCIETY FOR TESTING AND MATERIALS (1988). ASTM C273-61 - Standart test method for shear properties in flatwise plane of flat sandwich constructions or sandwich cores. Philadelphia.

AMERICAN SOCIETY FOR TESTING AND MATERIALS (1988). ASTM C393-62 - Standart test method for flexural properties of flat sandwich constructions. Philadelphia.

AMIN EINEA, P.E.; SALMON, D.C.; FOGANASI, J.G.; CULP, T.D.; TADROS, M.K. (1991). State-of-the-art of precast concrete sandwich panels. PCI Journal, v.36, n.6, p78-98, Nov.-Dec.

ASSOCIAÇÃO BRASILEIRA DE NORMAS TÉCNICAS (1978). NB 1 Projeto e execução de obras de concreto armado. Rio de Janeiro.

ASSOCIAÇÃO BRASILEIRA DE NORMAS TÉCNICAS (1989). NB 1259 Projeto e execução de argamassa armada. Rio de Janeiro.

BALLARIN, A.W. (1989). Propriedades mecânicas da argamassa armada com telas soldadas. São Carlos. Dissertação (Mestrado) - Escola de Engenharia de São Carlos, Universidade de São Paulo. 
CABRINI MONOLITE. Sistema de construção anti-sísmico e isolante termo-acústico. Idaiatuba-SP, s.d. (catálogo técnico)

CHANG, W.F. (1983). The prototype factory-built ferrocement home. Journal of Ferrocement, v.13, n.1, p.73-76, Jan.

HINTON, E. ; OWEN, D. R. J. (1984). Finite element software for plates and shells. Pineridge Press.

FROSTIG, Y. (1993). High-order behavior of sandwich beams with flexible core and tranverse diaphragms. Journal of Engineering Mechanics, v.119, n.5, p.955-972, May.

GIONGO, J.S. (1990). Argamassa armada: dimensionamento de perfis submetidos à flexão. Fundamentos e experimentação. São Carlos. Tese (Doutorado) - Escola de Engenharia de São Carlos, Universidade de São Paulo.

GIONGO, J.S. (1991). Argamassa armada: exemplo de cálculo de uma viga calha. São Paulo, Associação Brasileira de Cimento Portland.

HA, K.H. (1990). Finite element analysis of sandwich plates: an overview. Computers \& Structures, v.37, n.4, p.397-403.

HA, K.H. (1993). Stiffness matrix for exact solution of sandwich beam and frame systems. Journal of structural Engineering, v.119, n.4, p.11501167, April.

HARTSOCK,J.A.; CHONG, K.P. (1976). Analysis of sandwich panels with formed faces. Journal of the Structural Division, v.102, n.ST4, April.

LEE, S.L.; MANSUR, M.A.; PARAMASIVAM, P.; ONG, K.C.G.; TAM,C.T. (1986). A study of sandwich wall panel. Journal of Ferrocement, v.16, n.3, p.295-313. 
MACHADO Jr., E.F. (1991). Casas populares pré-moldadas em argamassa armada: procura de uma solução econômica e confortável. São Carlos. Tese (Doutorado) - Escola de Engenharia de São Carlos, Universidade de São Paulo.

MARKWARDT, L.J. (1951). Developments and trends lightweight composite construction. In: SYMPOSIUM ON STRUCTURAL SANDWICH CONSTRUCTION, ASTM, Atlantic City, p.3-31, Jun. Proc. p.3-31.

O'CONNOR, D.J. (1989). A comparrison of test methods for shear properties of the cores of sandwich constructions. Journal of Testing and Evaluation, v.17, n.14, p.241-246, July.

PICKARD, S.S. (1990). Welded wire sandwich panels: an alternative to wood-frame construction. Concrete Construction, v.35,n.4, p.363-366, April.

PLANTEMA, F. (1966). The bending and buckling of sandwich beams, plates and shells. London, Wiley and Sons.

\section{BIBLIOGRAFIA COMPLEMENTAR}

ALLEN, H.G. (1970). Analysis of sandwich panels: the significance of shear deformation. Composites, p.215-219, Jun.

ASSOCIAÇÃO BRASILEIRA DE NORMAS TÉCNICAS. (1983). NBR 8522. Determinação do módulo de deformação estática e diagrama tensão-deformação. Rio de Janeiro.

BANSULBUL, A.I.; SALEEM,M.; AL-SULAIMANI, G.J. (1991) Flexural behavior of ferrocement sandwich panels. Cement \& Concrete Composites, v.13, p.21-28 
BERTINI, A.A.; MACHADO JR., E.F. (1994). O painel sanduiche nas obras civis: uma revisão do emprego na construção de habitaçōes. In: CONGRESSO DE ENGENHARIA CIVIL DA UNIVERSIDADE FEDERAL DE JUIZ DE FORA, 1., Juiz de Fora, ago. 1994. Anais. Juiz de Fora, FEUFJF. v.2, p.77-88.

BERTINI, A.A.; MACHADO Jr., E.F. (1995). Investigação do comportamento à flexão de painéis sanduíche de faces de argamassa armada e núcleo de poliuretano. In: $27^{\circ}$ JORNADAS SUDAMERICANAS DE INGENIERÍA ESTRUCTURAL, 27., Tucumán, Argentina, set. 1995. Anais. Tucumán,ASAIE/FCET-UNT. v.1, p.119-130.

FÔNSECA, F.J.C. (1994). Projeto de painéis sanduiche de concreto prémoldado. São Carlos. Dissertação (Mestrado) - Escola de Engenharia de São Carlos, Universidade de São Paulo.

HANAI, J.B.; EL-DEBS, M.K. (1993). Uma revisão da aplicação da argamassa armada (ferrocimento) em habitações. In: SIMPÓSIO ÍBERO AMERICANO SOBRE TÉCNICAS CONSTRUTIVAS INDUSTRIALIZADAS PARA HABITAÇÃO DE INTERESSE SOCIAL, 3, São Paulo, out. Anais. São Paulo, CYTED/ABCl. v.2, p.435-446.

HURD, M.K. (1989). Expanded polyestirene wall forms. Concrete Construction, v.34, n.8, p.697-699, Mar.

HURD, M.K. (1991). Welded wire sandwich panels shotcreted. Concrete Construction, v.36, n.12, p.878-880, Dec.

LANING, A. (1992). Polystyrene wall forms assemble in a snap. Concrete Construction, v.37, n.3, p.207-209, Mar.

LUSH, A.M. (1985). An equivalent layer sandwich panel model. Comptures \& Structures, v. 21, n. 5, p.861-868. 
MACHADO Jr., E.F. (1994). Sistema construtivo para habitações de baixo custo. In: CONGRESSO DE ENGENHARIA CIVIL DA UNIVERSIDADE FEDERAL DE JUIZ DE FORA, 1., Juiz de Fora, ago. 1994. Anais. Juiz de Fora, FE-UFJF. v.2, p.65-76.

MACHADO Jr., E.F.; BERTINI, A.A. (1995). Determinação do módulo de deformação transversal $(G)$ de espumas rígidas, expandidas no local, de poliuretano derivado de óleo de mamona, destinadas a núcleos de painéis sanduiche. In: $27^{\circ}$ JORNADAS SUDAMERICANAS DE INGENIERÍA ESTRUCTURAL, 27., Tucumán, Argentina, Set. 1995. Anais. Tucumán, ASIEIFCET-UNT. Argentina. v.5, p.307-318.

NANNI, A.; CHANG, W.F. (1986). Ferrocement sandwich panels under bending and edge-wire compression. Journal of Ferrocement, v.36, n.2, p.215-219, April.

O'CONNOR, D.J. (1988). Point concentration in thick-faced sandwich beams. Journal of Engineering Mechanics, v.114, n.5, p.733-752, May

PFEIFER, D.W.; HANSON, J.A. Precast concrete wall panels: flexural stiffness of sandwich panels. Portland Cement Association.

ROBLES-AUSTRÍACO, L.; PAMA, R.P.; VALLS, J.; SINGH, C. (1983). Préfabicated ferrocement housing worldwide. Journal of Ferrocement, v. 13, n. 1, p.43-60, Jan.

SWIFT, G.W.; HELLER R. A. (1974). Layered beam analysis. Journal of the engineering mechanics division. v.100, n. EM2, p.267-282. April.

UNIVERSIDADE DE SÃO PAULO. Escola de Engenharia de São Carlos. Serviço de Biblioteca (1993). Diretrizes para elaboração de dissertações e teses na EESC - USP. São Carlos, SVBIBL. 